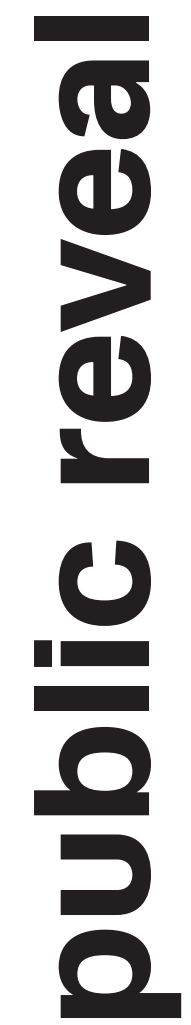

Finding a place for civic architecture in the contemporary city 


\section{Public Reveal}

Finding a place for civic architecture in

the contemporary city

By

Amber Venter
A 120 point thesis submitted to the Victoria

University of Wellington in partial fufilment of the requirements of the degree of Masters of Architecture (Professional).

Victoria University of Wellington School of Architecture$$
2020
$$

I would like to thank the following for their continuous support and encouragement. I could not have done it without you.

To my family; Tracy, Kruger and Brit, for always being a phone call away whenever I needed that pep talk.

To Chris McDonald, thank you for your guidance and supervision throughout the year.

To my friends, thank you for the endless laughs, conversations and constructive discussions, they will always be remembered. 
This research is an architectural enquiry into how the visibility of local government can mimic the performance of everyday political life. Using the conceptual framework of place and understanding of the collective community. The intention of this design proposal is to encourage the transparency of local authority through an architectural intervention in the city.

The driver of this research is the reduced physical presence of civic practices, with particular regard to the congregating place of local government. A framework is developed as a precursor to develop an understanding of the traditional civic architype. The aim is to reimagine a contemporary civic architecture which is detached from the corporate functions of local government. Architecture supports the celebration of collective rituals of movement and meeting.

An archetype investigation formalises a set design criteria by which the design case study is evaluated against. The background research comprises a critique of the spatial arrangement of the traditional town hall. An additional background task is consisted of a comparative inquiry into today's local government accommodation.

The site is located in Tamaki Makaurau/Auckland City. The site analysis criteria utilised by this thesis is grounded in the research of Jan Gehl and his understanding of architectures impact on peoples' behaviour in cities.

Finally the design case study is driven by dynamic circulation, which establishes a celebration of the formal and informal interactions between the participants of local government. Transparency and hierarchy are used to challenge the spatial and functional qualities of Auckland City Council. The result of the research will contribute to the inclusive understanding of the ordinary rituals of local government through architecture in the city.

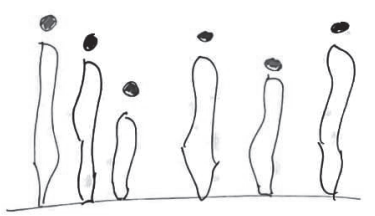




\section{CONTENTS}

CHAPTER ONE: INTRODUCTION

Introduction

Question

Aims/Objectives

Methodology

CHAPTER FIVE: CONCEPT DESIGN

134

Thesis Structure

$$
\begin{aligned}
& \text { Introduction } \\
& \text { Programme Planning } \\
& \text { Preliminary Design } \\
& \text { Conclusion }
\end{aligned}
$$

Theme Three: Power

CHAPTER SIX: FINAL DESIGN

Conclusion

CHAPTER SEVEN: DISCUSSION \& REFLECTION

Introduction

Evaluation

Conclusion

Analysis

Conclusion

Changing Civic Presence

Conclusion

Building Type Study

Conclusions

Design Criteria

\section{EIGHT: CONCLUSION}

Significance

Limitations

Further Research

Final Statement

List of Figures

Bibliography

CHAPTER FOUR: SITE \& PROGRAMME

Site Selection

Site Criteria

Conclusion

Programme

Design Criteria

Conclusion 


\section{Introduction}

The research investigates the contemporary role of a local government and its architectural expression within the modern city. The research begins with a critique of the design of the traditional town hall. The outcome of this research is a design case study which replaces the antiquated building type with a new civic architectural model. That is more responsive to a diverse community and the everyday rituals of local political practices.

The research is driven by a decreasing visibility of today's local government in cities across New Zealand. The institutions of local government have abandoned town halls and moved into generic office accommodation. Tamaki Makarau/ Auckland City is a prime example of a separated symbolic civic presence. The traditional town hall is no longer suitable functionally of symbolically for the practices of today's local government. A preliminary research inquiry critiques the formal spatial arrangement of traditional town halls across New Zealand. The results of the spatial critique is a division between the different

INTRODUCTION

QUESTION

AIMS/OBJECTIVES

METHODOLOGY

MAIN FINDINGS

THESIS STRUCTURE users; public and council staff. The analysis also acknowledges the solid architectural language which is used in the classical styles. From the exterior, the interior is concealed along with the events which occur internally.

A conceptual framework is established to ground this research. The theme of civic is understood through the work of Peter Rowe. His research outlines the symbolic relationship between architecture and civic experiences. He identifies the tensions between authority and society, which makes up the concept of the civic $^{1}$. These tensions can be leveraged to enhance a civic experience within the city. The concept of place forms an understanding of everyday life and how architecture plays a major role in the experience of place. Kim Dovey is a leading author on this topic and his understanding of the dialects which mediate place in the built environment establish a framework for this thesis. ${ }^{2}$ Jan Gehl is a third author contributing to the conceptual framework. His writing on how cities influence people's behaviour will inform the selection of a suitable site.

As a precursor to the design case study, a precedent study establishes an understanding of Western civic architecture. The architype critique of traditional town halls across New Zealand is supported by a further architype analysis of contemporary examples of local government accommodation. These inquiries help to establish a set of strategies for the experimental phase of this research. 
The aim is to enable interactions between human and built environment, which reflects the sense of place on the user in public. Architecture in the city has a strong influence in the way pedestrians move around. ${ }^{3}$ Jan Gehl's writing provides an understanding for the impact and selection of site for the research. He explores movement and other forms of human behaviour within cities. Working at different scales (urban, architectural, human), he analyses people's visual experience, which emphasises the threshold between architecture and the street. ${ }^{4}$ This research aims to foster positive relationships to the built environment through an understanding of site conditions. Gehl's research is operationalised into a set of criteria to inform to choice of the site for this research.

Architectural representation and the final design outcome can be ambiguous due to the representations of the design. Qualities that can be overlooked in physical drawings make up a large part of the human experience. Although the design of experiential environments should acknowledge a degree of individual interpretation.

The final design case study assesses a set of criteria, which has developed during the background enquiries. The criteria highlighted spatial and conceptual qualities for which this design case study. The concluding evaluation assess the design strategies functioned cohesively to implement the case study.

Architecture has the potential to encourage civic awareness, when operating in the social realm, to better the experience of the city. ${ }^{5}$ This design case study explores how the physical presence of architecture impacts the basic knowledge of everyday political practices, through a celebration of the rituals of meeting and pathways to establish a symbolic and emblematic space in the city.

\section{Question}

How can the practices of everyday political performance and the experience of the public influence the design of civic architecture?

\section{Aims/Objectives}

The aim of this thesis is to consider how civic architecture can be designed with the consideration of the human experience. With careful deliberation around the site selection process; in particular how pedestrians interact with the built environment. The research shows how the divergence and compliments of the experience inside and outside can act as a design driver.

Public Reveal argues about the importance of civic architecture to help establish a physical presence in the city. For the benefit of the collective community, this will convey transparency to the operations of local government. 


\section{Methodology}

This thesis follows a mixed method approach. It will utilise both research for design and produce a design case study as an example of how established design strategies can be executed.

Research for design will begin as a starting point to create a field of background knowledge in areas of civic, place and public experience. This research will inform and produce a series of criteria and therefore strategies which can be used to evaluate the design case study against.

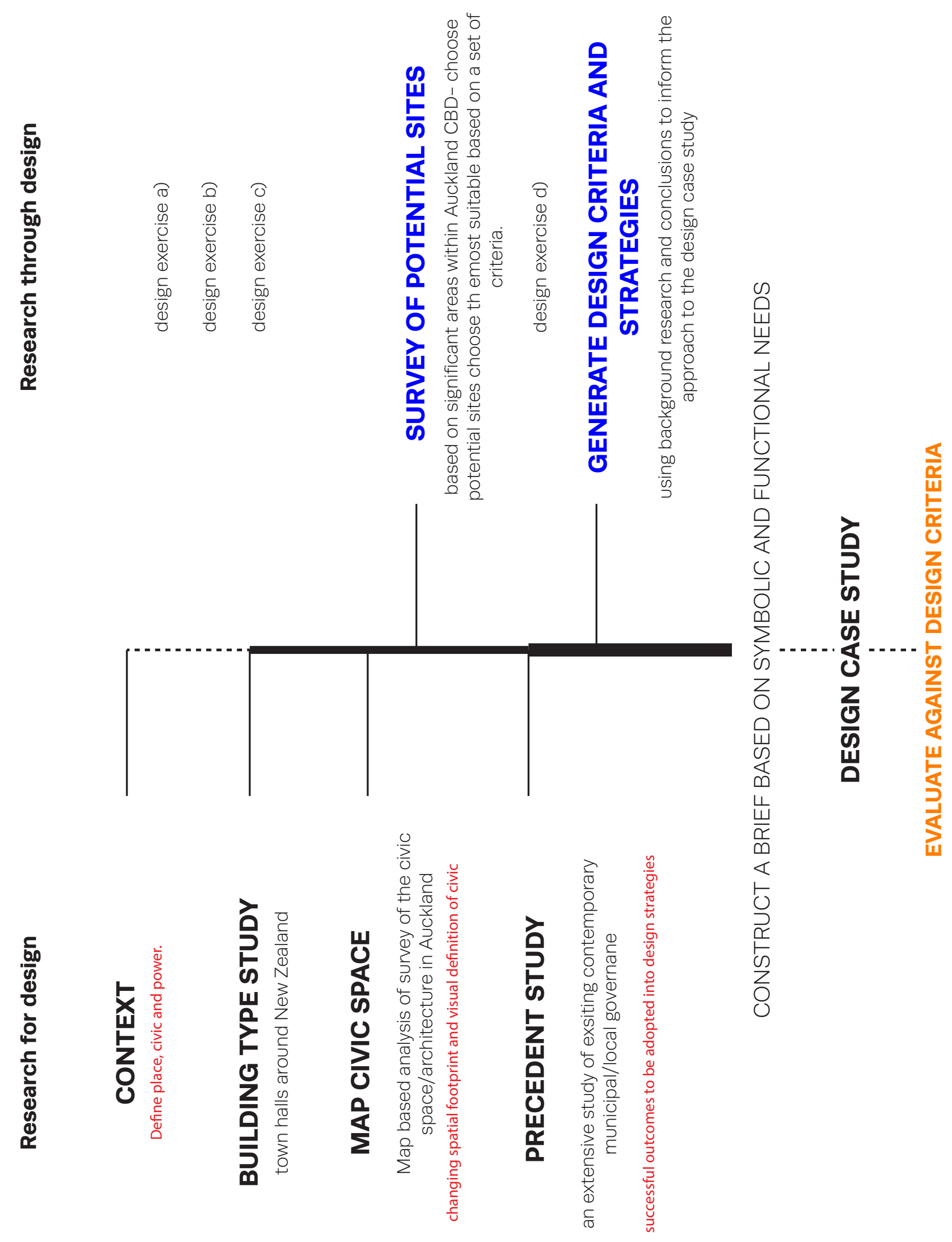

Research through design is considered during the second part of the thesis. As a part of visual exploration, smal design exercises which are informed by the background research will be generated. 


\section{Main findings}

This research has identified the decreasing physical presence of local government. However this design case study has used architectures role in the city as a beacon for the celebration of everyday political practices. Negotiating the society's tensions between authority and public engagement to create transparency in local government's organisation. This research highlighted the importance of circulation in architecture and its dynamic role in activating the built environment. Design strategies which were used to achieve this approach to civic architecture are as follows:

Relationship to the ground: achieving an inviting threshold for users; between the street and the building.

Q Various circulation routes: creating a dynamic rhythm of movement throughout the building, experienced from the inside and outside.

(4) Spatial hierarchy: confronting the traditional hierarchical arrangement of spaces in civic architecture to reveal everyday political operations.

( Manipulation and reorientation of opaque traditional town hall façade: achieves visual transparency.

\section{Thesis Structure}

2 This Chapter will outline the key concepts which this thesis will interrogate. These concepts include defining the meaning of civic, its impact on the built environment and the theoretical framework of place as an experiential outcome of architecture.

3 This chapter will establish a foundation for research. An inquiry into three traditional town halls in Aotearoa, demonstrates the outdated design of local government accommodation. A map based study of Auckland city shows a macro scale decrease of civic presence over a century.

4 As a pre-design stage, the site is chosen from six potential areas, based on a set of criteria, the pre-eminent option is chosen. A functional brief is constructed and informed by the above background investigations.

5 The concept design stage begins with physical modeling of the overall physica form and the concept of the relationship between the exterior and the interior The design criteria is operationalised based on the functional brief and the conceptual framework. A clear focus on circulation and the relationship between the interior and exterior is developed.

6 The design moves into an iterative digital and detailed stage where the interio arrangement is refined and appropriate materials are selected. The final design showcases the ability for civic architecture to facilitate the relationship of public and local government, exhibiting the workings of everyday political conduct.

7 This chapter is an evaluation, which assesses the final design outcome agains the constructed criteria. This reflects critically on the research as a design case study and how successfully the strategies have achieved the constructed criteria and principles. 


\section{Rowe, Civic Realism, 203}

Dovey, Framing Places: mediating power in built form, 18

Gehl, Close encounters with buildings, 33

Gehl, 30

Jones, Putting Architecture in its social place, 2532

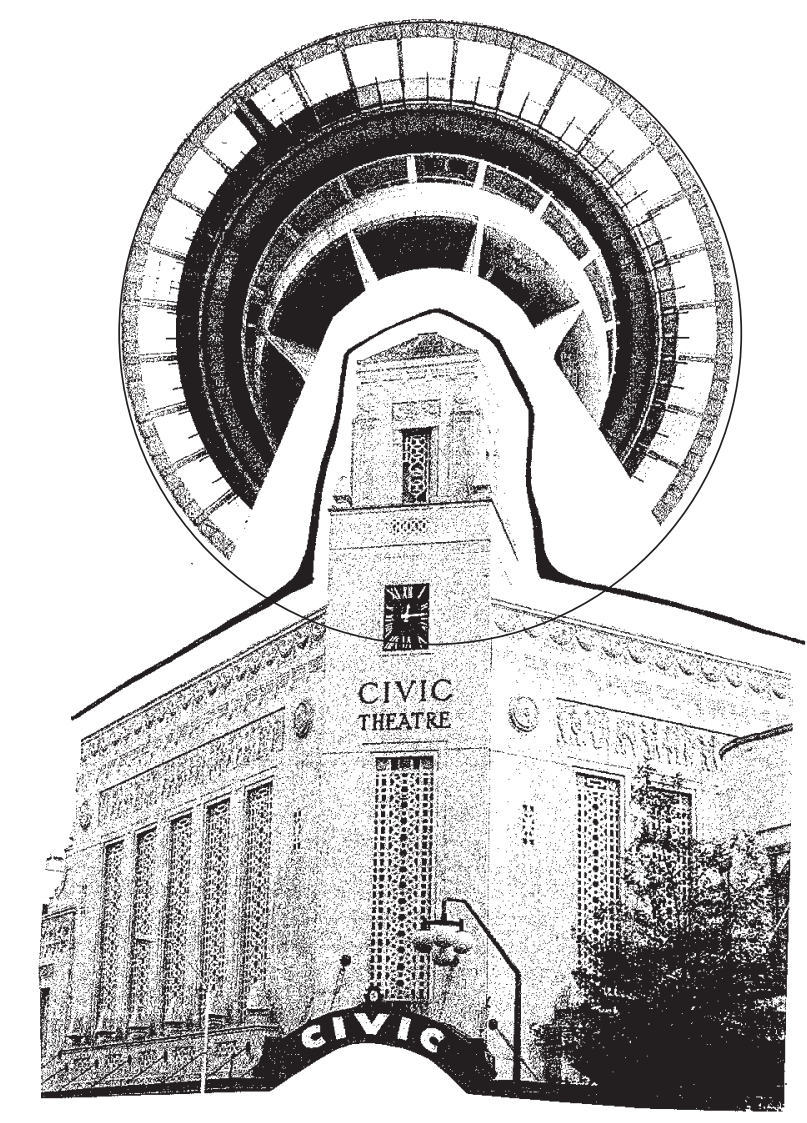




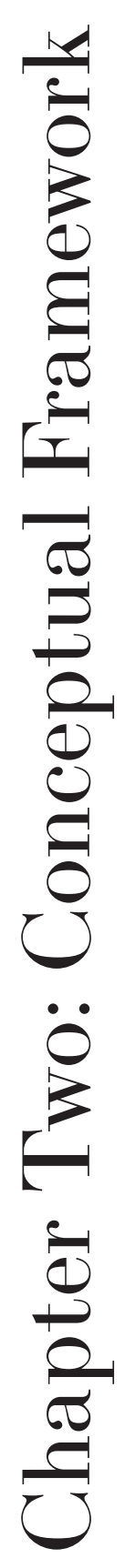

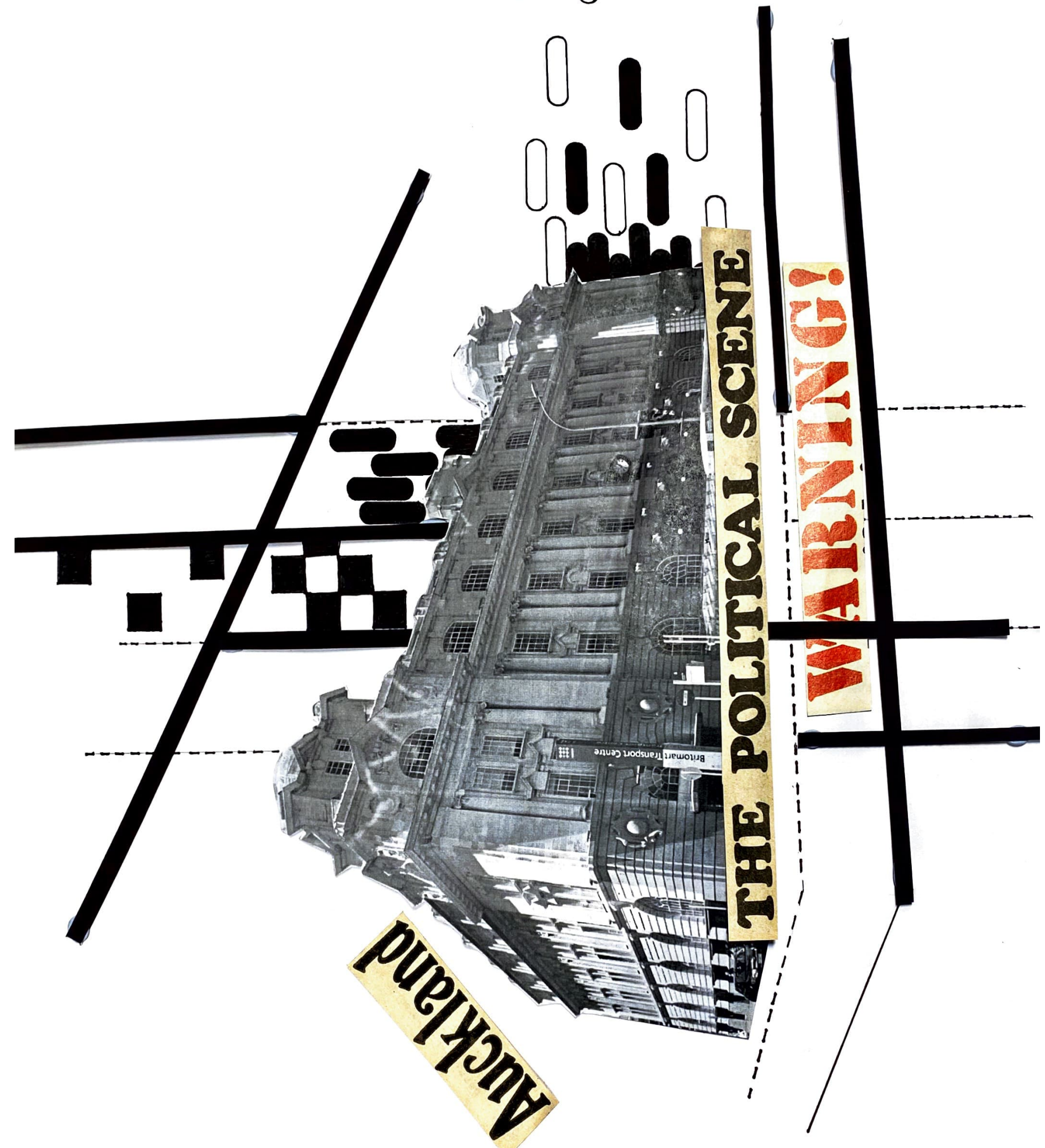




\section{Introduction}

This chapter establishes the conceptual framework for this thesis. The concepts which are discussed include place; its impact on architecture and the experience of an environment based on dialects. The key contributor of this theme is Kim Dovey, who's research favors architectures significant role in society and ways in places allows it to mediate. Another key contributor is Peter Rowe, his research is on the concept of civic. He discussed how historically architecture can stablise the tensions of the civic realm through principles, such as inclusivity and complexity. The end of this chapter will outline how power is mediated through architecture and the principles which both place and civic draw from. How power is asserted will be challenged in this research, proposing the opportunity for architecture to fabricate a positive experience of everyday political practices.

\section{Theme One: Place}

The concept of place will be studied throughout this "the function for social institutions is to work in harmony thesis, specifically, the ideas of Kim Dovey and his for the benefit of society" ${ }^{4}$ Assemblage is made up of understanding of architectures role in the experience certain parts and is considered to have a dynamic of place. The dimensions of place, defined below will relationship between each element. Parts can be removed contribute to a conceptual framework of this research. from one assemblage and worked into another where Centred on the interactions, connections and relationships interactions would be different.

we experience in the built environment, specifically the city for this thesis. Dovey suggests that because place is a dynamic experience; it cannot be easily defined According to Dovey, one discernable attribute of place is its ability to symbolise a power-

It is important to highlight that place is an abstract concept. This research will aim to implement the constructs of place as a method to understanding the symbolic meanings of the design case study. More specifically through the experiential characteristics of place which can be drawn from Dovey's breakdown of place, "place is at once experienced, structured and discursively constructed".

"Place is a dynamic ensemble of people and environmen that is at once material and experiential, spatial and social". ${ }^{3}$ The concept of place is experienced during everyday life, therefore it often happens without conscious thought. Dovey breaks down the concept of place through its social constructs, defining its importance between the connections of spatiality and sociality.

Dovey uses the concept of place as an assemblage for a theoretical framework. Assemblage is the connections and interactions, which transpire in a physical environment Architecture can be considered in this environment, and plays a role in the affect of assemblage. There is no hierarchy in connections or patterns in an assemblage,
By establishing an understanding of place and how it contributes to the experience of everyday life, this thesis will develop a framework for designing architecture which symbolises the complex concepts of civic and the balance between power to and power over.

Dovey uses the concept of power to help define place and the experience one has within certain places based on how architecture and urban design facilitates this power. He defines the term power, where this can have that this thesis is aiming to establish a balance between these dimensions of power. Where this is relevant to architecture Dovey states that the built environment has the ability to frame particular spaces and therefore determine what is happening in everyday life. Opening some opportunities and closing others "The built environment mediates, constructs and reproduces power relations". ${ }^{6}$ Place can be considered as spatial structures which are a combination of what Dovey defines 'smooth' and 'striated'. Where smooth spatial practices allow for change in identity and boundaries are blurred. Striated space is where social identities are controlled and there re stable boundaries two meanings; 'power to' and 'power over's. It is clear 


\section{Theme Two: Civic}

By analysing how built form mediates power, it is possible to better understand the experience of place. In particular Dovey puts importance on the inside/outside dialect of spatial planning and how this can be translated and perceived as social power. Through architecture the understandings of power are established. ${ }^{8}$ Architecture has a complex relationship between the interior and the exterior and what rituals are identified in the contrasting dialects. ${ }^{9}$

This thesis will not aim to design a self-contained place but rather contribute to a city's experience of place. Architecture which helps establish a place within the city achieves a sense of order, controlled by the state, while offering possibility for public engagement. Place should not be mistaken here as a sense of home or identity, it is not defined by its location. Rather place is determined by the location and the experience which is felt in this particular location. Architecture facilitates the experience of a place but does not stabilise or destabilise it. ${ }^{10}$

The concept of place affects the collective socia experience of the city. This conceptual understanding of place has highlighted the significance of location within the city and the architectural challenges at play between the inside and the outside. Selection of site for the case study will consider its position in the city. The dialectic of inside and outside will be established in the design criteria which this thesis will be evaluated against.
The following section will define the term civic and how it is interpreted in the architectural field. It will examine the writing of Peter Rowe and how he has established a set of principles which symbolise architectures place in the civic realm

This thesis will aim to establish a balance of civic values, through symbolic and physical representation in architecture. Civic architecture has the potential to embrace the tensions between the public sphere and the authority which aims to order society. Here, the term civic means to form a balance between the juxtaposed values of local power and local society

The following literature review will look closely at Peter Rowe's work and what he defines as civic realism. Rowe describes civic as a balance between everyday public life and the performance of political life; it could be understood as socio-political performance. ${ }^{11} \mathrm{He}$ focuses in particula on the aspects of civic place, exploring similarities in the physical form and conceptual framework which contribute to civic realism specifically. Emphasis is on the locality, accessibility and perceptibility of a civic place, which enables it to represent the qualities of a local community. To define civic realism is to have an urban architectural approach to the relationship of civil society and authority. ${ }^{12} \mathrm{Civic}$ realism is the appropriate theme fo which this thesis will use.

Rowe discusses the importance of understanding the public realm and the qualities of the public whic contribute to civic values. ${ }^{13}$ It is not the programme which defines architecture as civic but rather the themes, representation and symbolism of the built form which defines civic realism Civic architecture should represent the society in which it operates; how and what the society does in everyday life. It is therefore suitable for the design case study of this research to adopt the civic values which Rowe outlines.
Rowe states that society's shifts and changes are what causes the shifts between the boundaries of that of public and that of private. ${ }^{14}$ Civic spaces celebrate the complicated balance of the collective community and the state. It is part of civic architecture's objective to support a changing society, through the physical appearance and symbolic meaning of buildings and spaces.

Rowe argues that the architecture of civic realism needs no particular program, however he does define some characteristics; "a probing concern for everyday life". ${ }^{15}$ Here Rowe is suggesting that the subject matter must be somewhat generalised in order for the public to relate and engage with the architecture. It should be commonplace for most and widely accessible, through the shared xperience of the place.

To summarise, Rowe has made it apparent that civic is largely defined as being a part of the public realm, "the depiction, celebration, or constitutive aspect of everyday life must be either ennobling or critical, and not merely a matter of portrayal" ${ }^{16}$ Architecture in the civic realm ought to be a representation of everyday life and be able to advance with a shifting society. For civic is to be seen and heard in public, for a community to be proud of this concept.

"Civic realism presents a challenge and a critique to established orders and prevailing authority, yet also expresses a sense of common accord".

During classical and renaissance era open public spaces were areas of gathering and political development. It was these sites that gatherings occurred and civic conduct could be played out. Today civic conduct is distributed 


\section{Theme Three: Power}

across different sites in one city, there is no longer one location which defines political practices. ${ }^{18}$ The author Ash Amin argues that urban planning aims to encourage "the encounter between strangers" through civic engagement of the community.

In modern times the term civic has a wider meaning to what it was known back when there were public square for meetings. Civic culture can now occur in a collective of spaces; work, school, community. It can be defined as a place for human interactions, a place which offer social communion. ${ }^{20}$

Public spaces which are symbolic and recognised as site of public gatherings are seen as participatory political spaces. The success of civic space can rely upon the sociability, open accessibility and acceptance of the code of civic performance.

While there is no one architype that can be defined the model for civic architecture. It is more worth identifying similar rhythms which civic sites beat to. The everyday life of various civic spaces cannot be restrained to a single practice, multiplicity is crucial for collective engagement ${ }^{21}$ Lines of separation between a power divide become blurred when the "patterned ground" has multiple uses, a diversity of experiences. ${ }^{22}$

"Social capacity which grows from an active public sphere" Amin, p.23
These two themes of civic and place can be understood to have relating principles of power. This research wil look at the dualism between power and society, how they function together. How architecture can highlight this relationship. The aim is not to suppress the state or give rise to the collective, but rather to highlight this balance of everyday political practices.

For Dovey, the dialectics of inside/outside, in architecture this can have various everyday spatial meanings. For example the mundane act of entering a building can be symbolic of power balances. ${ }^{23}$ This thesis will use the spatial dialects of inside/outside to challenge the role of power in civic architecture.

Architecture as a field, promotes the stance that architecture can highlight political practices. These are both practices rituals, the movement of people around and in a space. While architecture is playing with this balance there is a stronger sense of order. As in this research it is architectures role to create spaces where there is order, so there is control. The architecture is a physical object which has a means to an end. "It is the fact of space that creates the special relation between function and social meaning in buildings". ${ }^{24}$

This thesis does not claim to solve societal problems or imbalances. Rather it will establish the physical presence of civic architecture and how the collective culture can benefit from the experience. Through the themes of place, which have been outlined about, both to be realised physically through site and conceptually through overal experience of space, material and human movement. Remove one element whether it be people, material qualities or the symbolic meaning and the experience does not become nothing it rather reconfigures into something else, a different experience within space. ${ }^{25}$ 


\section{Conclusion}

Notes

This chapter has established a grounding for the conceptual framework of this thesis. The theme of place has been defined as the elements which contribute to the overall experience within a physical environment. In the context of the city architecture assumes a physical presence, and therefore an essential element towards the construction of place. The concept of civic has been characterised by the relationship between society and in this research; local authority. Physical civic space can positively achieve a harmony of this relatioship. Within the themes of place and civic, there is a dialect of power. In the context of place, power is established through the spatial arrangement and the effect this may have on the experience of a space. A dualism of a community and authority is stabilised through a collective understanding of the other. Civic representation cannot be understood without a balance of power. The way in which the built environment constructs space and the movement of people will be used to establish to power balance. This balance is essential to realize a symbolic presence of civic architecture in the city. This understanding and intersection of themes will assist in this research through the analysis of the spatial arrangement of existing civic architecture and spaces. The design case study aspect of this research will assume strategies which will aim to reorder the traditional design of civic architecture. To establish a contemporary symbolic presence in the city, for the benefit of the collective.

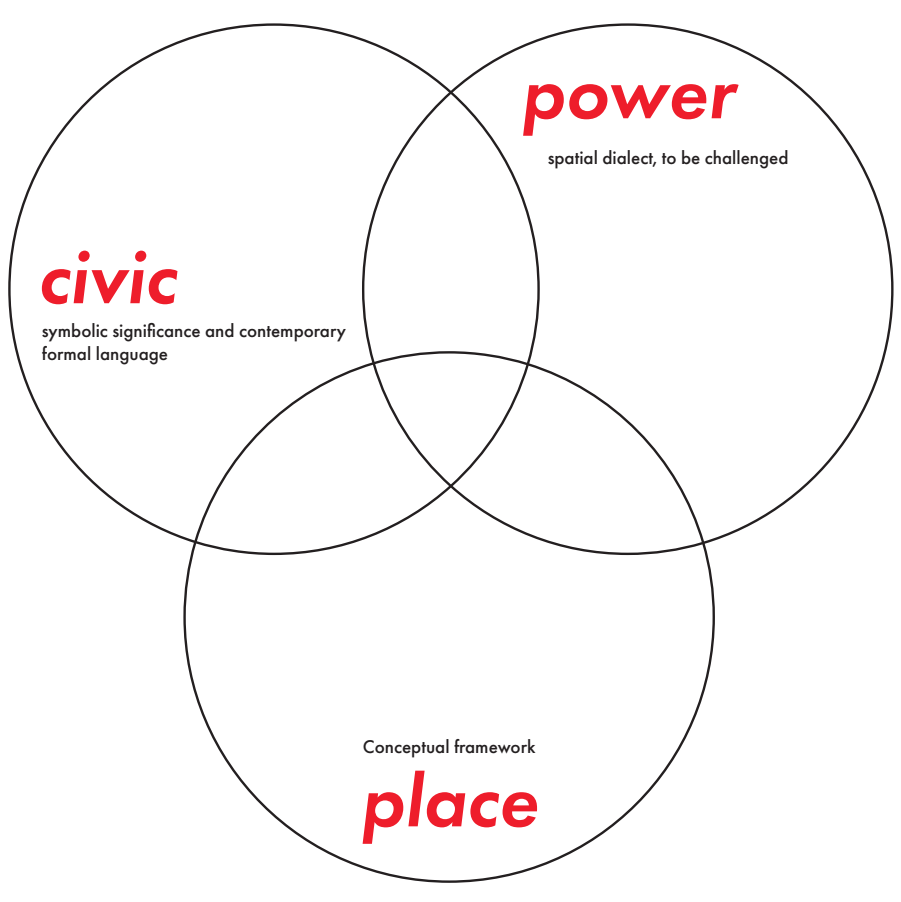

Social capacity which grows from an active public sphere." Amin.
Dovey, Becoming Places, 11

Dovey, 13

Dovey, 11

Delanda, A New Philosophy of Society Assemblage Theory and Social Complexity, 12.

Dovey, Framing Places: Mediating Power in Built Form, 11

Dovey, Framing Places: Mediating Power in Built Form, 1.

Dovey, 22

Dovey, 52

Dovey, 50

Dovey, Becoming Places, 24

Rowe, Civic Realism, 9

Rowe, 34

Rowe, 66

Rowe, 66

Rowe, 117

Rowe, 205

Rowe, 215

Amin, "Collective culture and urban public space", 6

Amin, 7

Amin 6

Amin, 10

Amin, 12

Dovey, "Dialects of Place" in Deplacing, 49

Hillier and Hanson, The Social Logic of Space, 1

Dovey, Becoming Place, 14 


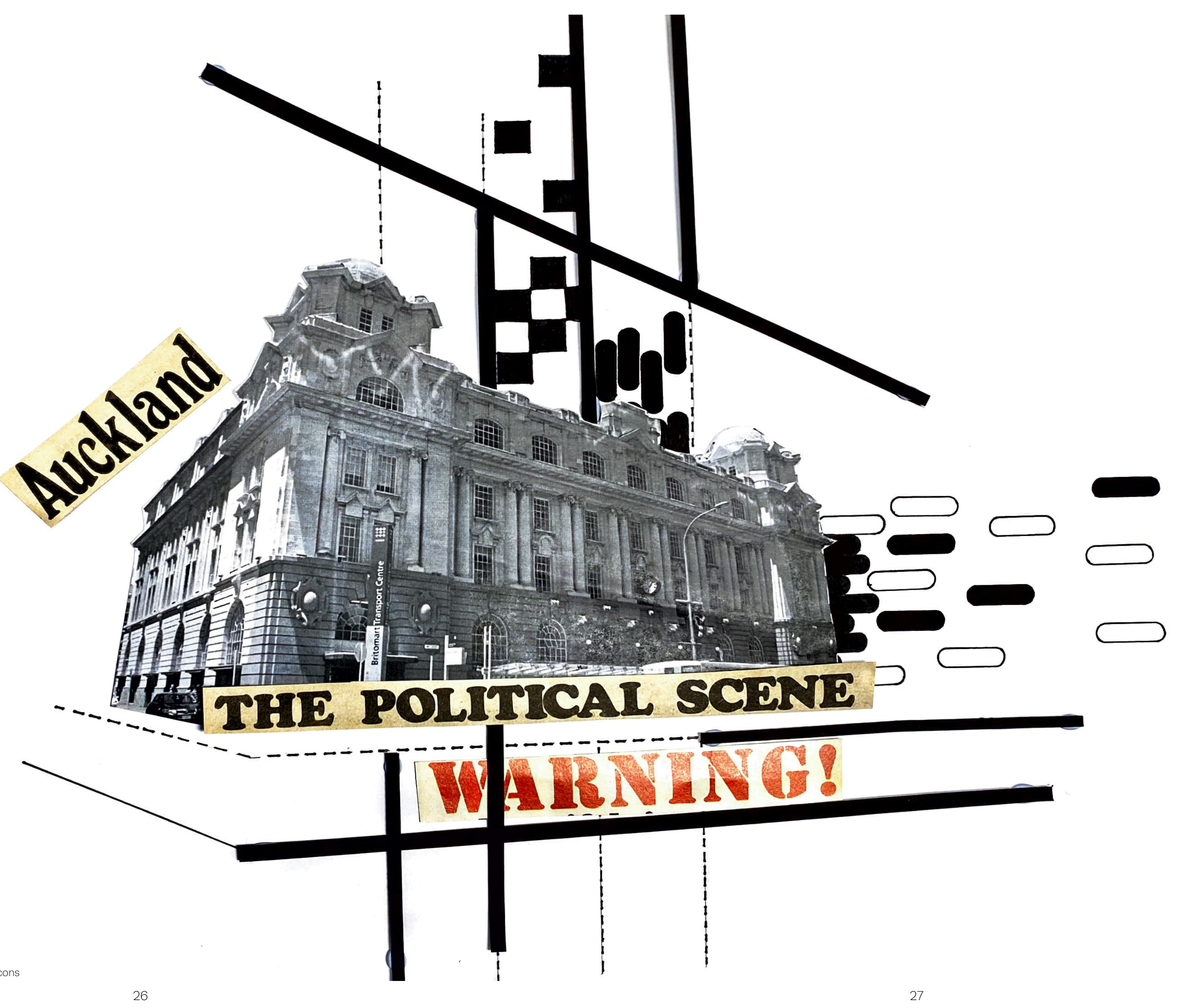


This chapter is an exploration and enquiry into the series of maps were used to analysis the changing historical background of the traditional town hall and the spatial footprint of civic buildings across Auckland City. civic presence in Auckland. A spatial analysis of twentieth The aim is to show that the physical presence of civic century town halls in New Zealand critiques design building is decreasing in a city. As a result there is an similarities. This outlined how unfitting the traditional absence of representation of the relationship between classical Town Hall design is for today's society. A local government and the collective which makes up the public

The Traditional Town Hall

Analysis

Conclusion

Changing Civic Presence

Conclusion

Building Type Study

Conclusion

Design Criteria 
The Traditional Town Hall

During the early 1900's various civic buildings held symbolic meaning of both community and authority, these included building types such as; municipal offices, town halls and courthouses. These buildings were recognised as the centre of civic life. ${ }^{1}$ The traditional town hall had specific functional requirements; to accommodate the city's public servants and host large events in a grand hall. The building type had a recognisable language which is common to many individual examples.

This following section makes an enquiry of the spatial planning of three traditional town halls across New Zealand, to develop an understanding on how town halls in the early twentieth century were spatially programmed.
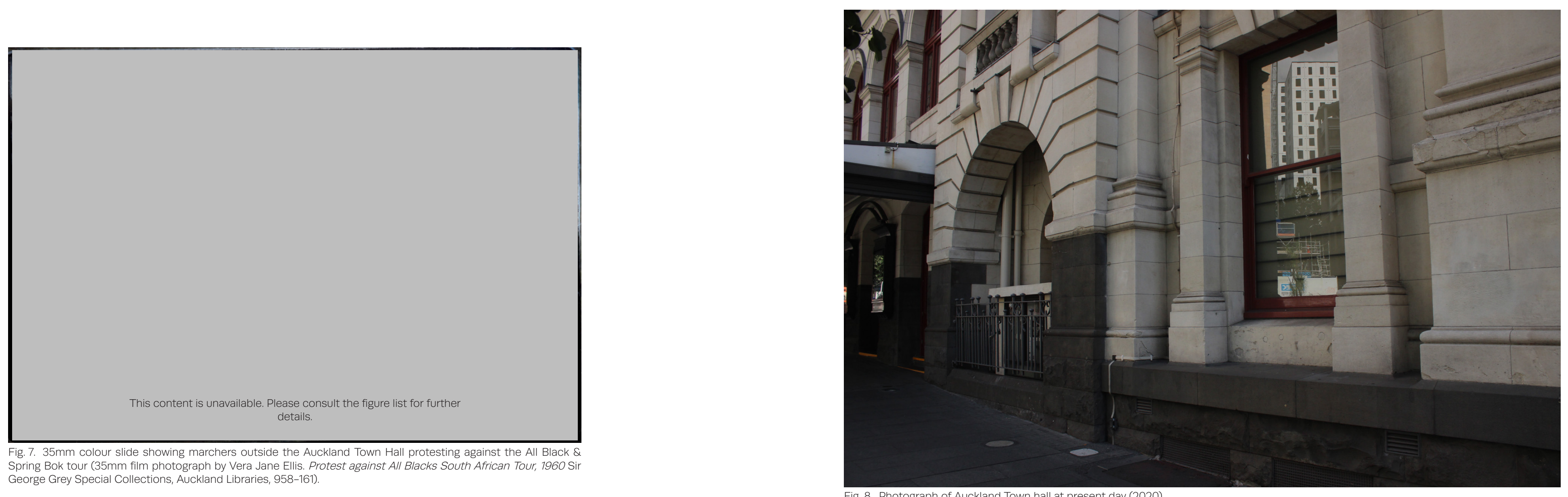
The Auckland town hall is an iconic piece of neoclassical the triangle. The council chamber, a room of high status, architecture. The auditorium, seating up to three thousand was located at the centre of the building with the mayor's people, hosted many cultural and social functions during office across the way. Hallways circle the council chamber the early twentieth century. Although by the 1960's, room, giving access to the offices. The different users; the number of staff in the Auckland City Council was public, staff and performers have separate spaces and already too large to be housed in the town hall. The would very rarely mingle or informally interact with one municipal accommodation was then moved to a modern another. The interior finish is of art nouveau character; Administration building next door in the 1960's but was these include stained glass windows, decorative tiles and vacated in 2014. The staff can now be found in 2 separate cast iron balustrades.

office buildings across Auckland city.

The Auckland town hall was designed by the Melbourne based Clark brothers, who won the design by competition. The Clark's were known for their design of public buildings across Australia. ${ }^{2}$ The design of the Auckland town hall took on a wedge shape, dictated by the shape of the site, the great hall positioned asymmetrically in plan, the local council offices at the slimmest point of 


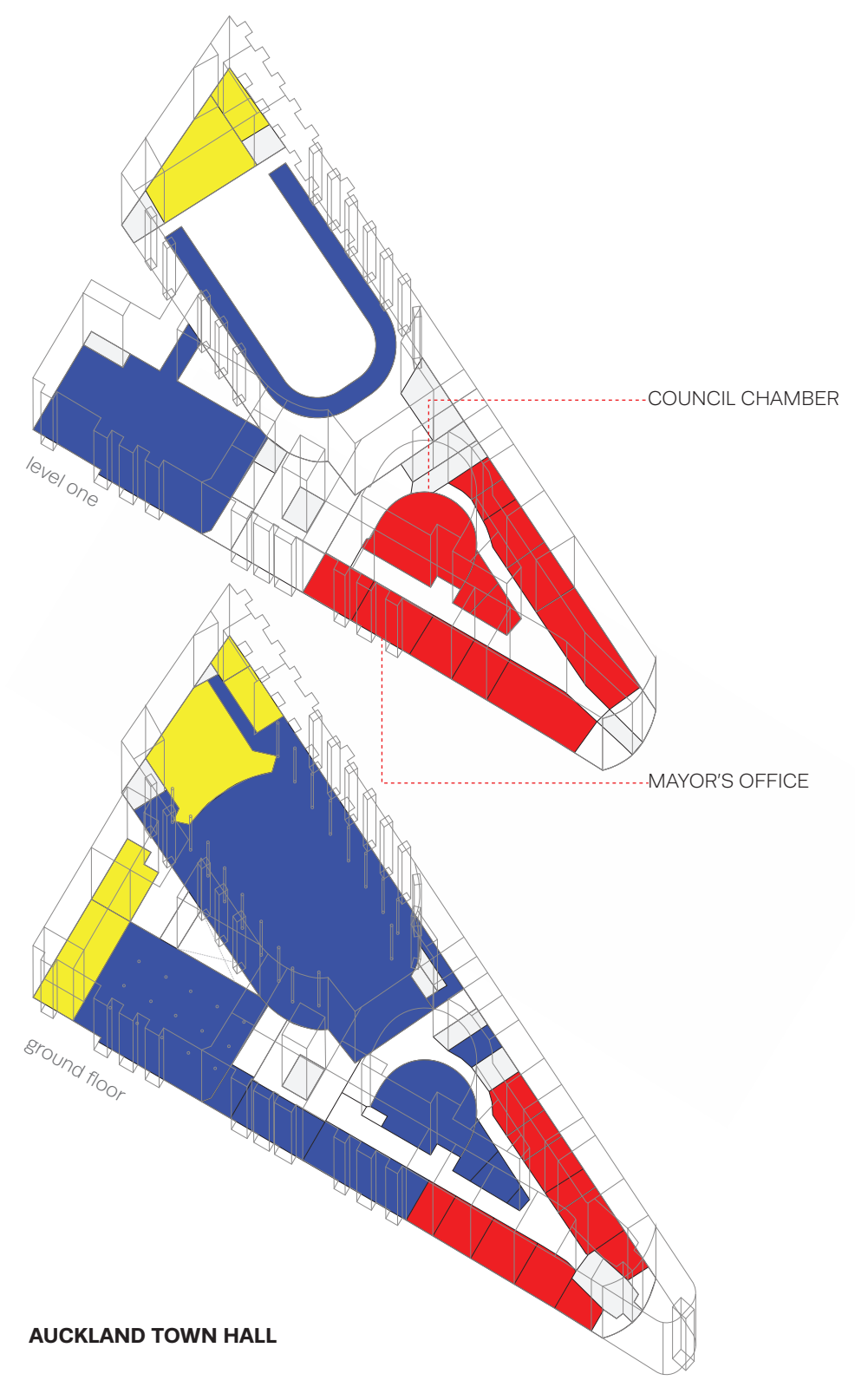

Fig. 11. Axonometric projection of Auckland town hall showing a graphic analysis of three main user groups and how they are spatially represented in plan. Council staff, performers and public with the other users of the town hall otherwise the organication limits the interaction-.
The dense Limestone facade is composed of symmetrical elements with classical motif styles surrounding the windows. The windows are proportionately small in comparison to the size of the building. Particularly when considering the design of current public buildings, where there is generous glazing. An iconic feature of many town halls is a clock tower, the Auckland town hall is no exception.

The location for the Auckland town hall allows for it to be visible along a central street in the city. It projects out and offers itself to Queen Street and to Aotea square, which was realised a few decades after.
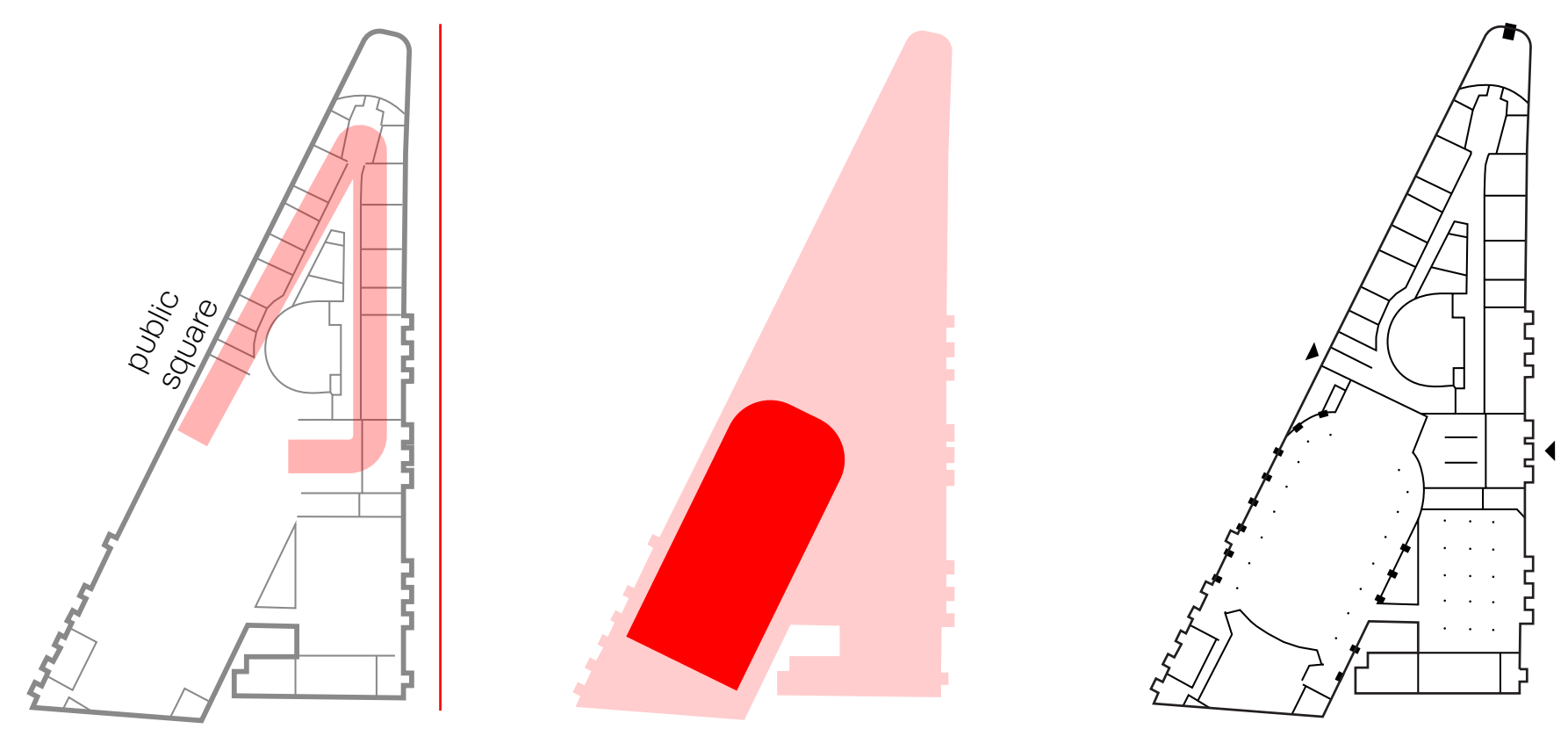

Fig. 12. (From left to right) Public circulation through the town hall, its relation to the road and Aotea square. Spatial hierarchy allocated to the main auditorium; offset from the centre. Main entrances are indicated at ground level. 


\section{Wellington Town Hall, 1904, Joshua Charlesworth}

The Wellington Town Hall was the first of the major town dominated one end of the well-known Cuba Street. In halls to be constructed in New Zealand. The design of the the 1970's it was threaten that the building would be town hall was built for the purpose of combing a space demolished, as the Michael Fowler Centre had been for cultural events to take place and a location for council established near the main entrance. The public valued administration to be under one roof. The local architect the historical and civic relevance of the town hall where Joshua Charlesworth's design won the competition for the outcome was preservation. ${ }^{5}$ When it was first built the new town hall. ${ }^{4}$ Like many town halls the Wellington the town hall had an additional concert chamber on the town hall was built with an iconic clock tower although second floor, throughout its lifetime the town hall hosted this was removed as precautionary measures if an many events in both the main hall and the concert hall. earthquake were to occur. Due to Wellington being prone The interior space can be considered to have been divided to earthquakes the town hall underwent removal and into two core spaces; the auditorium and the municipal alterations to exterior features, including the entrance offices. portico.

The main structure is brick and mortar, the exterior The overall shape of the Wellington Town hall is features were formed in concrete. With consistent concern conventionally four sided; the street front edge is more about damage caused by earthquakes, external elements irregular. When first constructed the town hall projected were removed from the original classical renaissance onto a street corner, the three storey high building design. 


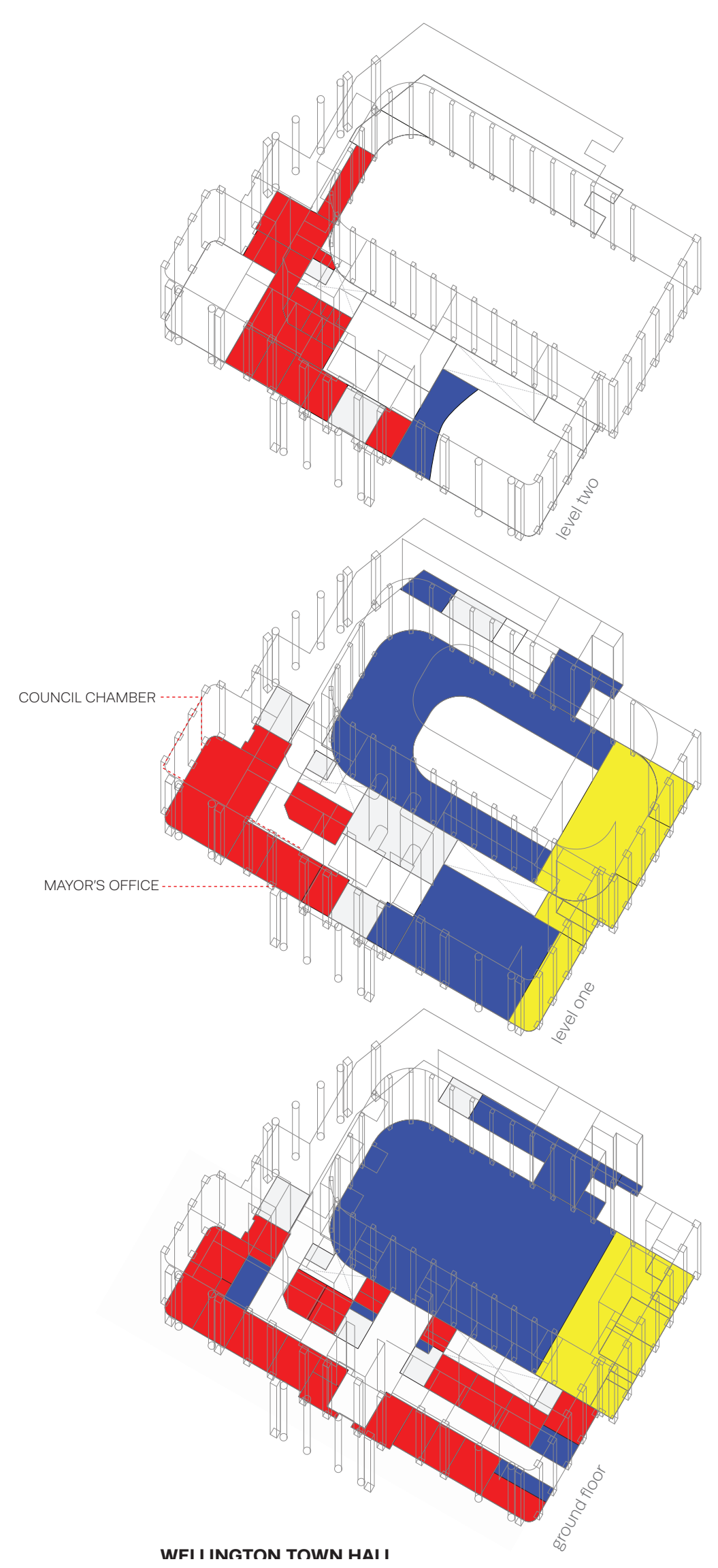

Fig. 15. Axonometric projection of Wellington Town Hall. Highlighted is a clear some cases the public are given "reception" or waiting areas amongst the council offices.
The overall form of the Wellington town hall is regular and symmetrical from the exterior, while the internal layout is asymmetrical. The ground floor is largely occupied by the main auditorium, off to one side, are the council offices and front of house occupy the other side. There is minimal interaction between the different user groups because of the separation between spaces, and specifically allocated waiting rooms for public. The mayor's office and council chamber could be found on the second floor corner with a view. This is typical of traditional town hall designs, spaces for those highly ranked in the City Council received desirable rooms/offices. The styles is a classical composition typical Edwardian features. ${ }^{6}$ While it has been documented that there were many events held at the town hall in the early twentieth century, these events were measured and ordered, the public would typically require an appointment or an event to attend the town hall.
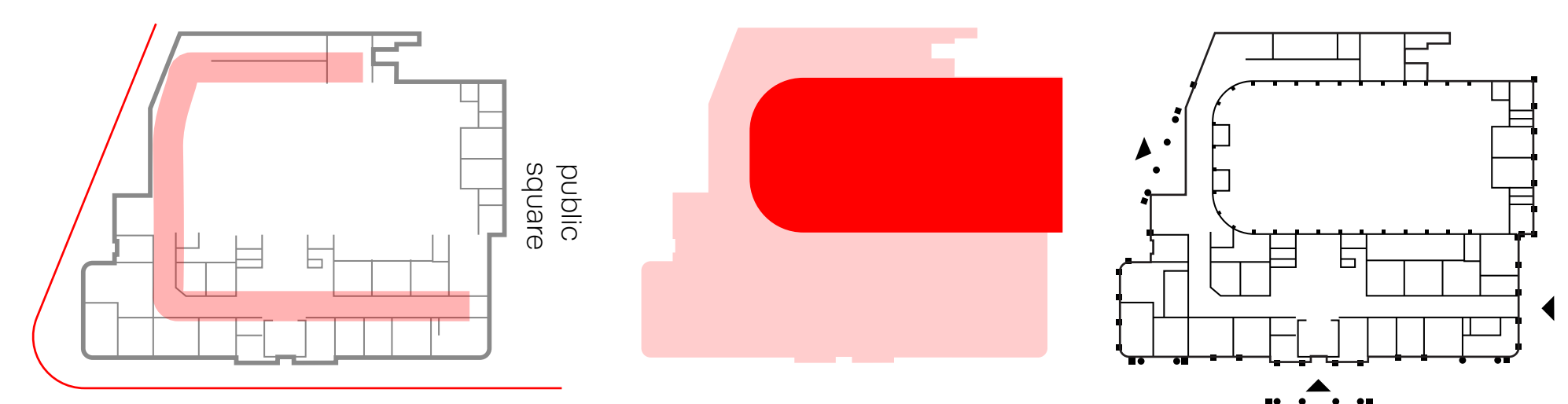

Fig. 16. Diagrams of Wellington Town Hall (From left to right) circulation through the ground floor, the main auditorium is offset in plan and various acce 
The Dunedin Town Hall is one of the few traditional The rectangular site allowed for a symmetrical design; styled town halls in the country that accommodates at one end the municipal offices and at the other end municipal staff in present day. It is located in what the main auditorium. Each functional space is divided is known as The Octagon, a central area in Dunedin's by what is known as the Glenory; a smaller conference spatial planning. Completed in 1930, the winning design room. In plan the town hall is divided into three of the town hall was realised by Henry Mandeno and Roy parts. The main auditorium is above a basement level Fraser. Mandeno and Fraser's design was an addition greenroom, musician changing rooms and storage space. to the existing municipal chamber, constructed back in The vestibule entrance of the town hall was a part of $1880 .^{7}$ the competition requirements. The original floor plans specify spaces where the public are able to access and wait to see staff. The mayor's office is found at a corner, which overlooks The Octagon. ${ }^{8}$ 
All elevations of the narrow town hall have a symmetrical design, Moray Place elevation is a classical styled design it appears grand for the publics use to the main auditorium. There are two staircases at either end of the Moray Place elevation which are visible from the outside. Typically

classical designs have solid facades, which does not

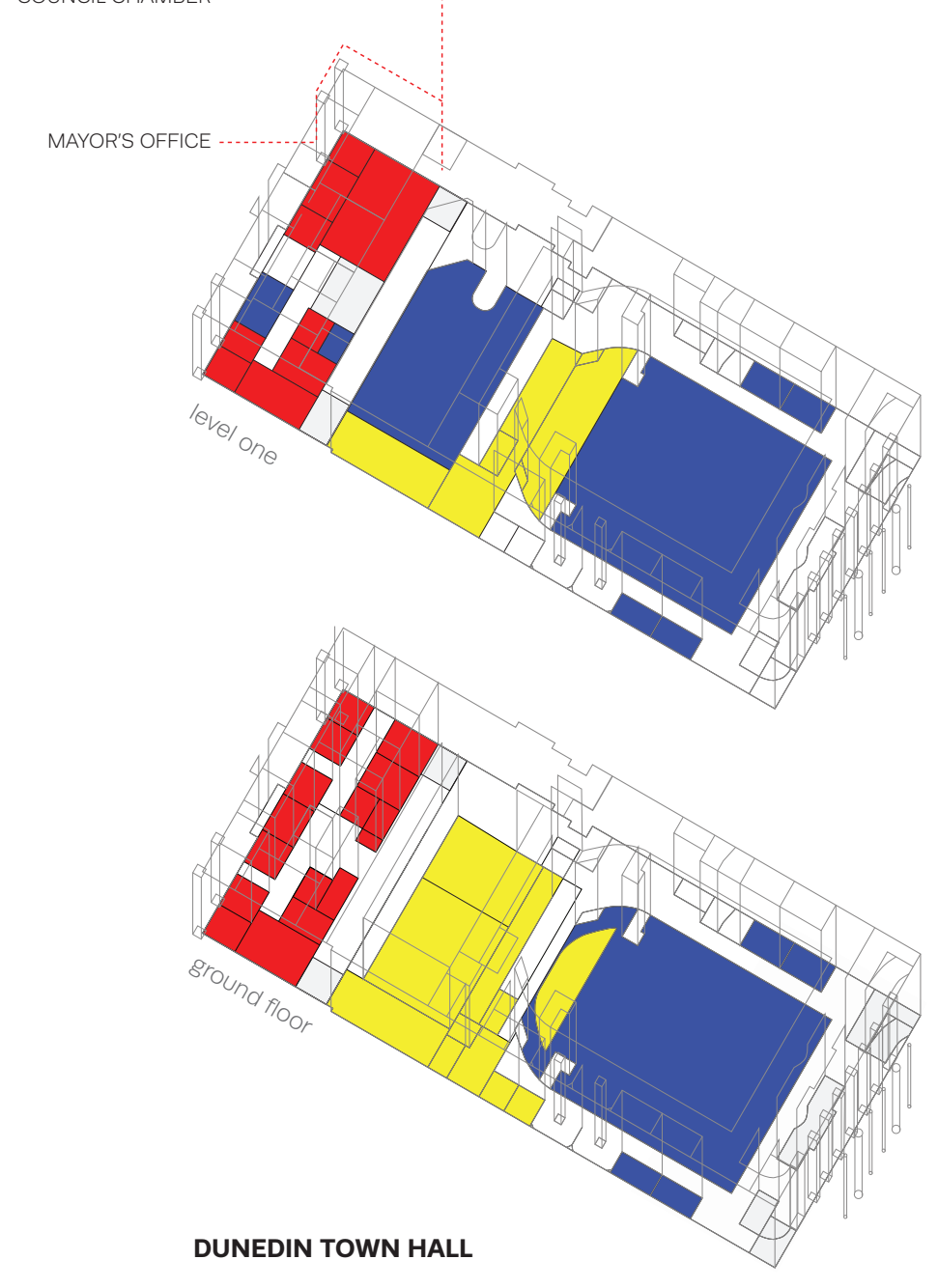

Fig. 19. Axonometric of Dunedin Town Hall, which shows the symmetry in the design and the separation, in the short airection, between the space and with performers or public.
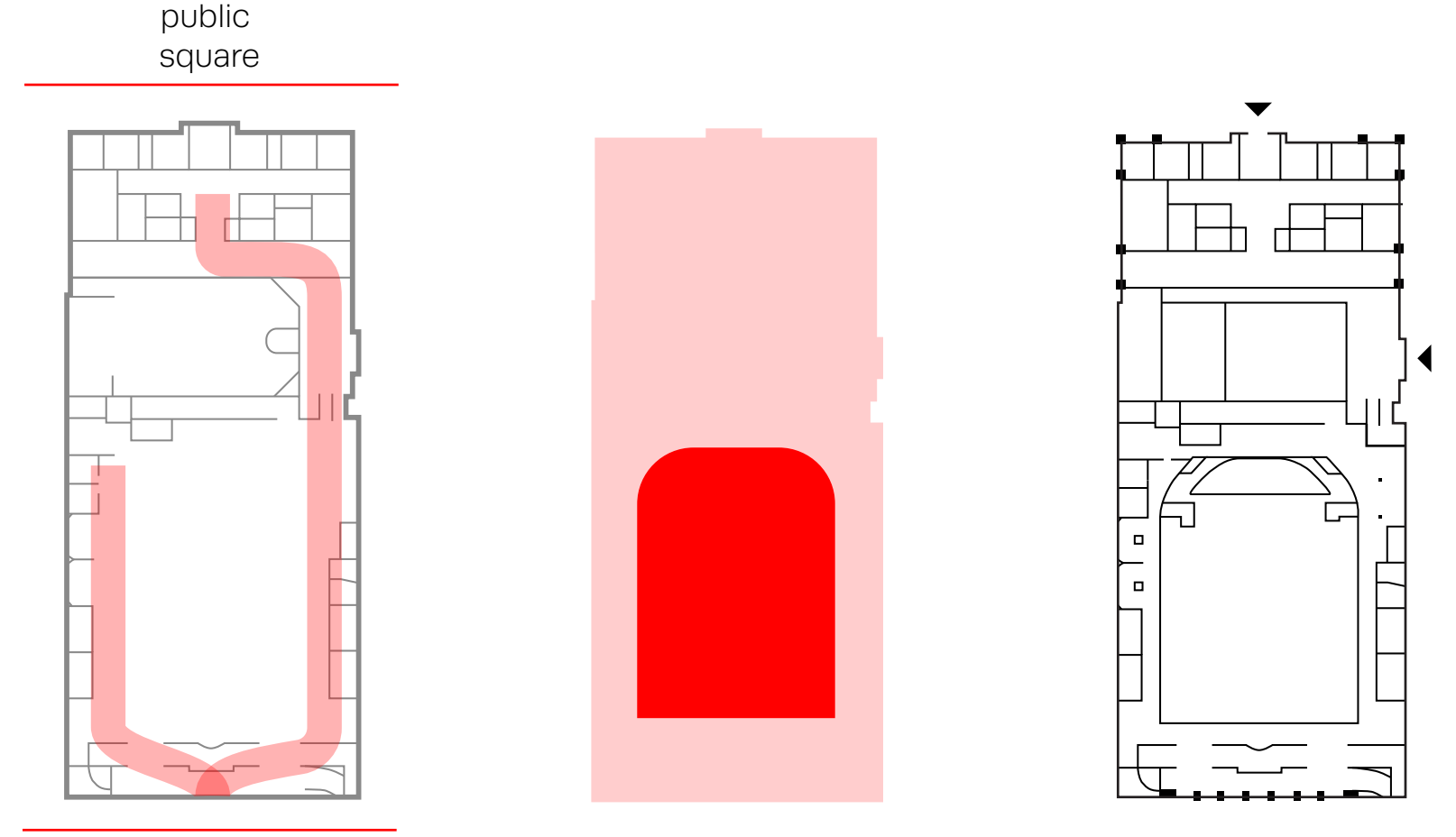


\section{Conclusion}

During this analysis it is clear in the past there was a particular design driver of civic buildings. The exterior was thought to be impressive and representative of a city's influence. The spatial design was driven by the functional requirements of the users; such as offices, meeting rooms and waiting rooms. Spatial hierarchy was given to the great hall, the council chamber and then the mayor's office. This is evident in the detail of the interior and the distribution of space. The placement of the three different large assembly spaces within the building's envelop is eccentric in all case studies, occupying the large portion of the floor which it is accessed from.

The location within the city of all three town halls is proven to be on prominent sites. In the vicinity of the city squares; a location where civic practices typically take place, particularly when first built. Whether the buildings were constructed before or after the civic squares were allocated, the location helped define central locations within each city.

Classical style town hall designs are generally no longer suitable for both the local government and for the public. The spatial programming does not encourage the collaboration of different user groups, resulting in a lack of unification between the community and the local authority. Another common element which this analysis identified was the dissociation of the interior and the exterior. From the outside the town halls appear solid and give seldom away of the proceedings inside. The spatial structure of the traditional town hall supports a dated structure of society. There is a lack of transparency and visibility in the everyday operations of local government. The research revealed that each town hall had an opaque façade, supported by the choice of materials and size of the openings. Exterior walls were made up of brick or stonework, which has a sense of solidness and concealment.
Features which appear common in town hall design include the clock town. When town halls were first constructed, cities the clock tower could be seen as a beacon within the city, visible from afar and a monument in the city. ${ }^{9}$ The symbolic meaning of height in architecture is a spatial dialect of power, traditionally vertical dominance is understood socially through concepts of power. ${ }^{10}$ The time during the construction of the town halls across New Zealand was during great urban development." Civic buildings and spaces encompassed civic life, symbolising the culture of that time. ${ }^{12}$ Today political practices have proliferated into work, school and communities. Civic participation can be experiences in a well organised inclusive public realm, within the city. ${ }^{13}$ This research critiques the outmoded approach to the design of town halls, where the architecture spatially divides users. Rather through the mingling and interaction of human in spaces, civic practices are strengthen across a collective.

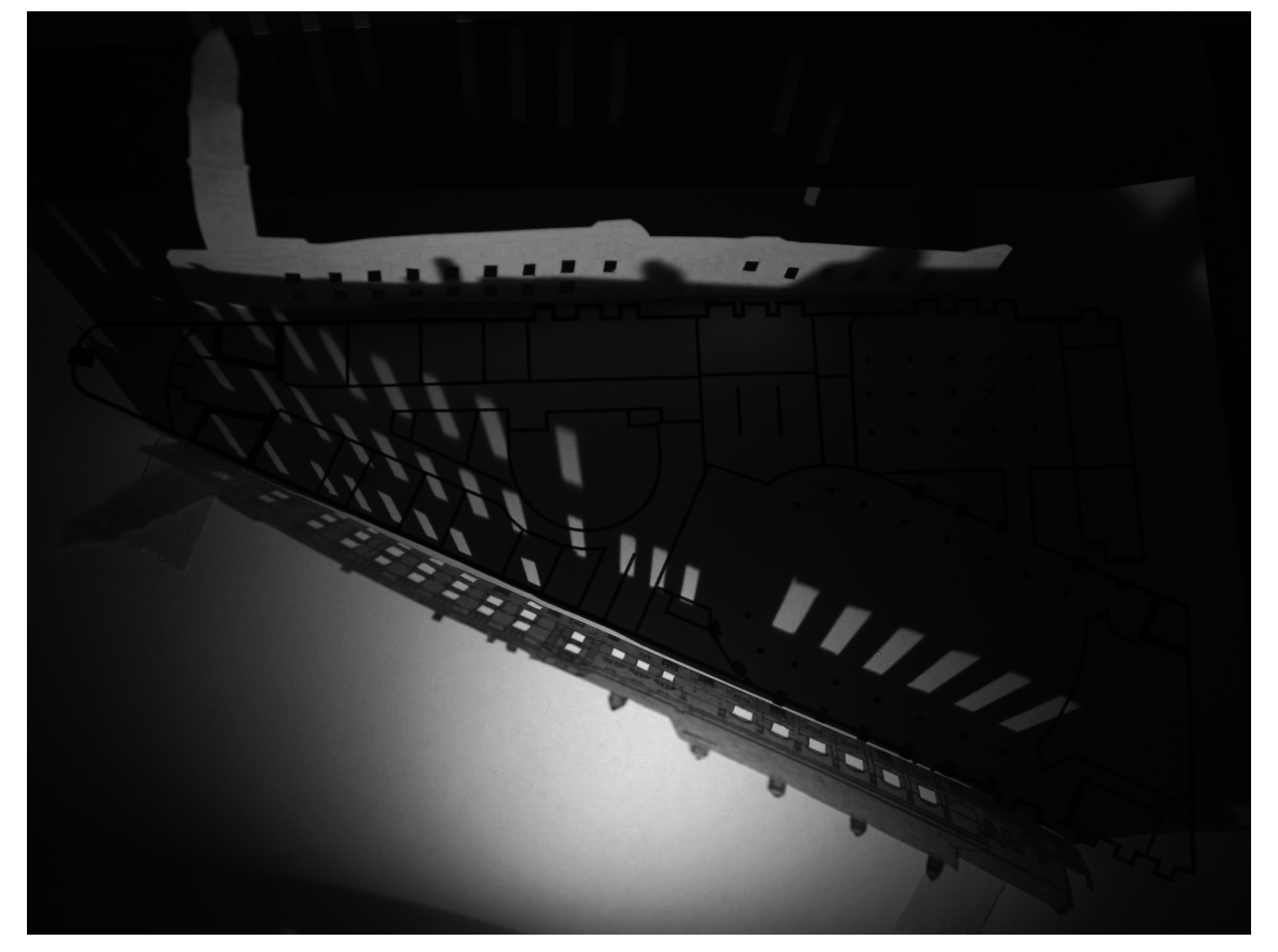




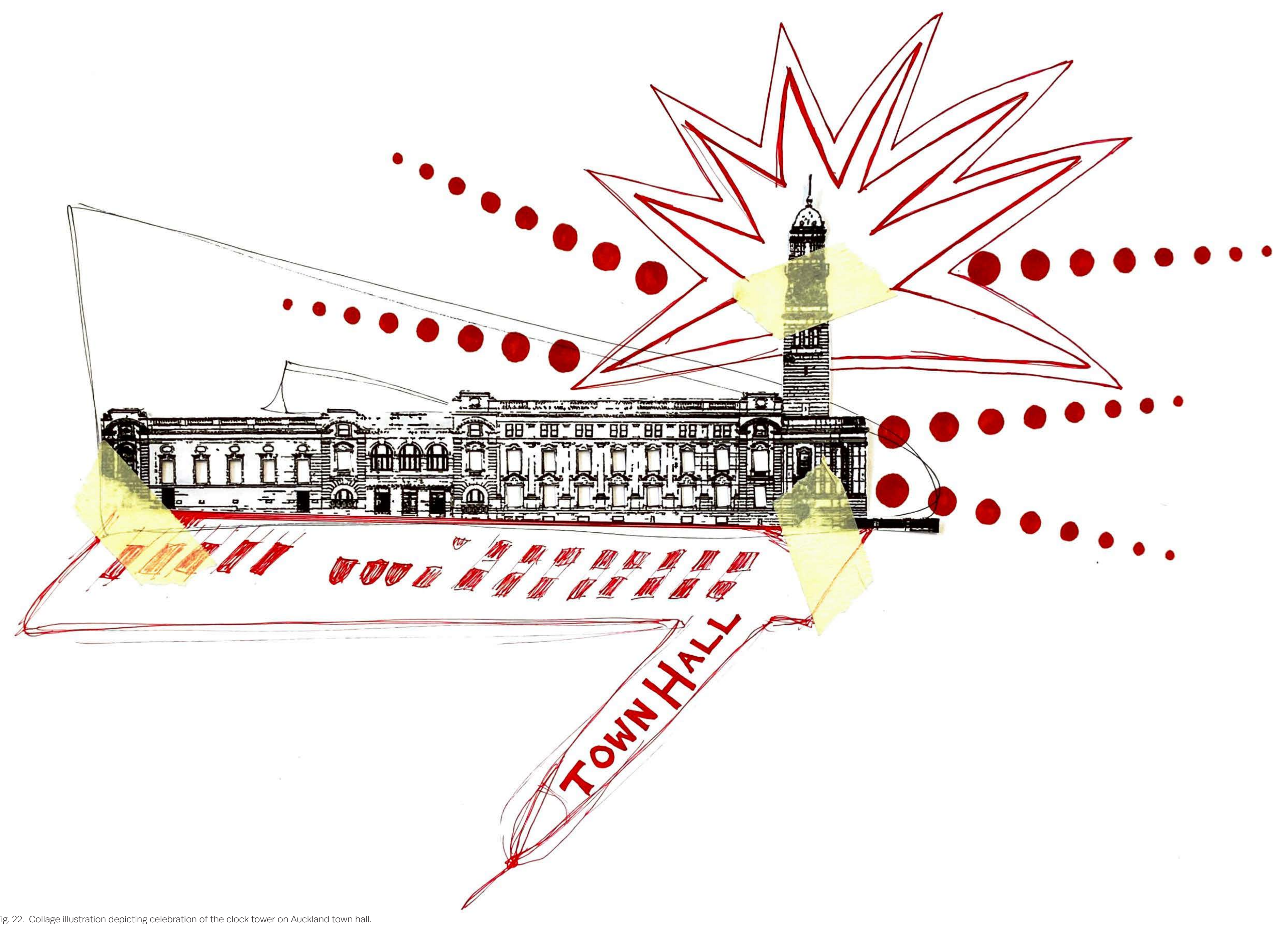




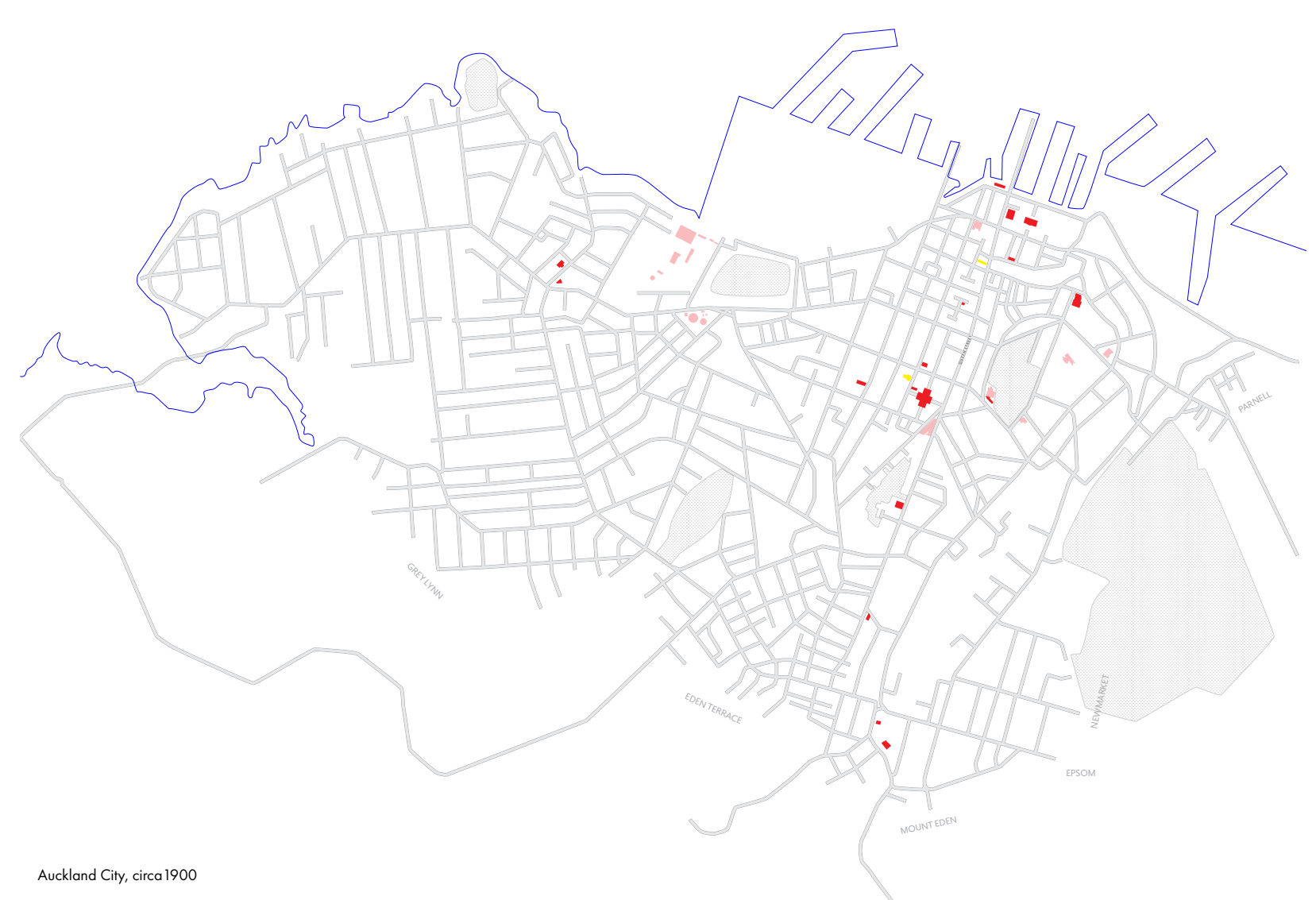

Fig. 25. This drawing shows the distributed spaces of civic performance. Spread across the city around 1900.

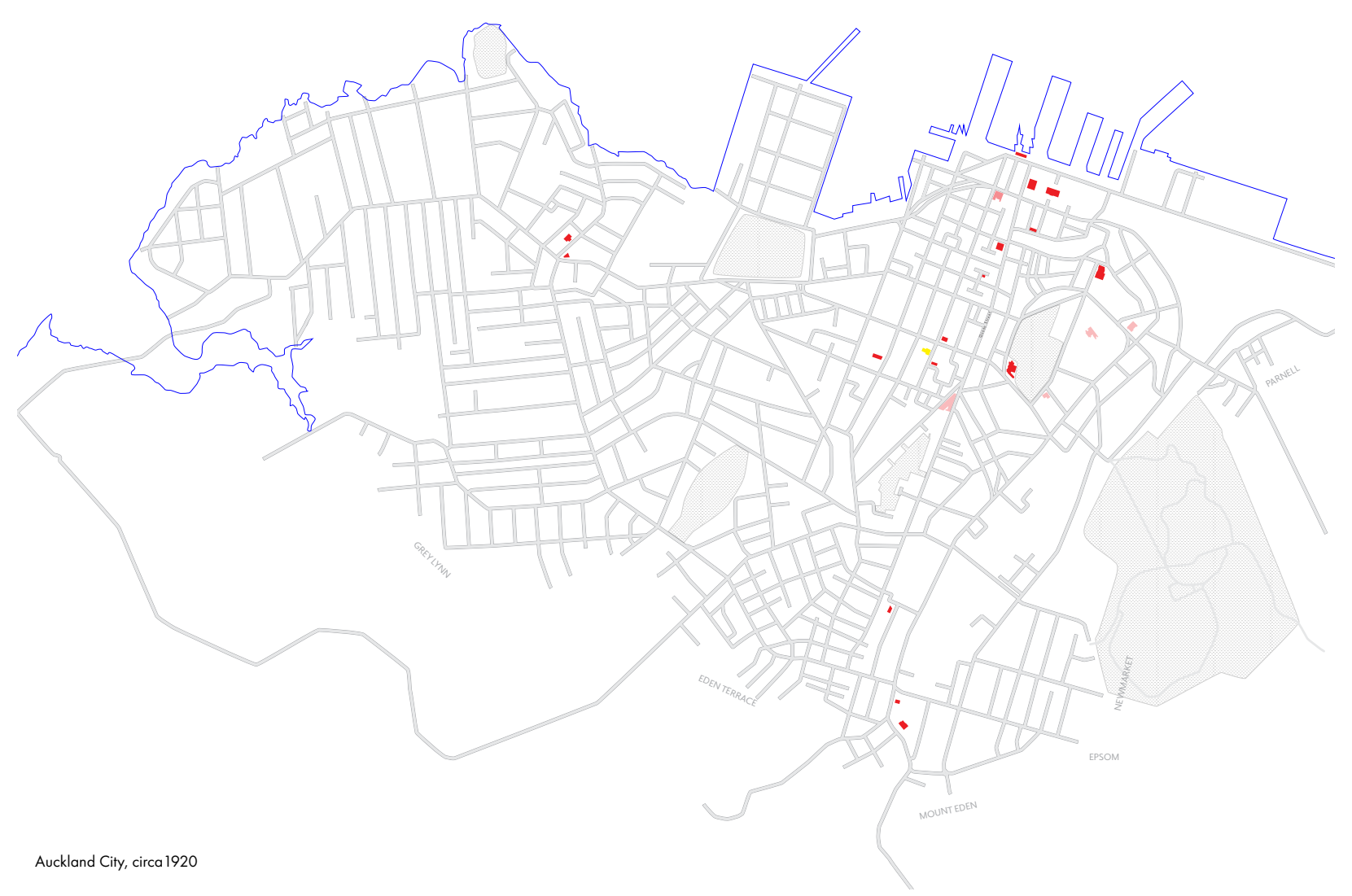

Fig. 26. Map of around the 1920's. Locations began to be more central towards the city. The outliers are libraries which still had a strong hold in the civic realm during the 1920

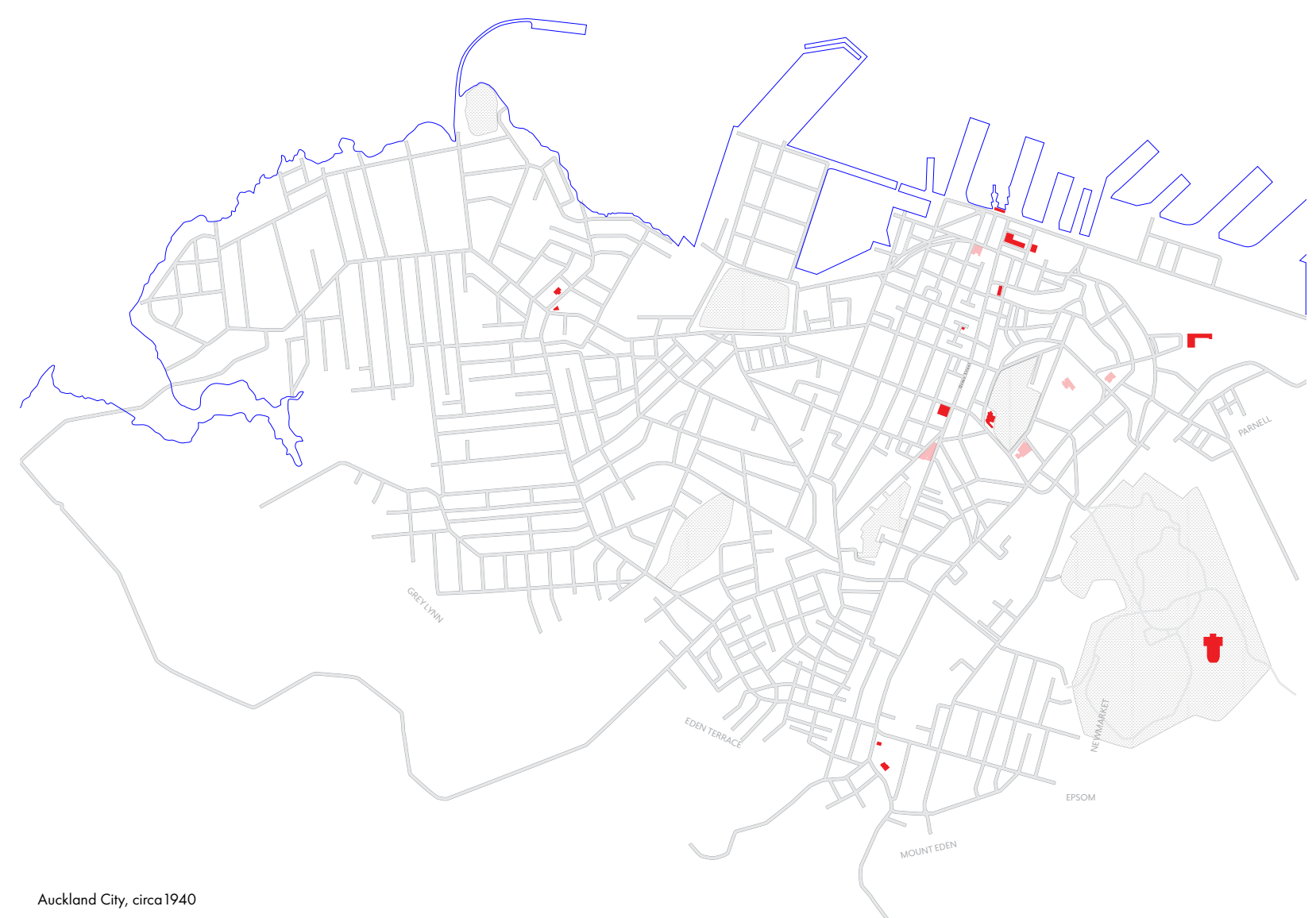
Fig. 27. (1940) There was visible development around the waterfront and at a similar time the civic footprint began to centre around
the city streets.

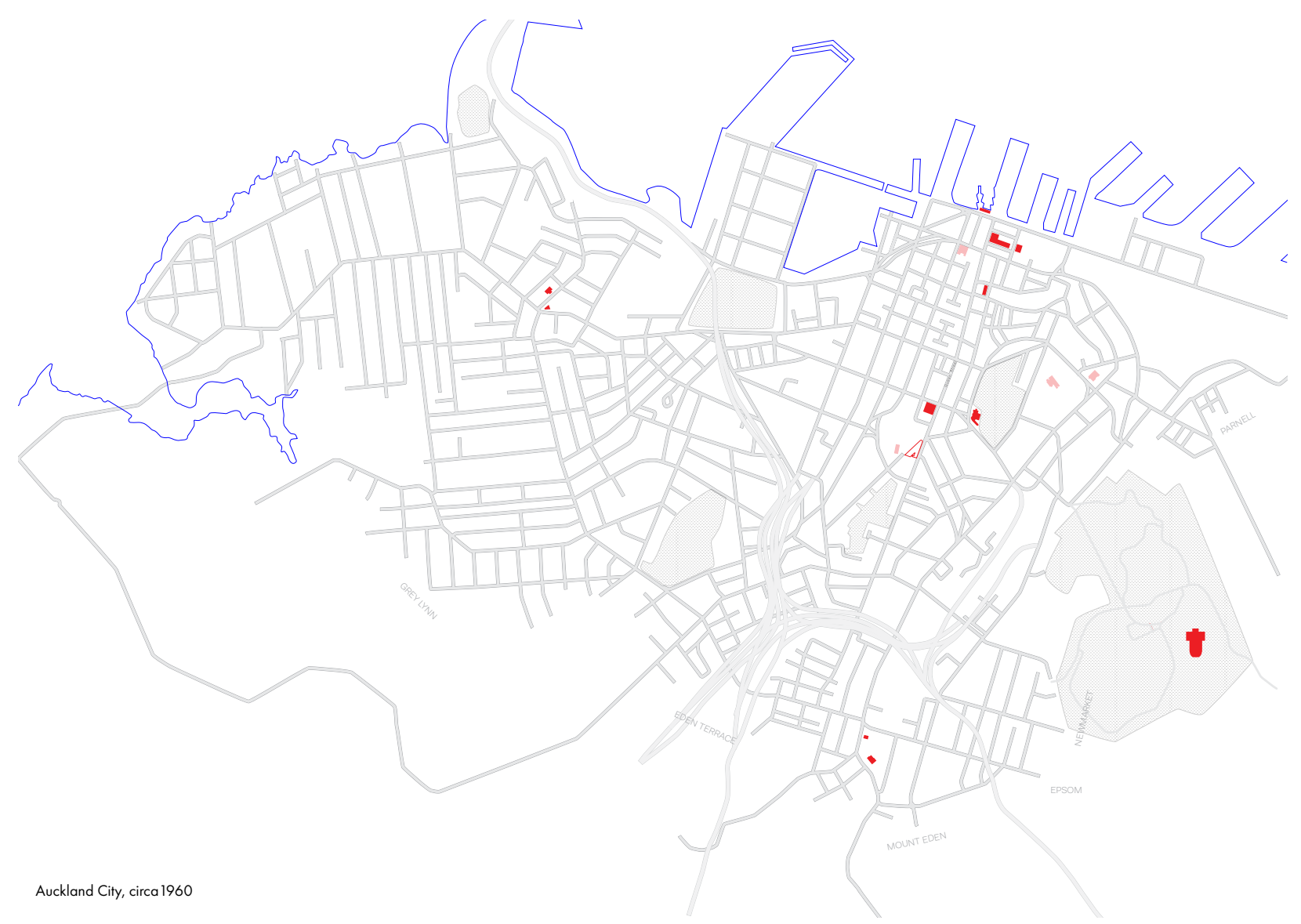

Fig. 28. (1960) Auckland began to sprawl with the motorway development, vehicle's dominated the city. It was during the 1960's that the Auckland City Council's Accommodation office block was constructed, leaving the town hall as a performance space.

50

51 


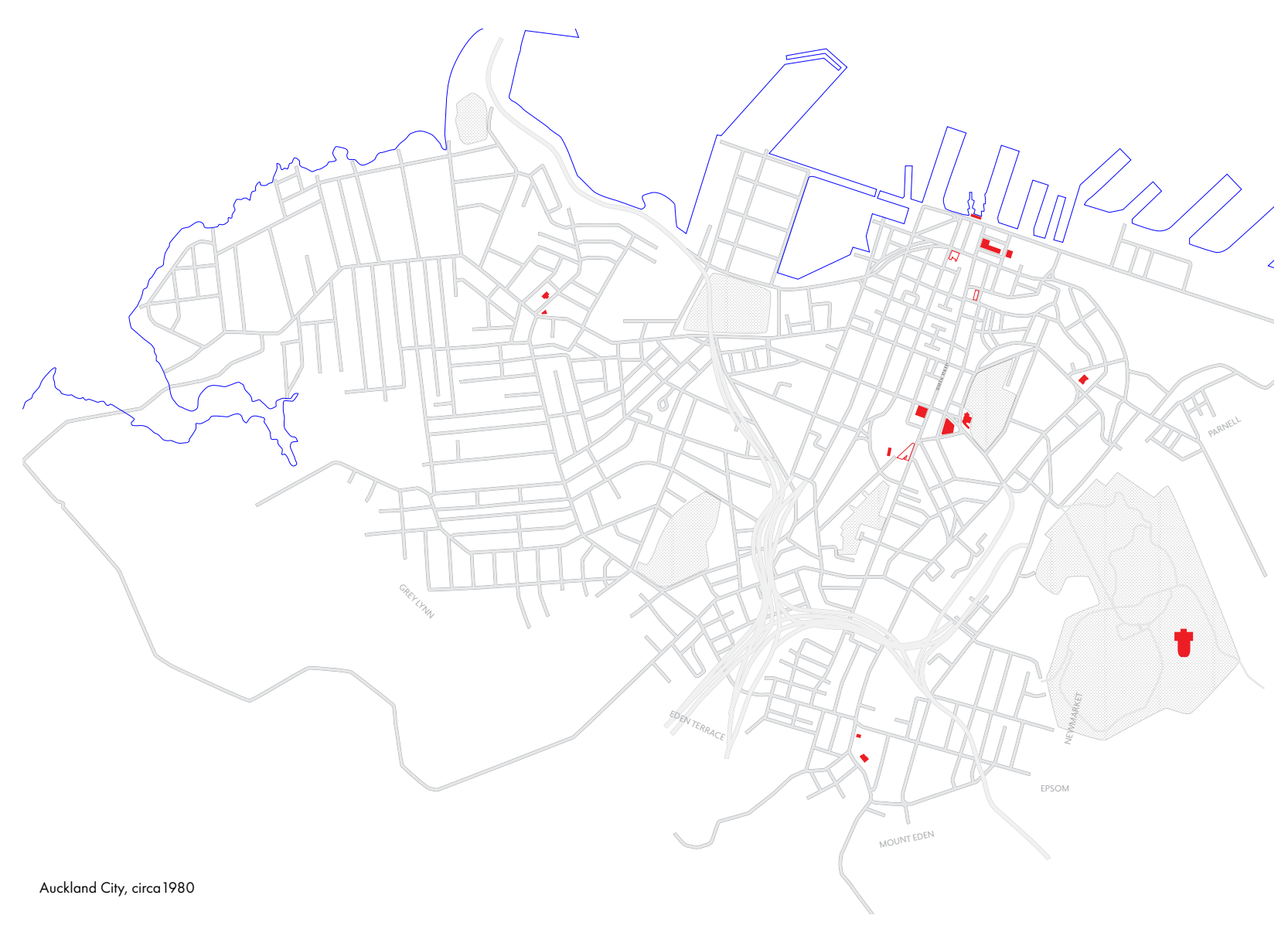

Fig. 29. (1980) During the 1980's there is a significant decrease of civic footprint across Auckland. Queen Street can be considered a corridor for civic buildings.

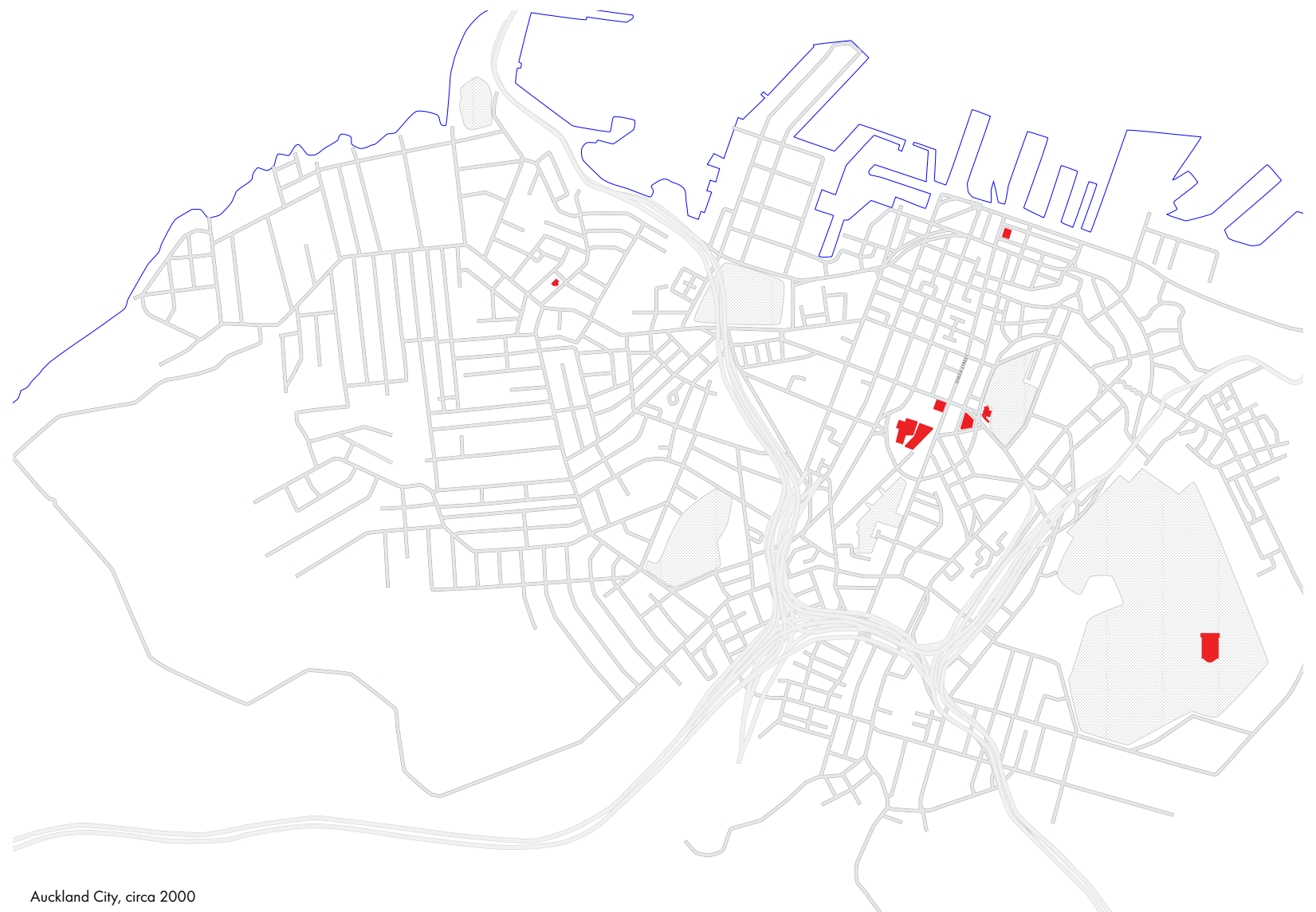
Fig. 30. ((2000) During the millennium civic building are considered libraries, art galleries theatres and museums. Places of public
gathering with a cultural factor.
With a variation of civic building going up over the last This study confirms that there is a decreasing footprint century there can be no single architectural style attached of civic architecture across the city. Although some to civic buildings, they have changed to accommodate original architecture still remains, it is what they for various users. ${ }^{19}$ For example, what is known now as represent as a symbol which has changed, calling for the Auckland City Gallery was first constructed to house a contemporary version of civic architecture. Over the

the municipal staff of Auckland city council and serve as century concentration was directed towards a single civic a public library. ${ }^{20}$

Currently spaces around Auckland city can be considered as successful public spaces, where a diverse group of people interact. These spaces include, the Britomart precinct, known as the central location for trades in goods and services when the European settlers first discovered Auckland. centre, orientated around the Auckland Town Hall and Aotea Square. This observation is visible in the maps fig 29. These maps (fig 25-31) have illustrated the changing and thereafter decreasing spatial footprint of civic spaces across Auckland City. An observation is made on the consistency of Queen Street being the central corridor for development. Queen Street has remained a central street where civic spaces are oriented around. This establishes a grounding for possible locations for this design case study.

This drawing (fig.31) illustrates the current spatial footprint of the Auckland city council. The mayor's office and the administration staff are found at 135 Albert Street. Where there are two customer service desks, 35 Graham Street and 24 Wellesley Street. These locations are accessed by the public only at ground level, while upper floors require appointments or scheduled meetings with council employees. 


\section{Conclusion}

This section has highlighted issues with the current An example of an architect whose work challenges spatial understanding of civic; symbolically and spatially, and arrangements to probe the social structure it is aiming to at various scales. At a human scale traditional civic represent is Rem Koolhaas. Koolhaas' intention is not to architecture no longer suits the relationship which is create a conflict with authority but rather programme a desired between public and local authority space to juxtapose users and functions. ${ }^{22}$ Koolhaas will often design the inside as if it were the streets of a city; The analysis which emphasised the decreasing civic offering many occasions for chance encounters. This can visibility in Auckland city over a century, indicates be considered a move towards, architecture not as the visibility in Auckland cisy over a century, indicates visual object rather as the facilitator of relationships and the changing view of civic, particularly what it means social interactions.

spatially. As this research outlines in the earlier chapter

civic is defined as a concept which highlights the

everyday performance of political life. This research will The shift in thinking of architecture as a field can be illustrate how architecture has the ability to facilitate the display of civic conduct.

understood through Stan Allen's writing. Allen defines the field condition as a spatial make up which allows the unifying of elements, with respect for the distinctiveness The town hall archetype analysis of chapter three has of each element. What is given importance is the illustrated an undesired the spatial working and meeting with city council employees and programming. ${ }^{23}$ the general public. From this a criteria can be formulated to guide the design of this thesis Stan Allen suggest that if architecture is considered a 'field condition', it can become a catalyst for relationship and interactions. ${ }^{21}$ Furthermore the civic mapping study has highlighted a lower profile of civic buildings within Auckland Central. This shift which has occurred over time, reinforces the need for this research to be carried out. In the search to establish an approach to a contemporary expression of local government. To have an emblematic existence in the city.

ए?

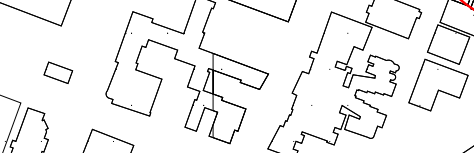

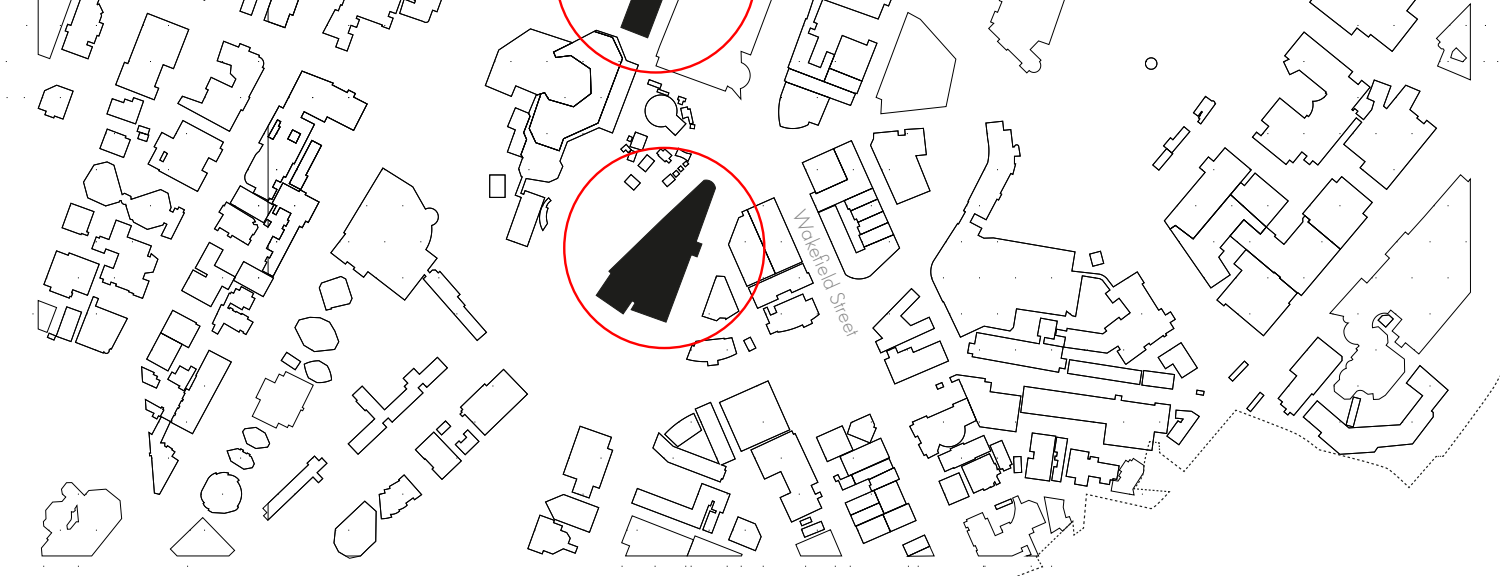

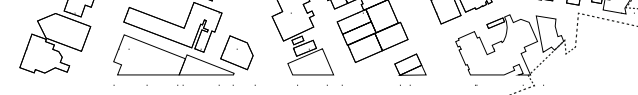



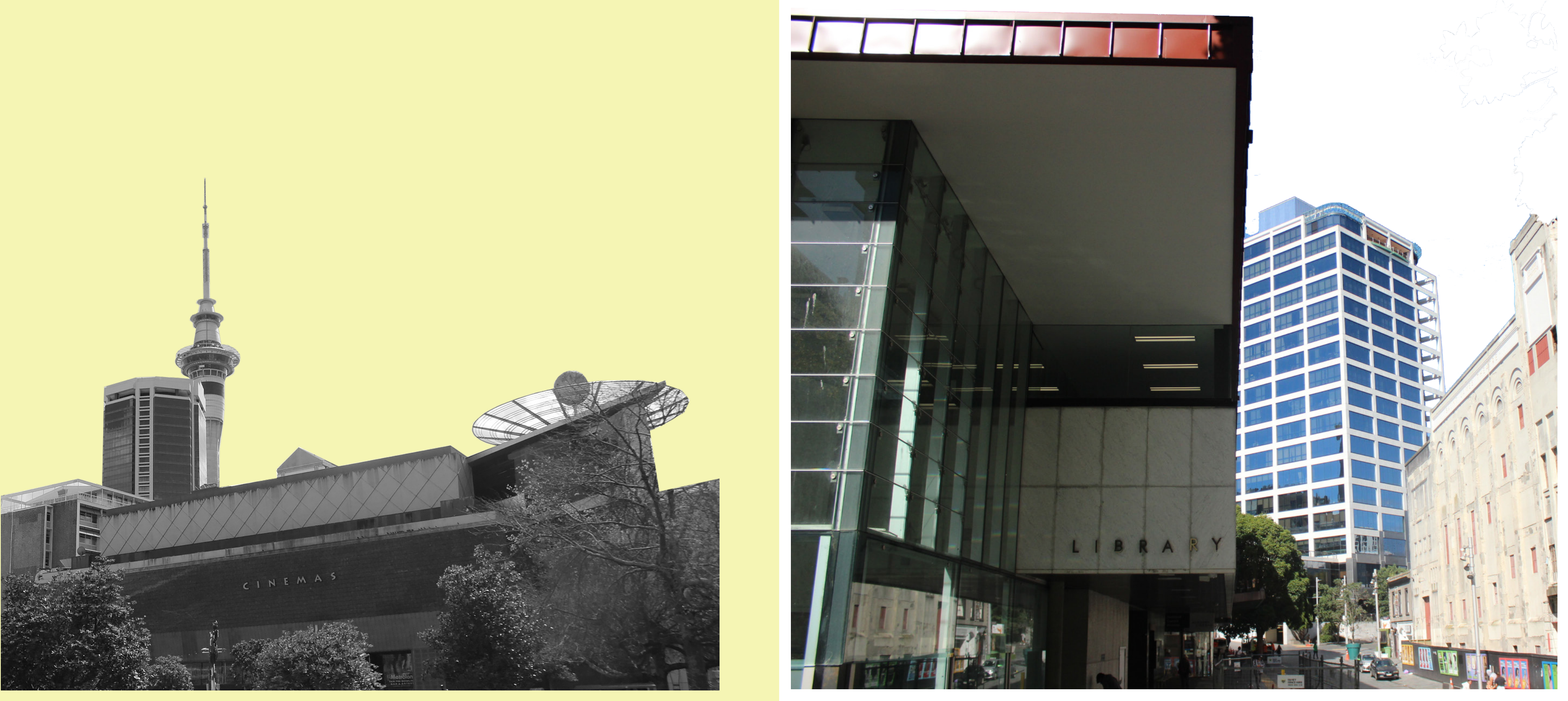


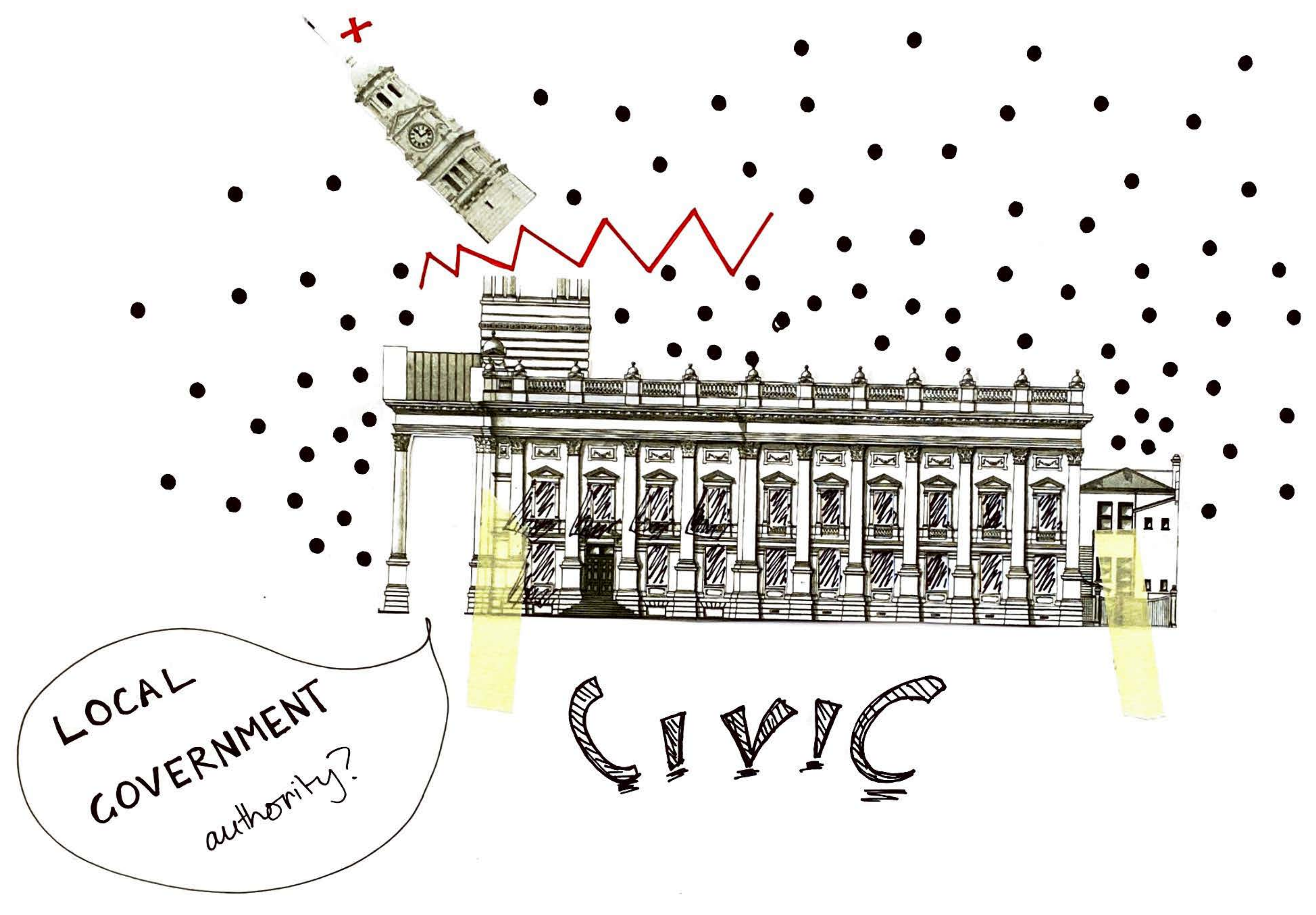




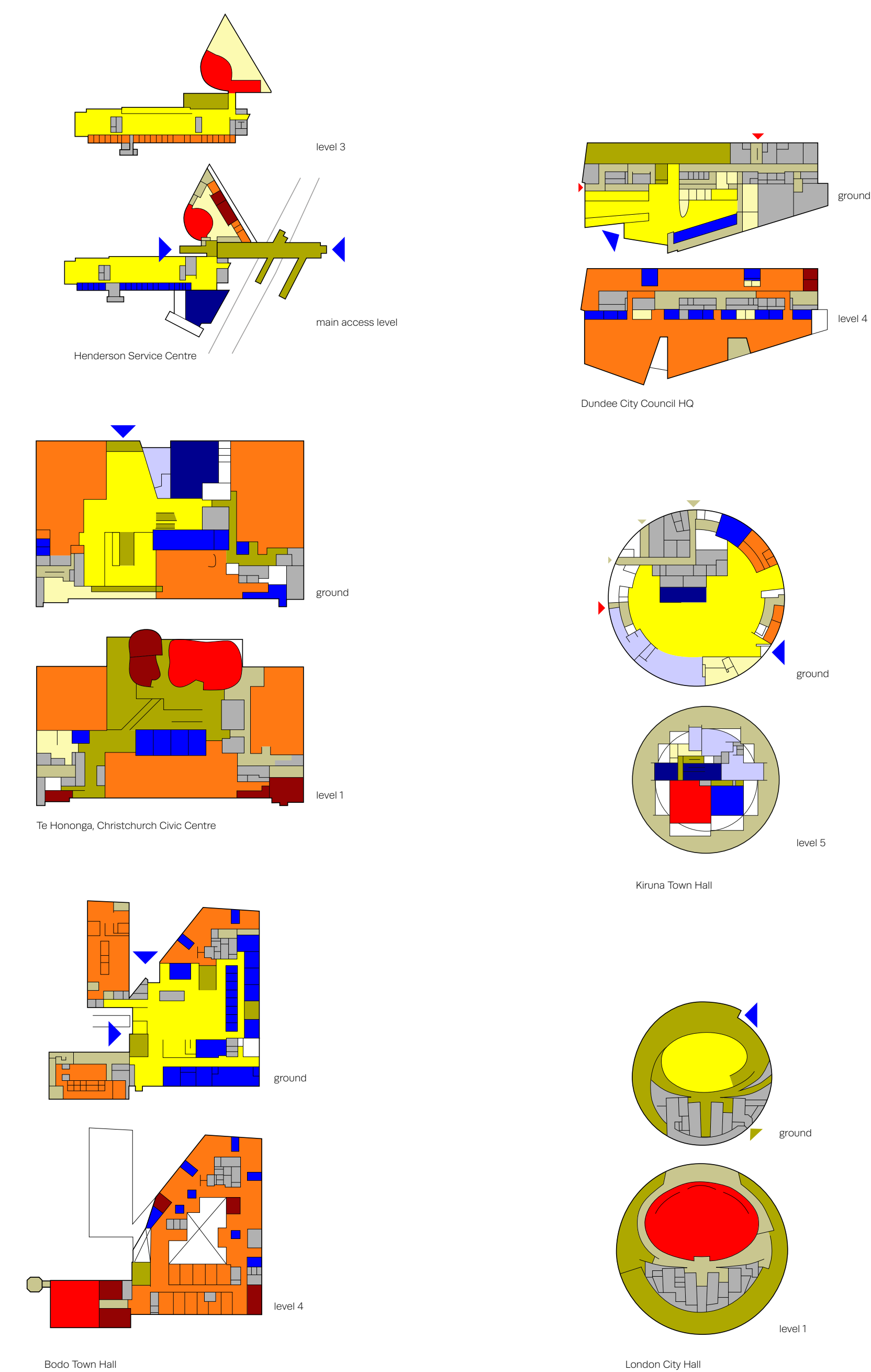
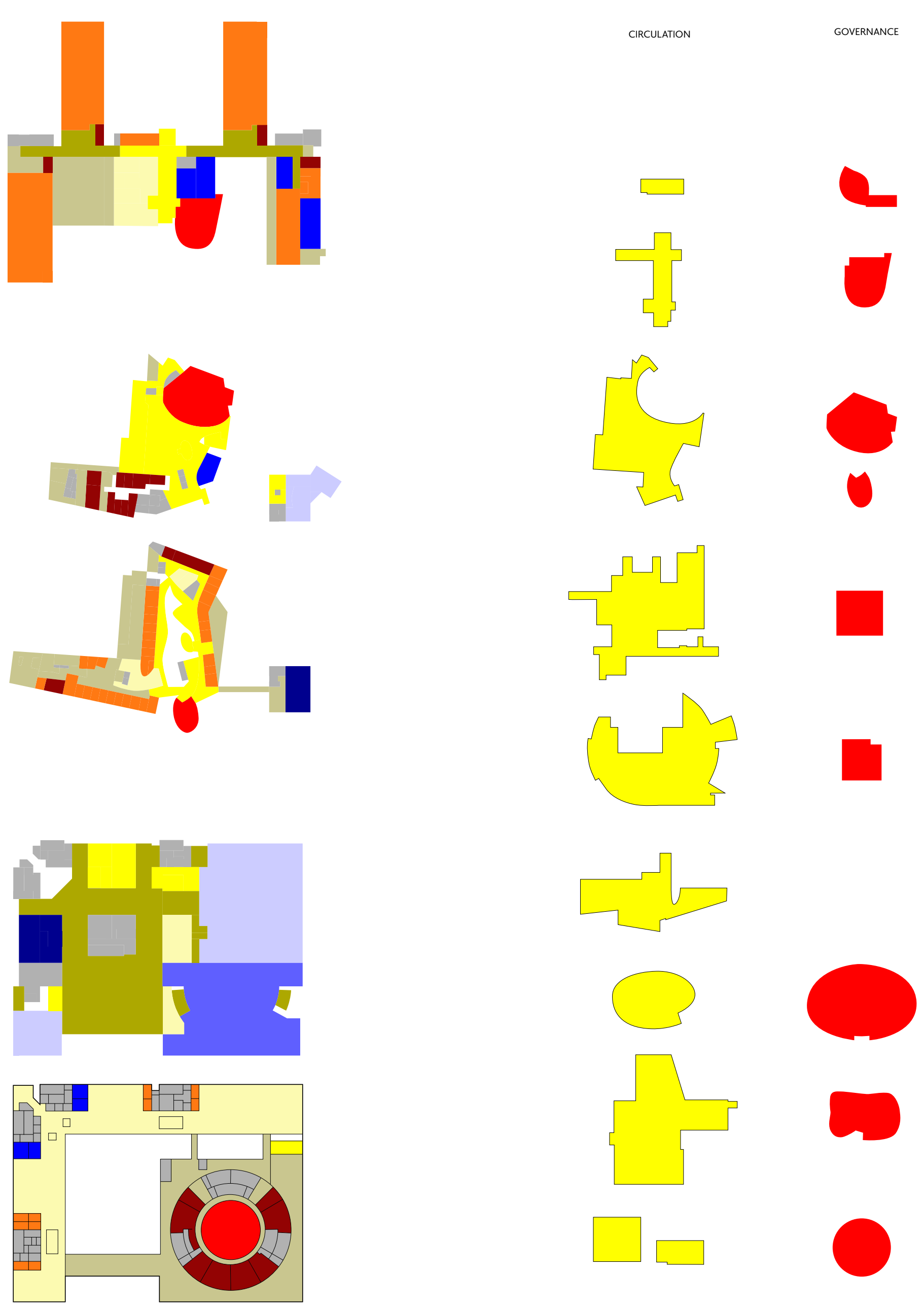
Designed by Atelier Lorentzen Langkilde (ALL), the brief asked for a refurbish of historical buildings and the addition of a new building. The new town hall is the connection between all the buildings at the civic site The exterior form is designed to reflect the angles and material of the surrounding natural environment. ${ }^{24}$

A full height atrium is at the centre of the building where interior spaces and intersecting floors and cantilever. This spatial arrangement gives off a folding gesture when experienced from ground level. From the atrium the contemporary offices and meeting rooms accommodate four hundred staff. ${ }^{25}$ This is designed mainly as open plan accommodation, with rooms which can be used by the public or staff members. The spaces are offset in plan, the new build a five sided form touches the existing buildings with the links of circulation.

From the programme analysis of two main floor plans, it is understood that the ground floor was allocated to the public and for circulation purposes. As one moves up the levels the rooms become more closed off and for specific functions. The immediate relationship to the surrounding buildings is modest and purely functional, with direct corridors from the public atrium.

The Bodo town hall is located on a historical site, therefore the immediate buildings having significant historical value on the city the addition contrasts with the old. This introduces alternative methods of work structure while not taking away from the existing heritage. ${ }^{26}$
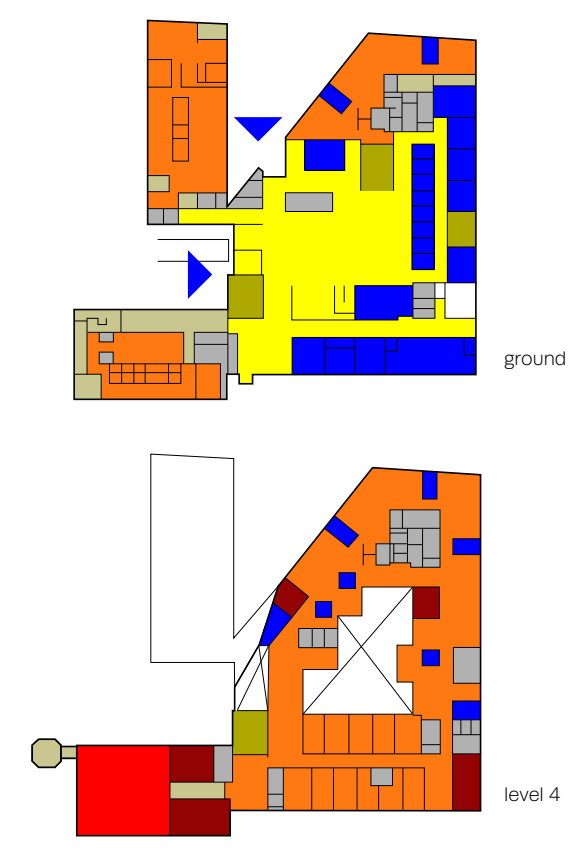

Bodo Town Hal

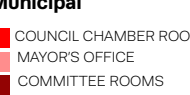

SERVICES

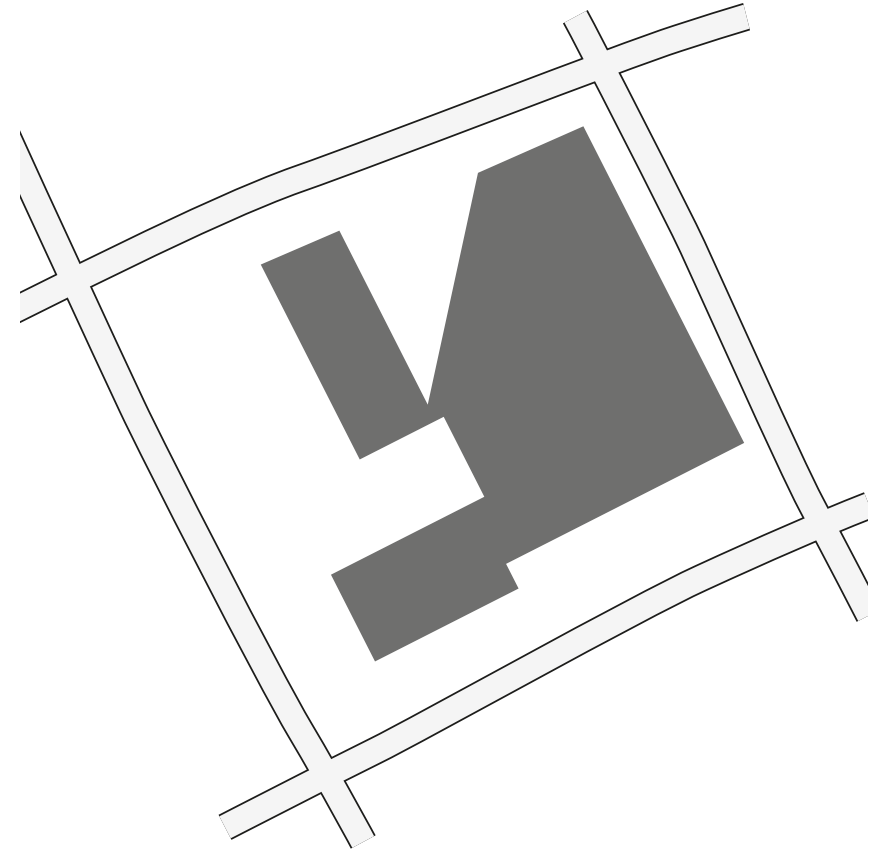

Fig. 41. Site plan diagram of Bodo town hall. Access is available from al edges. The building footprint does not occupy the entire block, wher

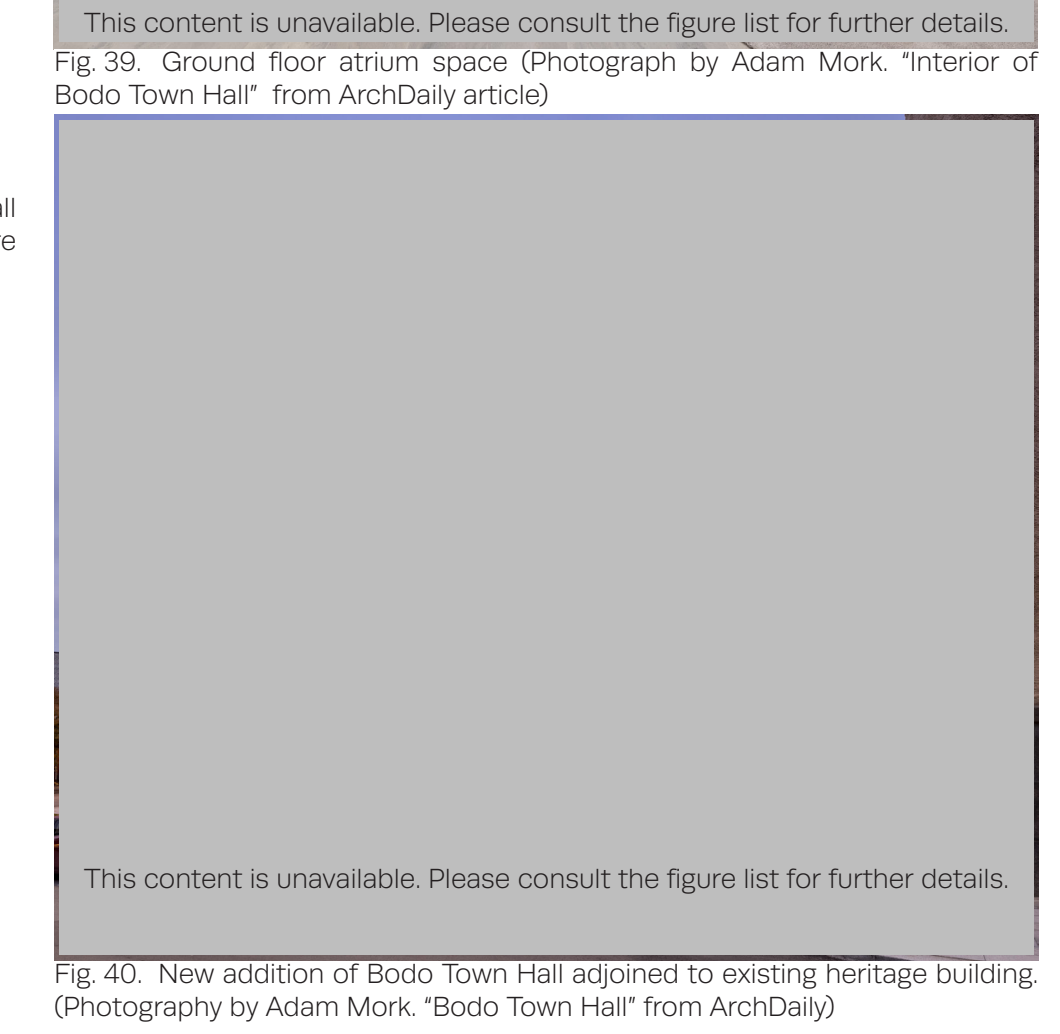


The Dundee Council House responds to the site and surrounding buildings, wrapping itself around a heritage building. The design attempts to be an icon within Dundee, considering the values of the citizens and offering a space for public engagement. Previous to the design the city lacked a civic centre, the intention of the new council house was to activate spaces within the city (Report reference). ${ }^{27}$

The design uses the ground floor for public use; offices and meeting spaces which can be engaged by the public. There is space for events and installations, public services are accessed easily on the ground floor. A design challenge was the inclusion of a 1910 historical building; a pint hall, the solution was to wrap the new building around the existing, creating a seven storey high void.

The upper floors are designed to encourage modern work styles; large floor plans which are separated by light wells and foot bridges. This accommodates for 1000 staff members. The floor plans can be divided by breakout rooms; larger meeting spaces, which determine the key points of the floor plans.

Attention was given to the materials and detailing of the building. Aware that public buildings are long term therefore need to be durable but also have an accessible appearance. The chosen material allows the building to stand out in the city while not being grandiose.

The Dundee Council House building is considered as having an administrative role in the city, rather than a role that is more ceremonial, the design does not include a space for performance or gathering. ${ }^{28}$ This is reiterated in the concealed council chamber, its location within the

building is not indicated from the inside or the exterior. The functional space; which is the ground floor, gives the public agency over a part of the building, giving them a place in the city.

Fig. 42. Ground floor and an administration floor

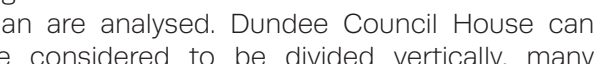
of the open plan offices have a similar spatial The ground to this level four which is analysed. are separate entrances for staff and public.

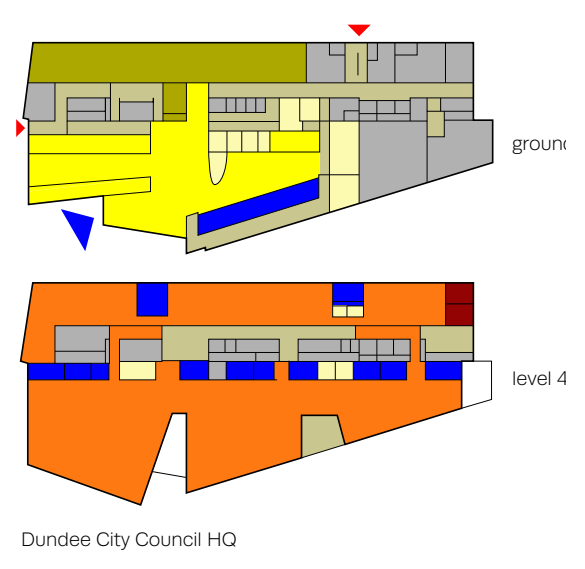

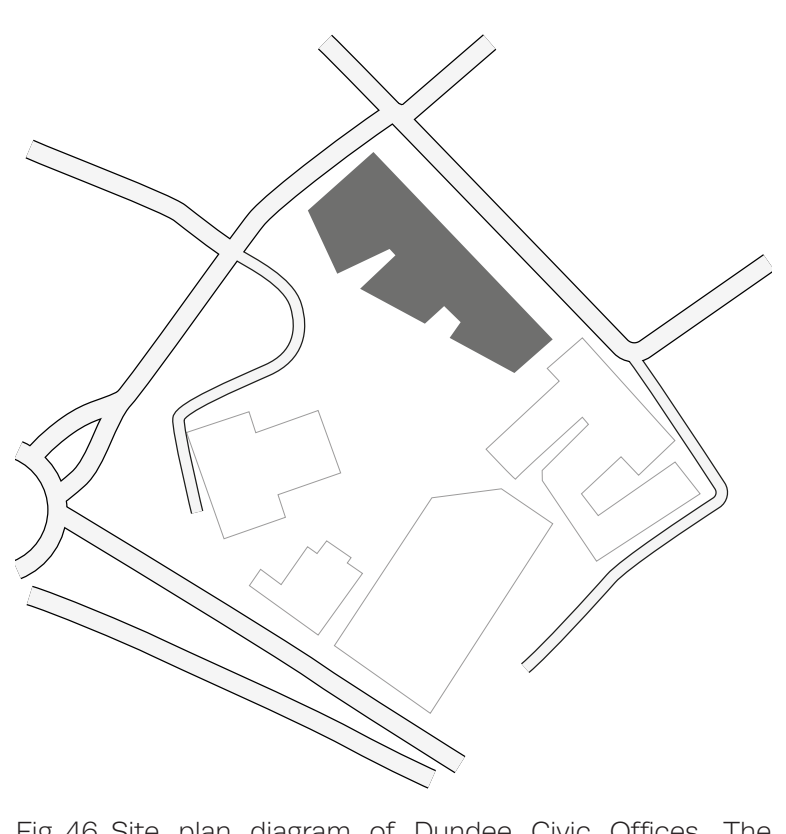

Fig. 46. Site plan diagram of Dundee Civic Offices. The south-west elevation is for public access, an edge which is not lacted on a street.
This content is unavaliable. Please consult the figure list for further details. ig. 43. Interior of Dundee Civic offices; contemporary Workspace. (Fhotograph py Dave Morris and Paul Zanre. "Inter
project report. Sleeper Publications)
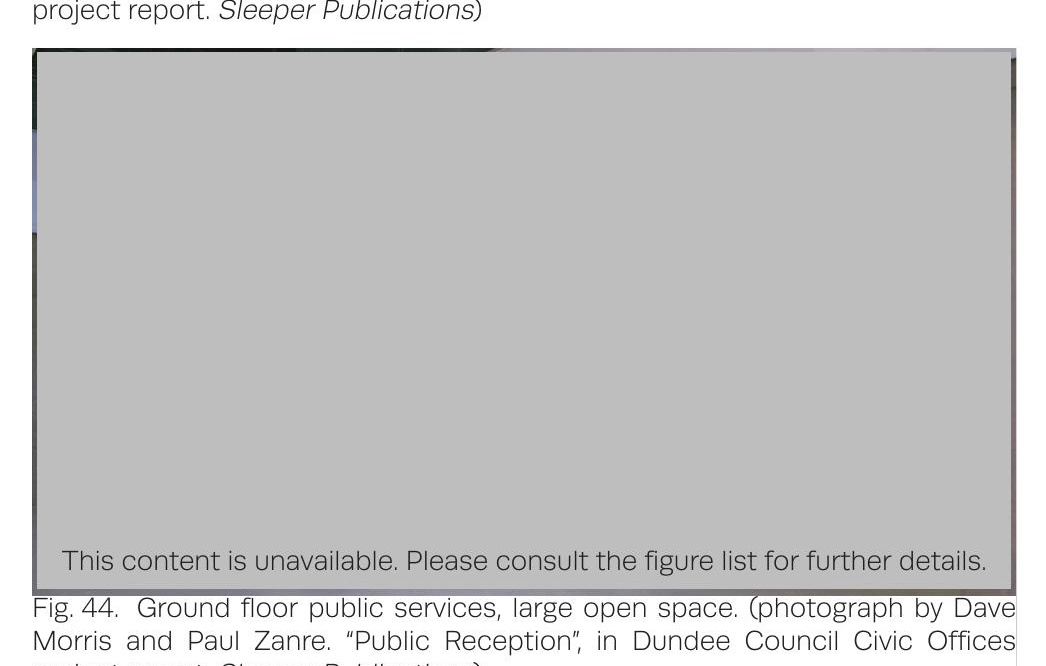
The London City Hall, is an iconic public building, with its unique shape that contrasts with many of London's other civic buildings. The design aims to create symbolic and physical transparency of the democratic system. The overall shape of the city hall resembles an oval, with a spiraling internal circulation ramp which cork screws the entire height of the oval.

City Hall accommodates for 500 members of staff for the greater London authority, as well as 25 members of the "London Authority". The top floor is known as the "London Living Room"; this is a space which the public can access and is used as a meeting and exhibition space..$^{29}$ The form of City Hall means the floor plates have rounded edge. The services are offset in plan, while larger spaces are centralised with access via the central ramp or around the perimeter.

The location of City Hall, found across the River Thame from London's traditional public buildings, is a symbolic statement representing the newly formed greater London authority. ${ }^{30}$ Vertically the building is divided by importance, with the public occupying the upper and lower levels. At the central levels the mayor and administration staff are housed. There is intentionally no front or back of the design, which is reinforced by the overall form of the City Hall.

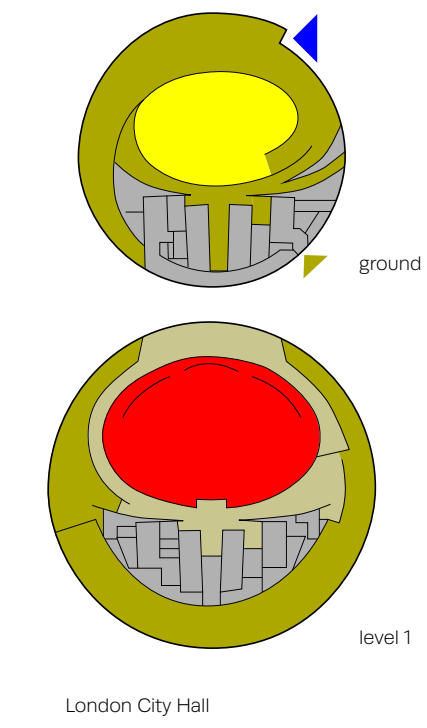

Fig. 47. Ground floor plan and level City Hall means the variation in plan does not vary. Circulation mimics the main functional spaces.

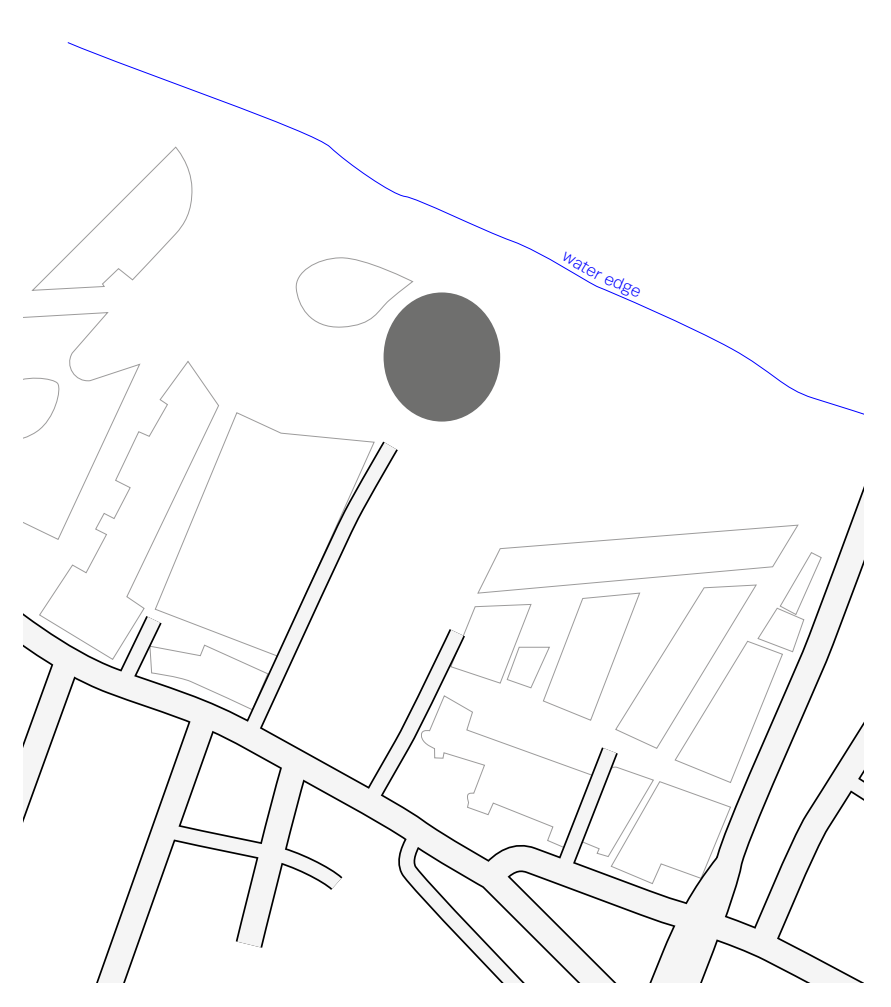

Fig. 48. Site plan diagram of London City Hall. City Hall itsef does not meet any street edges although it is located
This content is unavailable. Please consult the figure list for further detals Andrea Hamilton, "City Hall" in London Every Day project. AH Studio)

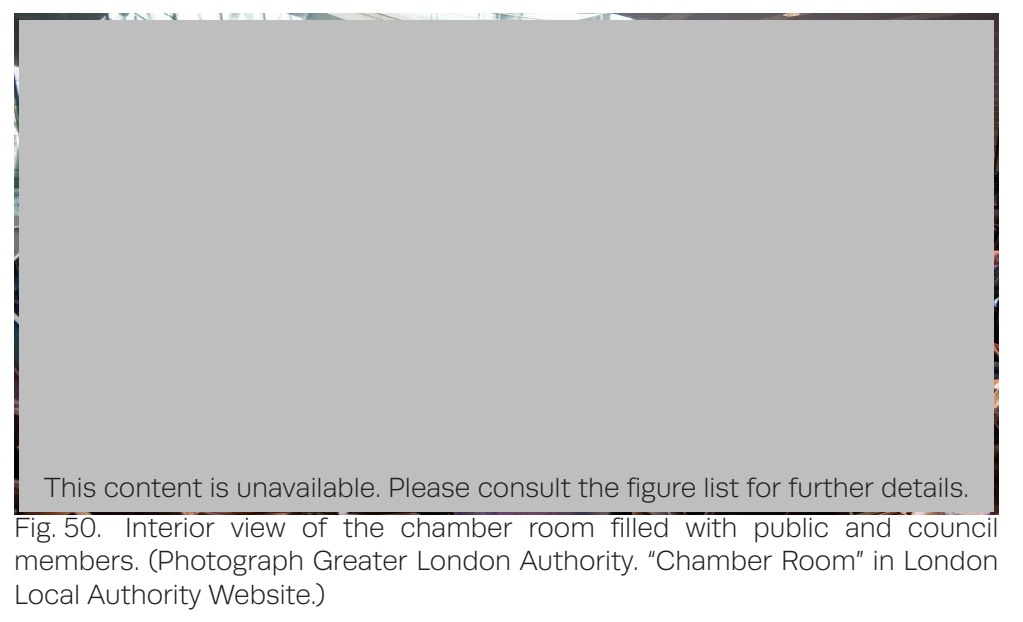
members. (Photograph
Local Authority Website)

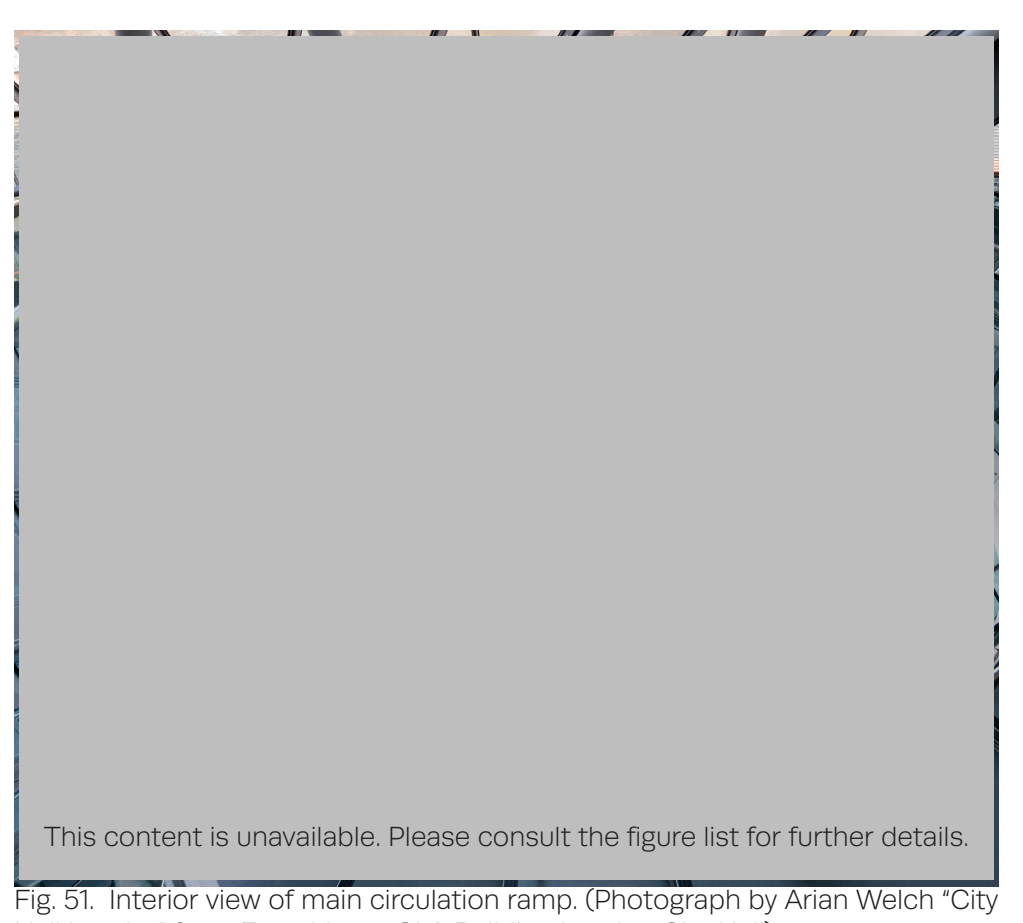

Hall interior" from E-architect, GLA Building, London City Hall) 
Brent Civic Centre, 2013

Architect: Hopkins Architects

The design of Brent Civic Centre integrates multiple programs under one roof and asserts itself as unifying the council and public services. A public library, counci front of house and cafe are a few of the services that are offered at the Civic Centre. The location of Brent Civic centre affirms its importance in the community; it is close to a variety of civic buildings such as Wembly Stadium. ${ }^{3}$

The offices space takes on an "L" shape in plan, which is where the design accommodates for 2000 administrative staff. A full eight storey high atrium ascends through the centre of the building, leaving the perimeter spaces to wrap around this space. A prominent circular shaped space is offset to one of the four corner of the rectangular form. This form juxtaposes the regular linear shapes of the workspace and is visible from both the inside and the outside. This can be accessed via over bridges, activating the upper foyer space. This contrasting shape is where the civic chamber is found, along with multi use community hall and library.

Community rooms, an amphitheater and green space are the numerous multifunctional spaces under the large roo of the Civic Centre. The large ground floor is inviting with a staircase that has the ability to host cultural events for a variety of users to experience.
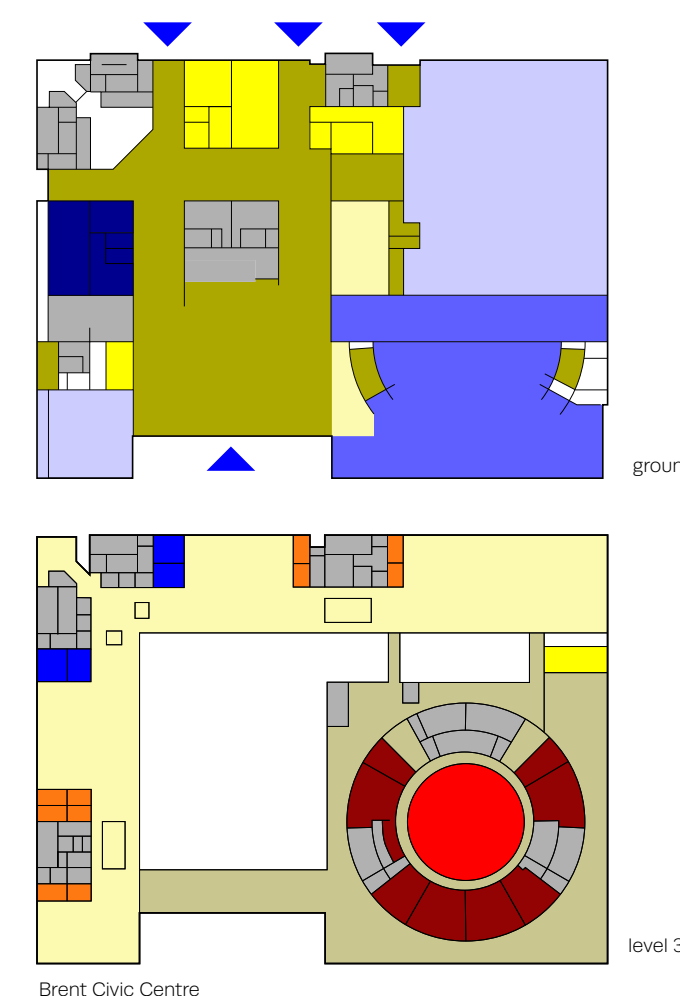

Fig. 52. Ground floor and level two are analysed. The overall form of the Brent Civic Centre is regular, the various functions but all can be utilised and accessed by the public.

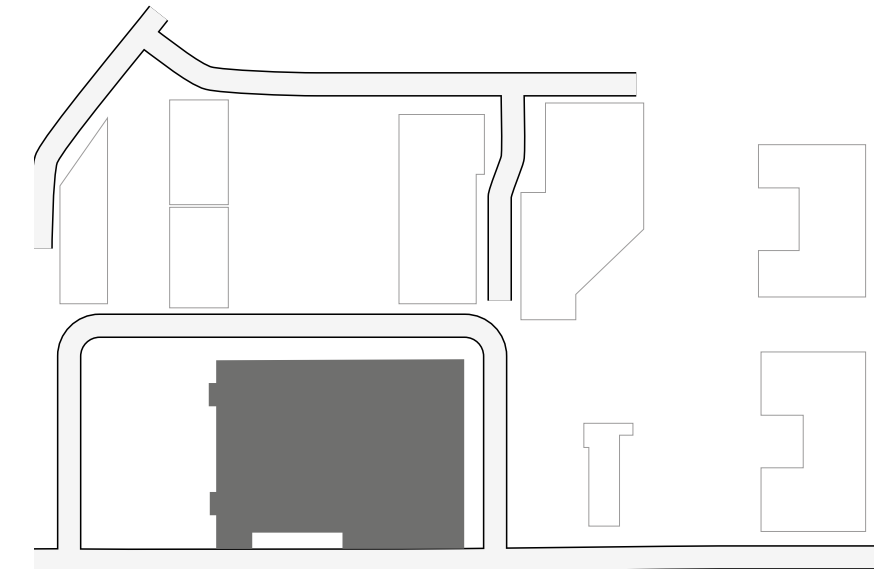

Fig. 53. Site plan diagram of Brent Civic Centre. The , allowing it to be accessed and visible from all edges.
This content is unavailable. Please consult the figure list for further details. Ig. 54. Exterior of Brent Civic Centre, The circular form is expressed with the

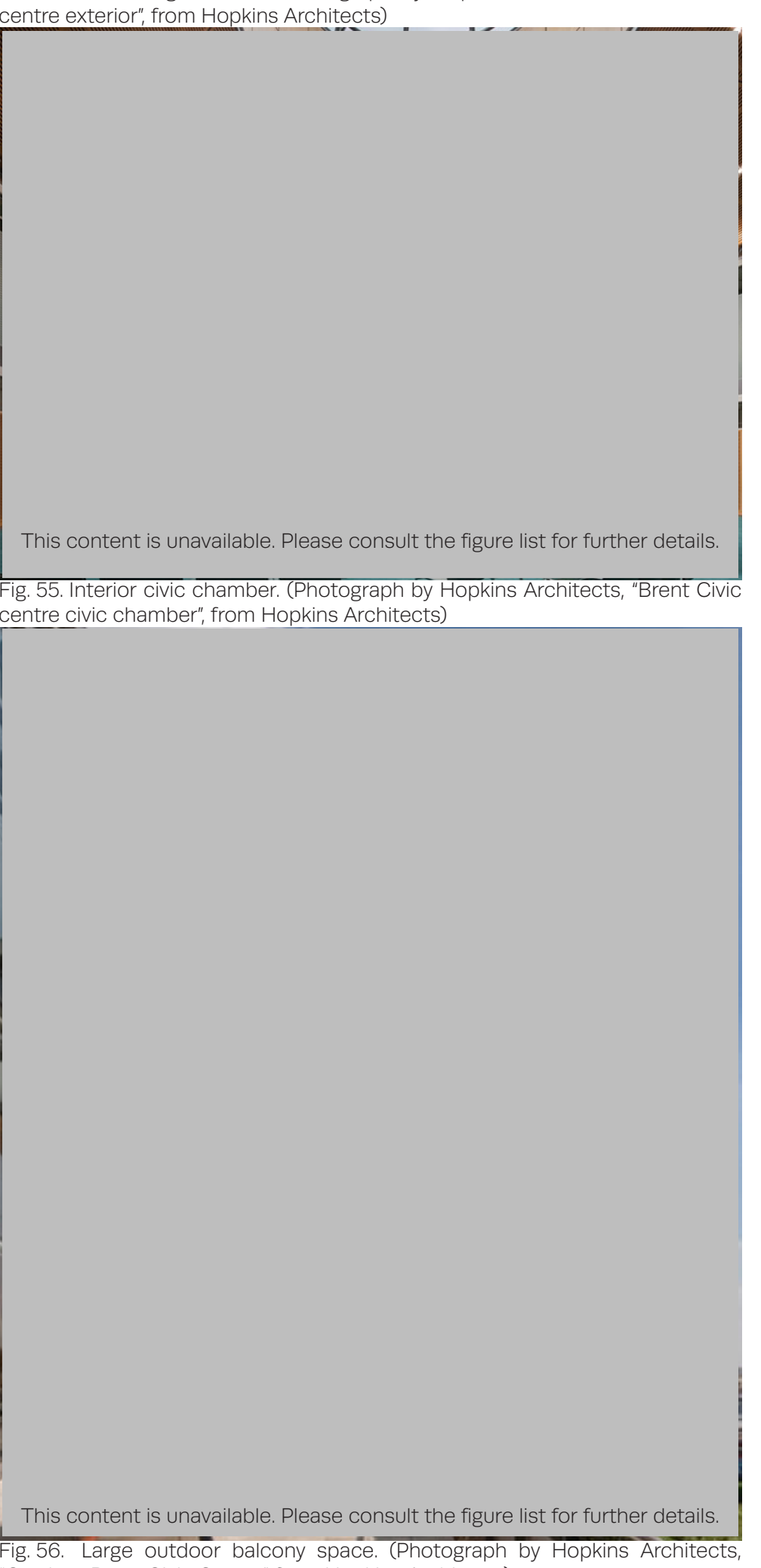

g. 56. Large outdooor balcony space. (Photograph by 


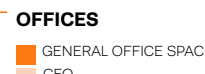

Selwyn District Council Headquarters, 2008 Architect: Athfield Architects

The design of the Selwyn Council building is a merging of a few buildings together, the use of materials and design features is what makes the outcome cohesive. The council serve a breadth of communities from various stretches of land. The design concept is derived from the natural landscape which surrounds this district; in particular the braiding of the river current.

For the surrounding landscape to be carefully considered throughout the design, courtyards are produced between functional spaces. These act as dividers, where parts of the building fork out, becoming their own functioning space."

While the design caters largely for the council employees of the Selwyn district, there are multiple entrances which can be seen in plan. A main entrance is for public use is made obvious by a large welcoming entrance, the space then continues to a reception. Close to the public entrance is the chamber room/main meeting space. This protrude out from the main building and its circular form is visible from the outside, the form contrasts the orthogonal spaces which make up the workspace. Fig. 57 . Ground floor analysedtrative spine. There is
out from the central administan a clean division in the spaces and various functions can be categorised by this arrangement.

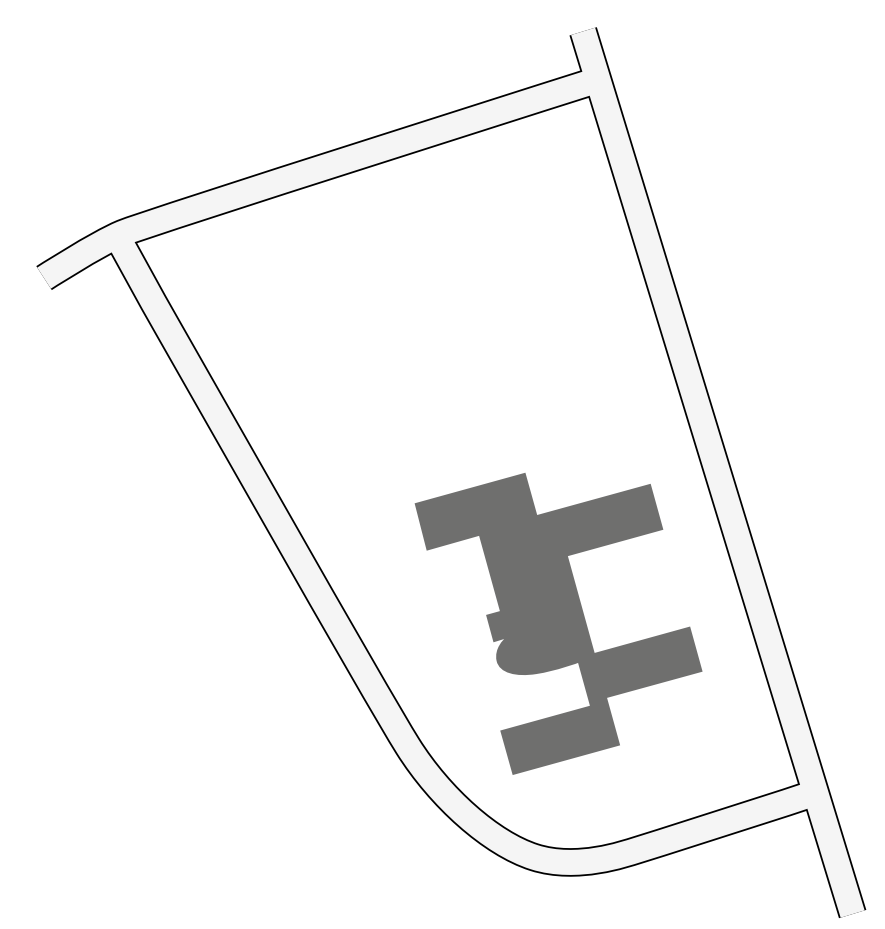

Fig. 58. Site plan diagram of Selwyn Council HQ. The where the building is flush with the street. Although the form creates obvious entrances and divisions between the spaces from the exterio.

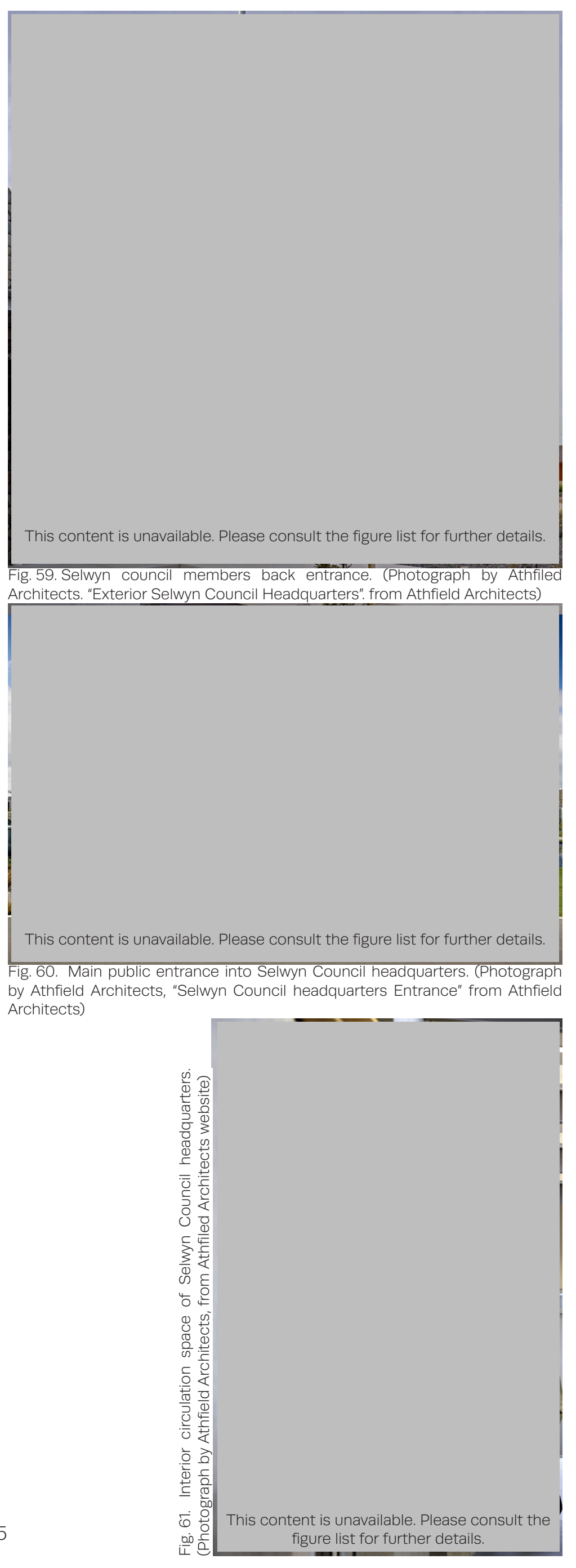


The Henderson Service Centre is a multi-functional design which accommodates for the public in their everyday activities as well as council staff members. The service centre serves the Waitakere ranges region, which is made up of a vast variety of indigenous flora and fauna. In order to align with the sustainable policies of the Waitakere council the design integrates energy efficient features throughout.

The design is considered to be split into three main functioning spaces. What is known as the Civic Wing, is where the council chamber and facilities can be found..$^{33}$ The shape is irregular and set off from the rectangular form. The regular shaped open plan council offices and public front of house is located in the administration wing. The final functioning space is the pedestrian link to the rail station and main access by public.

Each space can be identified in plan, the civic wing is distinct and the circular edge can be seen from the main entrance. The interior has a curved mezzanine floor which provides further seating for the council meetings which happen at the lower level. With a warm interior finish of timber and the vast glazing this establishes transparency between public and council members.

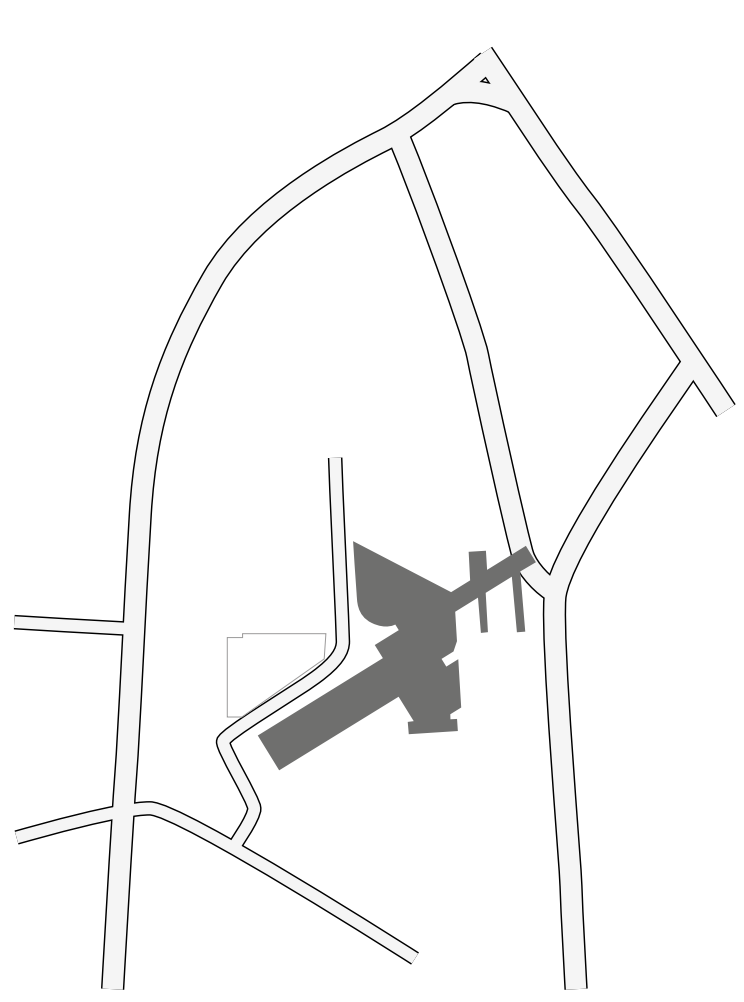

Fig. 62. Ground foor and level two are analysed. The three wings can be realised in plan. The irregular lofted shape is of high importance and contains the chamber public access: balance is achieved between the civic and the administration wings.
Fig. 63. Site plan diagram. Access is unique to this building, it has multifunctional use by the public as given spatial hierarchy in the building footprint
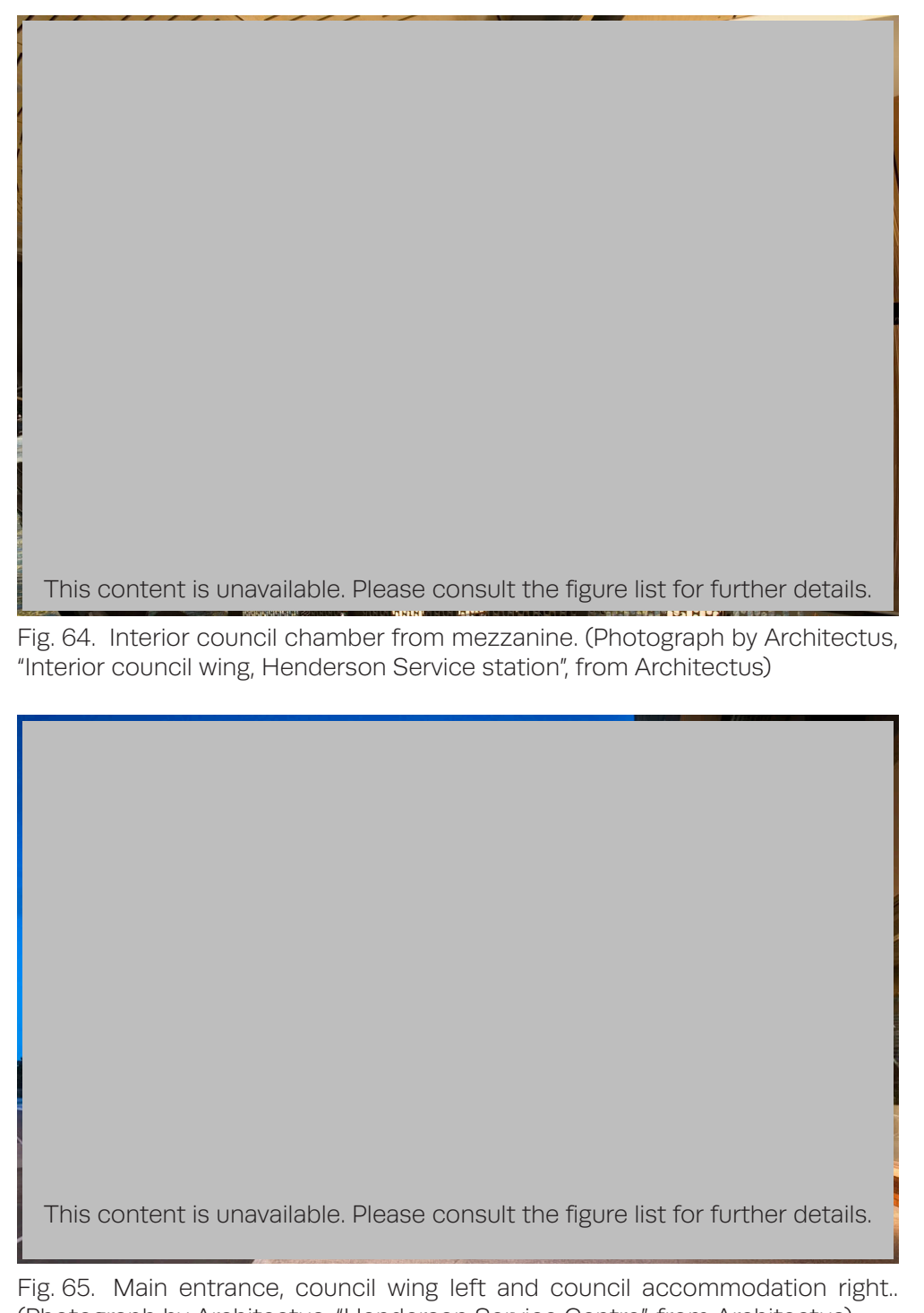

Fig. 65. Main entrance, council wing left and council accommodation right.
(Photograph by Architectus, "Henderson Service Centre" from Architectus) 
OFFICES

Te Hononga, Christchurch Civic Building, 2010 Architect: Athfield Architects

The Christchurch civic office is an adaptive reuse of the old New Zealand Post building. The completed design has an approachable entrance with a cladded façade that softens the original Brutalist style concrete slabs. ${ }^{34}$ The ground floor is an inviting element of the design, it can be accessed by the public and used as a thoroughfare. The overall form is a solid gesture in the city, this was partially thanks to the original concrete structure that the brief had to work with and the other part to the restoration by Athfield Architects. ${ }^{35}$

There is a vertical gradient of public access and use; the ground floor integrates the public while accommodating for the special meetings which will occur in the chamber room. The top floor is then allocated for the mayo and committee and councilor meeting rooms. The four floors which make up the rest of the building provide accommodation for over 1200 staff members.

The design pays close attention to the interaction of the building at street level, specifically how the public uses it as a pedestrian thoroughfare. The Civic Chamber room is given careful consideration in its design, which is eviden in the uniquely curved form. This space is visible and distinguished from both the inside and the outside.
$\nabla_{\mathrm{B}}^{\mathrm{LB}}$

-

CIRCULATION

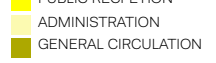

Municipal

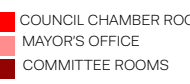

InERVICES
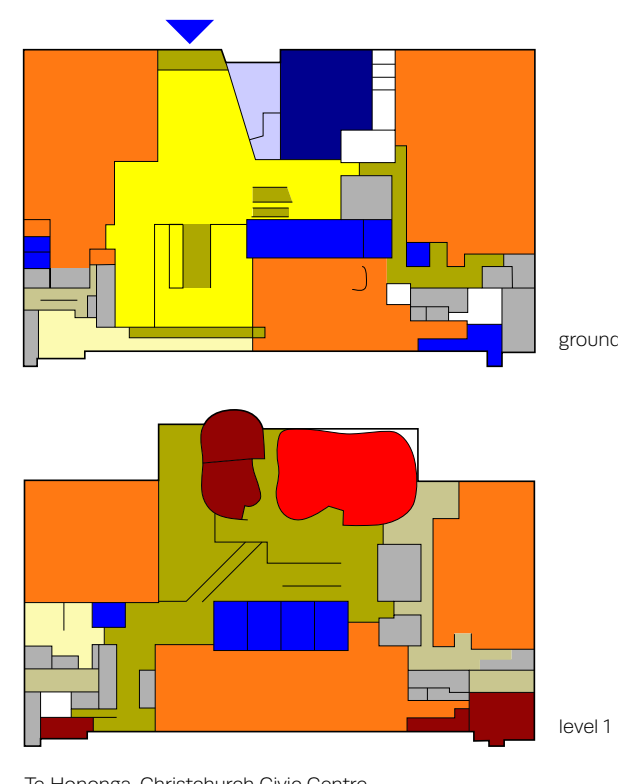

Te Hononga, Christchurch Civic Cente

Fig. 66. Ground floor and level one are analysed. The regular elevations, as circultion is added the spaces become unique; staircases, meeting rooms and the chamber room

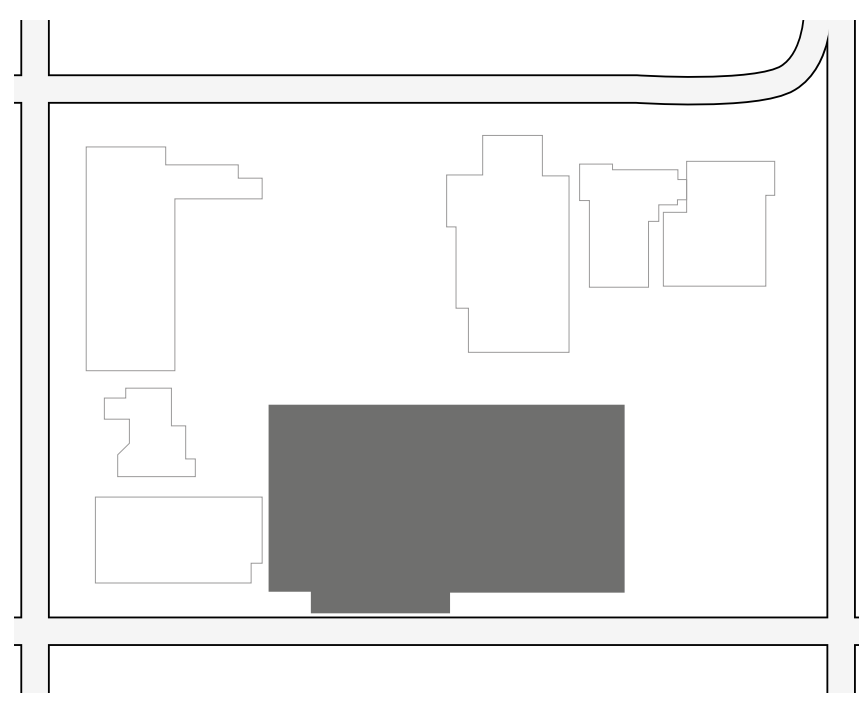

Fig. 67. Site plan diagram of Christchurch civic centre. The ground floor is considered a public street, the edge uses suggestive elements such as the large entrance canopy figure list for further details.
fult the

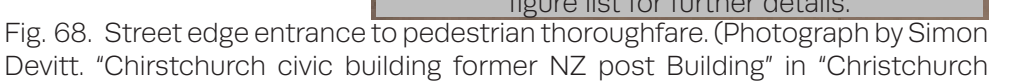
Devitt. "Chirstchurch civic building former
Civic building", Architecture Now 2, 2013).

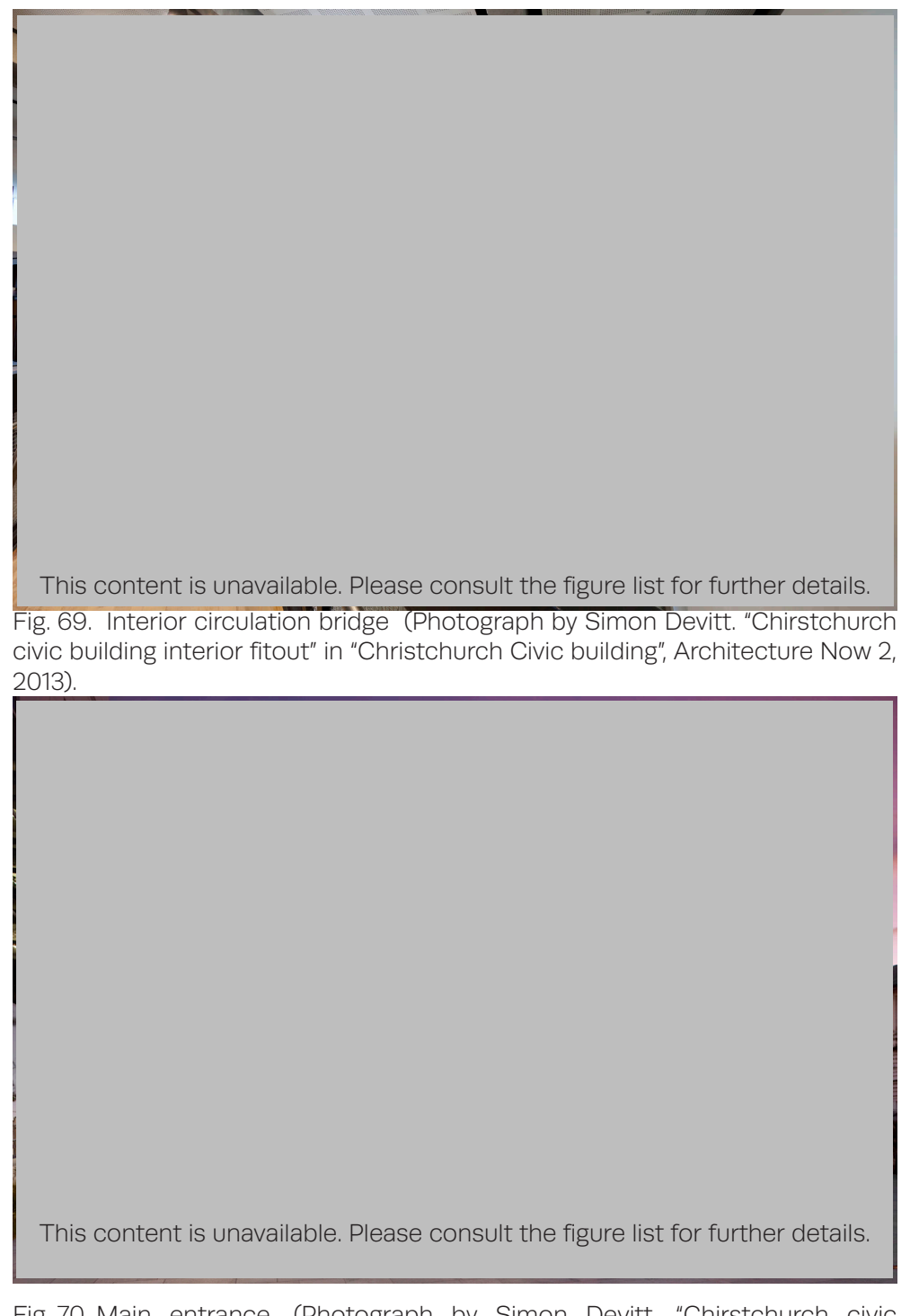

Fig. 70. Main entrance. (Photograph by Simon Devitt. "Chirstchurch civic building" in "Christchurch Civic building", Architecture Now 2, 2013). 
Bagnolet Town Hall, 2014 Architect: Jean-Pierre Lott Architecte

The Bagnolet town hall can be distinguished by the three oval volumes, which project out from the regular building form and contrast with the historical aesthetic of the town

The design of the Bagnolet town hall had five objectives driving the outcome. One of the five design objectives was for the buildings scale to be complimentary to the surrounding buildings. Another design objective accommodated for pedestrian users; in the developmen of community life and their route through and around the new design. ${ }^{36}$

Externally it is apparent that each space is divided and one can be sure of what inhabits the space. A mesh facade protects the offices of council staff from direct sunlight. The three protruding discs appear solid from outside, although when examined at plan one can be seen to host meetings.

The large internal atrium was designed to be experienced from all levels. This unifies the building and is experienced at ground level by the public. Public use areas are located on the first two floors, with the ground floor accommodating for exhibition and public meeting spaces.
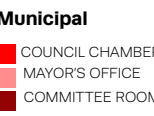

SERVICES

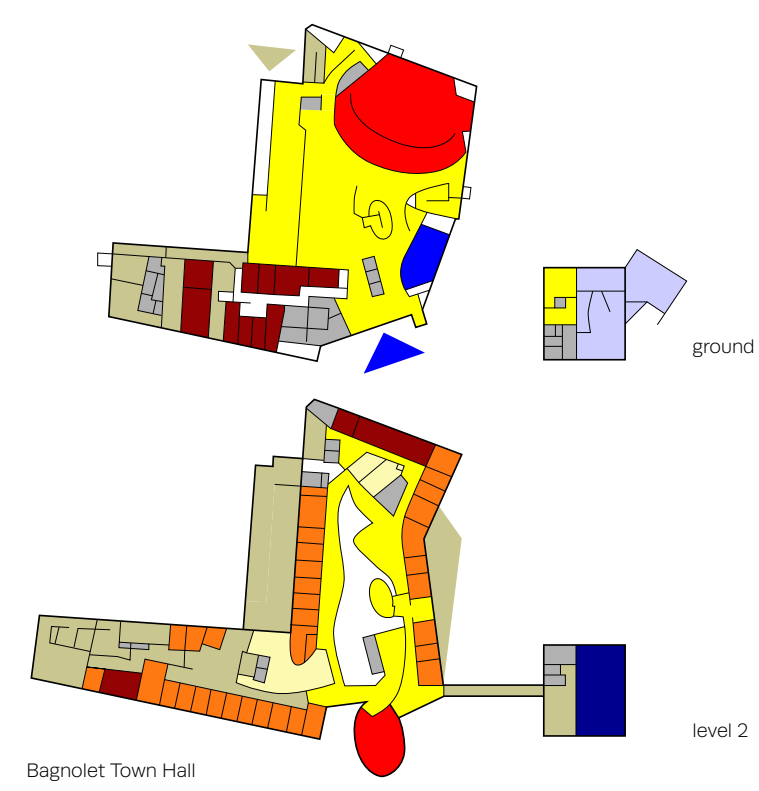

Fig. 71. Ground floor and level two are analysed. The spatial arrangement starts from the perimeter and works towards the organic interior; where trium core is a circulation atrum. The

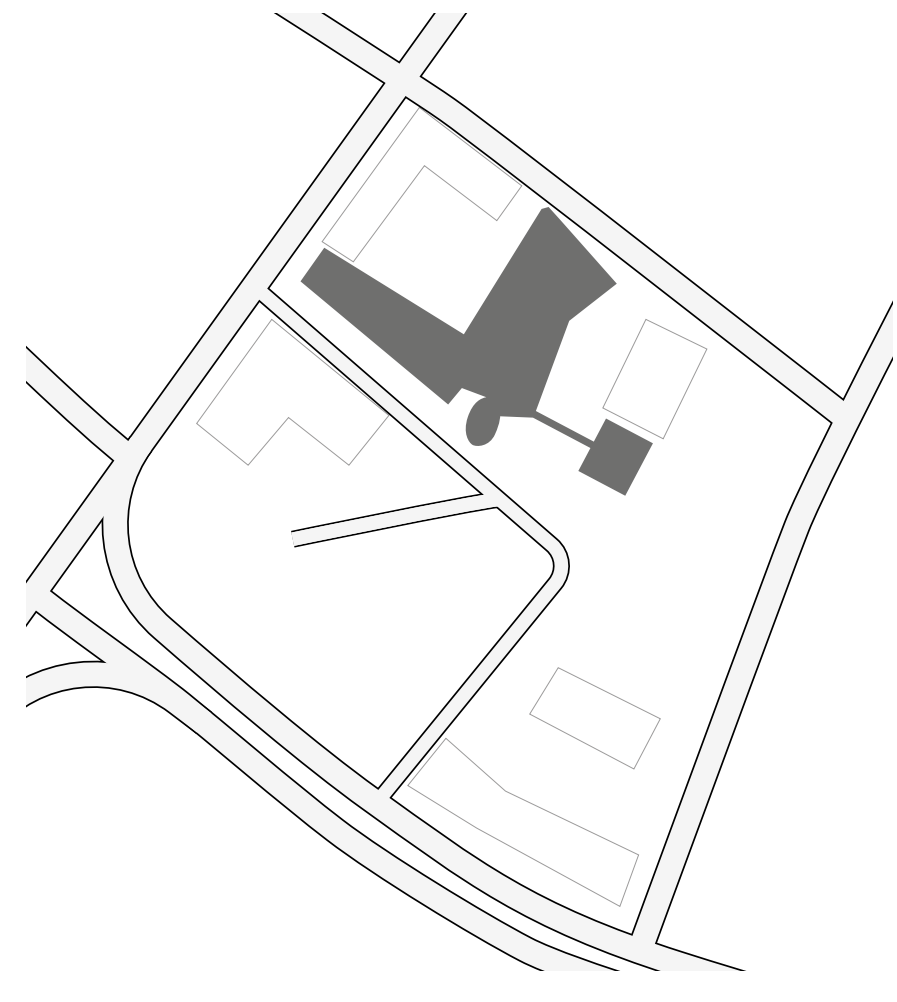

Fig. 72. Site plan of Bagnolet town hall. The city hall is a secondary street edge and developing civic square.

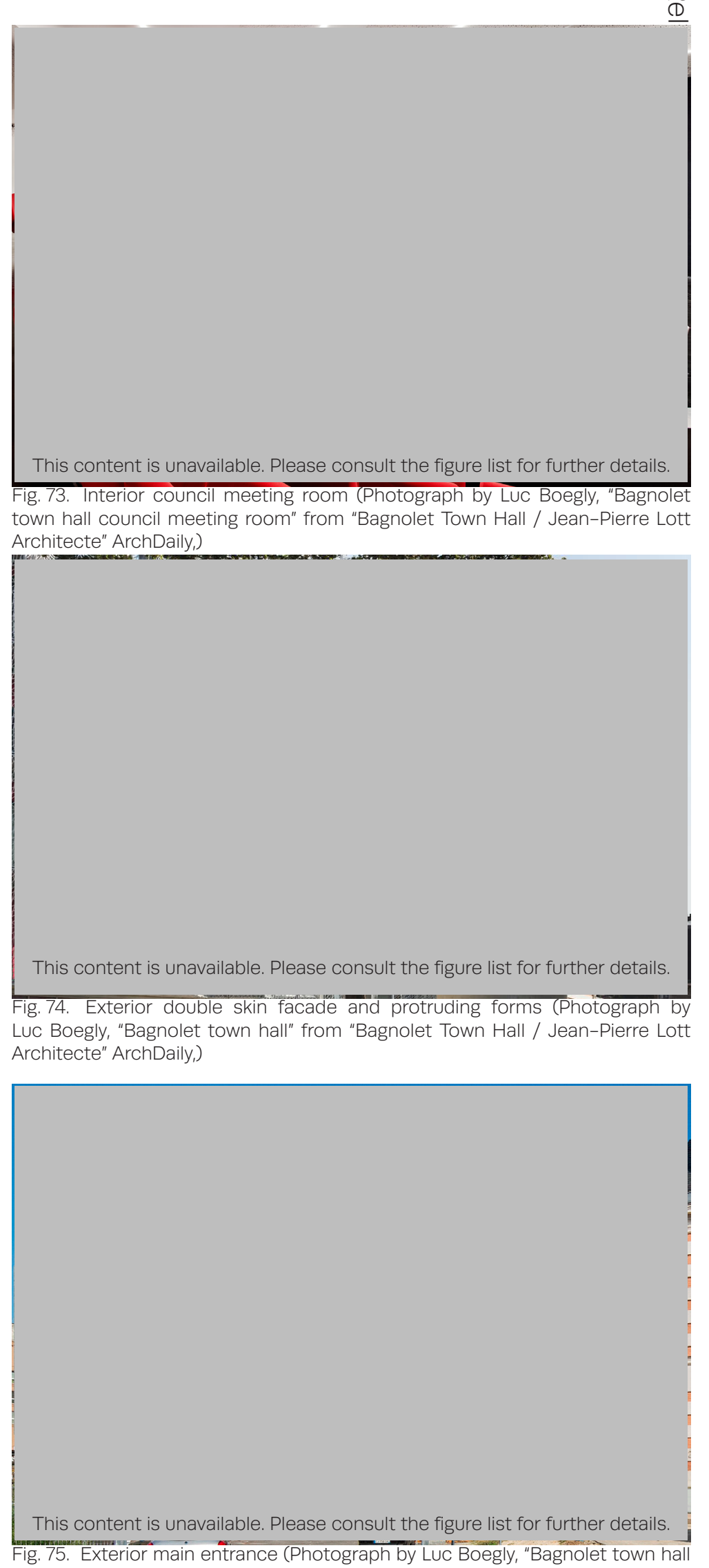

tegnolet town hall

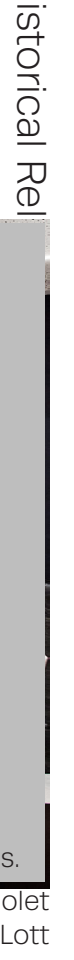


Kiruna City Hall: The Crystal, 2018 Architect: Henning Larsen

The design of the new city hall in the town of Kiruna will facilitate the unique circumstances which Kiruna is experiencing. The town needs to be relocated due to intense mining of the city. The Crystal is the firs building to be found in the new location and a physical representation of the new beginning for Kiruna. The identity of the town is being challenged and the city hall is an opportunity to exhibit to the community a pledge to the future. ${ }^{37}$

The Crystal can be analysed as two buildings in the plan, the outer ring accommodates for office space and municipal services. At the heart of the building is a social space; exhibition halls, meeting rooms and workshop spaces are all accessed in the centre volume. The groun level has significant space allocated to the public, with an amphitheater, large staircase and front of house service facilities. The centre of the ground floor encourages use by the public, a space where people can come together and socialise during the cities transitioning time. It is during these circumstances when the role of civic architecture can be rested, where the public can find a place of symbolic familiarity.
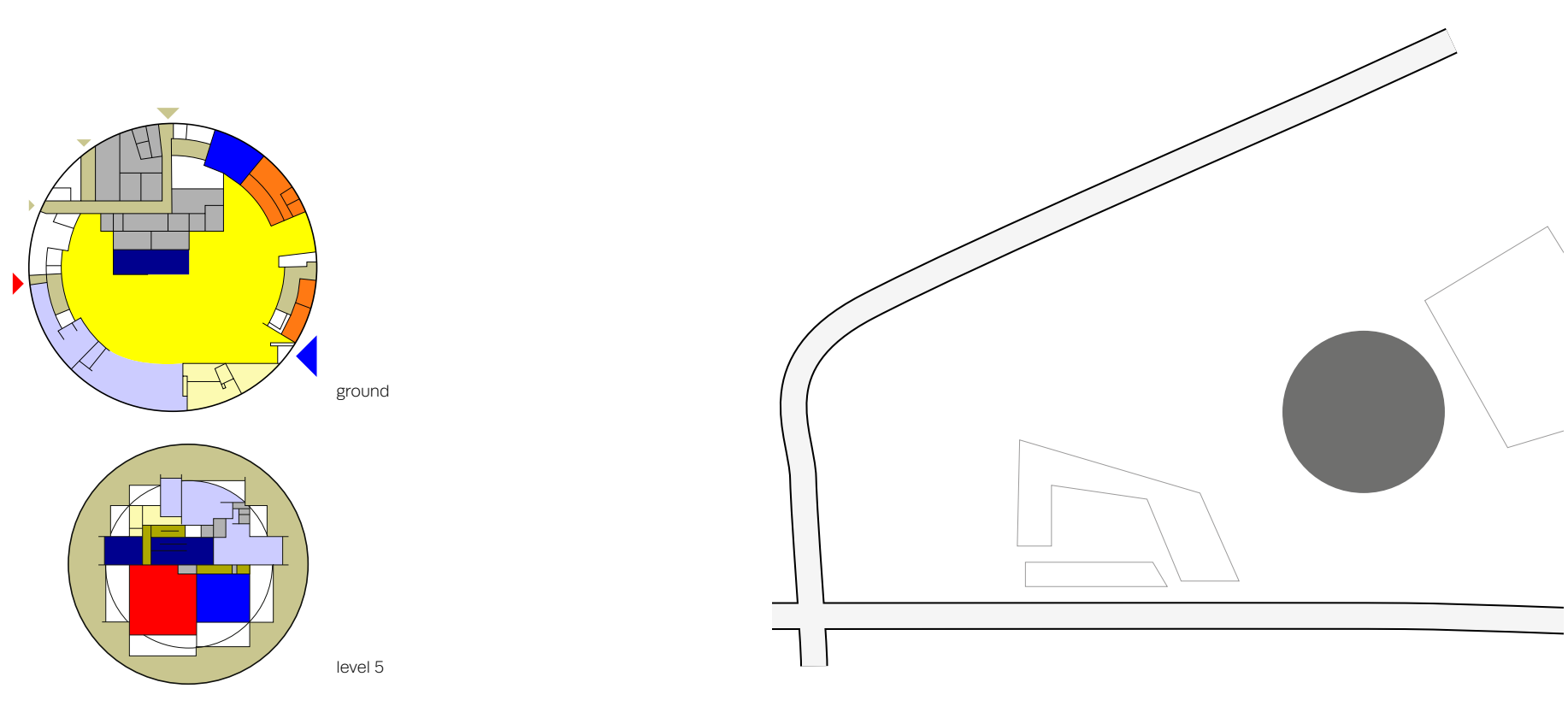

Kiruna Town Hal

Fig. 76. Ground floor and level five are analysed. Each floor has various floor spatial order be ground perimeter and on the upper floors the order is visible at the centre of the building.

Fig. 77. Site plan diagram. 'The Crystal' is not on the street edge, offering space for users to receive the building as they enter from the road. Th Crystal is a foundation for the town
- ENERTanmer

CIRCULATION

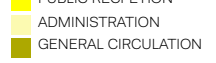

Municie

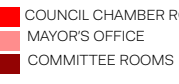

SERVICES

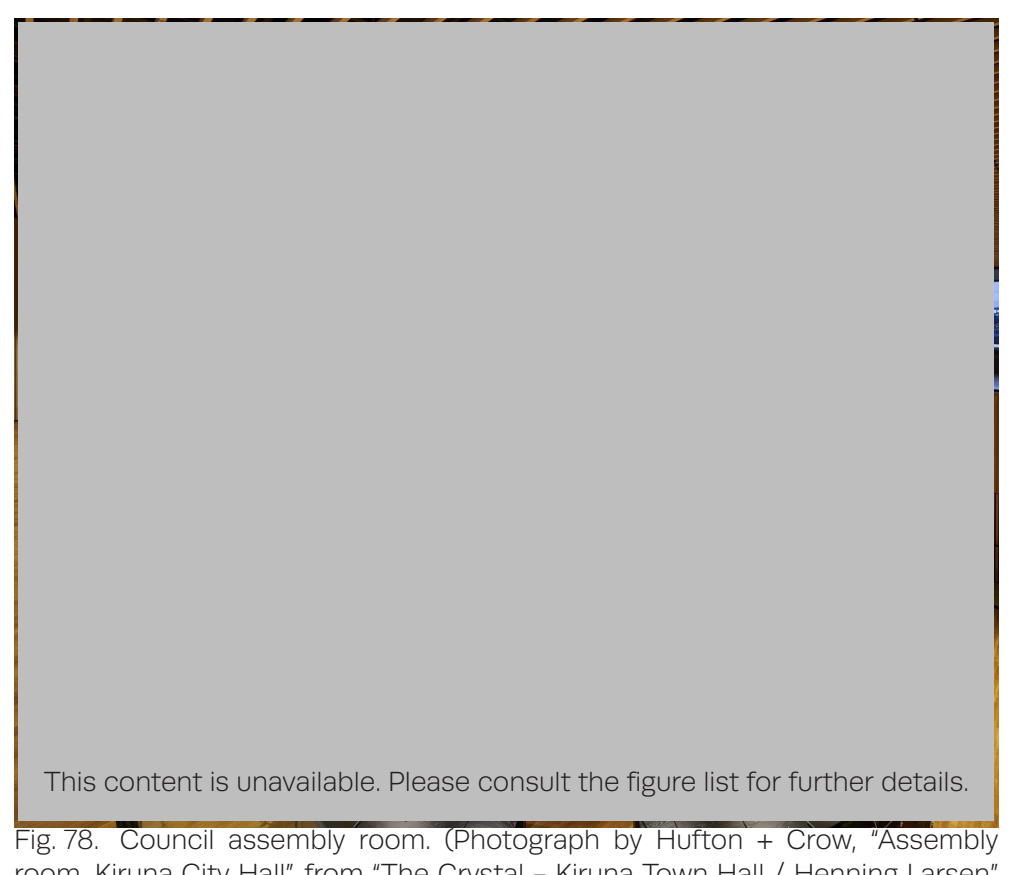

1g. 18. Councill assembly room. (Photograph by Hufton + Crow, "Assembly
room, Kiruna City Hall". from "The Crystal - Kiruna Town Hall / Henning Larsen"

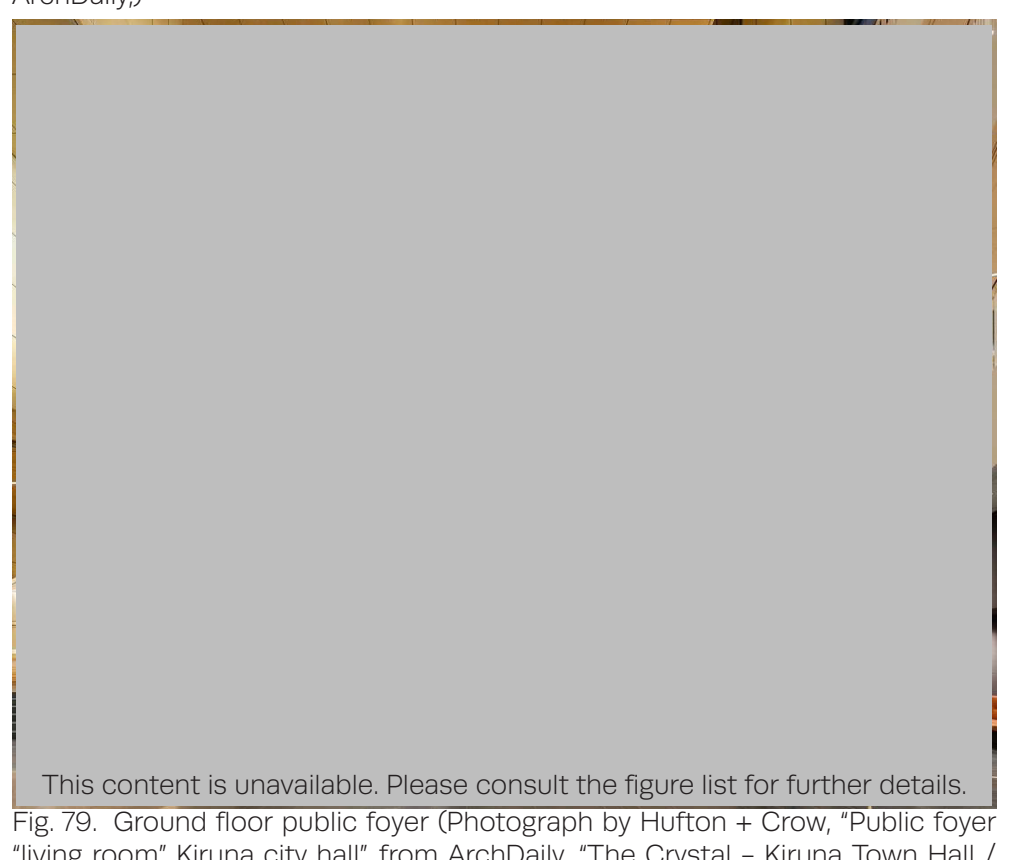
living room" Kiruna city hall", from ArchDaily, "The Crystal - Kiruna Town Hall /

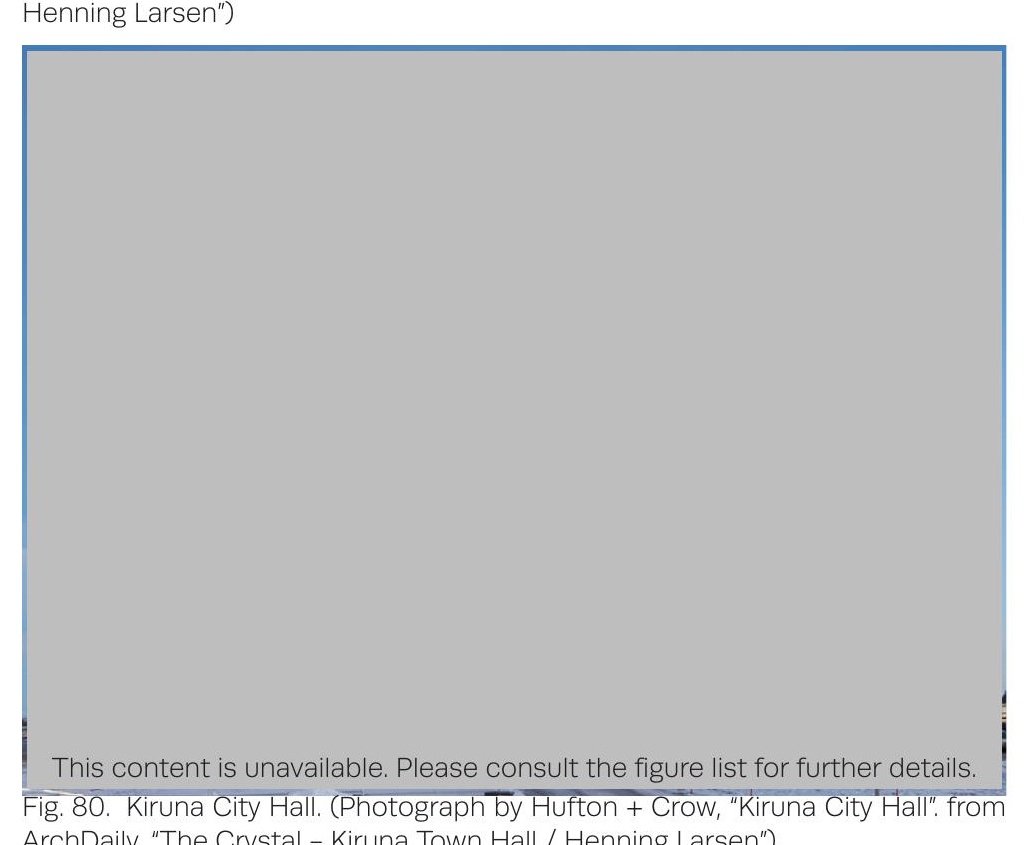
ArchDaily, "The Crystal - Kiruna Town Hall / Henning Larsen") 

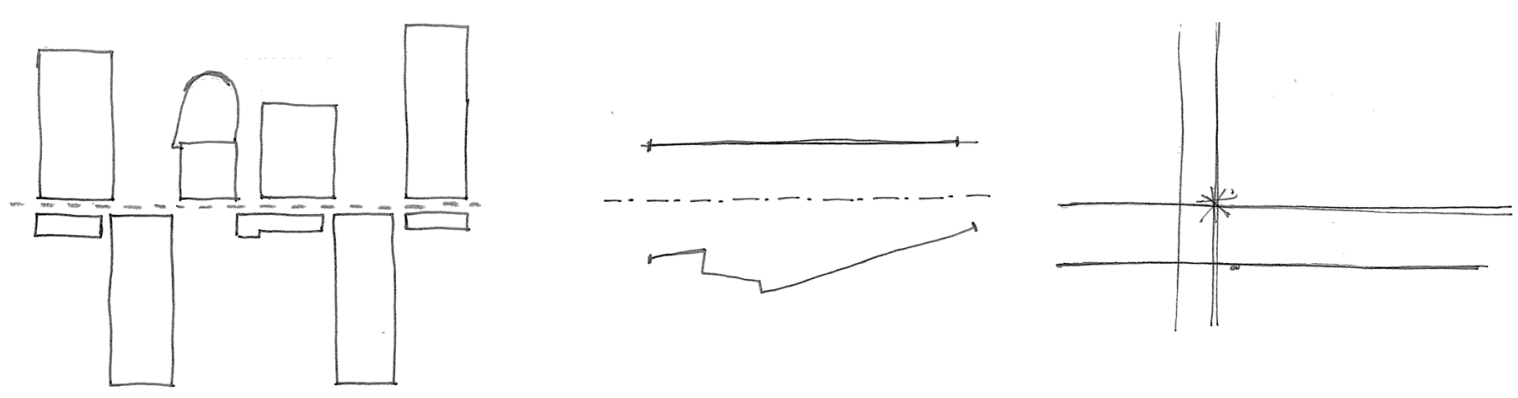

\section{Conclusions}

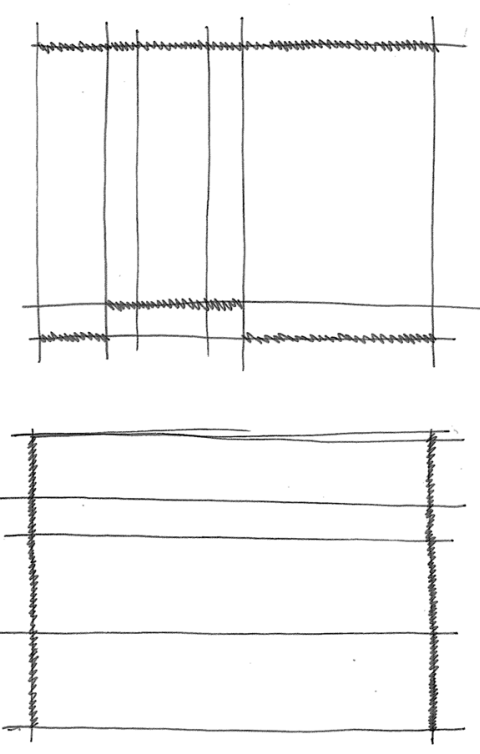

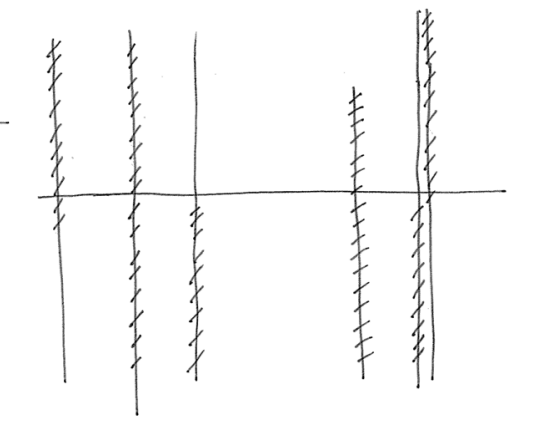
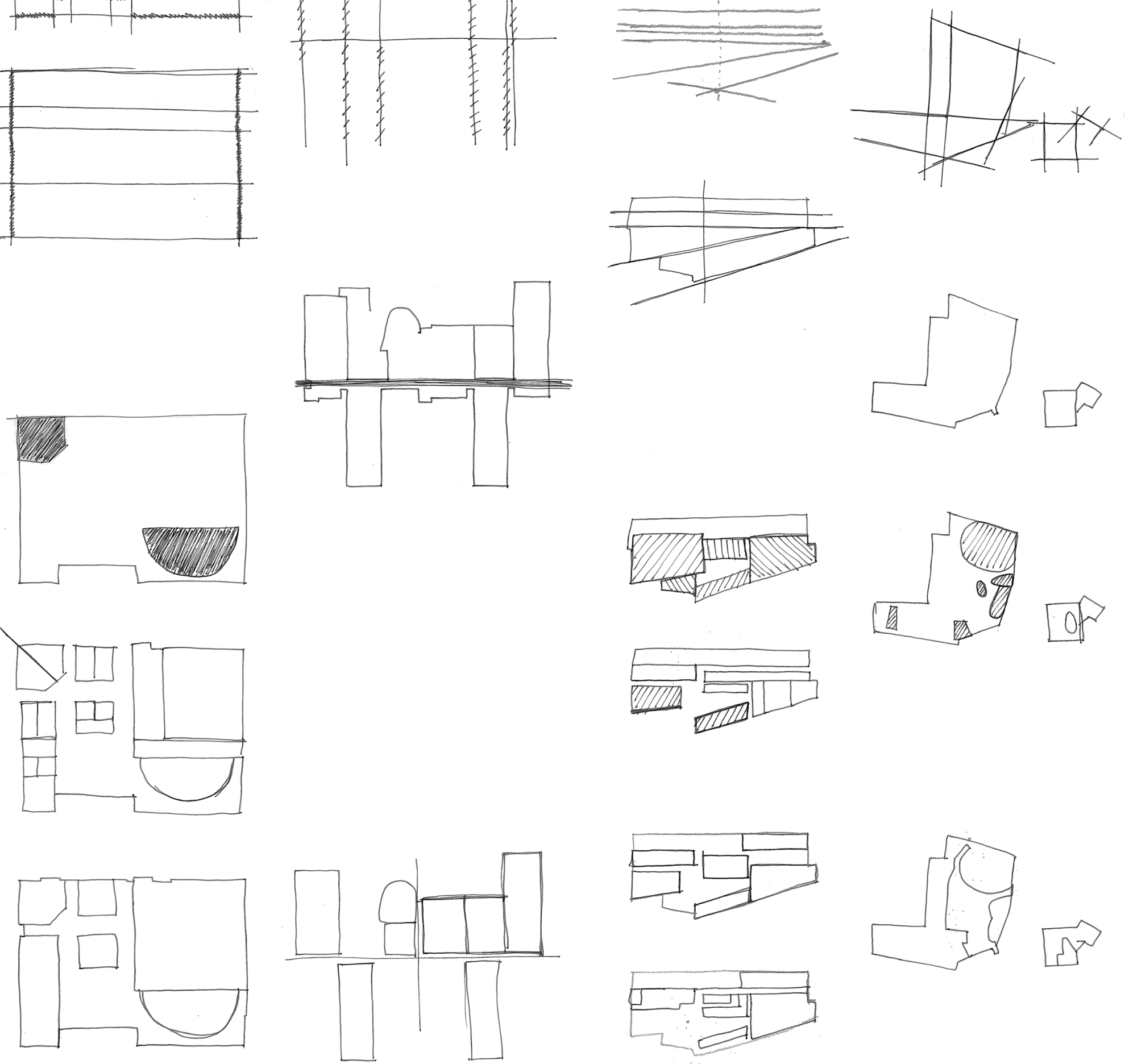
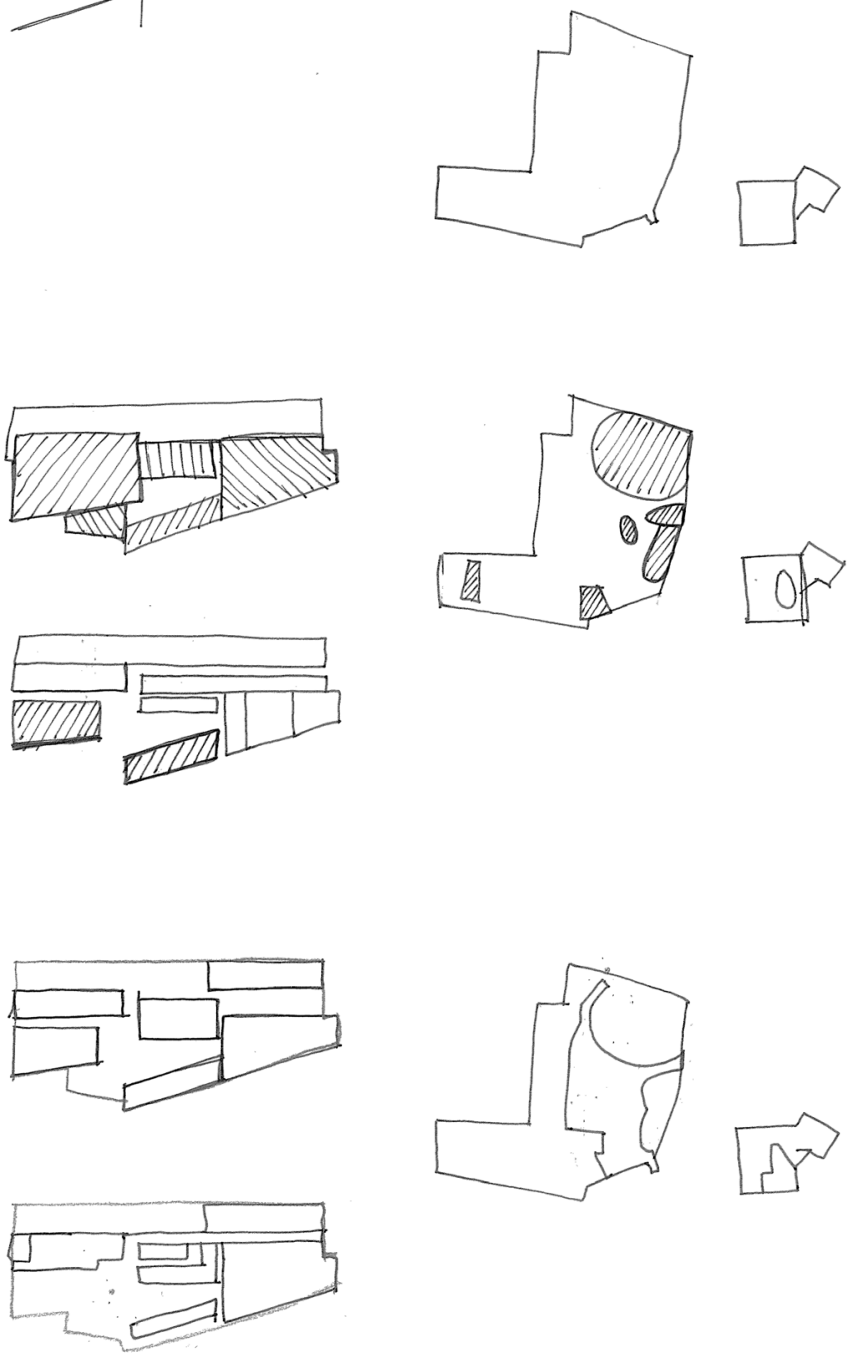

The selected case studies are a collection of contemporary Another feature which stood out in the planning of these town halls or city halls. They are all dependent on the kinds of buildings was the space allocated to circulation culture and country which defines their title. Nevertheless, and organisation. Often it is the remaining space which each case study is a symbolic representation of a becomes circulation, for all users; public and employees. communities local authority; a place of civic conduct.

As such every example has some reliance on public engagement.

Examining the patterns and forms of the overall forms and spatial layout of the buildings revealed spatial hierarchies and common patterns. This was not necessarily dependent The analysis critiqued the floor plans of various local on the functional requirements of the spaces, because this council accommodations, which revealed that there is consideration was ignored during the exercise.

no longer a standard approach to designing these public buildings. While there was a typical attitude towards traditional town hall architecture during the nineteenth century, many factors such as accessibility, inclusivity and diversity now play a major role in impacting the design.

The preceding study indicated public use was regularly considered during the design process. Entrances were prominent; in some examples the buildings had multiple public entrances. They were unambiguously represented with architectural elements such as canopies and transparent materials.

Prominence was given to the meeting spaces of the council members, more often than not in an unusual shape or form. These unique forms directly translates the importance and the activity of the space which it contains. The council chamber spaces contrast with the conventional work spaces these accommodation provided. With generally regularly arrangement and following a loose grid that could either be closed off or open plan working environments. The juxtaposing spatial makeup makes it easy to recognise from the outside and inside the building what function a space is given. 

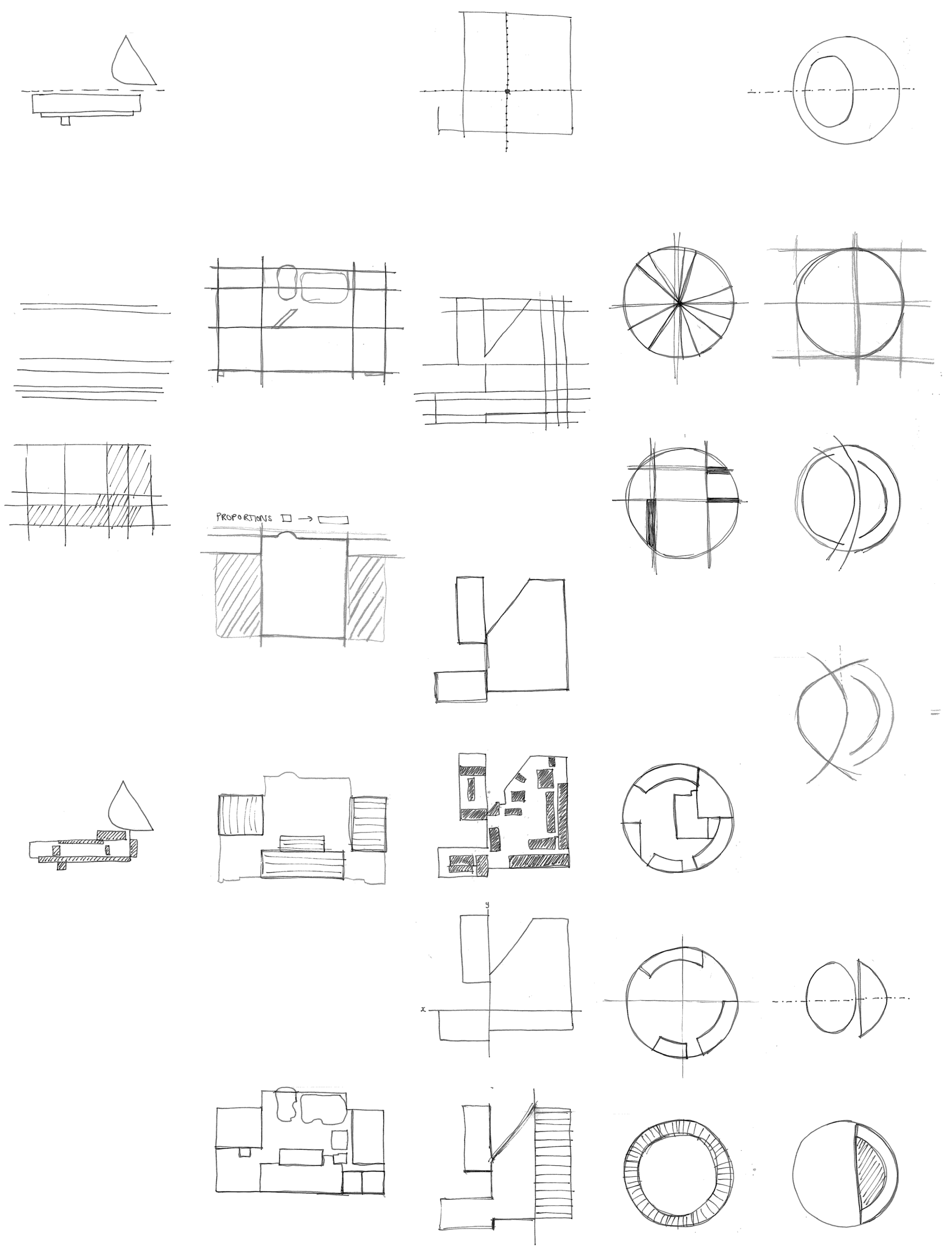

\section{Design Criteria}

As an outcome of this analysis three strategies for the design case study can be defined.

A. Hierarchy: through form and vertical arrangement spatial hierarchy can be determined and challenged. The spaces can be organised by public, semi-public and corporate.

B. Circulation: this will be considered a design driver for the following design case study. It is a functional element of the design where informal activities can take place.

\section{Various entrances: a variety of entrances are to be located at different} edges of the site. These can accommodate for the different users creating a dynamic threshold.
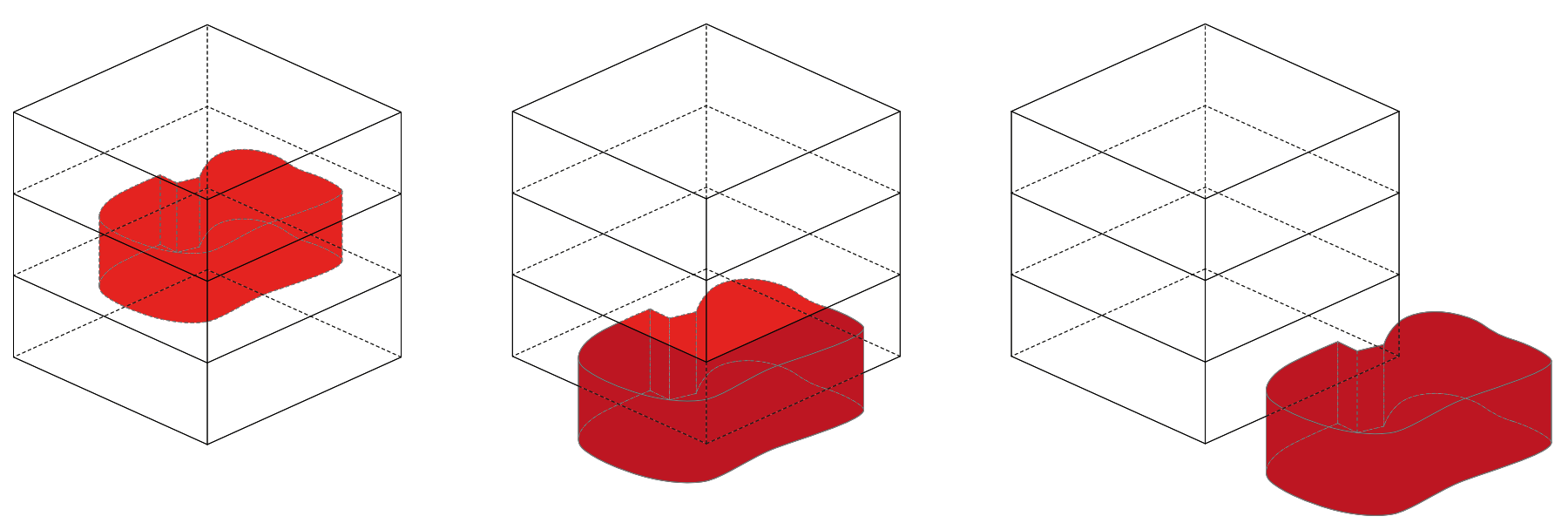

Fig. 83. This diagram symmantses and expresses the varlations of the redatonshp between the "important space" the chamber room or main meesing room, to the
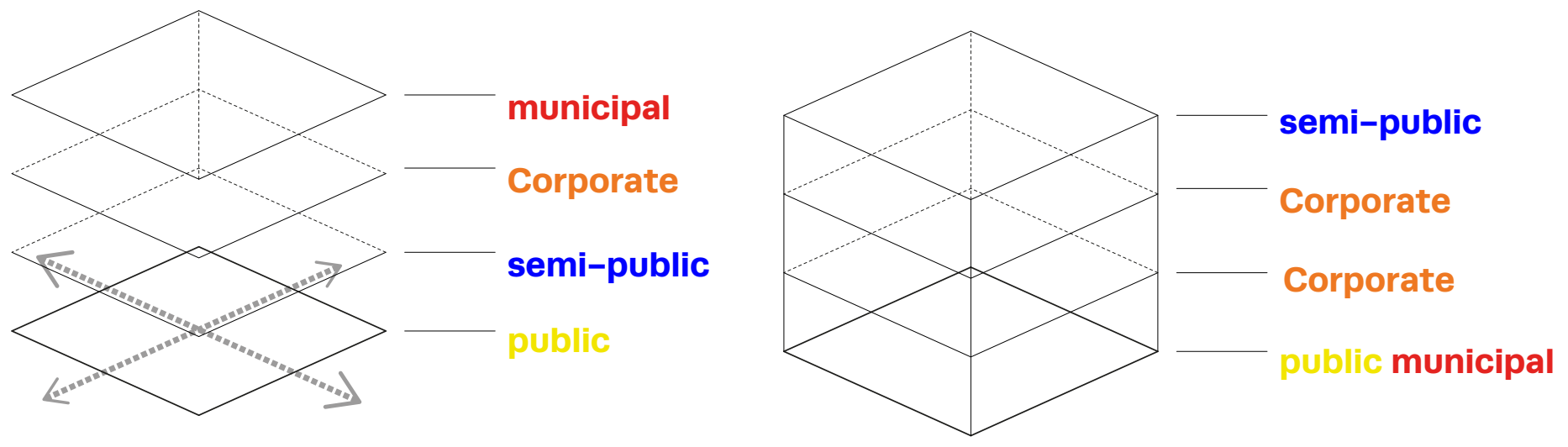

Fig. 84. vertical hierarchy is another strategy which will be implemented. This diagramillustrates the open ground floor and coupling of functions to the same level. 
Schrader, "Public buildings - Civic and cultural buildings"

Jones, Auckland Town Hall

Jones

Collins, Wellington Town Hall, 2

Collins, 4

Collins, 2

Monsalve, "Dunedin Town Hall", 54

Monsalve, 58

Gideon and Sert, Nine points on monumentality, 1

Dovey, Framing Place: mediating power in built form 49

Pownall, "Metropolitan Auckland 1740-1945: the historical geography of a New Zealand city, 118

Schrader, "Public buildings - Civic and cultural buildings"

Amin, Collective culture and urban public space, 6

Amin, 11

'First Parliament buildings'

Yoffe and Mace, Auckland City heritage walks, 43

Schrader, "Public buildings - civic and cultural buildings"

Smith, "A Short History of the Sixties Downtown"

Yoffe and Mace, 59

Allen, From object to field, 119

Dovey, Becoming places, 104

Allen, From object to field, 120

Astbury, “ALL designs faceted façade to create a play of light across Bodo City Hall”

Pintos, "Bodo Town Hall/Atelier Lorentzen Langkilde"

Astbury, "ALL designs faceted façade to create a play of light across Bodo City Hall"

Lewis, Dundee Council Civic Offices, 5

Lewis, 6

Sudjic, "The thriller on the river"

"City Hall"

"Brent Civic Centre"

"Selwyn District Council"

"Henderson Service centre and transport change"

Gates, "Christchurch Civic Building", 54

Gates, 58

"Bagnolet Town Hall / Jean Pierre Lott Architecte"

Gonzales, "The Crystal - Kiruna Town Hall / Henning Larsoen" 
This section is a pre-design stage, regarding the analysis of potential sites across Tamaki Makaurau, Auckland City's central business district. The following is predominantly a visual analysis of six sites along the Queen Street axis in Auckland. This analysis extracts the positive aspects

of each site in order to choose the most suitable location for the design case study. Using Jan Gehl's research this analysis will aim to show how the choice of a site for civic architecture can impact the design.
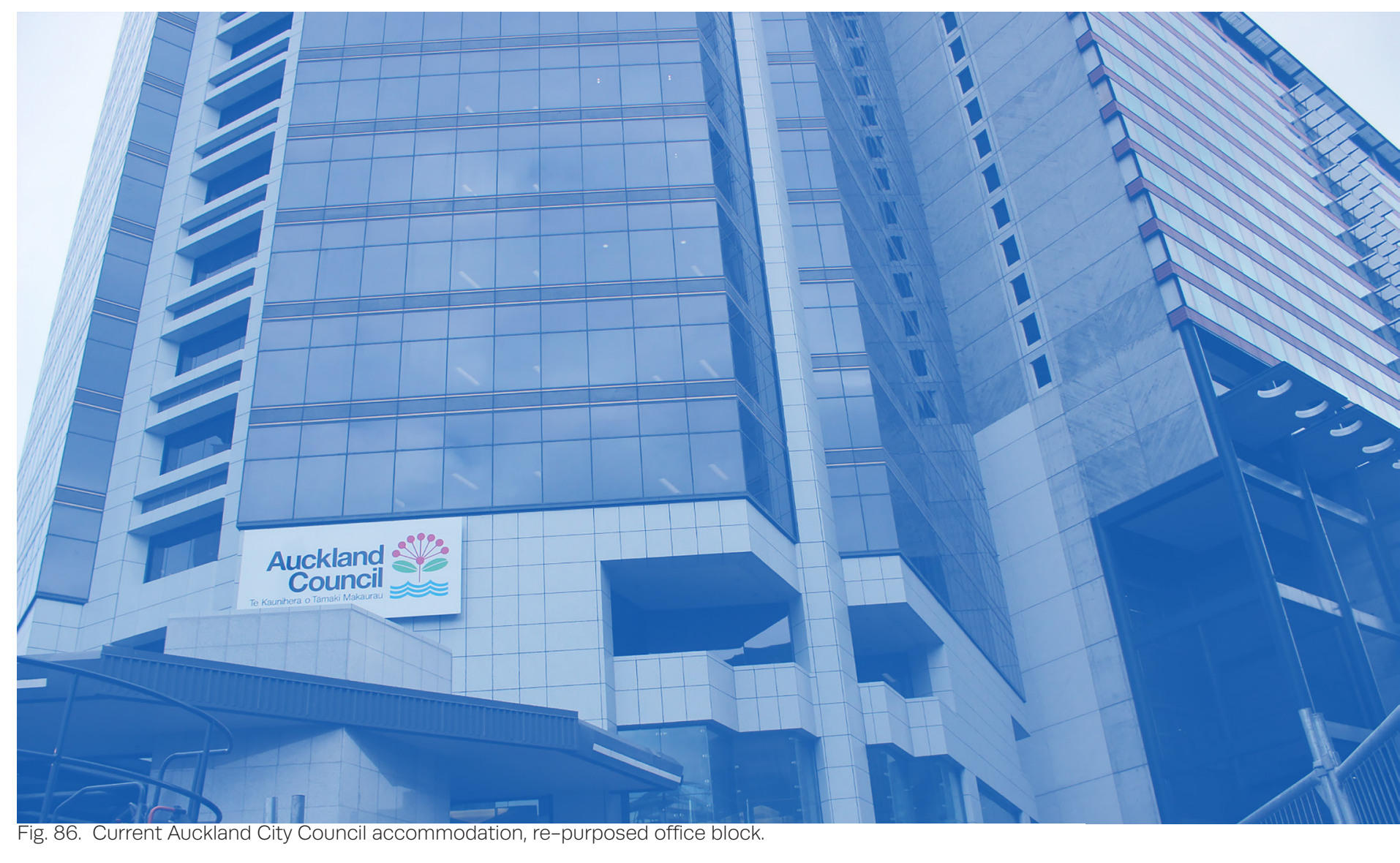


\title{
Site Selection
}

\author{
Introduction
}

The location for the design case study will be Tamaki Makaurau, Auckland City, in particular the central city. Potential options are narrowed down to council owned sites across the city. There are a limited number of vacant sites in the city centre as it is high value real estate. Site selection has a significant impact on the following design case study. The scattered locations of contemporary civic buildings has caused a decentralised local physical presence. With appropriate site selection, this design intervention has the possibility of becoming a beacon for a return to a more overt collective culture.

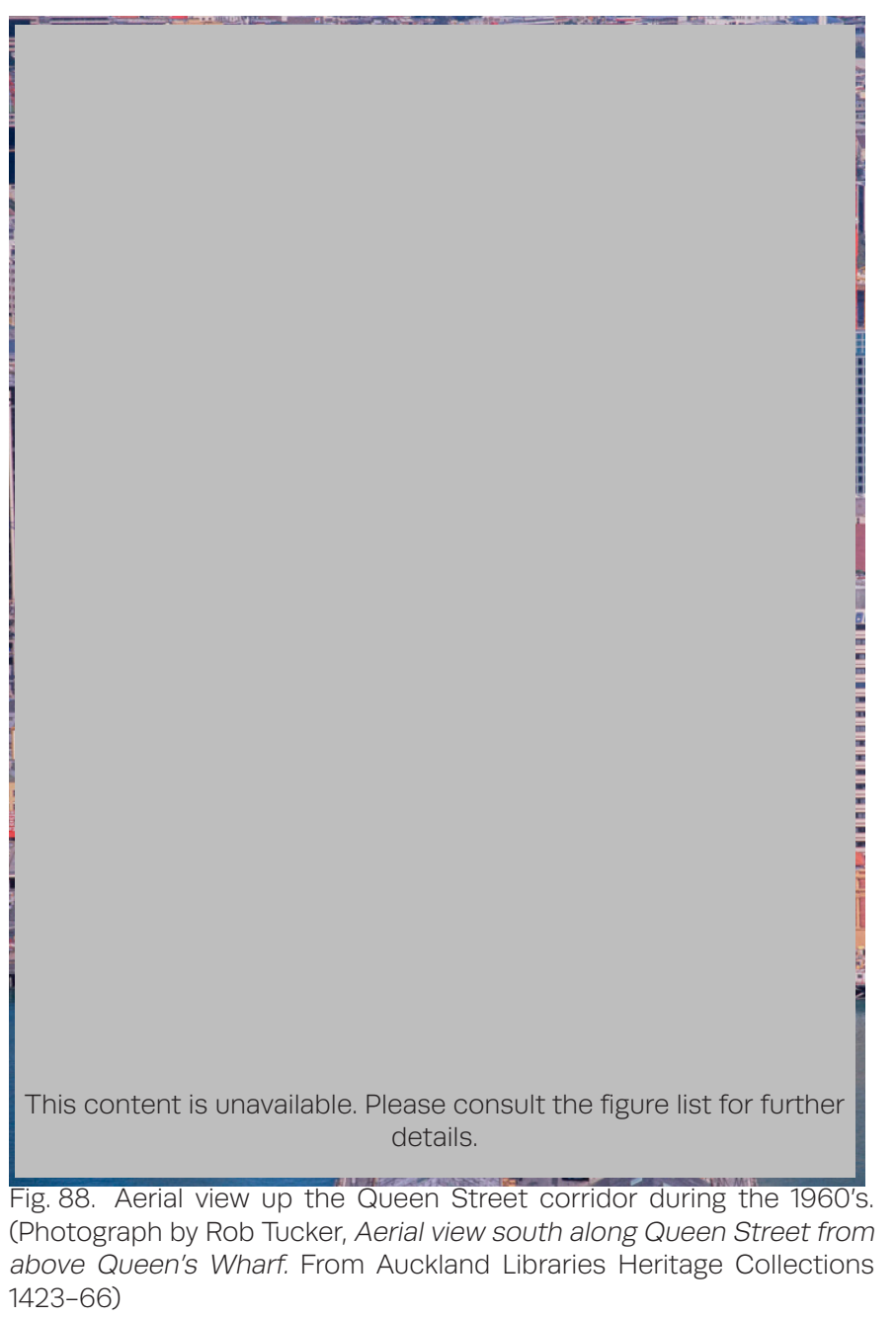

Tamaki Makaurau/Auckland 


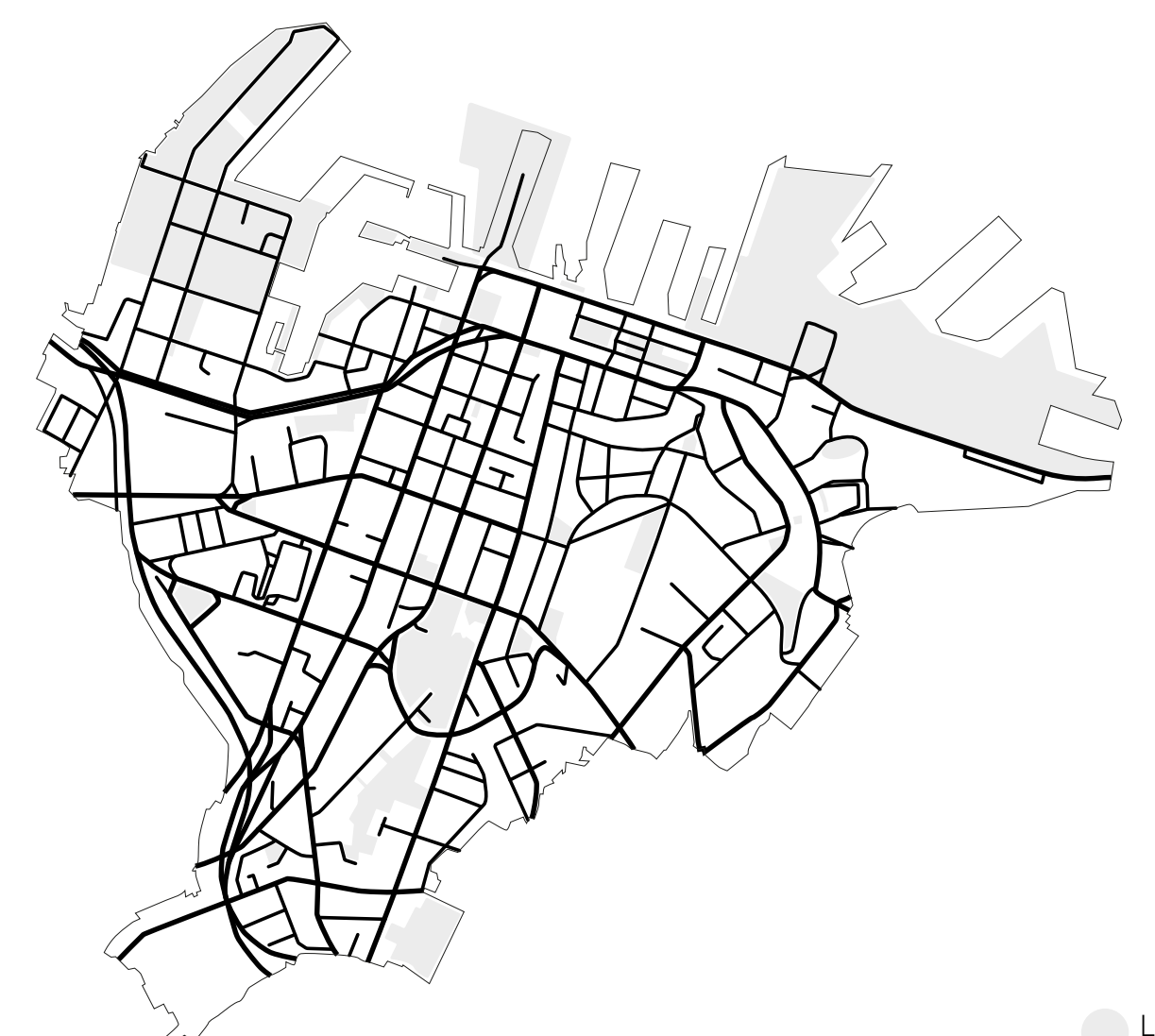

Local Authority owned land

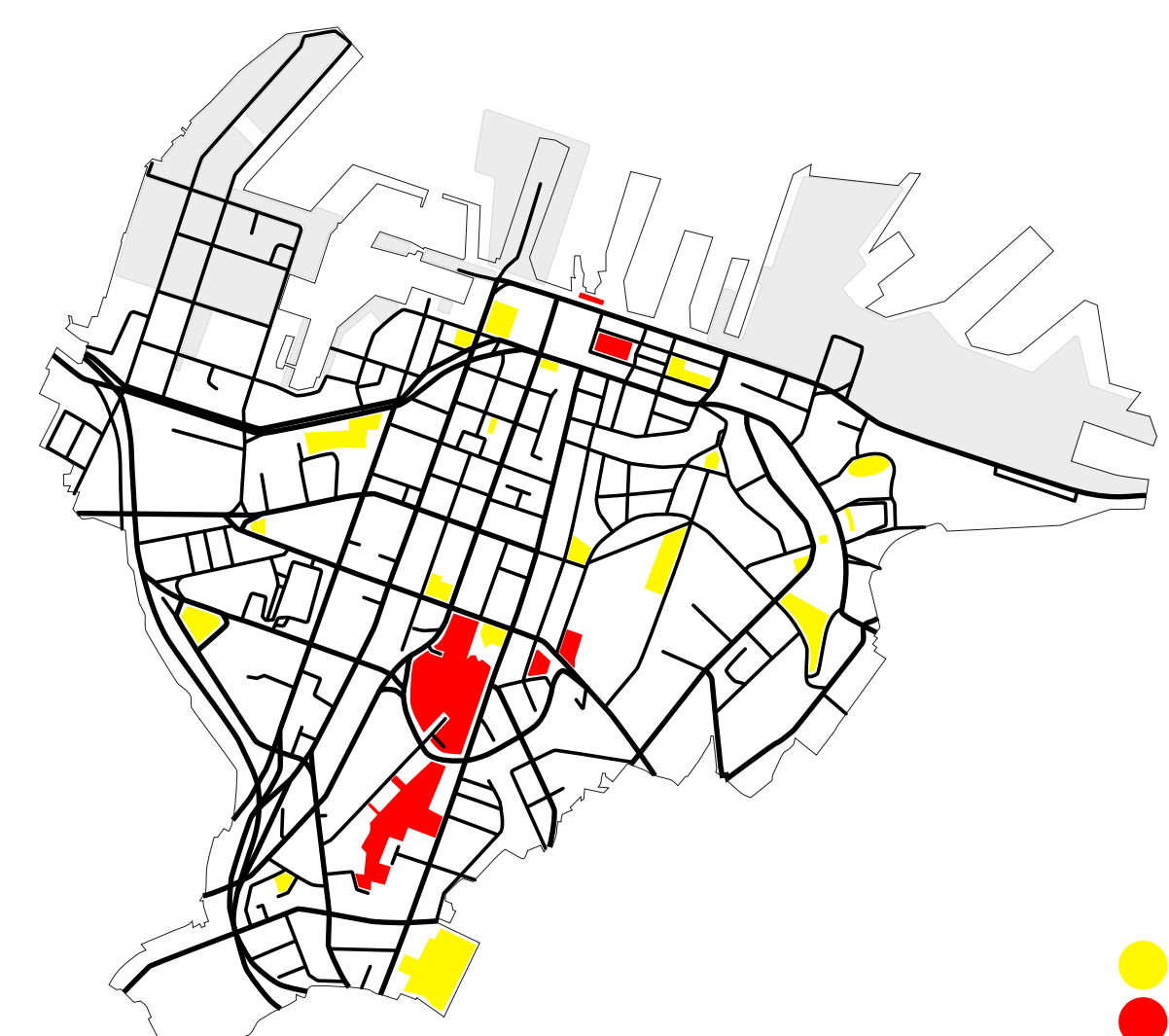

Original "Civic Space" (earlier defined) Sites on Reclaimed land 



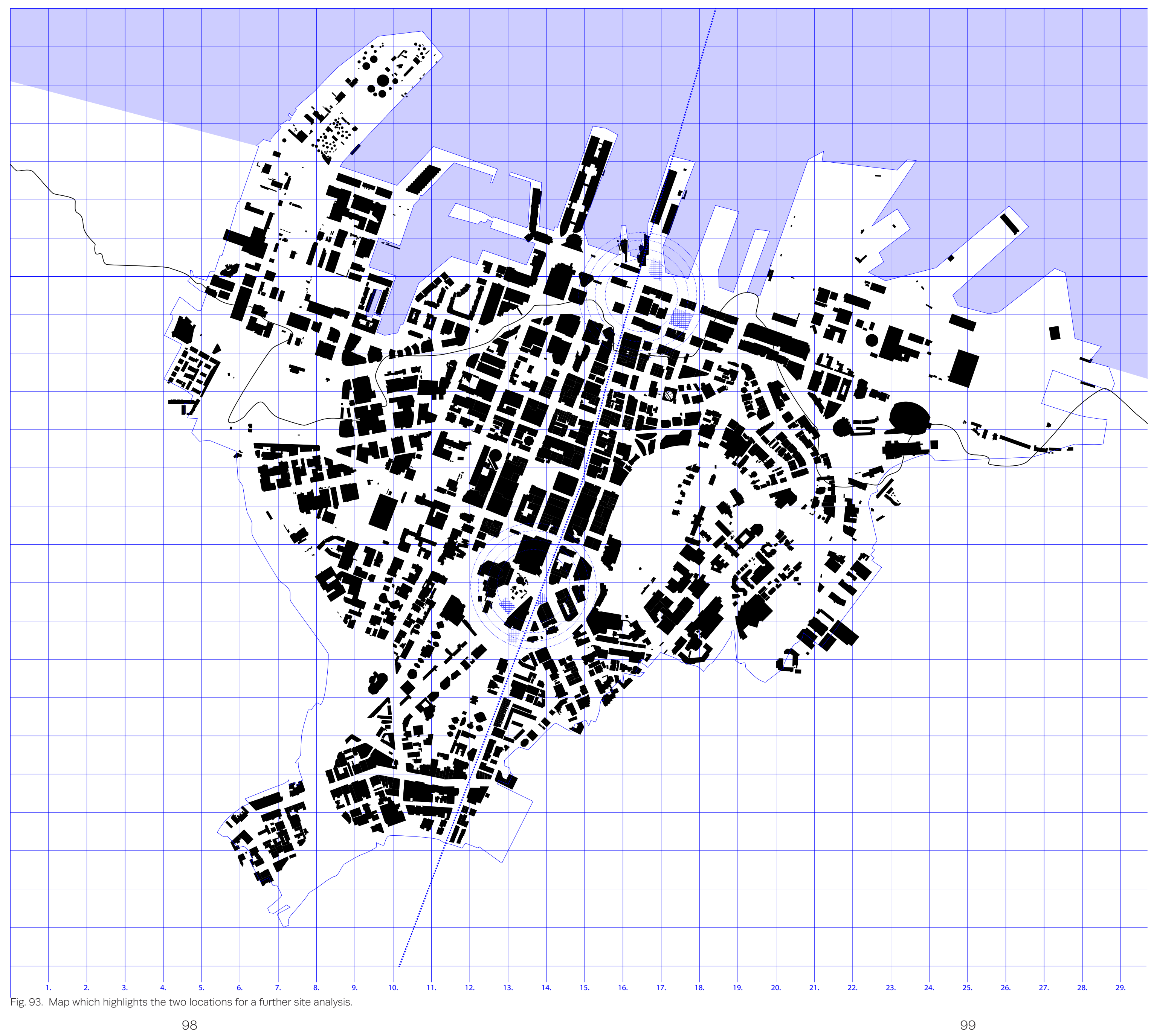



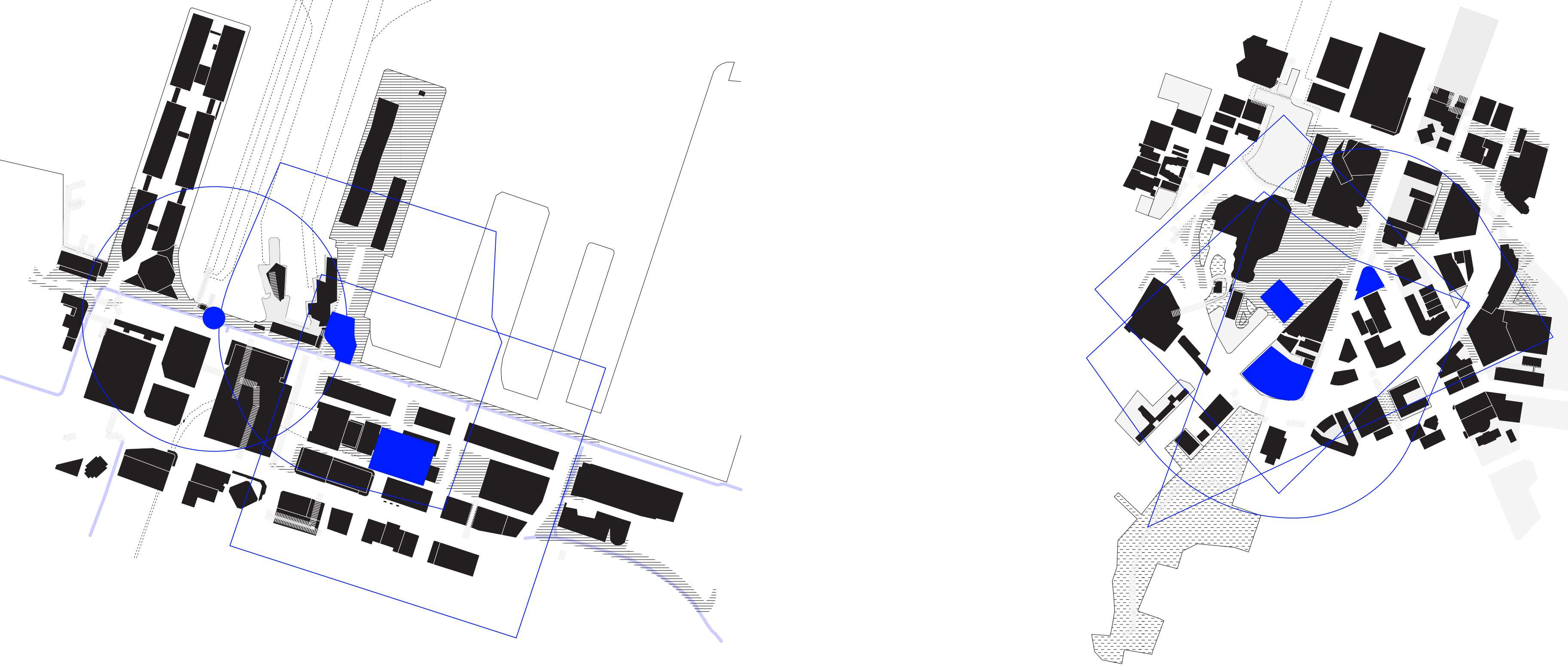

Auckland 


\section{Site Criteria}

The following exploration predominantly uses maps as The work of Jan Gehl informs a set of criteria which will Plan projection allows the six sites to be split into two areas.

spects of the buitt envirain forms of human interaction. In the city the architecture should give opportunities for meetings and gatherings, where people can see, hear and experience the activities of the collective community. Gehl's research is based on The six different site possibilities were distributed observations of human behavior in public spaces. In his between two areas; the waterfront of Waitemata Harbor $\begin{aligned} & \text { observations of human behavior in public spaces. In his } \\ & \text { observational research and findings he has found that }\end{aligned}$ and Aotea Square. All options have a variety of positive observational research and findings he has found that features, including ample pedestrian usage, a variety their daily lives. ${ }^{1}$ The rhythms of daily rituals which of building types; retail, accommodation and corporate occur in many places in the city, inside buildings and in function, and proximity to amenities, these are some of the spaces between buildings. With a large part of the the criteria which are important for selecting the site. In the spaces betwe buration (t) strengthen the social chosen site must optimise pedestrian recognition and function of city space as a meeting place that contributes public use. This analysis will help inform the design toward the aims of social sustainability and an open and outcome and strategies.
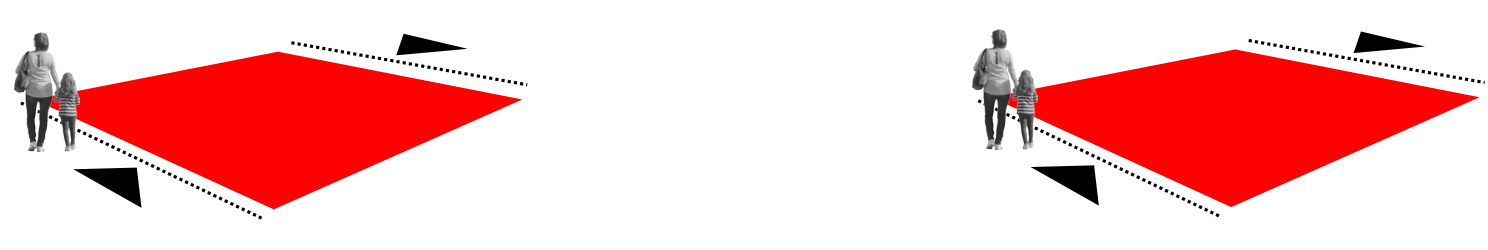

EXISITNG SPATIAL STRUCTURE

EXISITNG SPATIAL STRUCTURE
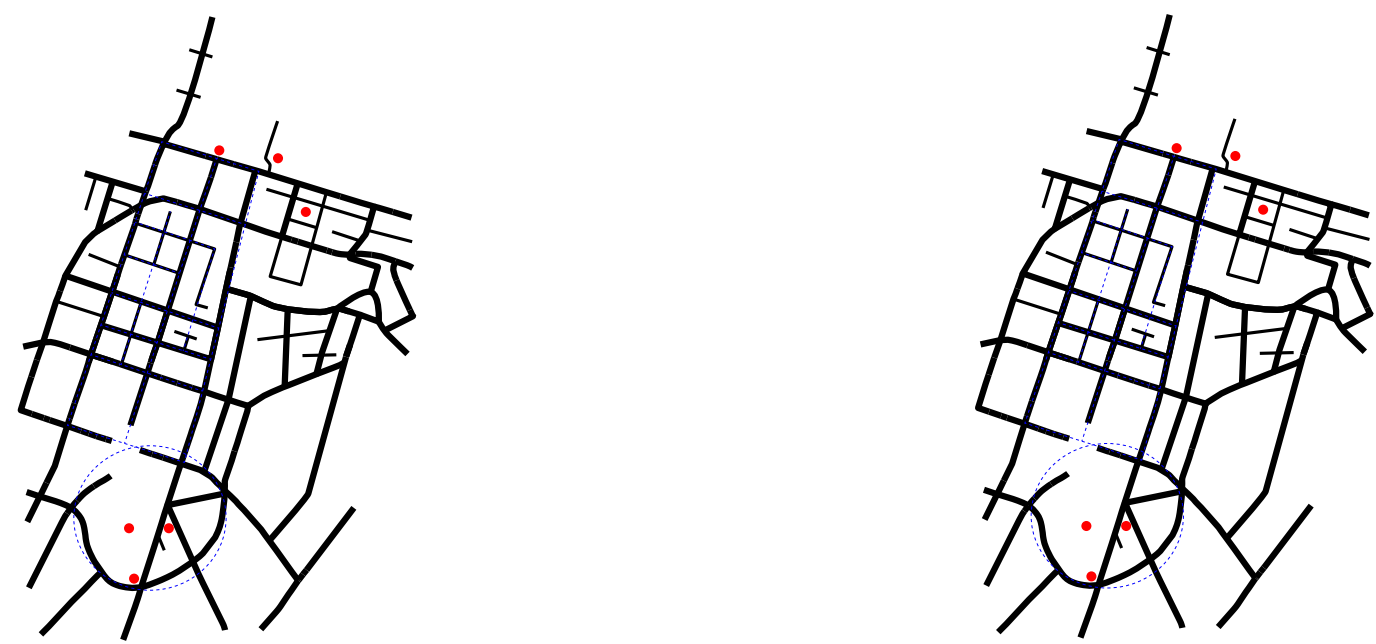

PROMINENT VISIBILITY

PROMINENT VISIBILITY
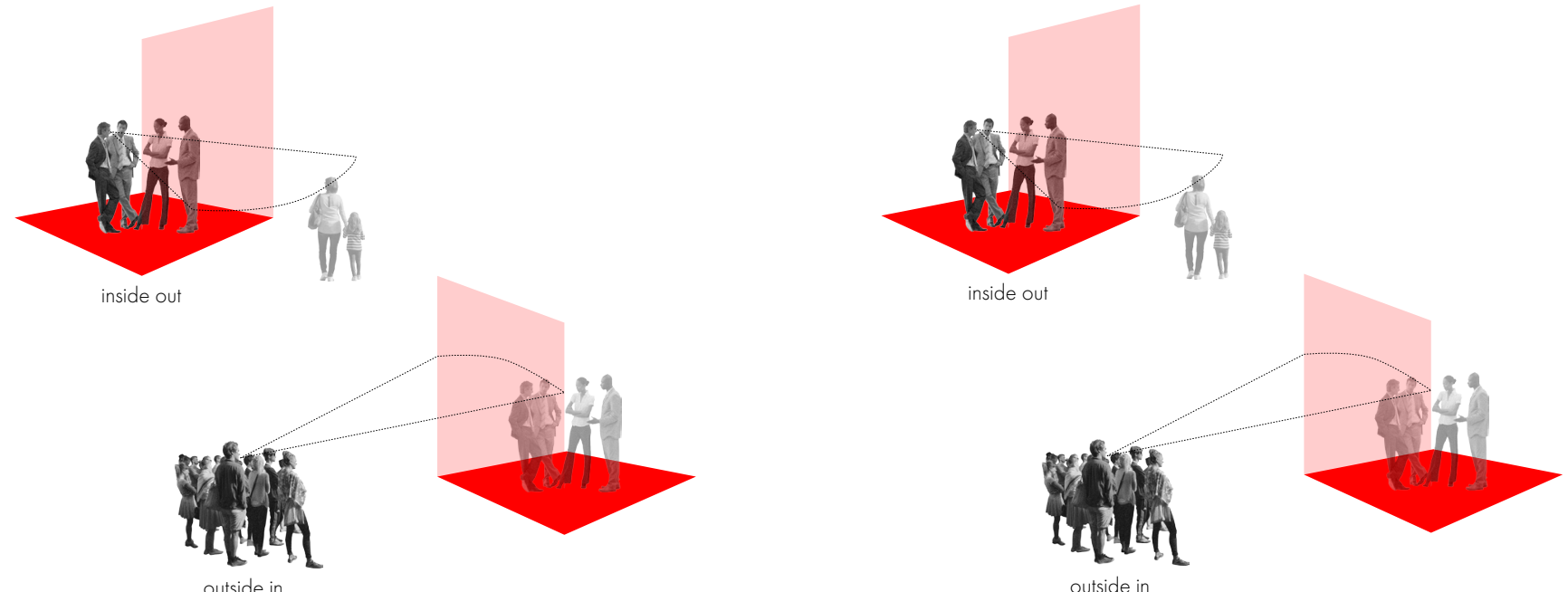
Access to and around the site should be focused on pedestrians, with opportunity for the design to achieve multiple thresholds or approaches. In Gehl's literature "Cities for People" he discusses the importance of activity and mobility of humans. To improve the experience of the human and their interaction with the architecture, consideration of the human scale at the initial design stage can facilitate this experience. ${ }^{3}$ This can be considered a the threshold, between architecture and human; where one physically enters a building.

This diagram indicates the access of the possible sites at the Auckland Waterfront.

With site W3, occupying an entire block makes acces from all edges available. Whereas site $\mathrm{W} 1 \& \mathrm{~W} 2$ are both on the waters edge and it becomes more challenging to access these sites. Although locations on the waterfron have plenty of pedestrian access points.

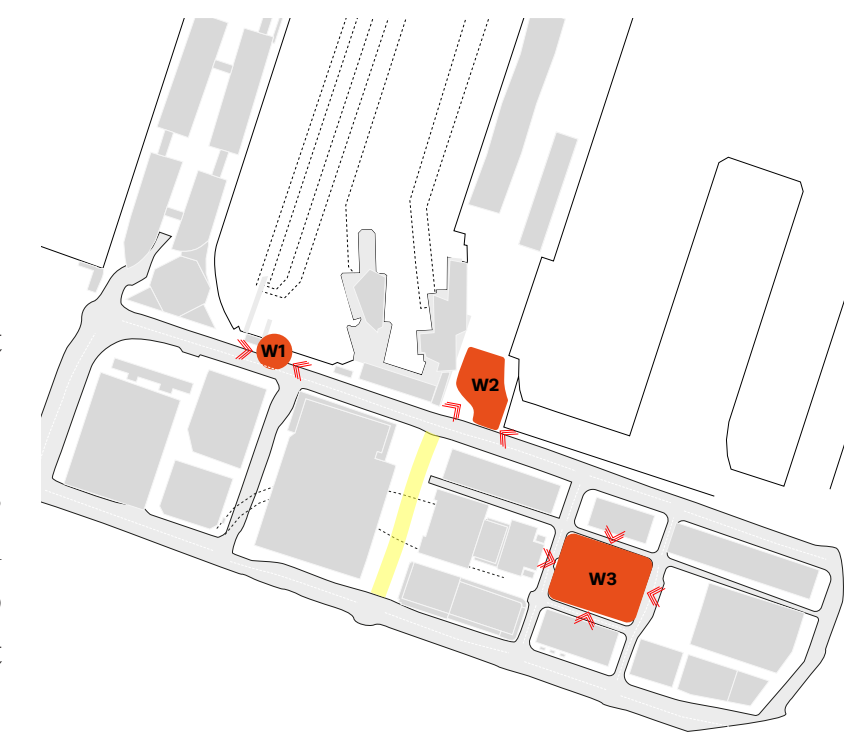

Fig. 97. Locations W1, W2 \& W3. access point map.

This diagram shows the access of all the sites around the Aotea Circle.

Site A1, has pedestrian access from all edges, located in Aotea Square it means there is only pedestrian access. Site A3, has access from three sides although backs onto the town hall therefore the north edge cannot be accessed.

Site A2, is triangular shaped and has pedestrian access from all edges. The location at an intersection favours this criteria.

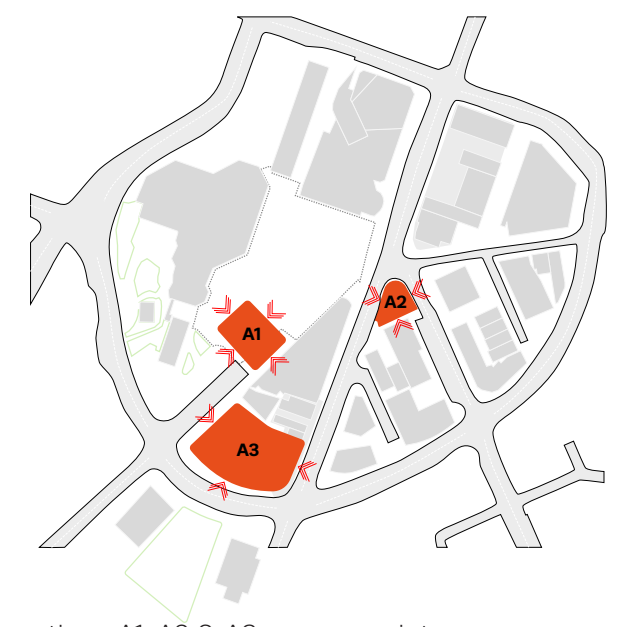

Fig. 98. Locations A1, A2 \& A3. access point map.
One of the driving principles of this thesis is for an architectural intervention to have physical presence of local government in the city. The appropriate choice of a site must allow for the architecture to be distinguished by the public. Therefore the site should be visible from the street or surrounding buildings, conversely there should be views of important city features from within the site. These are some of the criteria which follows. Among the various options for the site, some are more prominent for pedestrians and some more prominent for vehicle traffic. This research is established on the importance of the relationship between architecture and the public sites which are considerable beneficial for pedestrian movement have an advantage.

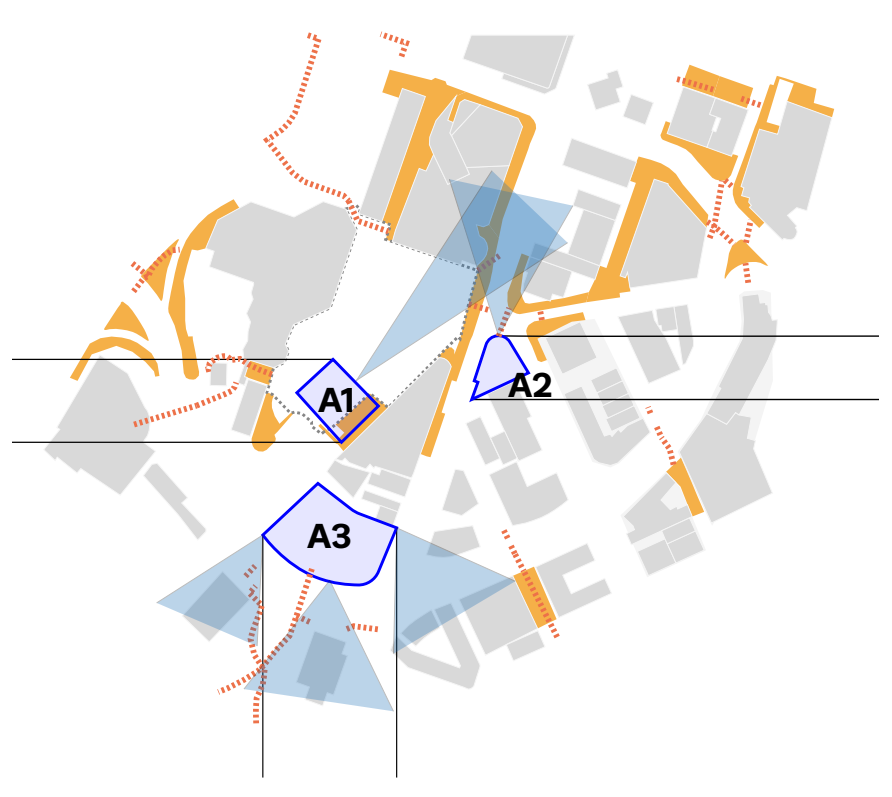

Fig 99 . Aotea sites options. Diagram shows views out towards main treets Orange represents the pedestrian areas 


\section{Existing Spatial Structure}

Auckland City is made up of various grids, where prominent intersections create nodes for both pedestrian and car traffic. Queen Street can be considered a central datum in the city, it leads from the waterfront up to where the grid structure starts to change and divide during the twentieth century. Auckland was re shaped and influenced by the cars, this decision impacted the development of street in the metropolitan area during the 1950's (Auckland Regional Council, p.19). ${ }^{4}$ Although the development of the roads in Auckland was for the benefit of cars, this does not deter pedestrian usage of the plentiful sidewalks. The roads created the spatial geometry of the cities layout.

The waterfront has a regular grid; streets run parallel and adjacent to one another, along the water's edge or towards the water's edge. This is regular structure is supported by the development around the viaduct area which has lead to successful social spaces. ${ }^{5}$ In contrast the Mayoral Drive streets have an axial geometry, Queen Street is the main axis, with smaller streets intersecting at the centre of Mayoral drive loop. This loop road helps create the more complex geometry resulting in a concaving of streets and therefore building fronts.

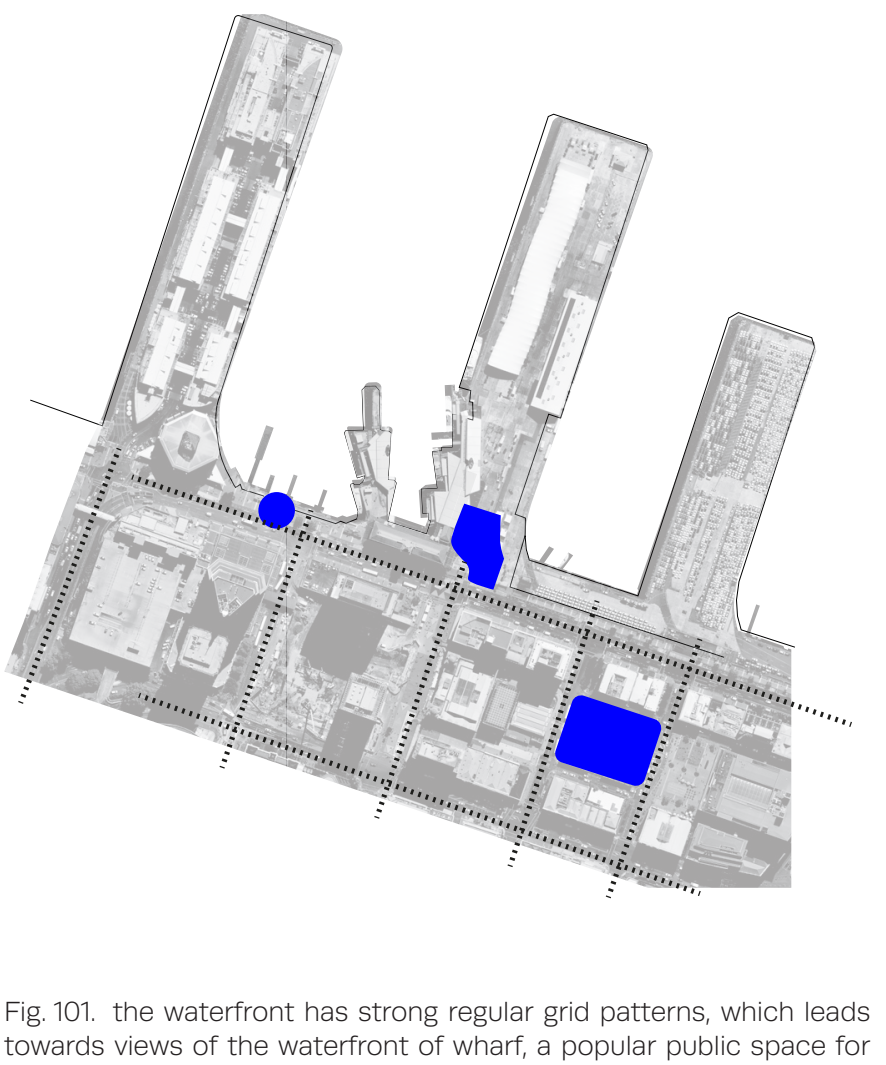

towards views of the waterfront of wharf, a popular public space for

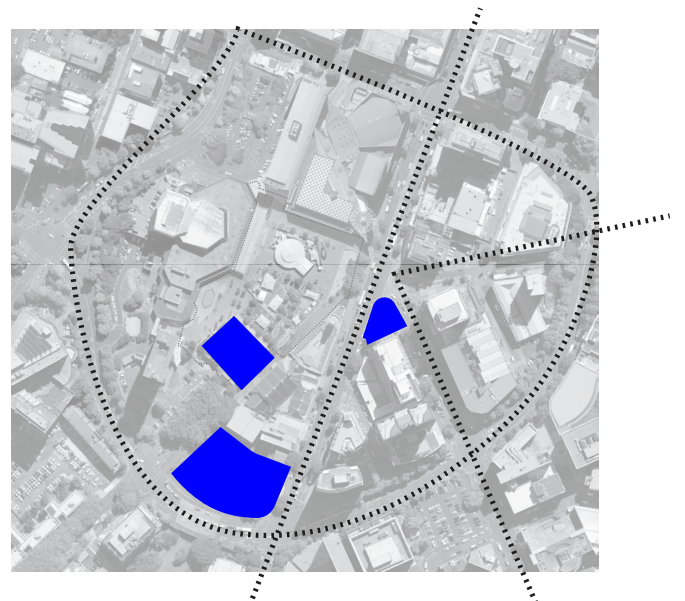

Fig. 102. The Aotea sites are centered around the Mayoral Drive loop, Fig. 102. The Aotea sites are centered around the Mayoral Drive loop.
Size/Shape

The area of the site has the potential to be a design Site A2 is triangular, only offering three sides, although advantage. Some sites; (A1, A3 \& W2) are four sided. with access to all sides this is desirable. There is a clear This can be considered an advantage as all edges can front and back, where the top corner offers itself to the be activated. Site $\mathrm{W} 2$ is an irregular shape and located queen street intersection. It should be acknowledged that on the water's edge. This location is more challenging this site has a smaller spatial footprint in comparison in terms of factors such as front and the back access to the other sites, but with the immediate neighboring and façade treatment. W1 is another challenging size, building ten storey's high it offers an elusive backdrop. the footprint would need to be small and it too is on the water's edge, minimising which edges can be accessed by foot. Although the water's edge sites do have advantages such as views. Their location means the visibility around downtown Auckland would be prominent, both for outwards views and towards.

\begin{tabular}{|c|l|}
\hline W1 & $279 \mathrm{sqm}$ \\
\hline W2 & $825 \mathrm{sqm}$ \\
\hline W3 & $1742 \mathrm{sqm}$ \\
\hline A1 & $710 \mathrm{sqm}$ \\
\hline A2 & $410 \mathrm{sqm}$ \\
\hline A3 & $1702 \mathrm{sqm}$ \\
\hline
\end{tabular}

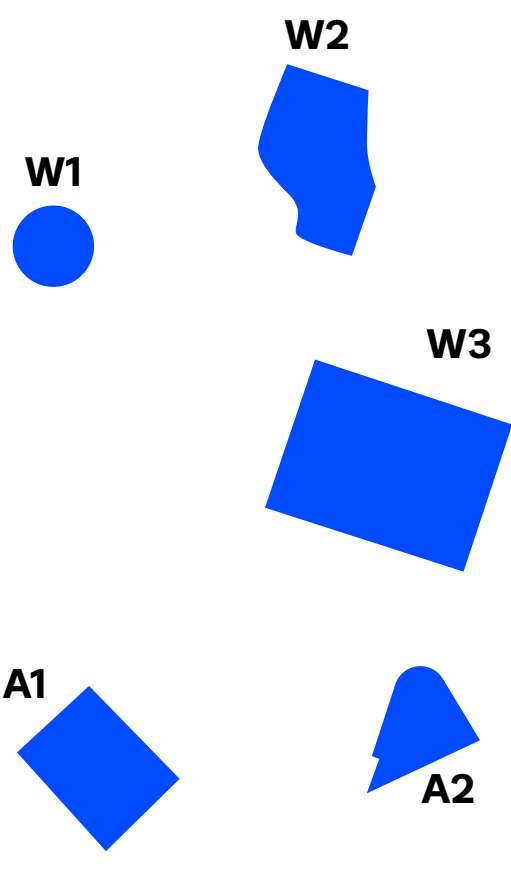

A3

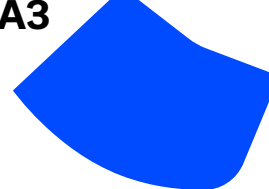


Historical Relevance

Auckland city has rich history around the development of the streets, buildings and surrounding suburbs. The Auckland shoreline has served a purpose for both Maori and settlers; the ocean as a food source, the bays as key transportation and trading locations. ${ }^{6}$ Mayoral Drive and its corresponding buildings and streets is considered significant location, since the construction of the town hall in 1911, the area has observed careful consideration and conversation. It was in the 1970's when there was discussion about the design of a town square the Mayora drive area, had further civic connections.

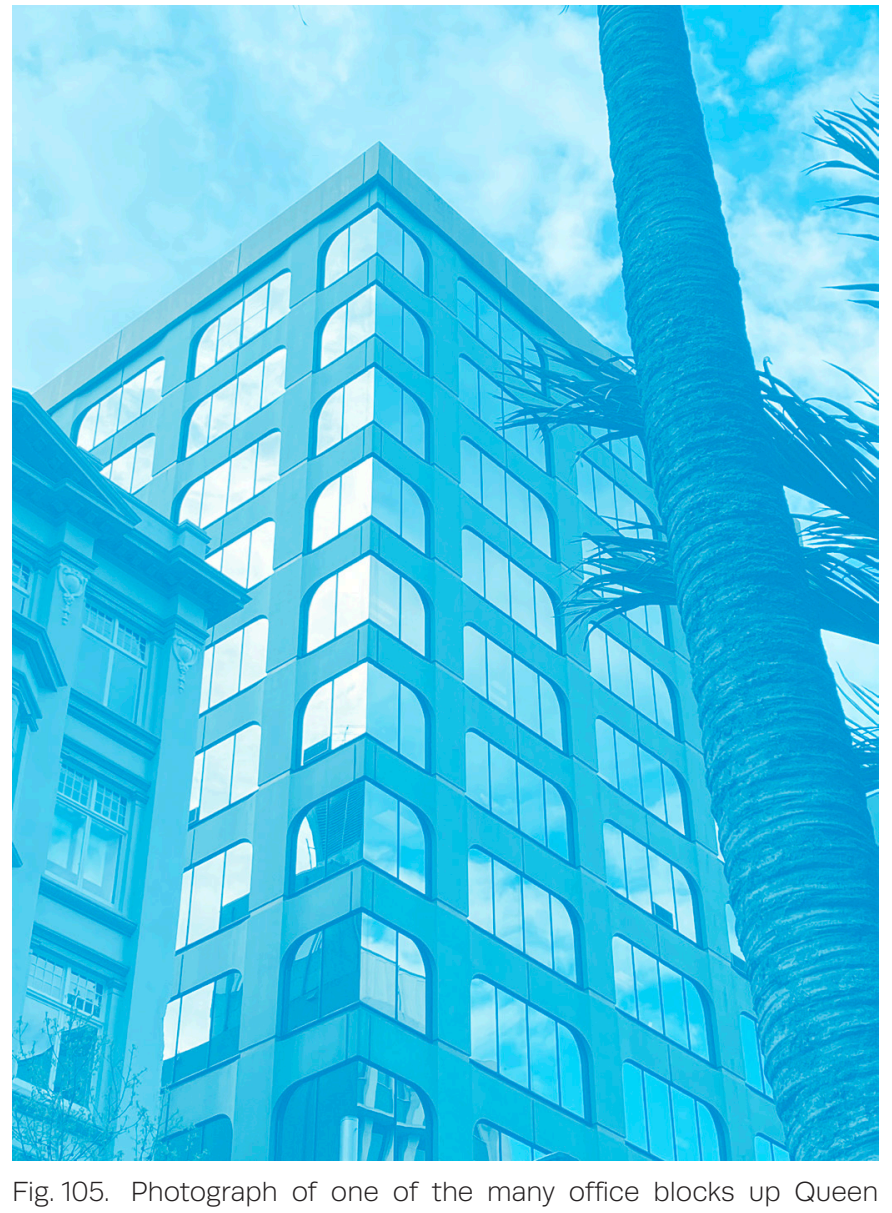

Fig.

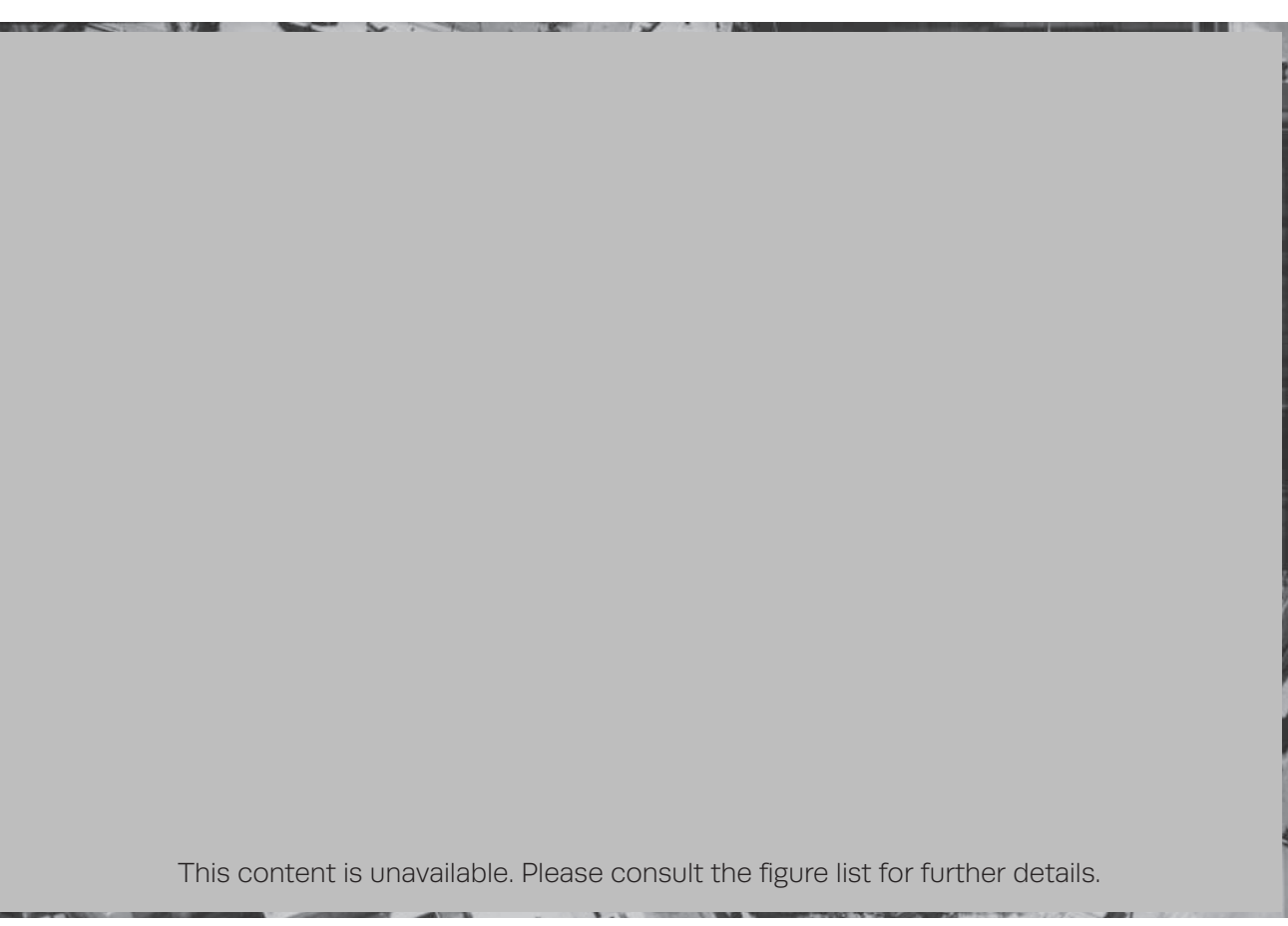

Fig. 104. The construction of Street and site A2 in the upper left corner (Photograph by unknown, From Auckland Libraries Heritage From Auckland Lib
Collections 7-A5218)
Proximity to civic \& public amenities
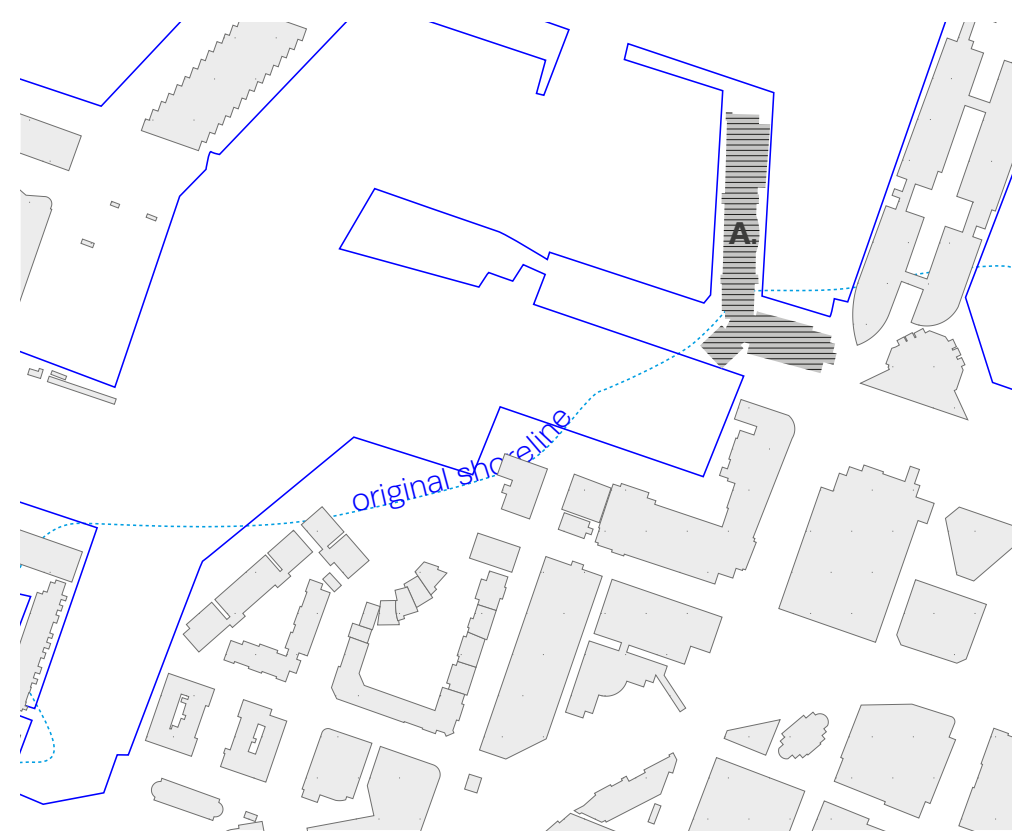

Fig. 106. Surrounding civic amenities near the waterfront. (Defined with

hatched key)

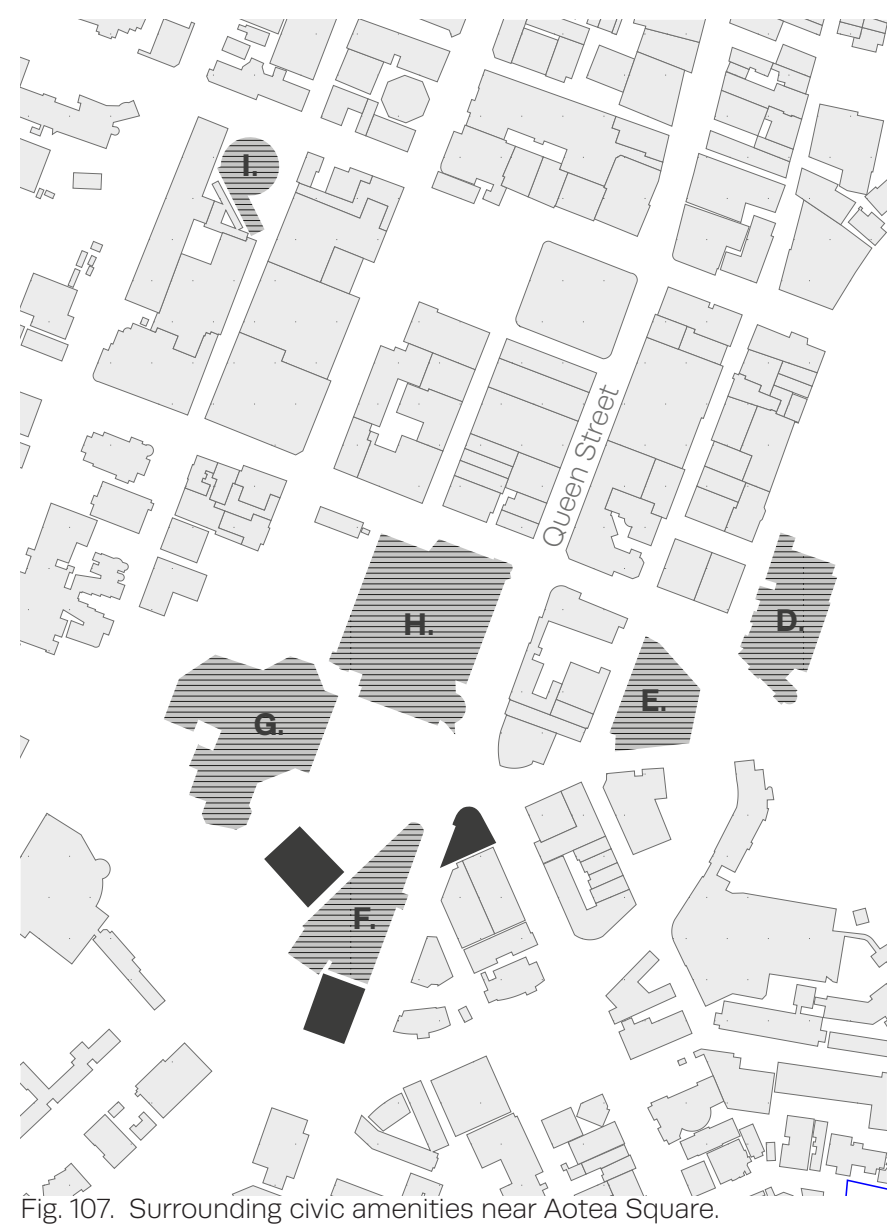

Where the site is in close proximity to public services across town, this will deliver a diverse group of users to the space. In Gehl's research he specifies that activities in public space can either be segregated or integrated. Integrated spaces are preferable because they have multiple functions and diverse activities happening. The integration of space is beneficial for society, it gives opportunity for a display of collective culture. ${ }^{7}$ A site which has a variety of public amenities close by will integrate the activities and daily rituals of their users. With Auckland City made up of diverse and various groups there is potential to locate this design intervention so that it serves as a catalyst for integration.

This map shows the sites located around Aotea circle are in close proximity to multiple civic services. These include Auckland Art Gallery (D), the Aotea Centre performing arts centre $(\mathrm{G})$ and the Public Library $(\mathrm{E})$. 


\begin{tabular}{|l|l|l|l|l|l|l|}
\hline & \multicolumn{3}{|c|}{ AOTEA SITES } & \multicolumn{3}{|c|}{ WATERFRONT SITES } \\
\hline \multicolumn{1}{|c|}{ CRITERIA } & A1 & A2 & A3 & W1 & W2 & W3 \\
\hline $\begin{array}{l}\text { 1. access (pedestrian; } \\
\text { number of street edges) }\end{array}$ & & & & & & \\
\hline $\begin{array}{l}\text { 2. legible Existing } \\
\text { Spatial Structure }\end{array}$ & & & & & & \\
\hline $\begin{array}{l}\text { 3. prominent Visibility } \\
\text { (views to and views out } \\
\text { "social field of vision") }\end{array}$ & & & & & & \\
\hline $\begin{array}{l}\text { 4. proximity to other } \\
\text { civic/public amenities }\end{array}$ & & & & & & \\
\hline $\begin{array}{l}\text { 5. historical } \\
\text { relevance/associations. }\end{array}$ & & & & & & \\
\hline 6. size/shape & & & & & & \\
\hline
\end{tabular}
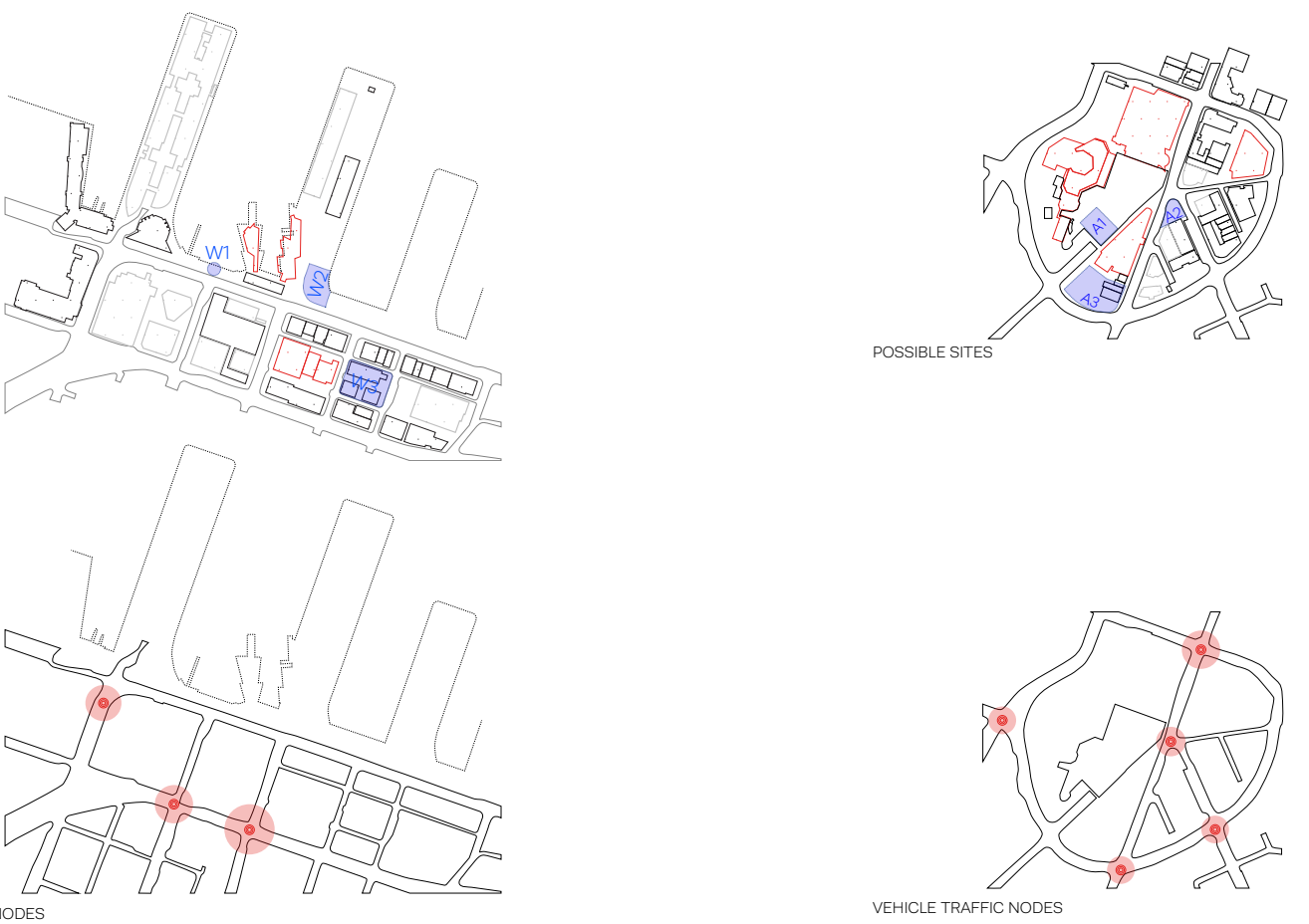

Meets assessed criteria with success

Some aspects could be better

Minimal aspects of criteria are met

Table. 1. Traffic light assessment of established site criteria.

Table. 1 shows how site $\mathrm{A} 2$ is the best suited location based on the above criteria.

The discussion has outlined site A2 as successful in most criteria. Criteria size/

shape is identified to be met with satisfaction rather that success, based on the smaller size in comparison to the other site options. Although the overall shape gives opportunity for multiple access points, the size can be overlooked.
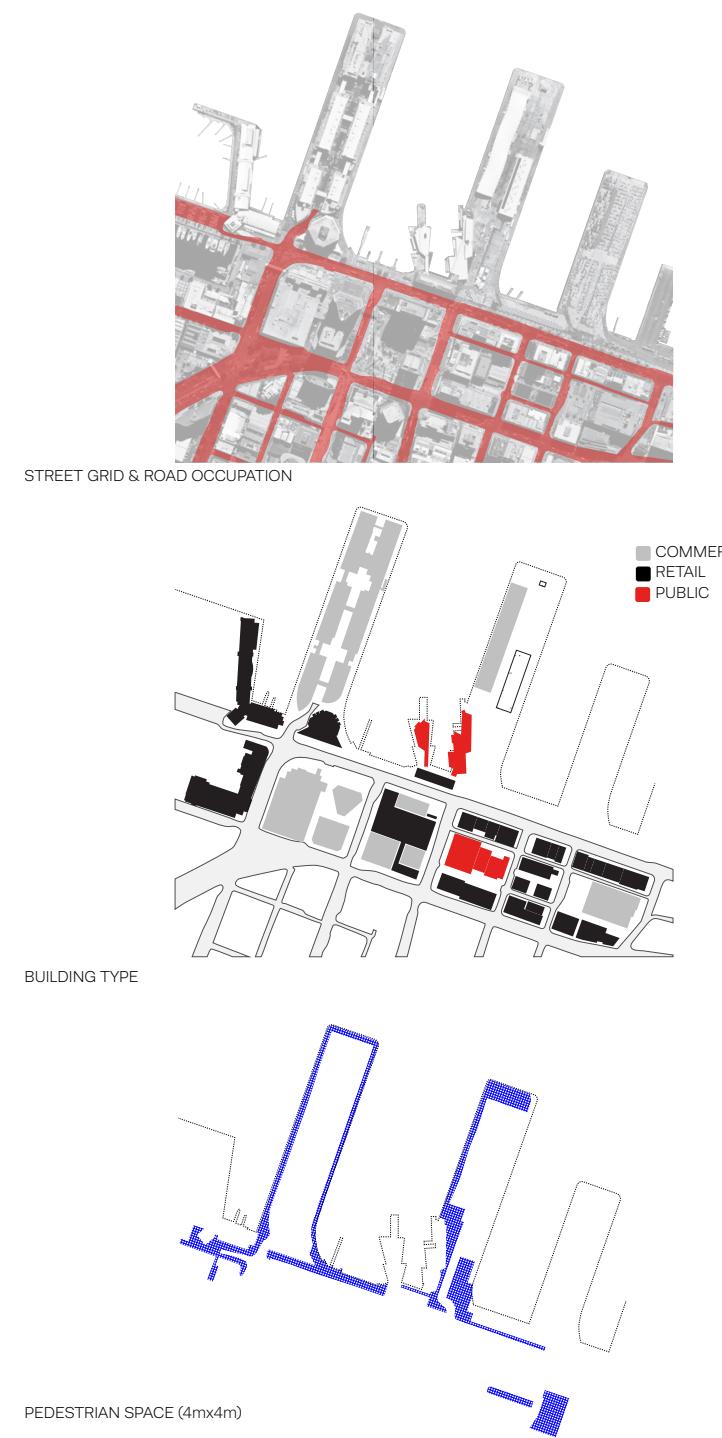

Fig. 108. Waterfront site diagrams showing various criteria. (Top to Fig. 108. Waterfont site diagrams showing varlous chteria. (Top to
bottom) site options locations (blue), vehicle nodal points, building types in the area, pedestrian areas 


\section{Conclusion

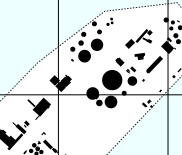

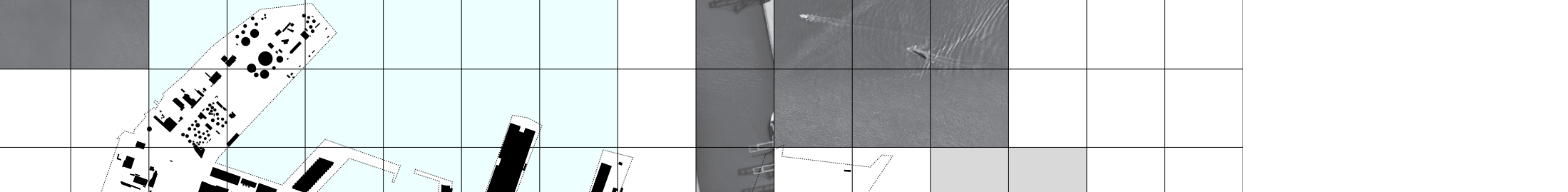

, 1

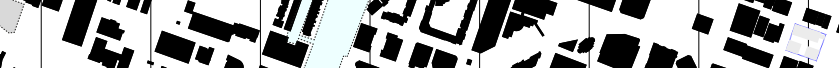
(1) A th

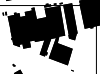

stistist

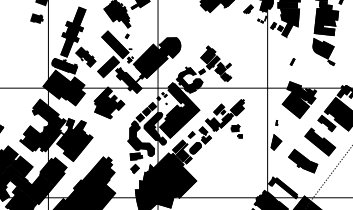

(a)

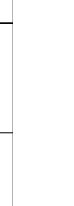

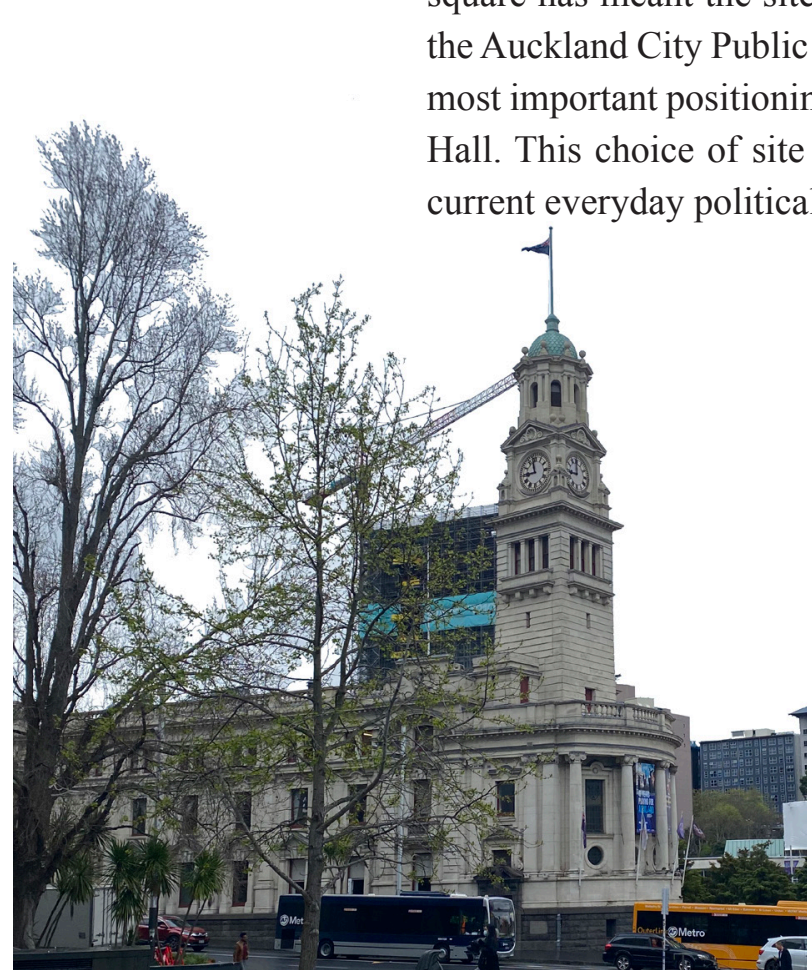

This chapter presented a visual and investigative site analysis of six potential sites across Tamaki Makaurau, Auckland city. Through the guidance of a criteria informed by Gehl's studies on human behaviour in public space, the most appropriate site was chosen: a site where all edges are exposed to pedestrian use, there is prominent visibility along the major Queen street axis, it is visually linked to other existing civic buildings. These are some of the criteria which identified the irregular shaped Queen Street (A2) site as the most favourable option. Gehl has substantial knowledge on the patterns in which people use space and buildings. In particular he studies the human senses and these relate to each other and one's surroundings. Some conclusions which Gehl has come to is the use of the horizontal plane, where people move along the ground/horizontal plane. ${ }^{8}$ When consideration is given to the horizontal plane then there is further understanding of how people perceive an environment. When a space is of modest dimensions it becomes easier for human sense to adjust to a space, feeling intimacy and closeness. ${ }^{9}$ The human dimension and relation to the ground plane is a key driver in this thesis.

The selected site is in the dense heart of Queen Street, across the road from the current Auckland Town Hall. It is perched on an active intersection, enclosed by the semi-circle of Mayoral Drive circle and where Queen Street meets Wakefield Street. The intersecting of the roads creates an irregular triangle site shape, allowing access from all three edges. As one ascends Queen Street the location offers itself to the road. The high visibility from and towards the site is one of the features which stood out in the deliberation. Proximity to Aotea square has meant the site is near various civic amenities, with a sight line to the Auckland City Public Library and the Auckland Council Office block. The most important positioning is its neighbor across the road; the Auckland Town will be a reminder of what once was and what the irrent everyday political practices of Auckland City Council are. 

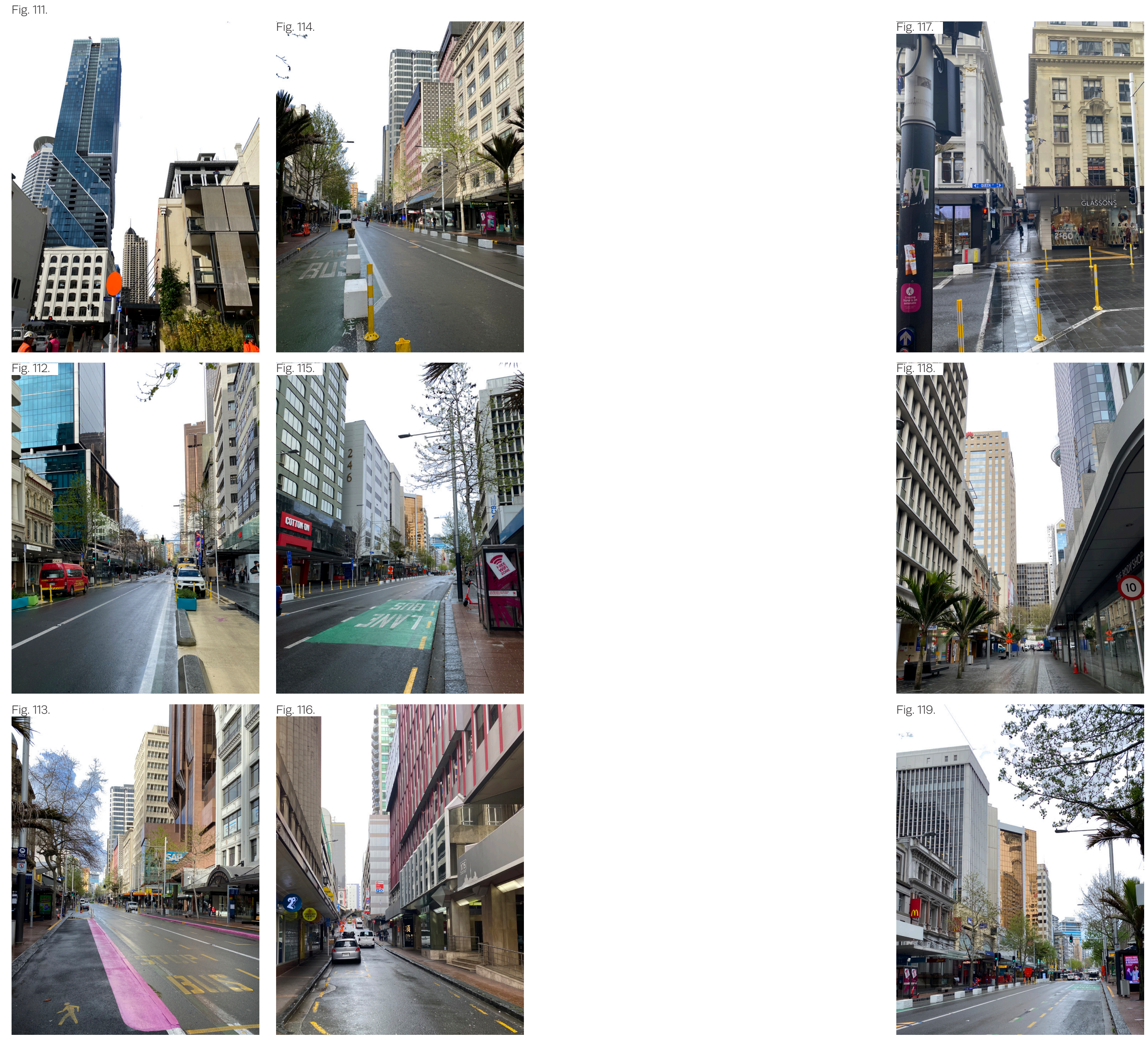

(Fig 111- 119): Photographs around Auckland cities streets, many office blocks and development is happening around the city. Buildings create corridors for 


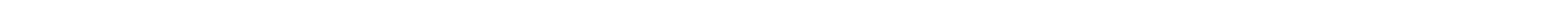




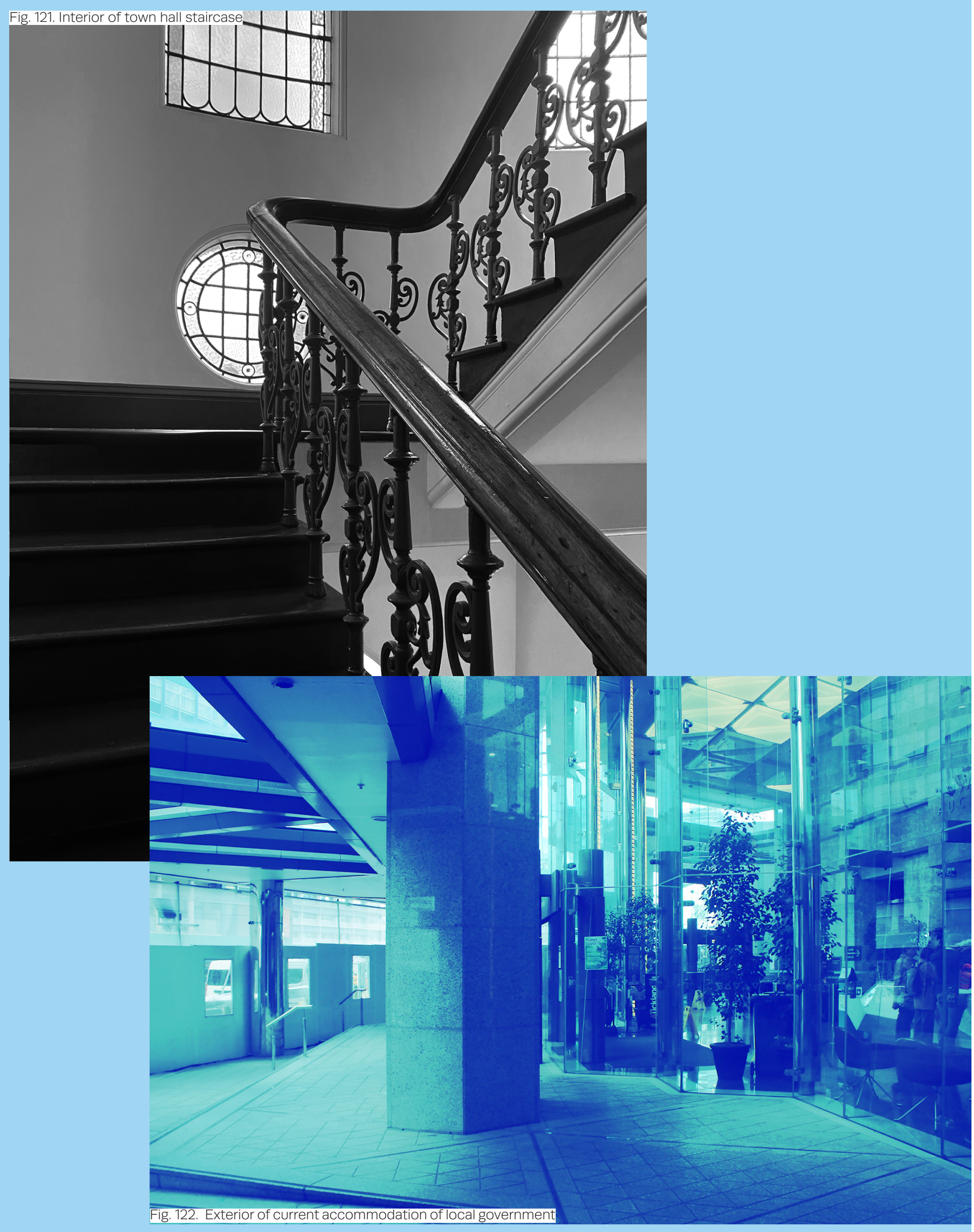

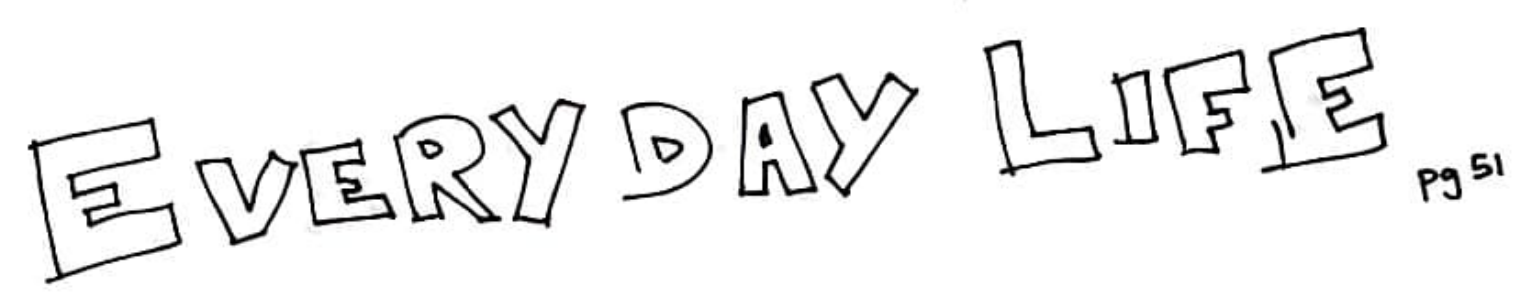

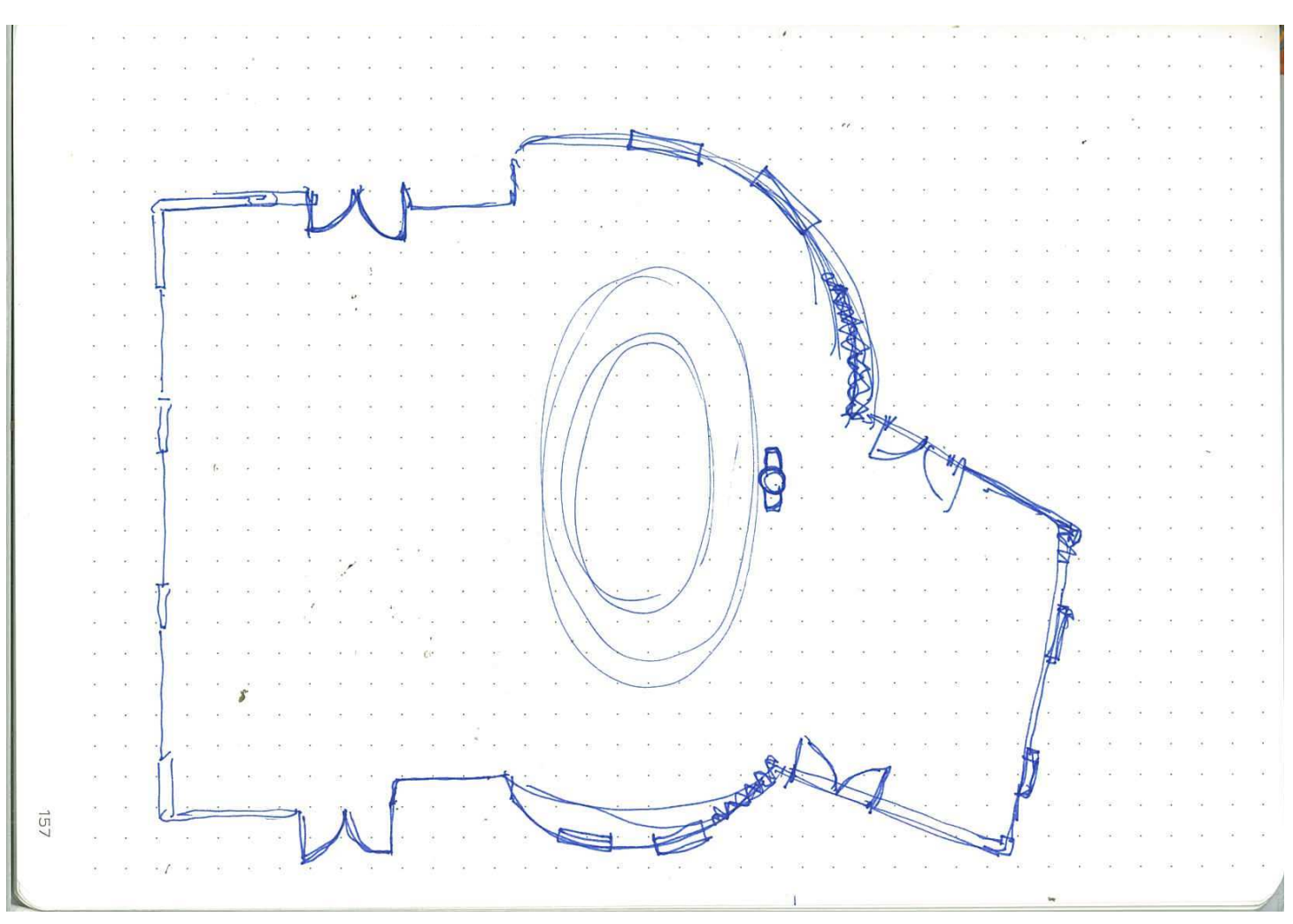

Fig. 123. Author's sketch of current chamber room plan. Interpreted from attendance at council meeting. 


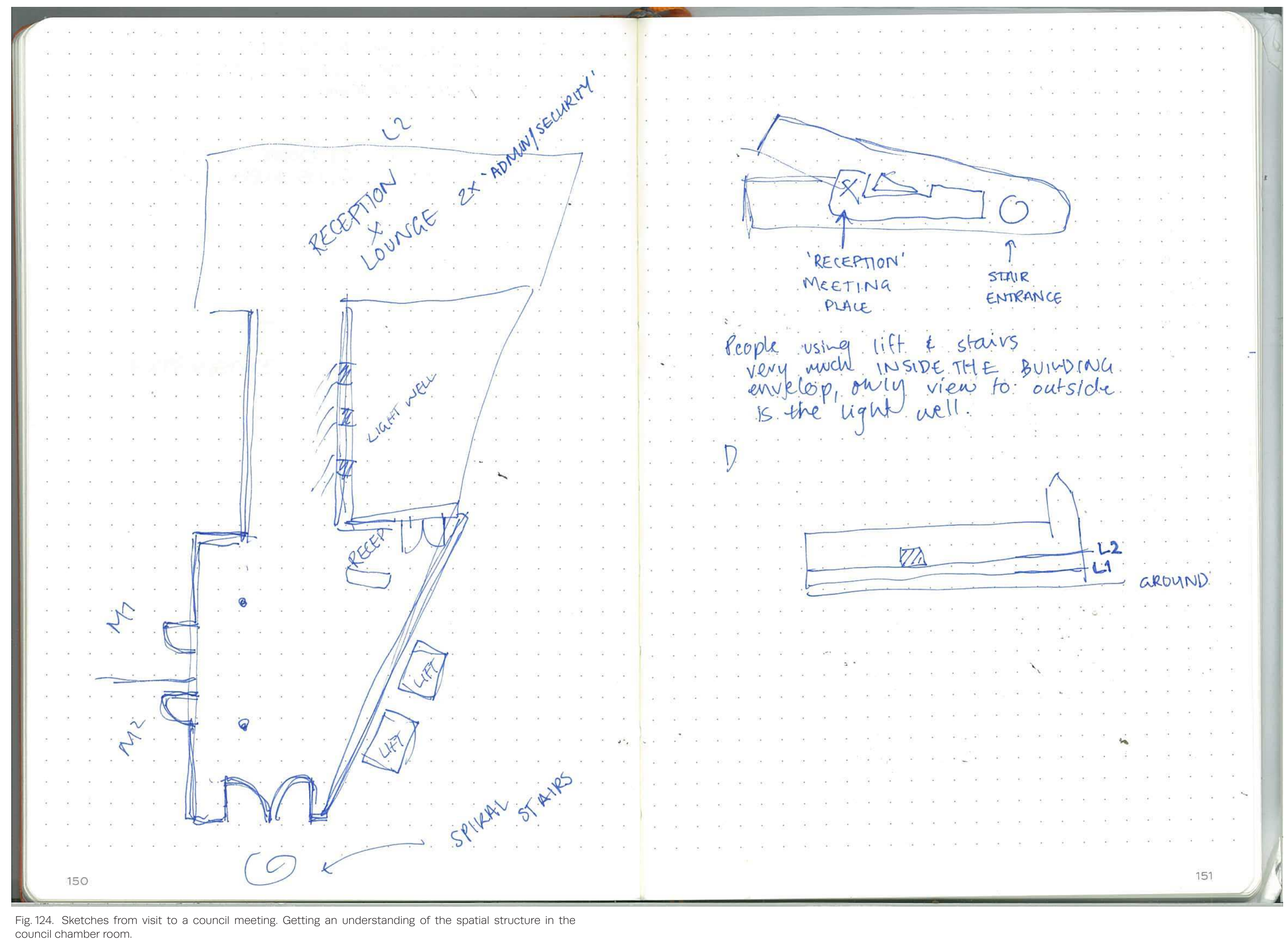

Fig. 124. Sketches from visit to a council meeting. Getting an understanding of the spatial structure in the
council chamber room. 


\section{Programme}

The following section is an outline of a functional brief. This was grounded by the analysis of the architype study, which informed contemporary approaches to accommodation for local government. An understanding of the current Auckland City Council is important to inform the spatial arrangement.

The council is made up of a variety of groups and committees; governing body, local boards, the staff organisation and council-controlled organisations. There are twenty one local boards which represent different areas across Auckland City. Governance and decisions are made as a collective by the governing body and the representatives of the local boards. In the Auckland Counci local governance statement is a public document which details the workings of Auckland council. The section which highlights the meeting process states, "the principle is that whenever the council exercises functions and powers given to it by Parliament under legislation this should be transparent and open to the public to observe." ${ }^{10}$ In addition to the collective decision making a large part of the council is management, which can be considered the corporate function. The various groups operate and communicate through meetings and discussion. ${ }^{11}$

At present the Auckland City Council can be found across the city in four different locations. These different locations vary in function; the town hall hosts larger meetings and leases out to the Auckland Philharmonia Orchestra 135 Albert Street, is the main location for the council's management staff, housing roughly 3000 staff members including the CEO's and the Mayor's office. 135 Albert Street is considered as the corporate function of the Auckland city council, where the public is allowed access by appointment only.

The other locations include the Bledisloe Building, on Wellesley Street West, (near Aotea Square). The ground floor has multiple customer service desks and enquiry stations. With private access to the upper nine floors where the occupancy changes.

In addition to the Bledisloe Building there is another customer service location at Graham Street. This building accommodates for the property staff, in addition to seven meeting rooms, three with public access and one larger training room. Graham Street accommodates for property regulation, licenses, building and resource consent.

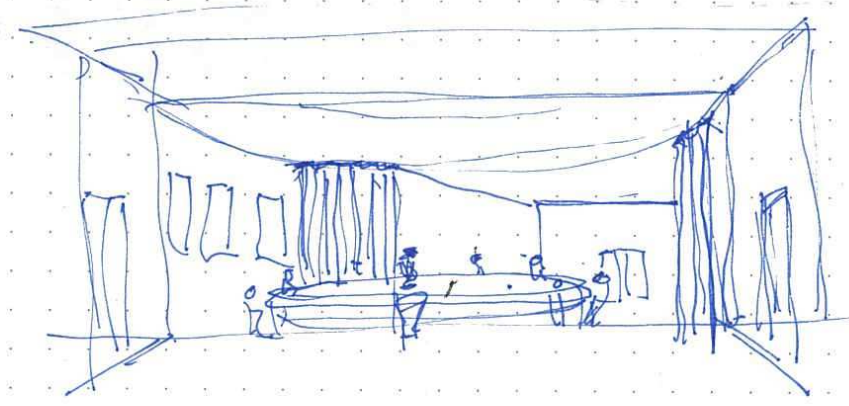

Fig. 125. Author's own sketch of Auckland Council meeting vist.

\section{Working in the best interest of our community}

Throughout the research of the traditional town hall and the contemporary accommodation it became clear that spatial hierarchy was given to the places of meeting. In a traditional sense these places were the council chamber, the official meeting place of the council. In a contemporary sense places of meeting can be official and informal spaces. The informal spaces can be considered as atrium or circulation spaces. It is in these spaces that architecture creates a field, where people, materials and strangers collide. What makes up this field is the functional roles a space is given and the opportunity for agency in such a space. Amin discusses that there are series of elements which contribute to a collective culture participating in public space. ${ }^{12}$ It is a series of elements which allow the democratic system to work as it does. 


\section{Functional Brief}

This design case study requires functional spaces to operate simultaneously. The following will recount the spaces required in the design; this is informed by the contemporary precedent case study analysis in the earlier chapter.

The organisation of the Auckland City Council helps determine the spatial arrangement. It is made up of a governing body, of twenty one members, and local boards. Major decisions are shared across the local boards and the governing body.

Central meeting room: This space will replace the traditional council chamber; a fundamental space for both the public and the council members. This space can be seen as a threshold, where there is a transparency and a critique of the system. The current; council chamber room located in the Auckland town hall hosts meetings for the governing body. Where public, media and council staff are able to attend. The space is currently divided into three isolated areas the overall space is $\mathbf{4 0 0} \mathbf{~ s q m}$. This central meeting space plays a vital role in the discussion and progression of the council and therefore can be the focal point of the design. Max allocated 380sqm

Additional to the central meeting room are smaller committee meeting rooms. These accommodate for the committees that make up the council. The various committees which meet are committee, advisory panel, local board, and council controlled organisations. These meeting spaces must be multifunctional, when not necessary for a committee meetings, the spaces should not be limited to a meeting function. Max allocated each room can be $50 \mathrm{sqm}$.

Circulation plays a key role in the function and symbolism of this design case study. Circulation will bee throughout various areas of the building, with opportunity for informal meetings to take place in non-meeting spaces. Drawing from the ideas of the city as a meeting room; circulation, corridors and thoroughfares can act as nodes for user interaction. Circulation must have a direct visible link to the outside and pockets of space which will allow for informal meetings.
The prominent space which public will be encouraged to use is a customer services area. This can be considered as a threshold space, where public are physically interacting with the council. This space required visibility from the outside, to create an appealing and engaging space. This space will see the coupling of the current Bledisloe and Graham Street public services centres. Max allocated 156 sqm

As advised by the constructed design criteria an additional function of civic architecture improves community and public engagement. With a space that has the ability to host exhibitions, small performances and public talks. Max allocated space $\mathbf{1 3 0}$ sqm

\section{Queen Street}

The brief specifies requirements for meeting rooms and public services, with the understanding of the Auckland City Council make up. In addition there will need to be administration accommodation. The site located next to a ten storey office building, which is currently occupied by the New Zealand School of Tourism. As a conceptual aspect of this design case study the neighbouring building, 360 Queen Street will be repurposed and occupied by the Auckland City Council immediate administration of the committees and public services. The variance between the two buildings is determined by the desire to uncouple the governance and corporate/administrative roles of the Auckland City Council.

The adaptation of the 1970's office block, will look to repurpose the building by stripping it back to the reinforced concrete column structure. Keeping the bones and the location of the core, the floors will be of open plan office design. The ground floor will act as a public forum and serve as a circulation space, with vertical access to the upper floors which will connect the main design intervention. The use of this building will allow the design case study to focus on a smaller aspect of the Auckland City Council's accommodation. Therefore the design case study can be considered as a public emblematic civic building. For the focus of this design case study the office block will function for vertical accessible circulation to allow for an emblematic design case study for Auckland City Council. 


\begin{tabular}{|c|c|c|}
\hline SPACE & SIZE & REQUIRMENTS \\
\hline Central Meeting room & $380 \mathrm{sqm}$ & Visible location \\
\hline Smaller committee meeting rooms & $50 \mathrm{sqm}$ & adaptable features \\
\hline Circulation & "accessible" $1.2 \mathrm{~m}$ wide & multiple routes \\
\hline Customer service area & $150 \mathrm{sqm}$ & visible and public \\
\hline Multi-functional room & $130 \mathrm{sqm}$ & accessible significant features \\
\hline
\end{tabular}

Table. 2. Functional space requirements

The programme and functional brief have been defined for the design case study. This was informed by the research of Jan Gehl and his understanding of the influence of design in the city. With particular emphasis on the human dimension and the horizontal plane in the perception of a space. A brief specifies spaces and sizes, which is based on the preliminary architype studies and the operations of Auckland Council today.

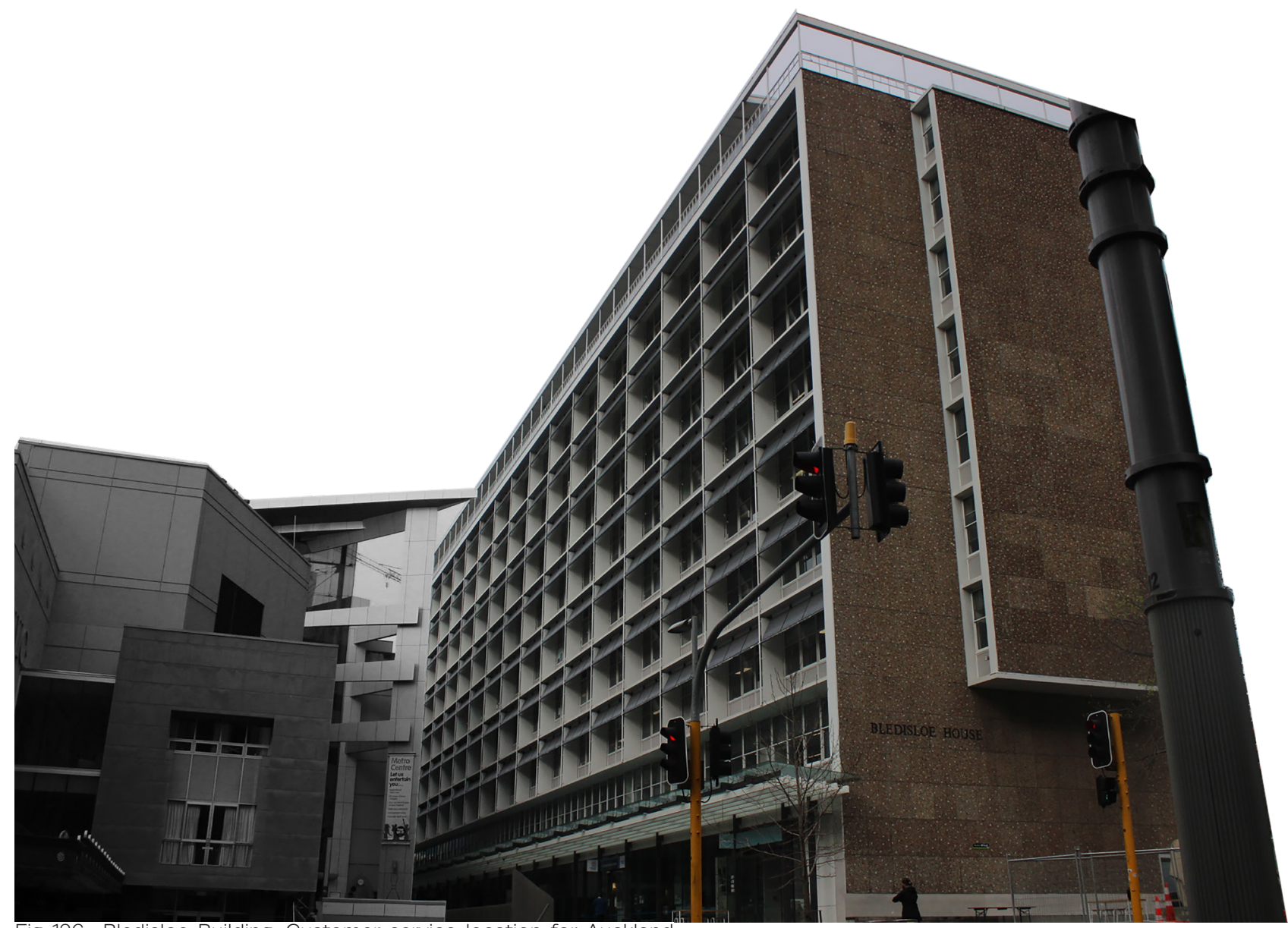

\section{Design Criteria}

"The most productive opportunities for creating civic spaces, urban -architecturally speaking, arise across the conceptual divide between the state and civil society." Rowe ${ }^{13}$

Rowe has defined that in order for civic architecture to be successful there must be a balance between five major principles. This section will detail these key principles and use them to assess the design outcome on how successfully it has been resolved. It is important to define these principles as both conceptual and architectural While some will be simply functional others will have a stronger conceptual stance in the work. ${ }^{14}$

\section{- COMPLEXITY \\ - BALANCE \\ - SHIFT \\ - EXPERIENCE \\ - PATHWAY}


The first objective will aim to express qualities of diversity: "civic realist projects are inclusive but affirmative". ${ }^{15}$ For this, architectural intervention should have significance for a wider variety of society, both symbolically and functionally. The architectural language of the overall design will have a complex shape, it will not be a simple unity, and rather it will have intersecting components. This principle represents the complexity of the relationship between authority and society: "a tension is presumed to exist between civil society and the state". ${ }^{16}$ Rowe describes Bernard Tschumi's design for the Parc de la Villette, "explored relationships between architectural concepts". With an absence of unity in the design, program overlaps with disjunction between private and public spaces. ${ }^{17}$ The Parc de la Villette is a successful design in its complex nature. There are many juxtaposed elements across the vast site the juxtapose creating a rhetoric of society and the state. A variety of architectural languages can translate conceptually into the acceptance of diversity for the users and for those which this architecture is a symbol for. In approaches which is more functional the ideas of complexity to represent the inclusiveness of the architecture objectives as followed should be measured during the design process;

C The ground floor is reserved for entirely public access.

Q All sides of the building contains access points.
The second objective balance, is established to achieve a sense of common solidarity; reflecting a harmony in the authority it is representing. A datum can be understood as an appellative of this objective, where there is chaos the design can be drawn back to a central point of line, this can be used as a reference point. Where there are spaces are of higher importance throughout the building, detail will be balanced with simplified elements. Scale in all dimensions will help identify areas and therefore events of importance. The design works unanimously to represent both authority and society. Where there are tensions there will be contrast which means balance is created. To recognize balance as an objective can established in the design, these following strategies will be present in the design;

Q The design concept can be understood at different scales.

( A datum passes through the composition, which users can position themselves in relation to this reference.

\section{SHIFT}

This principle reflects the dynamic aspects of society, society is frequently changing and evolving; aiming to represent the public aspect of the civic theme. Where architecture is not often considered as ephemeral. Rather it is very much permanent and long term. The collective experience of the user in the space will present itself as shifting. Where the functional brief outlines requirements for certain spaces and programme, there is the ability to have more flexible rooms and what can be considered the in-between; circulation and informal gathering spaces.

G Spaces which can be adaptable and multifunctional will allow the shif

4 Architectural references which can symbolise to the public the events/activities taking place. 


\section{EXPERIENCE}

Aspects of everyday life will create familiarity in the design, a principle which can facilitate the public to feel able to use this civic architecture. Although avoiding drawing on the more mundane acts which can be dull and unexciting. The relationship of the building to the ground plane and therefore to the passerby will be of high importance. While people carry on with their daily routine, commuting by foot, the design will offer an insight into the inner workings of the local government. Here we should consider architecture as the creator of fields. Earlier in this research it was discussed the shift from architecture as an object to architecture as a field. One which facilitates relationships within, creates encounters between those users. ${ }^{18}$ The functional design of the spaces will emphasis particular aspects of everyday life to be visible from the interior and the exterior.

Choice of site; street corner/interacts with passerby/ casual engagement with site

Clear pedestrian and circulation routes can be seen from the exterior.

Q A strong physical connection to the ground plane.

\section{PATHWAY}

The final objective requires a place for practices and rituals of a collective. Movement and routes are rituals which we experience with those around use, getting from one location to another can be facilitated through the intentional design of a pathway, "places provide for collective practices and rituals, while remaining congenial for individual habitation". ${ }^{19}$ Gatherings and meetings are a key event which takes place in civic architecture, both formal and informal. Pathways have the ability to act for informal gathering or chance encounters.

( The combination of program; public involvement and practice of democratic duties to work simultaneously, spatial hierarchy is unanticipated.

The overlapping of spaces and the ability for these spaces to change.

\section{principle}

COMPLEXITY to inegrate a diversity of users

BALANCE haramony where spaces are neutral

SHIFT

dynamic

ephemra

EXPERIENCE commemorate

everday activity

PATHWAY

fields of encounters
This table summarises the principles which it has been discussed, based on the premise that civic architecture achieves harmony between each principle. The criteria was established through the background research.

Access has shown importance in the building type case study. Where it was a common feature in all designs. Functionality will allow for a variety of users to engage in the architecture through its approaches to circulation, and allocation of functional space. In previous chapters the discussion of power and the opportunity to challenge hierarchy is a symbolic aspect of the proposed visible civic architecture. Through site and an understanding of pedestrian movement in the city, appropriate scale should be investigated. Finally composition encompasses a symbolic approach to the representation of local government and the collective. lic and private access$$
\text { points }
$$

Transparency

$$
\text { plane }
$$

Pedestrian/circulation routes

Adaptable and multi-functional$$
\text { spaces }
$$

$$
\text { Façade }
$$

\section{in meeting room spatia}

Choice of site

Reference line

Architectural elements function in unison. 


\section{Conclusion}

Notes

\section{COMPLEX/入 \\ physical accessibility}

\section{BALANCE}

datum

\section{SHIFT}

continuous

ephemeral

4. EXPER/尺N

everyday life

routine

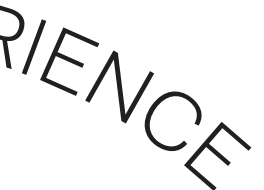

5. PATHWAY
rituals of a collective

simultaneous
Chapter four concludes the predesign and background investigations for this design case study. Design principles have been established based on the research of Peter Rowe, aiming to create a harmonic experience of civic architecture. These principles were operationalised through a set of criteria, which the design will be evaluated against. The programme and functional brief has specified spatial requirements, which the design case study will fulfil through strategies.
Gehl. Life Between Building, 29

Gehl, Cities for people, 6

Gehl 9

Auckland Regional Council, "A brief history of Auckland's urban form", 19

Murphy, "Third wave gentrification in Auckland, 2535

Pownall, "Metropolitan Auckland 1740 - 1945: The historical geography of a New Zealand city",110

Gehl, Life between buildings, 10

Gehl, 69

Auckland Council, "Auckland council local governance statement", 36

Auckland Council, "Auckland council local governance statement"

Amin, "Collective culture and urban public space", 14

Rowem Civic Realism, 203

Rowe, 203

Rowe, 214

Rowe, 202

Rowe, 74

Allen, "From object to field", 120

Rowe, 218 


\section{Introduction}

The following chapter is the preliminary design, which is an exploration of programming, spatial

arrangement and overall form. Design driver include

spatial hierarchy; which spaces are of high importance

and where their location is in plan and section. In

sequence to the programme studies, concept design

of the overall form is explored through the medium

of card. Themes of inside and outside are adapted to

express how the interior form can impact the exterior

form. This exploration follows an iterative process. The

scale is consistent in this exploration, sizes are based

on the dimension of the chosen site. The focus is on

developing an overall formal language with awarenes

Introduction

Programme Planning

Preliminary Design

Conclusion 


\section{Programme Planning}

This following section will focus on the conceptual design stage. How the design process began and the

ways in which the programme was used to drive the

design.

The aim of this exercise is to challenge the traditional hierarchical arrangement and spatial patterns of

current civic architecture. The focus of this research is to explore how the public can be considered during the design process, and the political practices can be

The following exercise explores various arrangements physically represented through architecture.

of the previously defined functional spaces. Considering

spatial hierarchy horizontally and vertically. The overal

size of the site is $380 \mathrm{sqm}$, which is roughly the size of

the current used council chamber room.

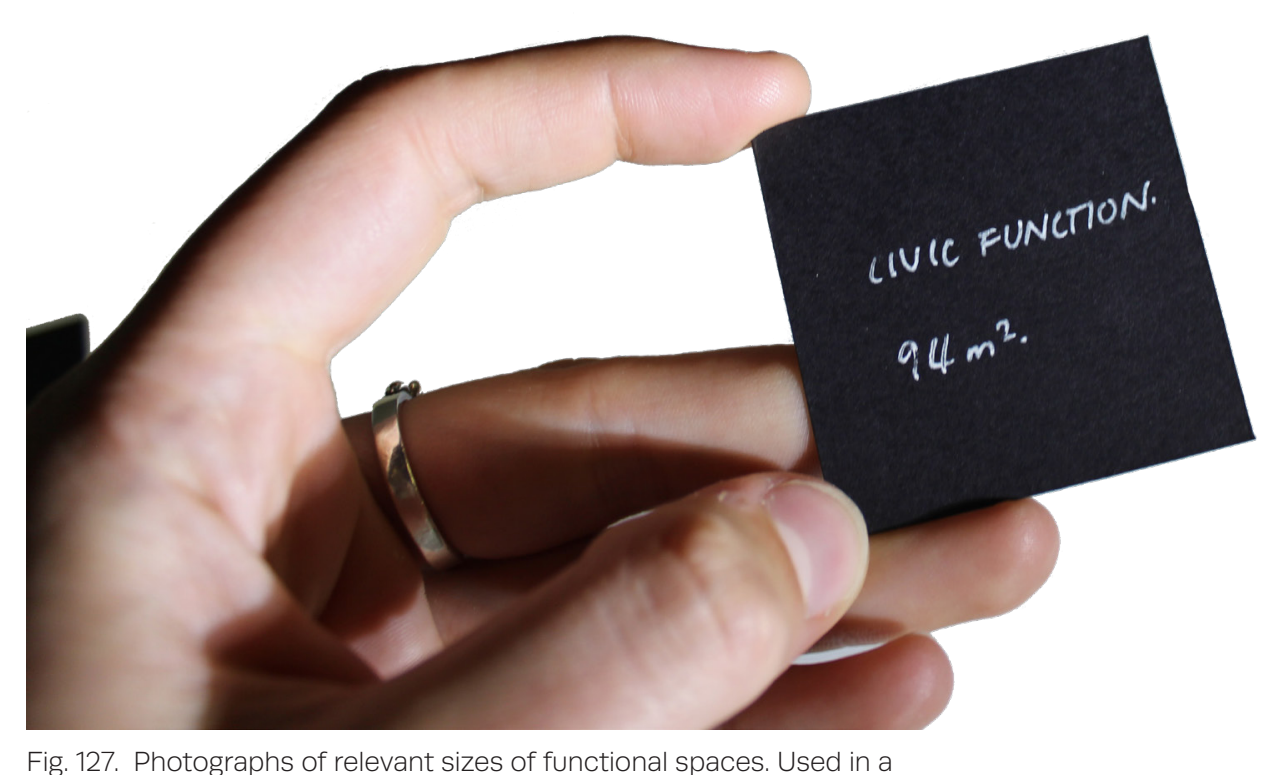

Fig. 127. Photographs of relevant sizes of functional spaces. Used in
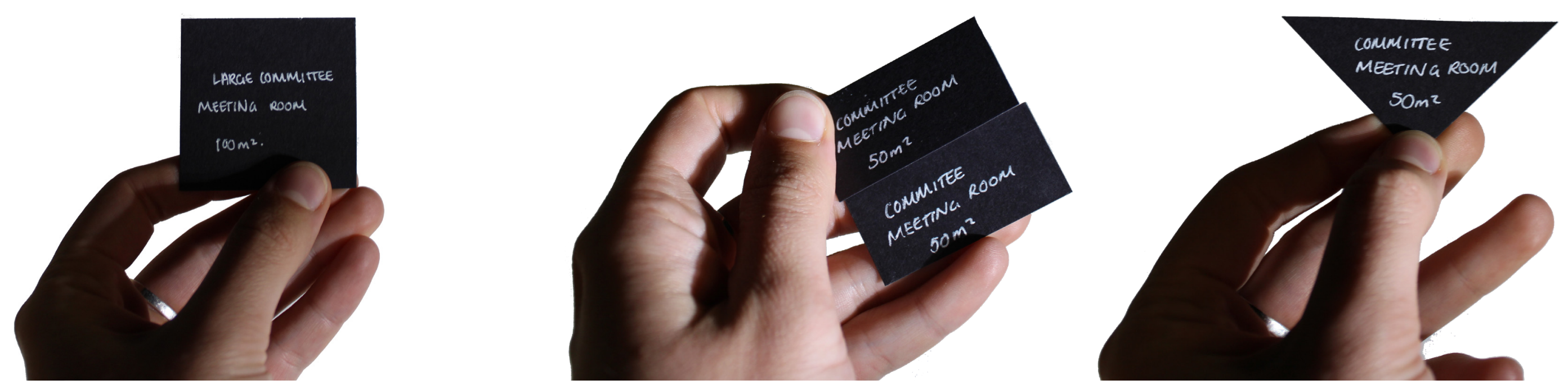

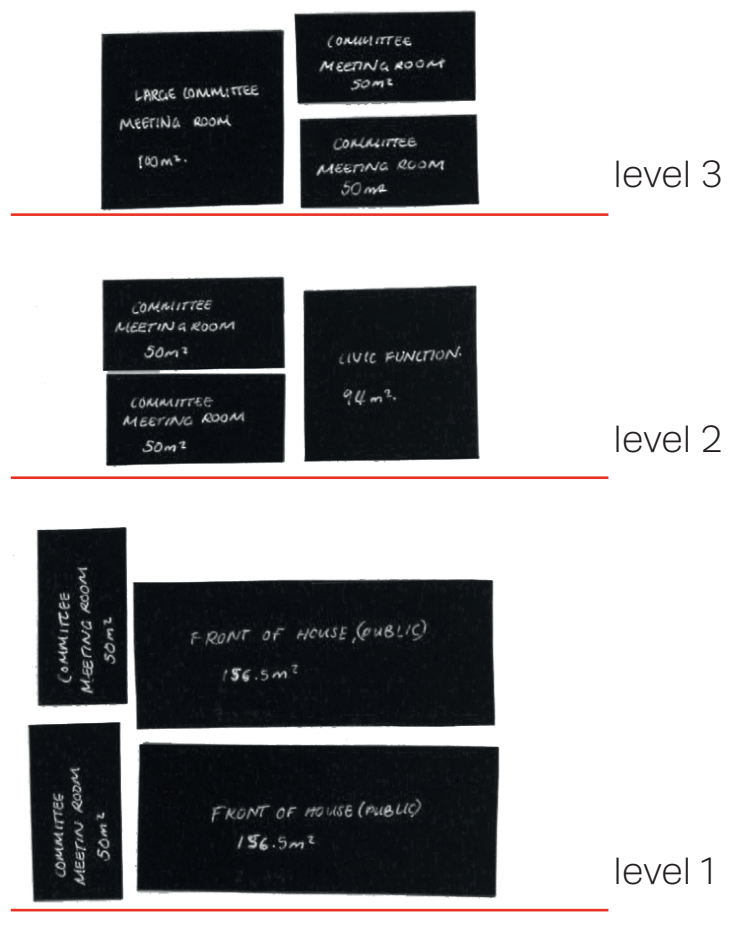

level 1

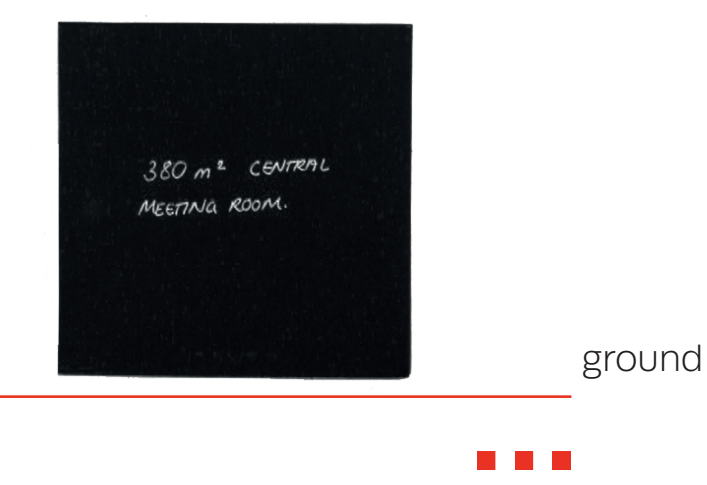

Fig. 128. The four options ( $A, B, C, D)$ explore possible vertical room on the ground floor. With smaller spaces throughout the middle. Options B) \& C) gives verticl
locating it on the top floor.
Option B.

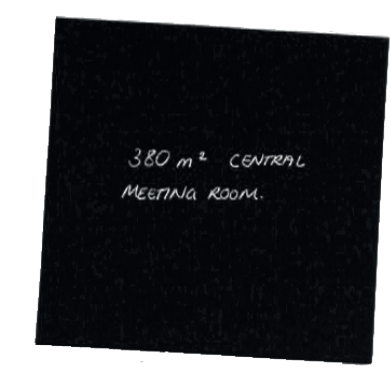

level 3

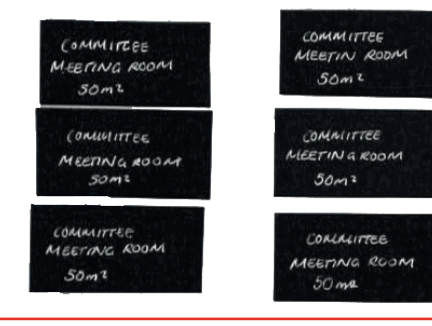

level 2
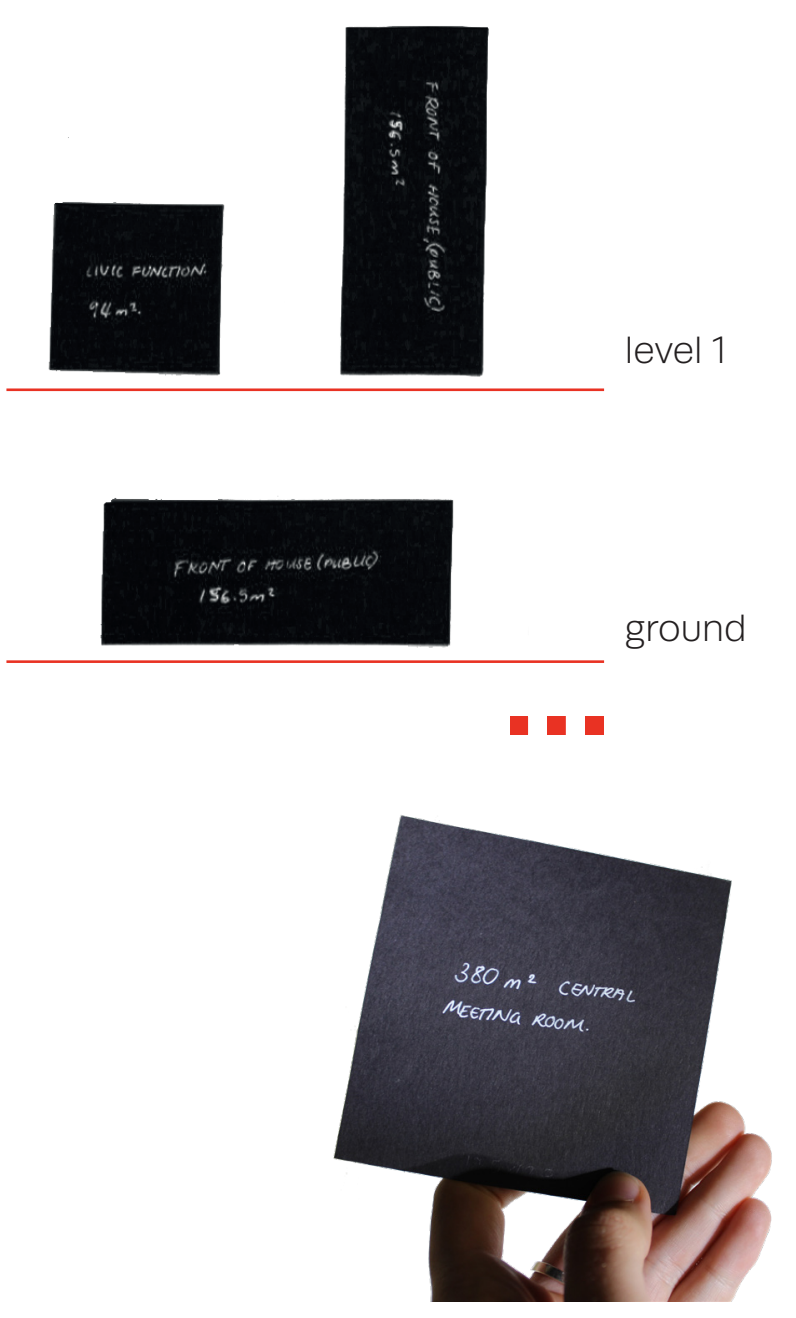

Option $\mathbf{C}$
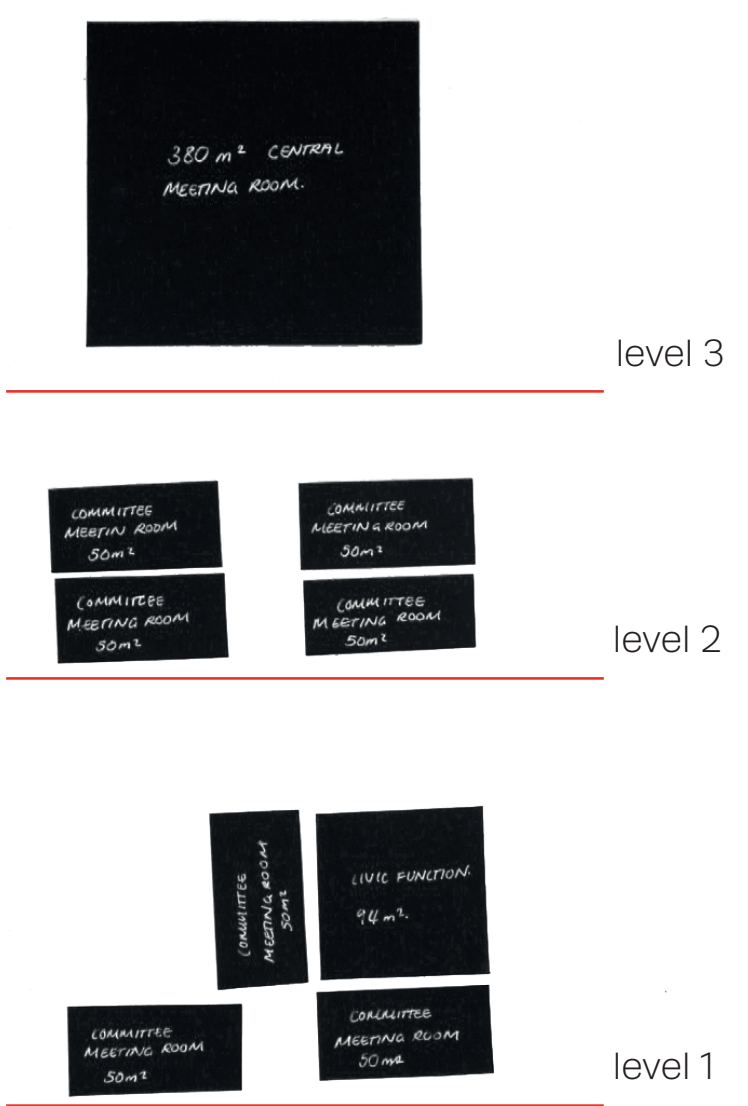

level 1
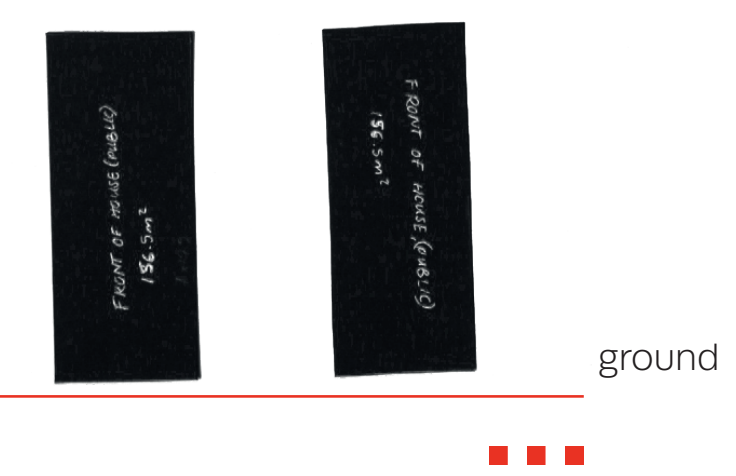

Option $\mathbf{D}$.

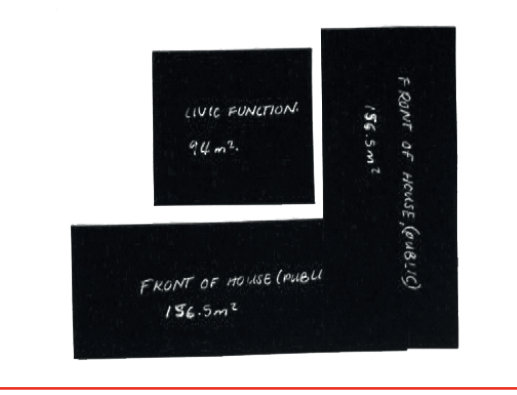

level 3
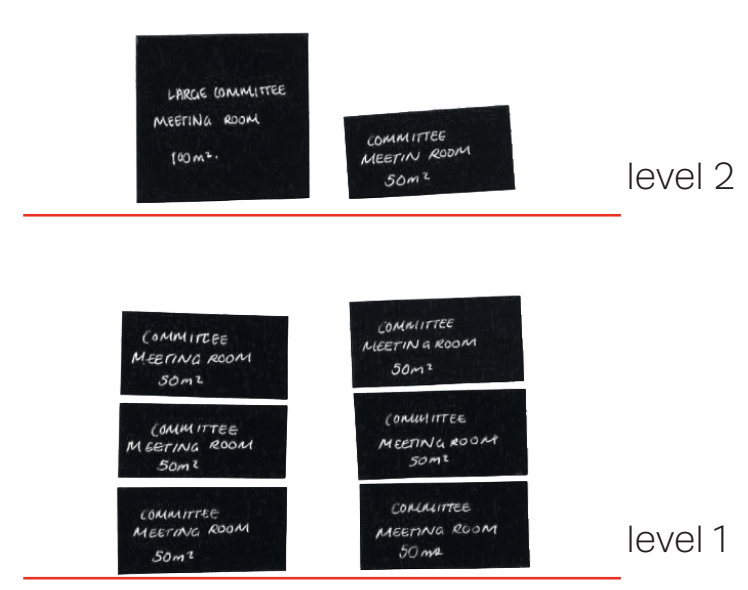

level 1
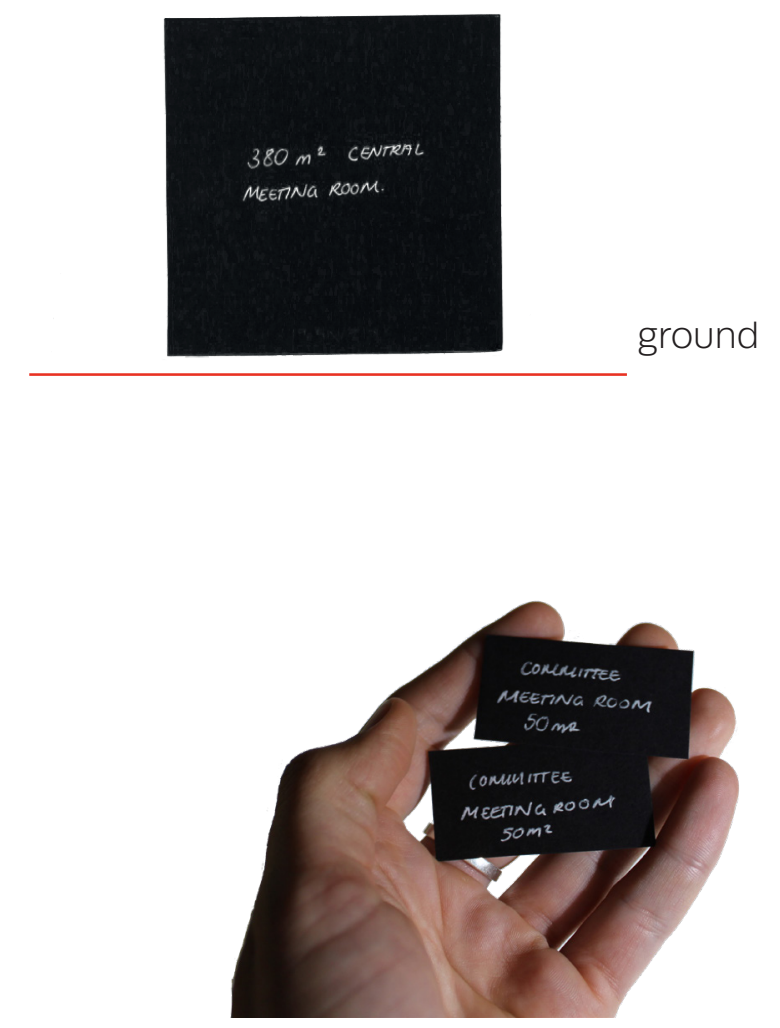


\section{Ground Plane relationship}

Each option is then explored in section. By overlaying the spaces to consider their relationships to one another. Here the white can be considered the thickness of walls and the black to be the rooms.
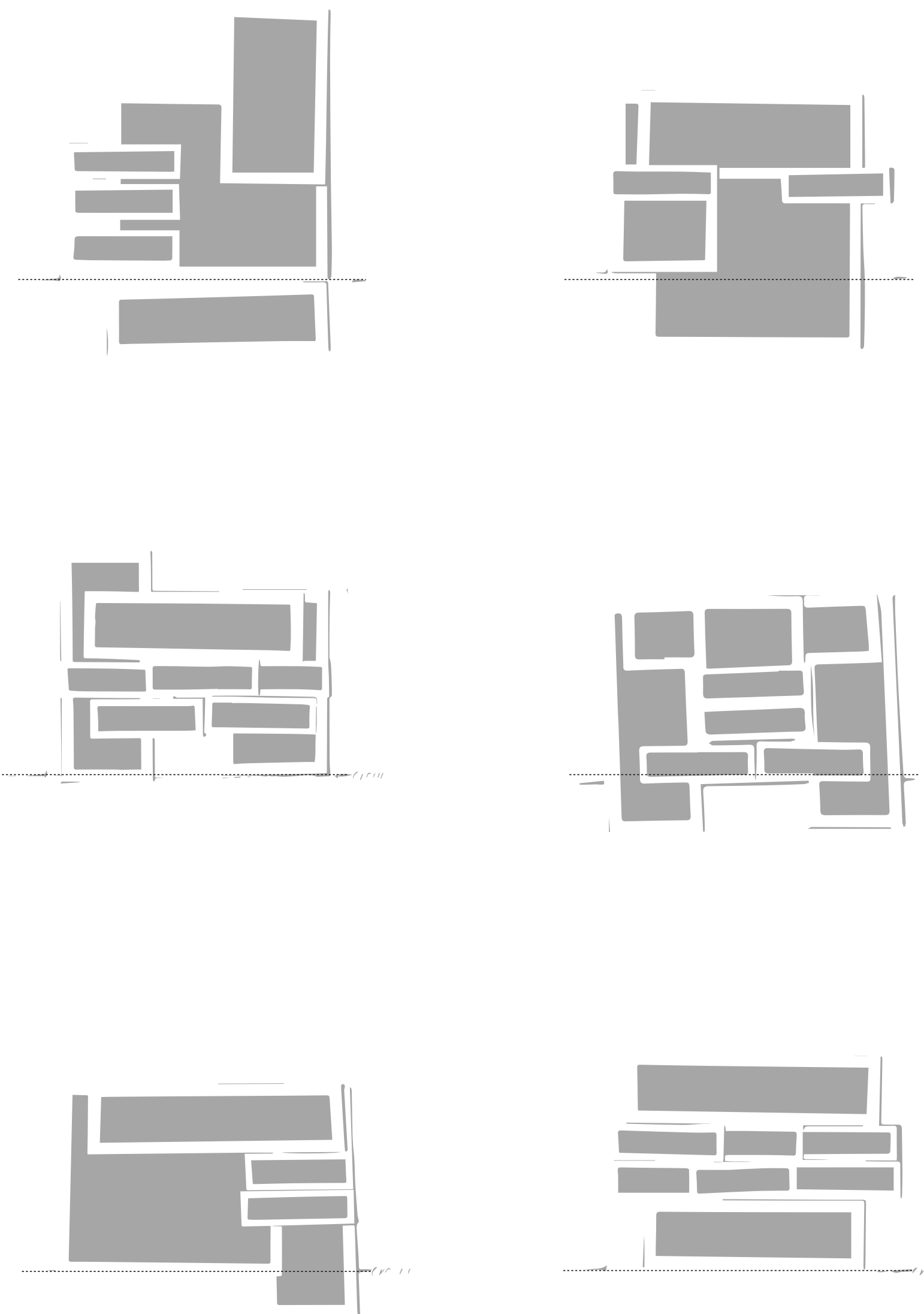
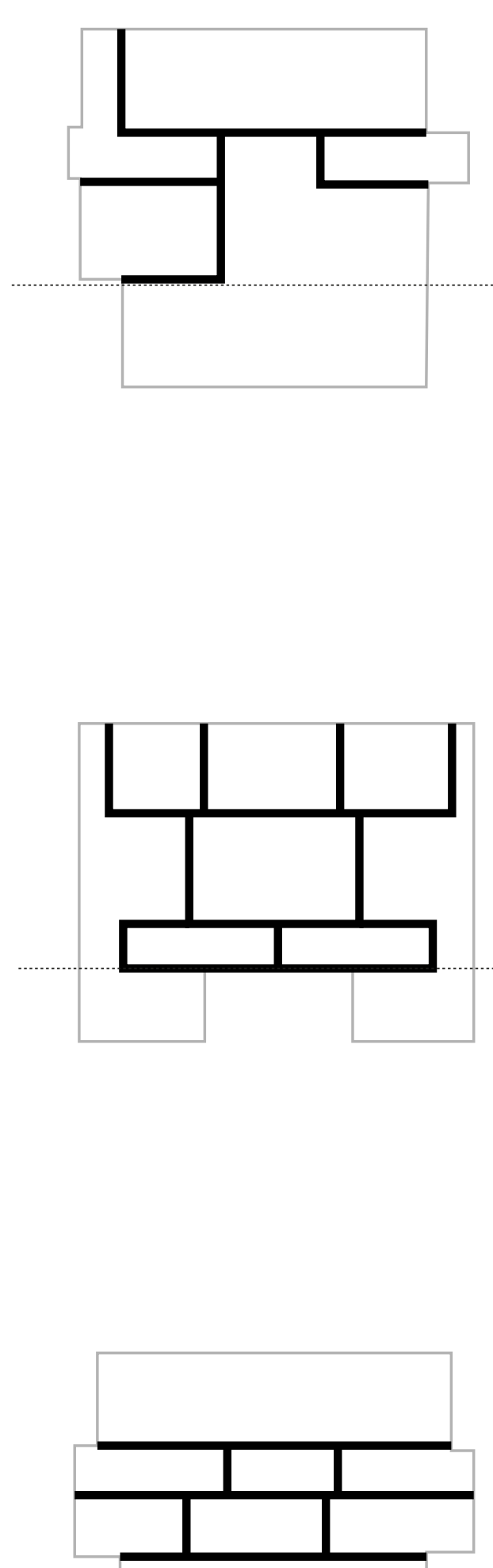

Fig. 131. Programme exercise of variations and
section, from analogue representation to digital.

The inside/outside dialect of architecture can be reflected upon to drive this designexercise. Robert Venturi's writing informs an architectural understanding between the relationship of the interior and the exterio He uses examples from both classical and modern

The inverse of the section exercise represents walls architecture and how different architects realised the and floors as black and spaces white. To begin a three contrast or contradiction between the interior elements dimensional exploration of the programme exercise balsa and the exterior expression. This concept of inside/ wood models are constructed. 
outside is further supported by Kim Dovey as a mediator of power in architecture. Threshold spaces such as entrances can be approachable or deterring based on their scale and position. ${ }^{1}$

A design exercise using physical modelling explored the concept of "poche" Venturi defines this as leftover space. ${ }^{2}$ Where there is a breakaway from the the change or articulation of a new space.

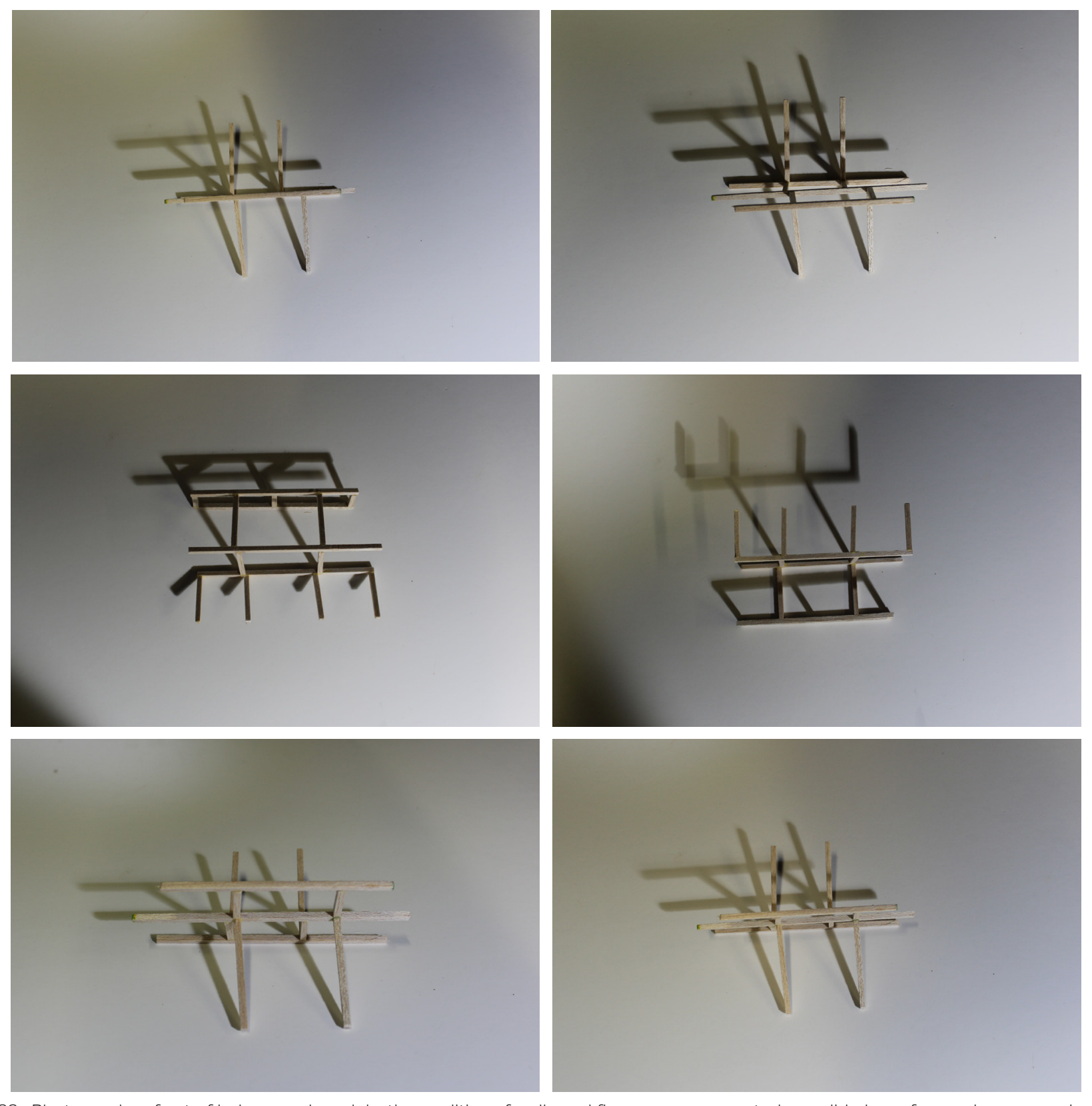

"Poche"

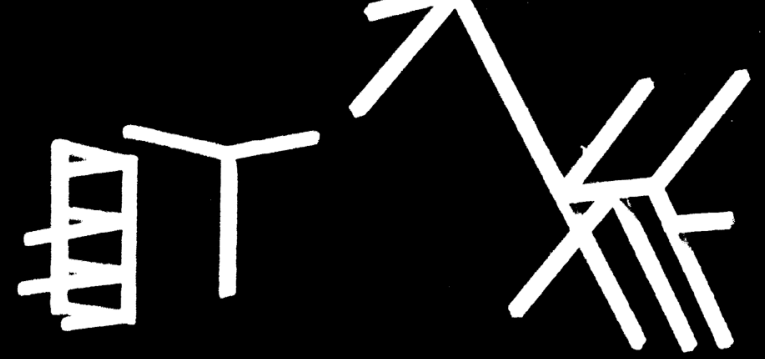
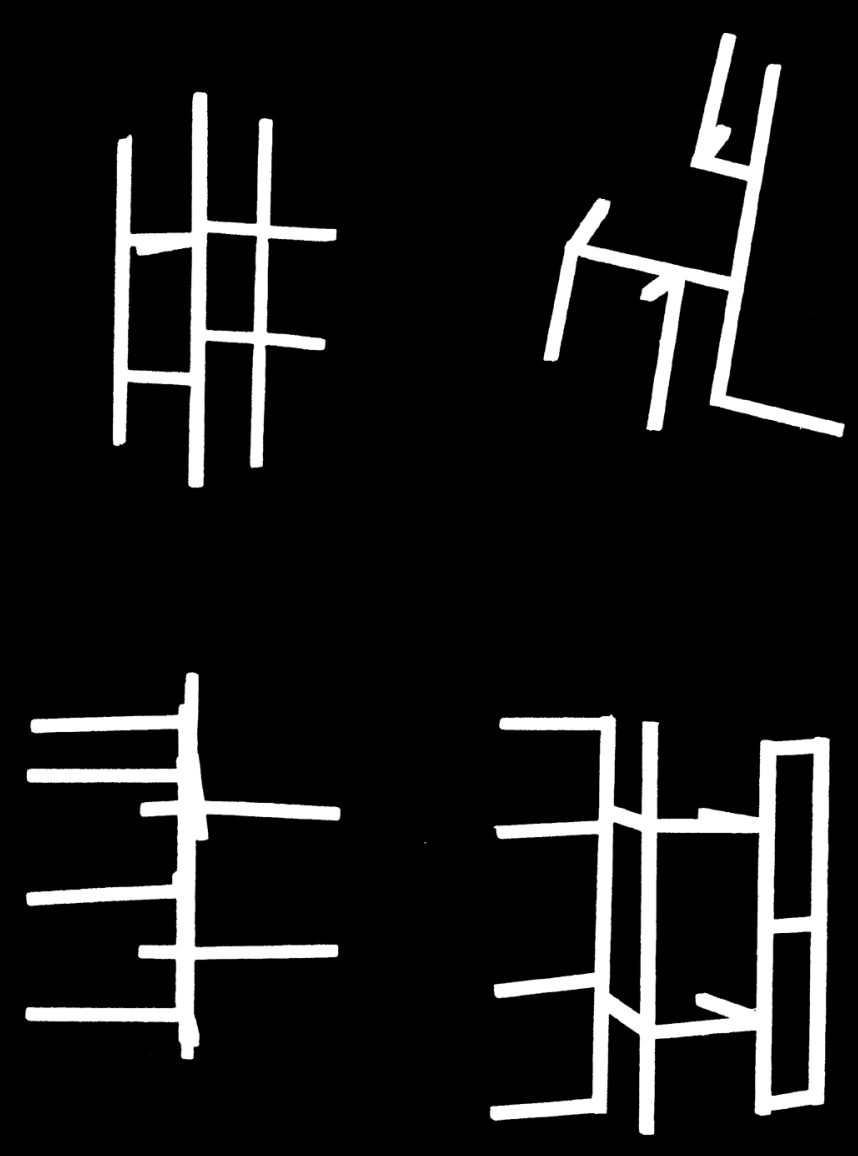

Fig. 134. Models made from balsa wood to explore the potential structure or how the in between space can

These "poche" models have qualities of figure ground drawings, with three dimensional aspects. There is negative space and positive space (balsa). Although walls are suggested by the alignment of the solid, rather than a typical planar surface, the spaces do not become whole, there is fluid movement between what would usually be considered a room. Upon reflecting on these models structure starts to present itself. The exposure of structure can symbolise the placement of spaces, when not directly within the building. 

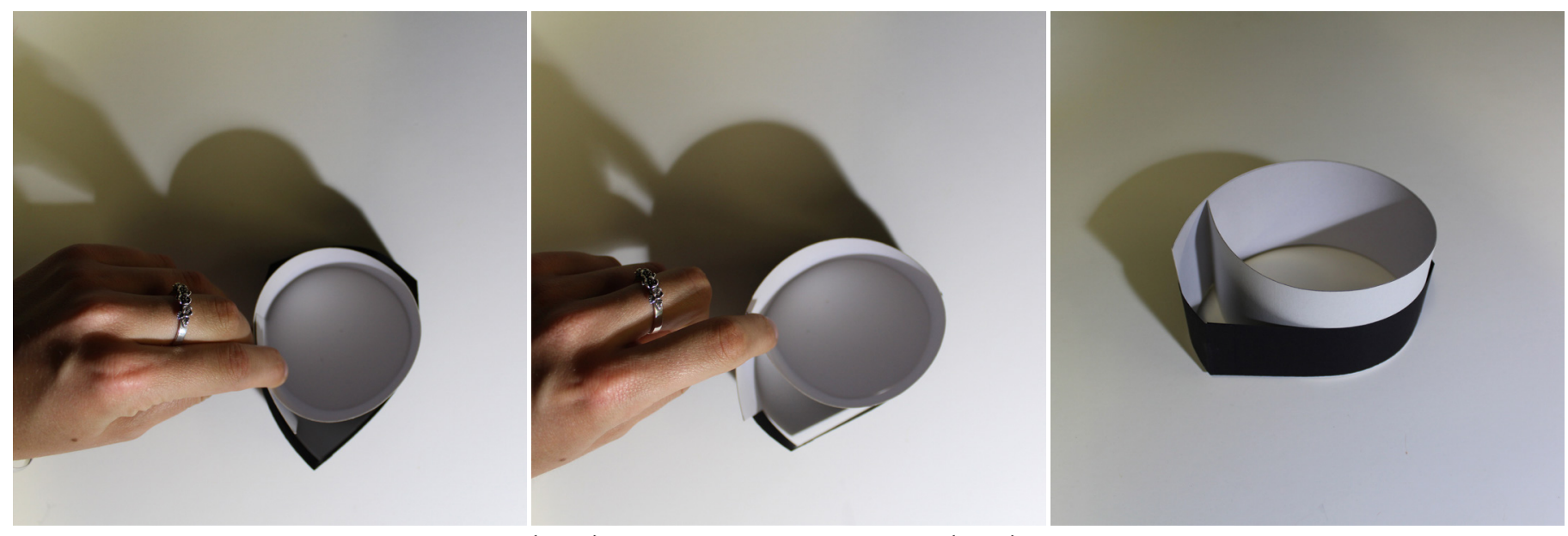

Fig. 137. Manipulation of the size of the interior (white) space imposing on the exterior (black)

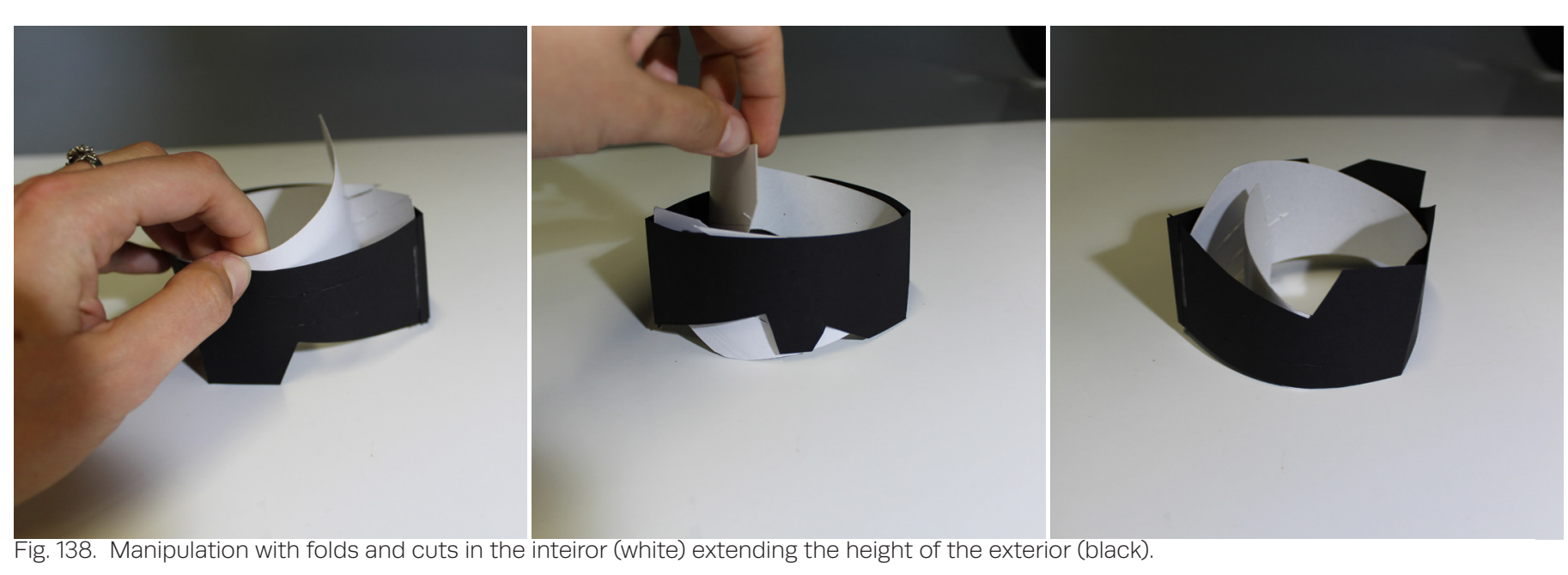

$$
\text { (⿸丆口 }
$$
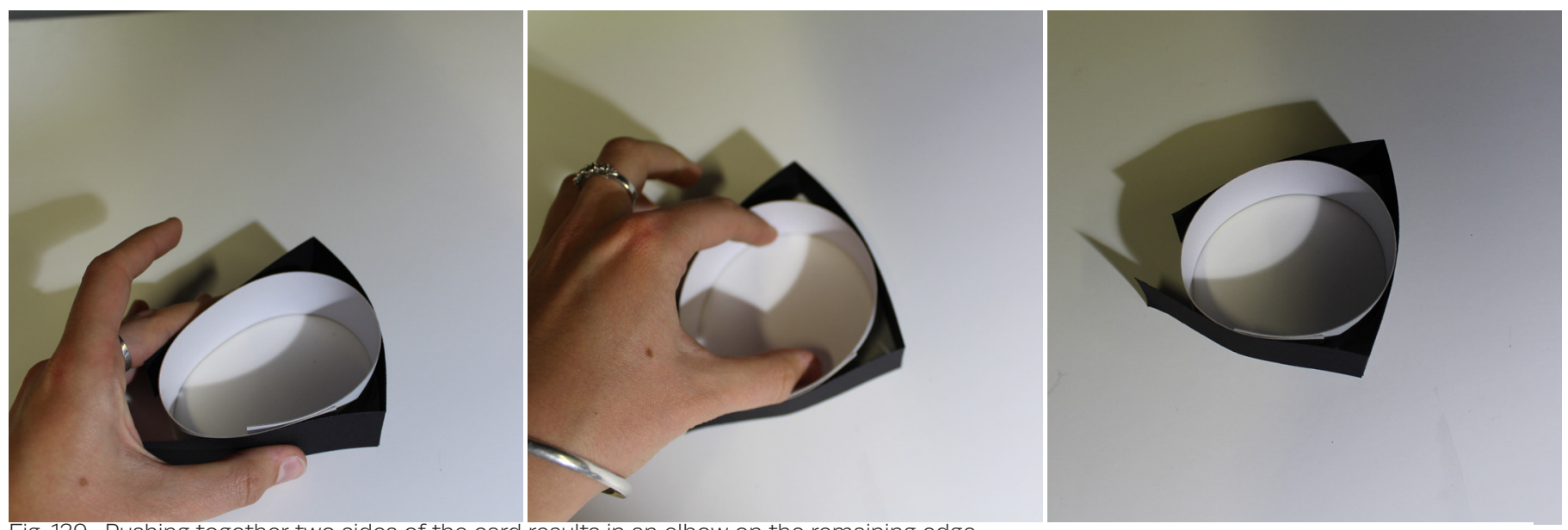

\footnotetext{
Fig. 139. Pushing together two sides of the card results in an elbow on the remaining edge
}

The physical modelling process began with an

exploration of 1:200 scale card models. Starting with the dimensions of the site, this is considered the exterior envelop. The interior assumes a contrasting form. The models allow the natural flexibility of the card to take over, this results in the exterior to billow, pushed by the interior.

Initially three sided triangular shapes are juxtaposed Initially three sided tian forms took on extuded, phan charactistic, with forme interior and exterior faces touching one with some interior and exterior faces touching one another. The folls or the exterior envelope so a lo as walls or the exterior envelope, so far neglecting

openings, entries and floor levels. The juxtaposition of linear and circular is detrmined by the shade of card, although the natural properties of the card, flexes the forms, which alter the original architectural language.

The form models further signify the negative space (i between white and black card) and positive space (the centre). Although walls are represented with a solid consistent medium (paper), rather than a planar surface.
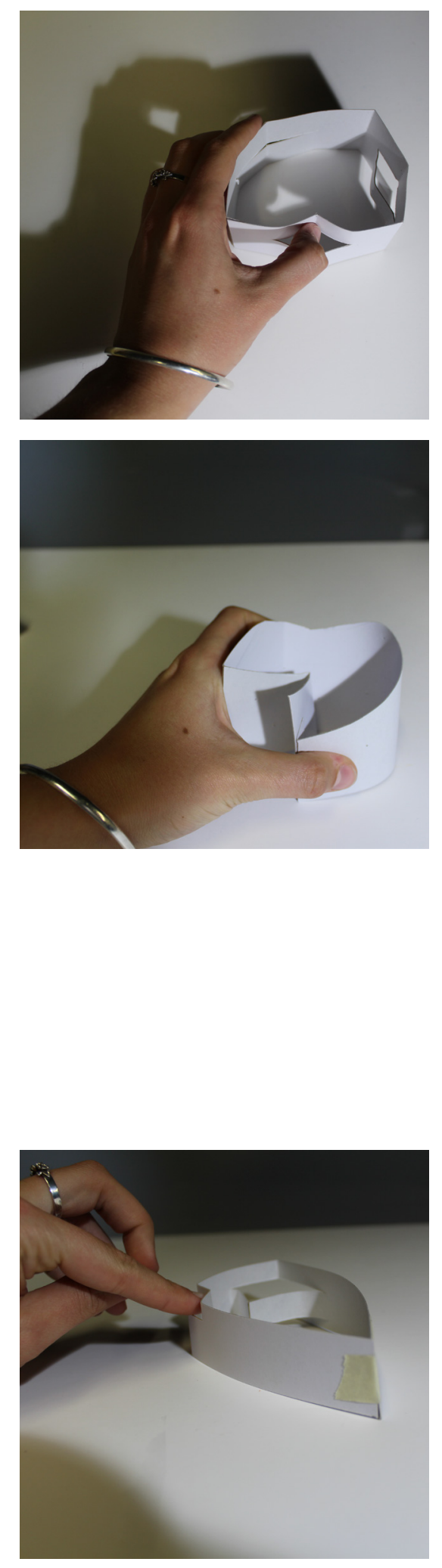
There are some limitations to this approach of

peresented as

a plas $1: 200$ scale retricts the consien undulated

levels and walls inside.
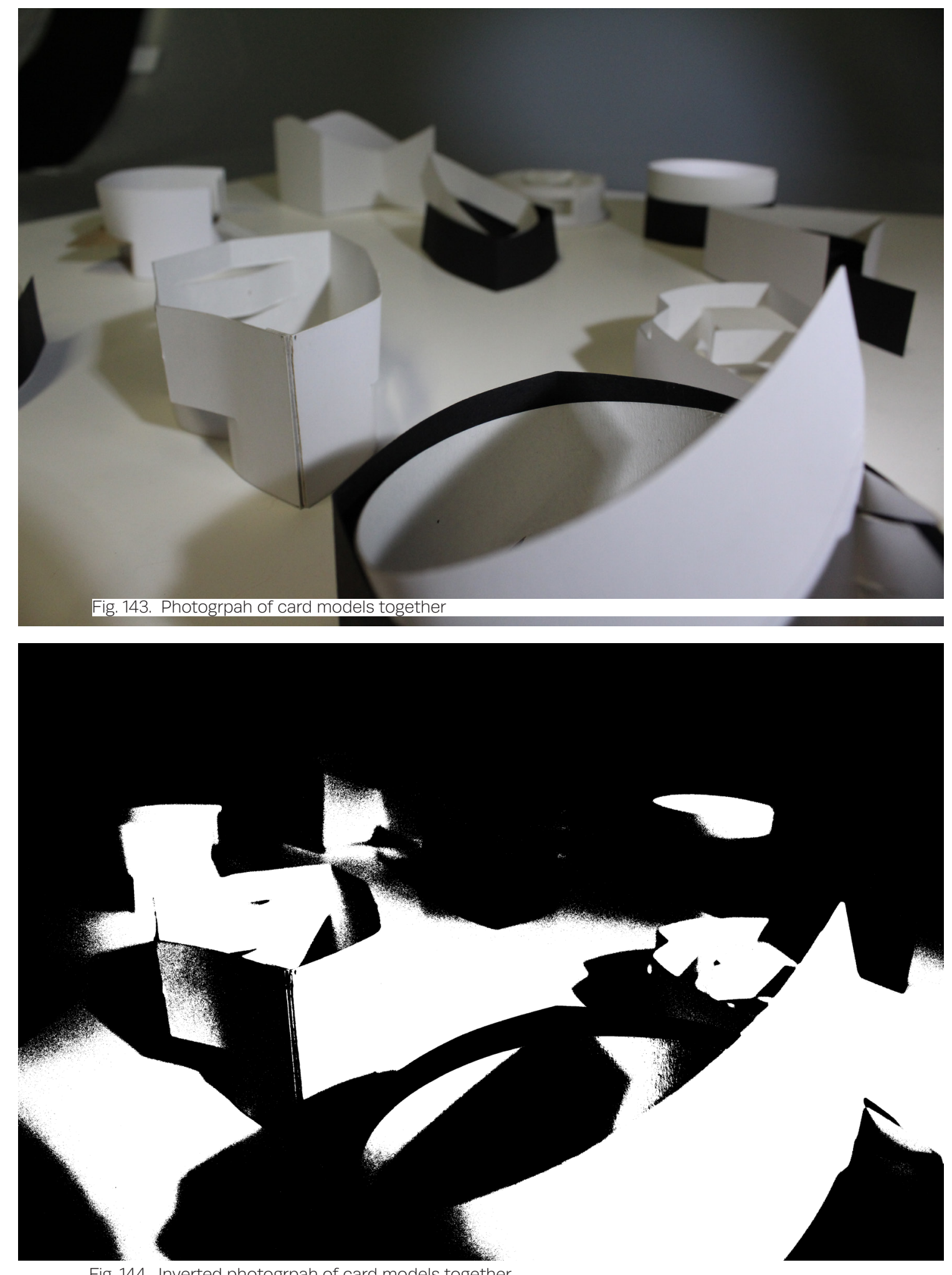
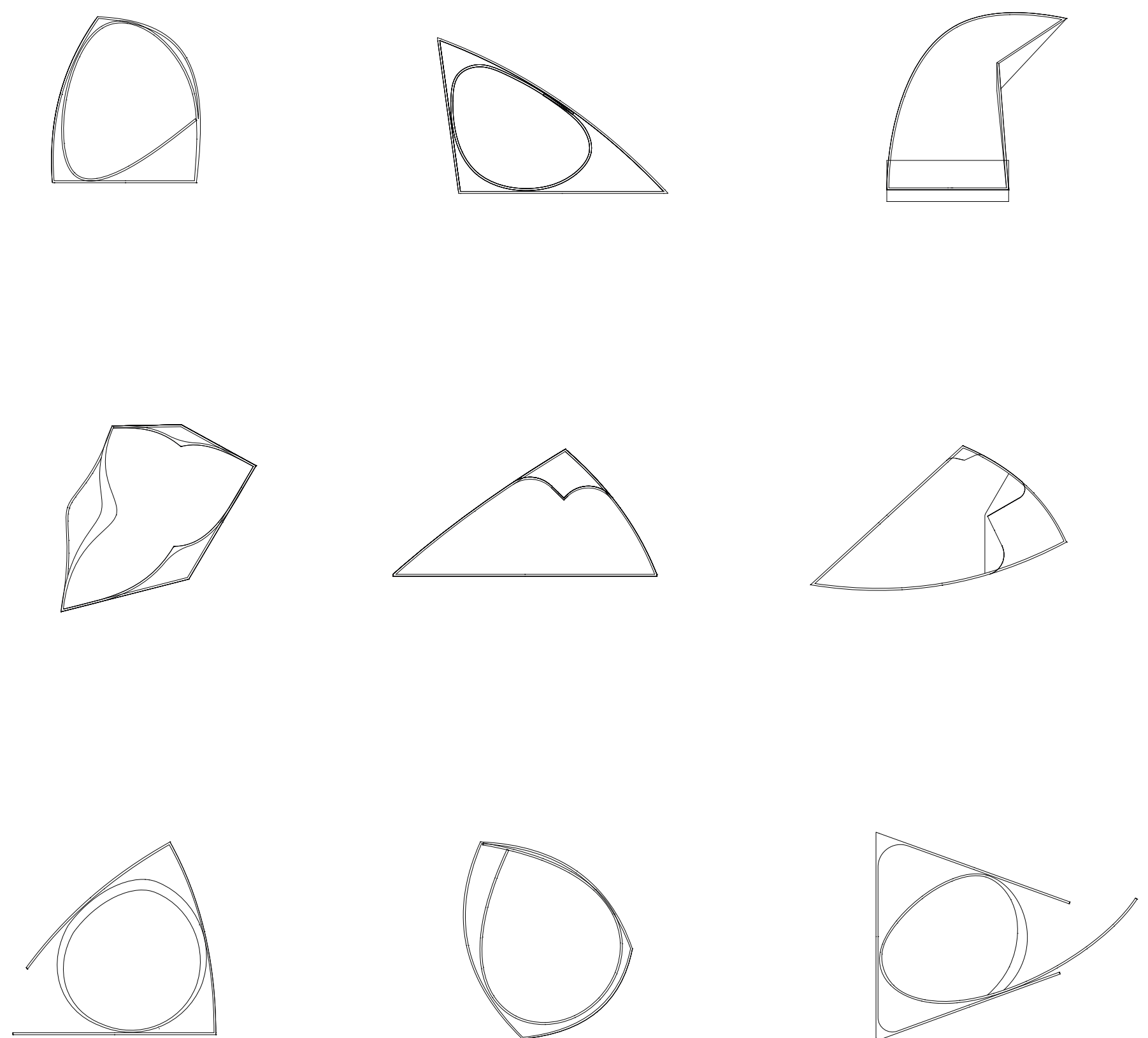

Fig. 145. Plan drawings of digital versions of the card models

The outcome of the physical modelling to begin the design process helped create a language between the design press he the ext the exterion whe following step uses digital nodening tools to get an process to move faster and consider the floor levels. 


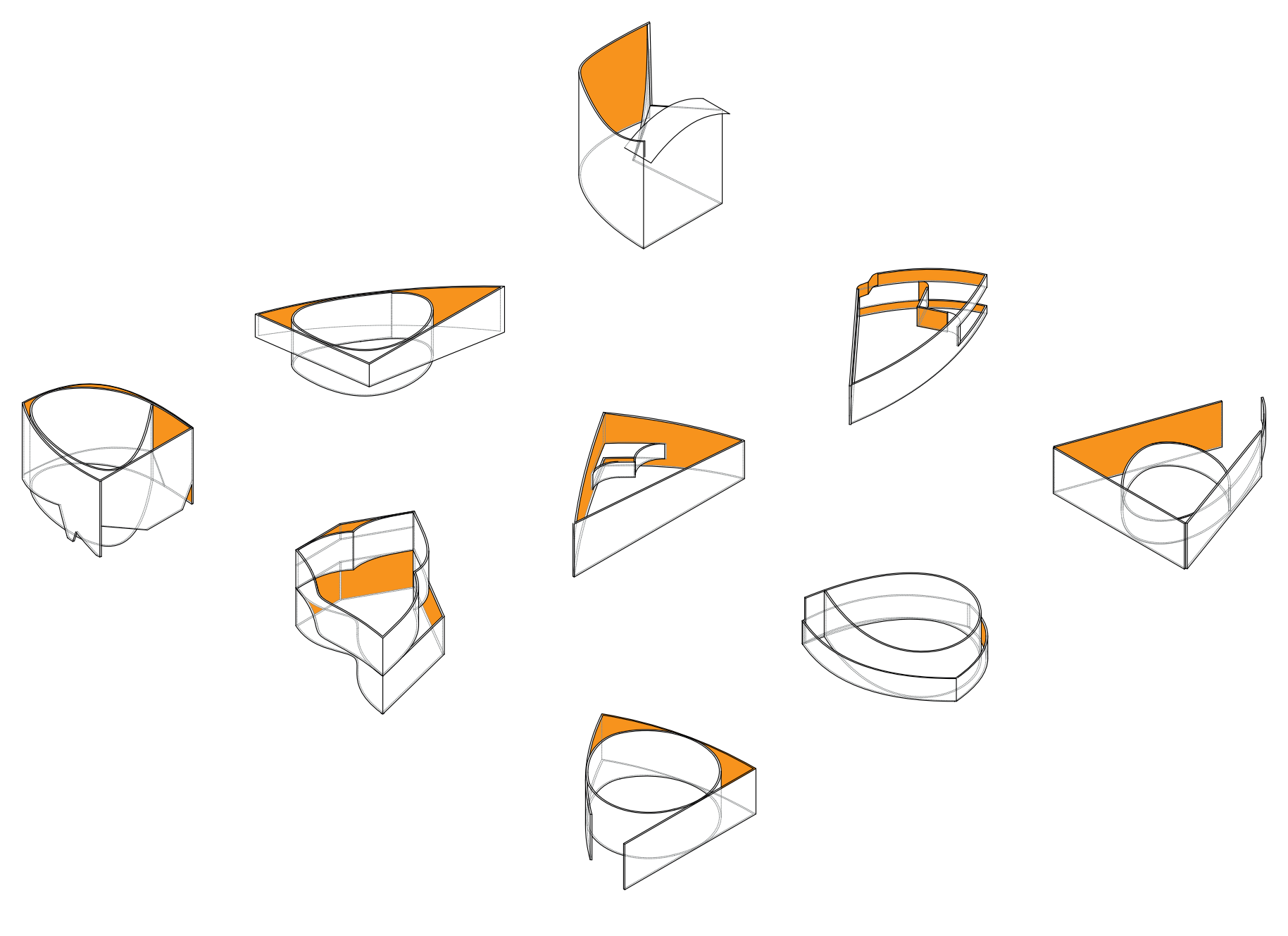
Fig. 146. A matrix of card concept models digitised. Each
orange represents the interior of the outermost card.
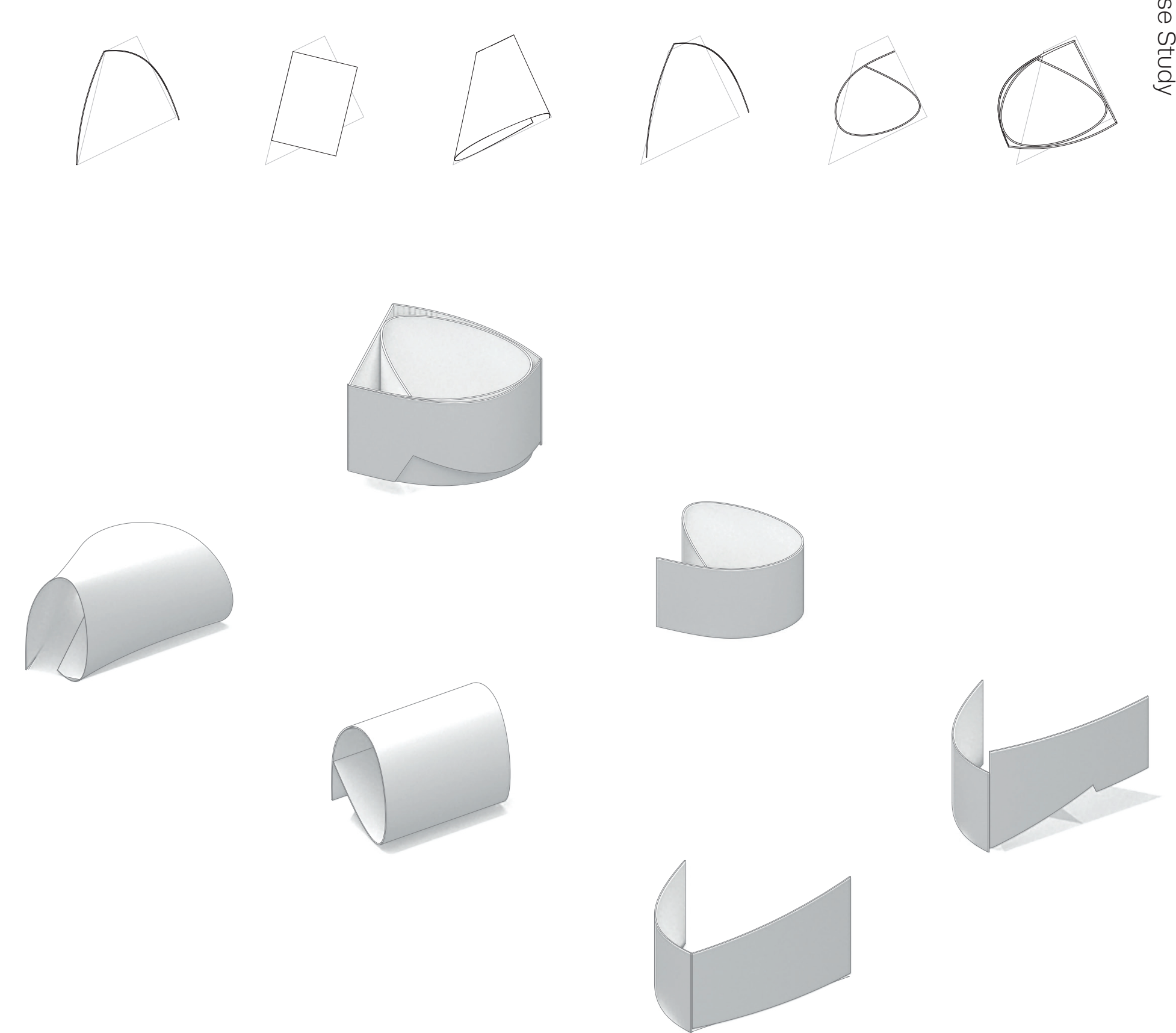

Fig. 147. A model and form was chosen to explore further. What was desirable about this model was the openings on what can be considered the ground floor. These could be entrances or access points

The significance of the chosen paper model were the 'cuts' and openings around the base of the model. These

could be considered as openings for access, entries or

windows. Rotating and wrapping this card model started

to resemble a building envelop.

By rotating the "interior" element 90 degrees the curve began to make a tunnel shape. This has a back and front. Further manipulation resolved a funnel with open sides at the base/ground level. 
Curved Form Development
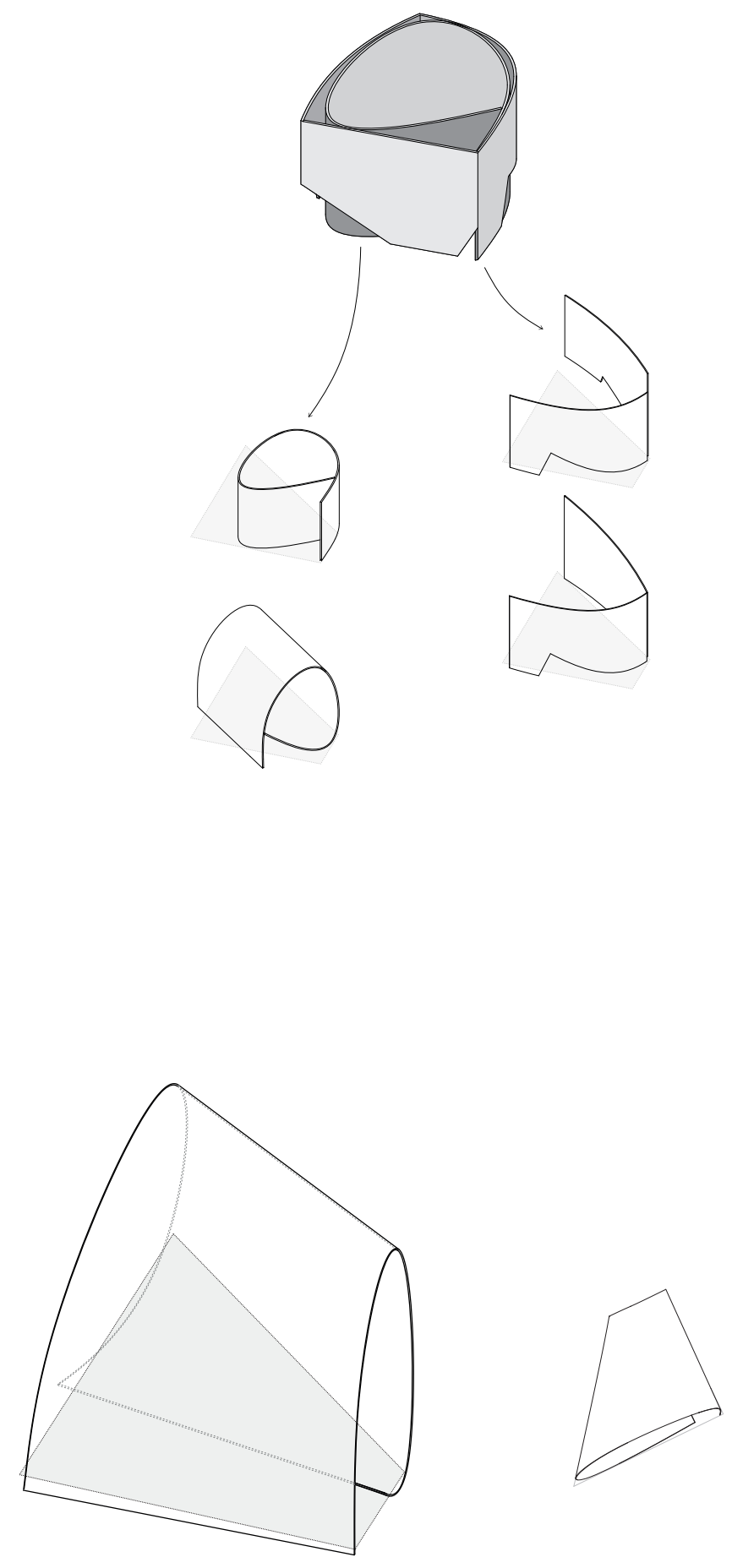

Fig. 148. The wrap form was funneled to apply to the site. The form
tappers towards the intersection (Queen Street edge). tappers towards the intersection (Queen Street edge).
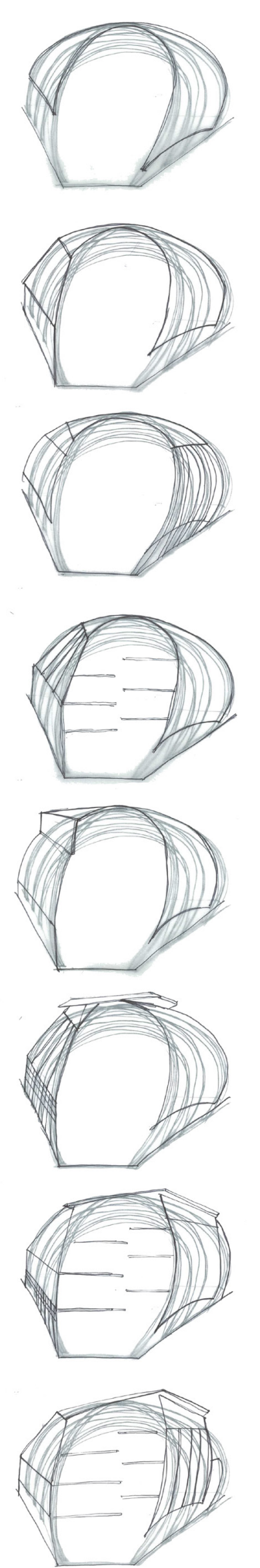

Fig. 149. Sketches of breaking up the fluid form in section and
the envelop.

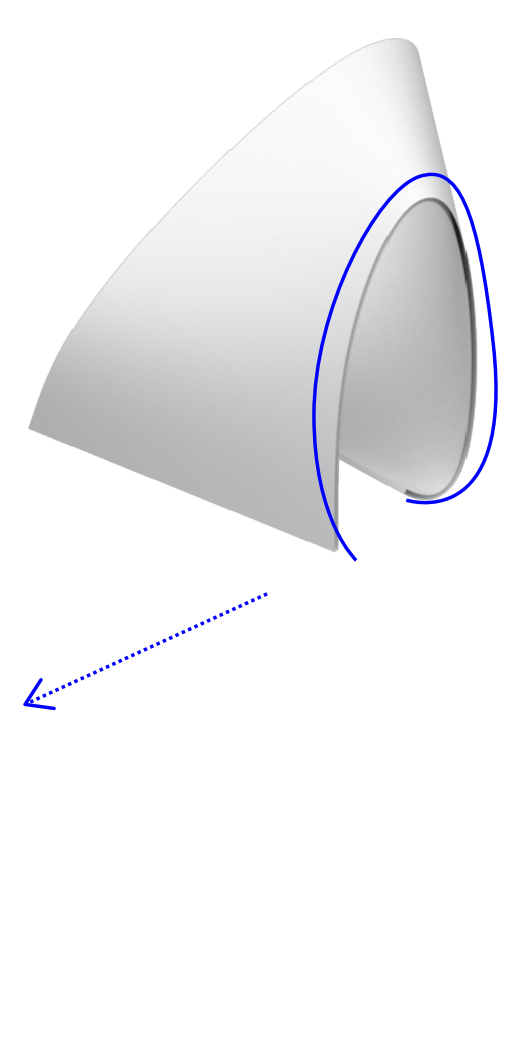

列

Fig. 150. Illustrations shows the development of the curved form, from its manipulation of the paper model, to a refined shape which does not encompass the

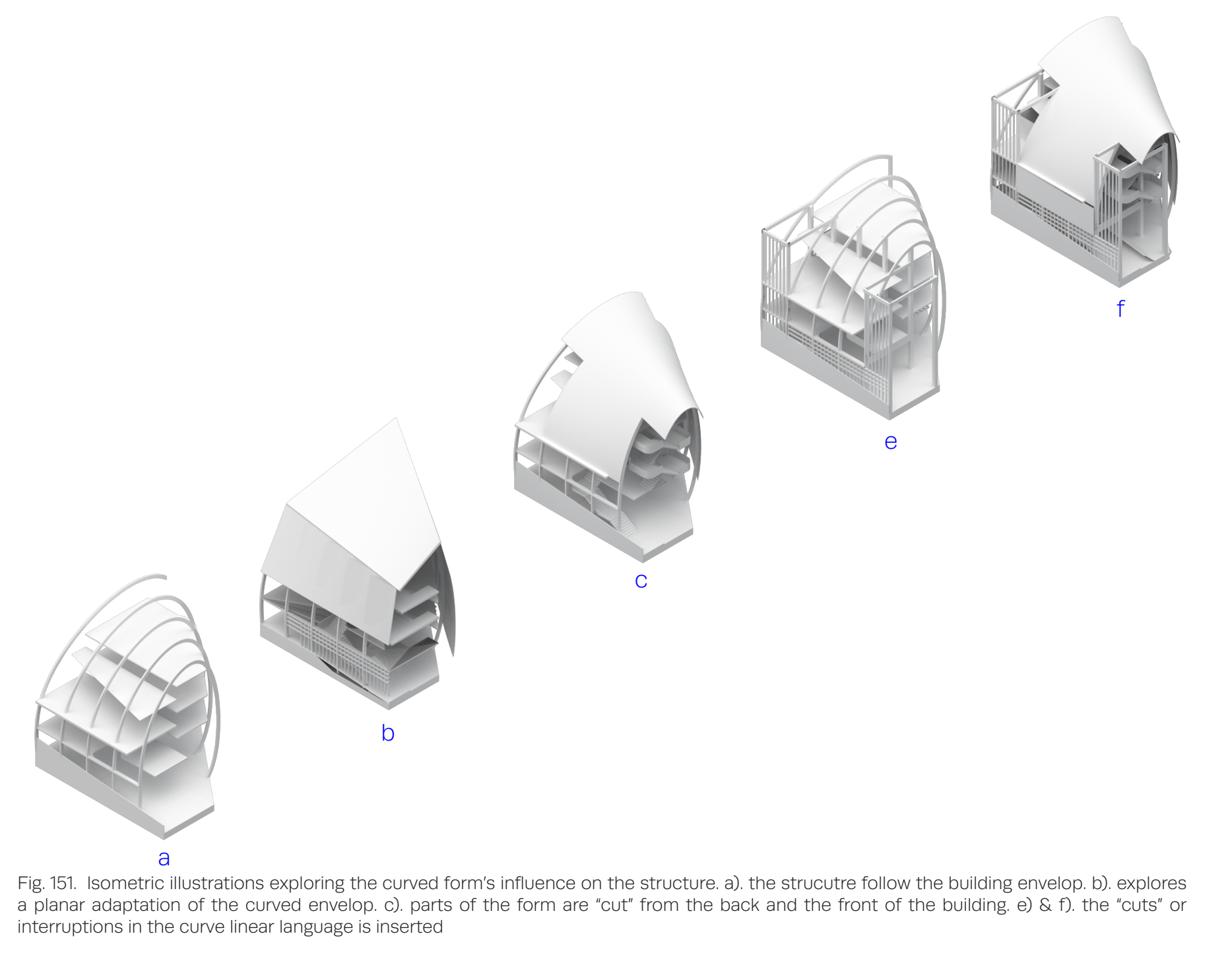



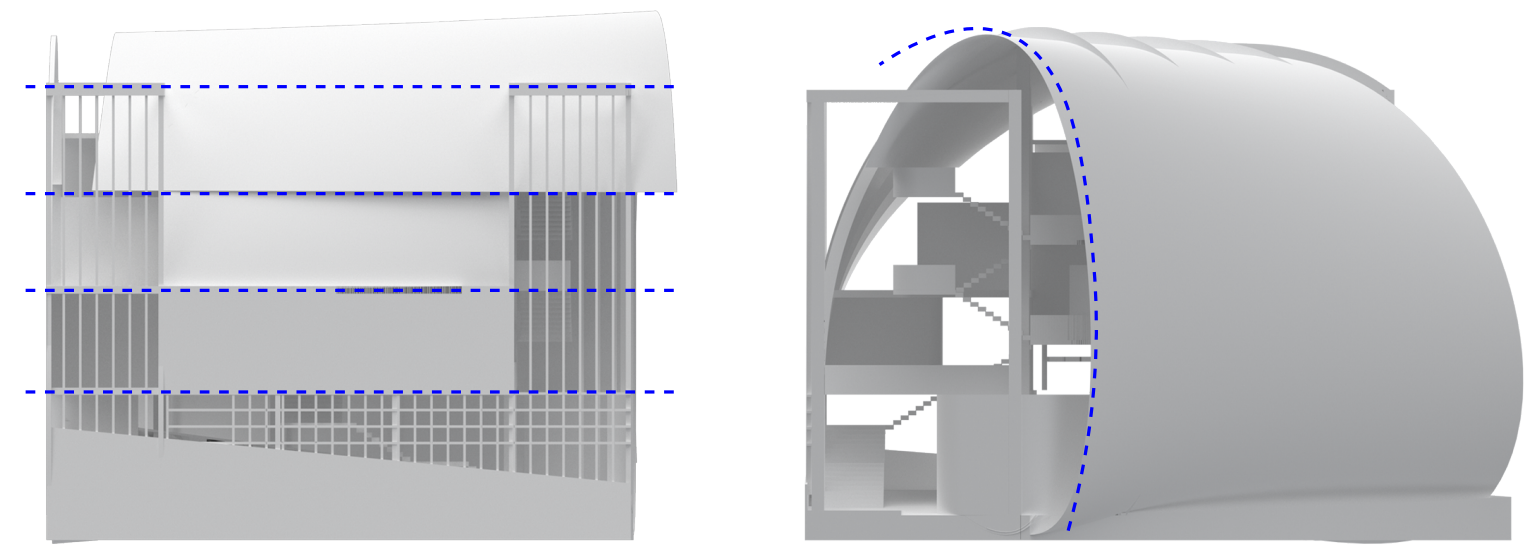

Fig. 152. The linear composition contrasts the curved form of the envelop. Aligned at floor levels in the front and east elevation
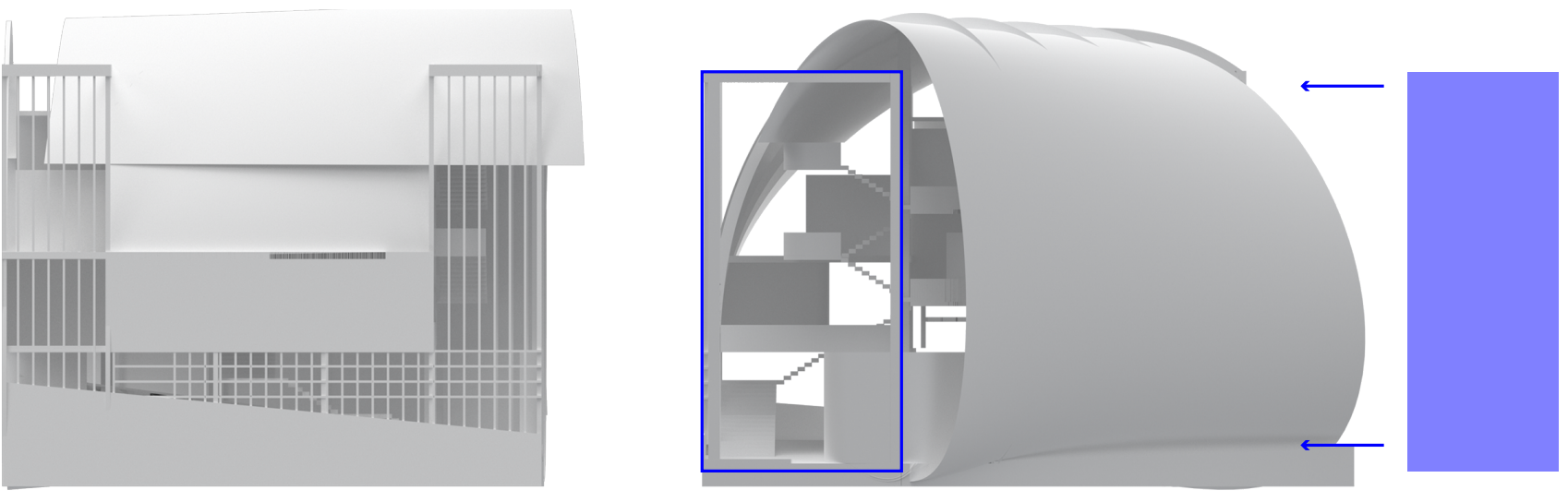

Fig. 153. The contrasting linear forms insert themselves into the curved building envelop.

列

The contrasting language of the earlier physical models is developed into the digital stage. Linear form/language interupts contrasts with the fluid form of the curved

envelop. The structure is developed based on the form

Moment frames support the curve, columns and beams

are inserted into the sides of the curve.

The final design resolves the human scale aspect of the design. Jan Gehl's writing on human experience in spaces defines spatial dimensions for particular encounters to occur. He defines them as intimate, personal, social and public. ${ }^{4}$ While this design case study aims to encourage human interaction and informal meetings the dimensions of social and public

will aid in the developed design of the case study. Transitional spaces

will flow and be gradual, this allows for the human senses to adjust to the environment; the material spaces and the activities occurring.

+ intimate distance

+ personal distance

+ social distance

+ public distance

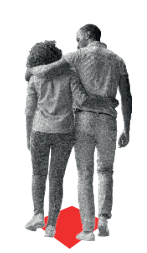

$45 \mathrm{~m}$

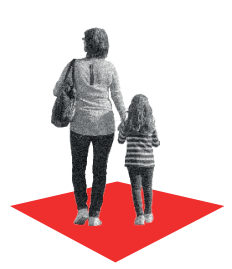

$1.3 \mathrm{~m}$

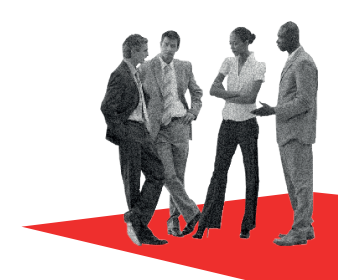

$3.75 \mathrm{~m}$

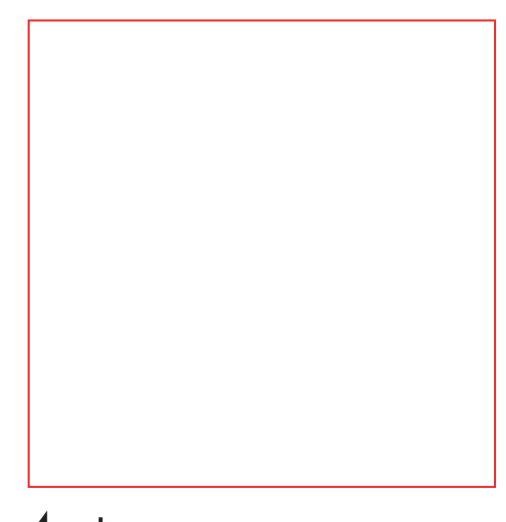

$4 m+$

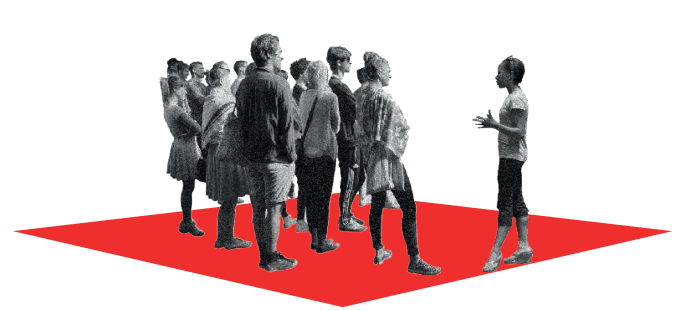

Fig. 154. Diagrams show various dimensions informed by Jan Gehl's research established 


\section{Conclusion}
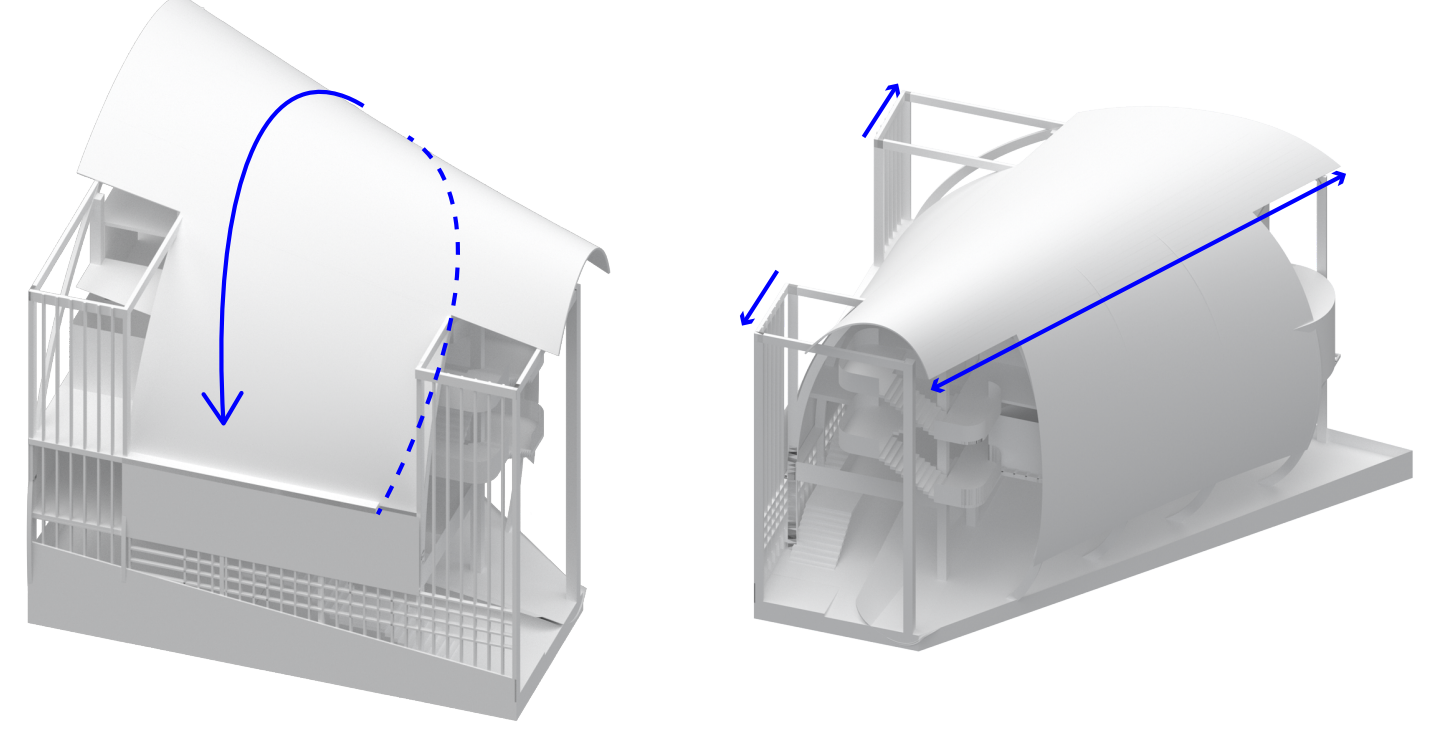

The conceptual design chapter explores relationships

between the interior and the exterior form, based on the

dimensions of the total site. Physical card modelling

began this section, which moved to digital modelling.

The conclusion of this chapter has a building envelop,

floor levels and the circulation, supported by envelop,

floor levels and the circulation, supported by an exposed

structural grid, which compliments the forns. The

following chapter illustrates the developed final design case study.

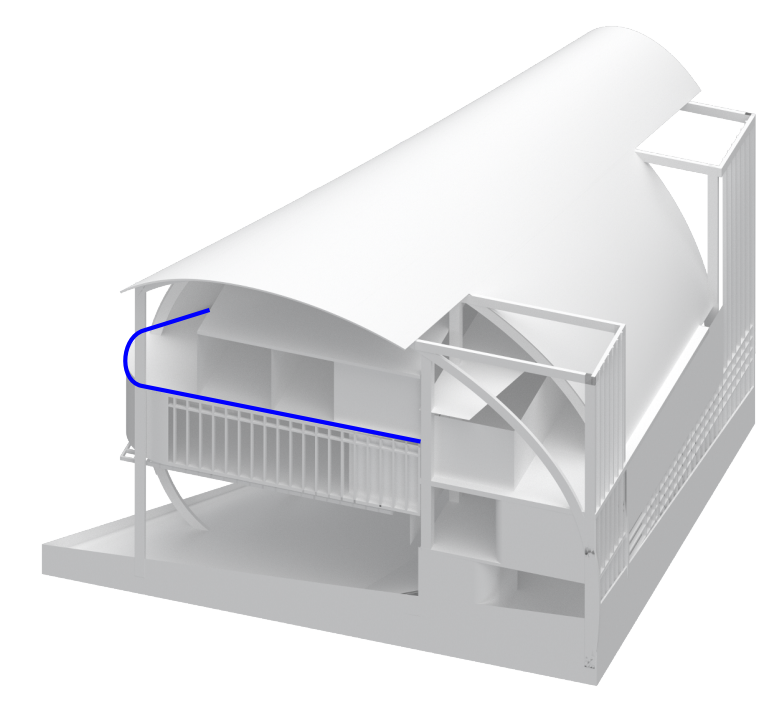


Notes

Dovey, Framing Places: Mediating power in the built form, 123

Venturi, 80

Venturi, "The Inside and The Outside", 86

Gehl, Life between buildings, 69

Gehl, 61

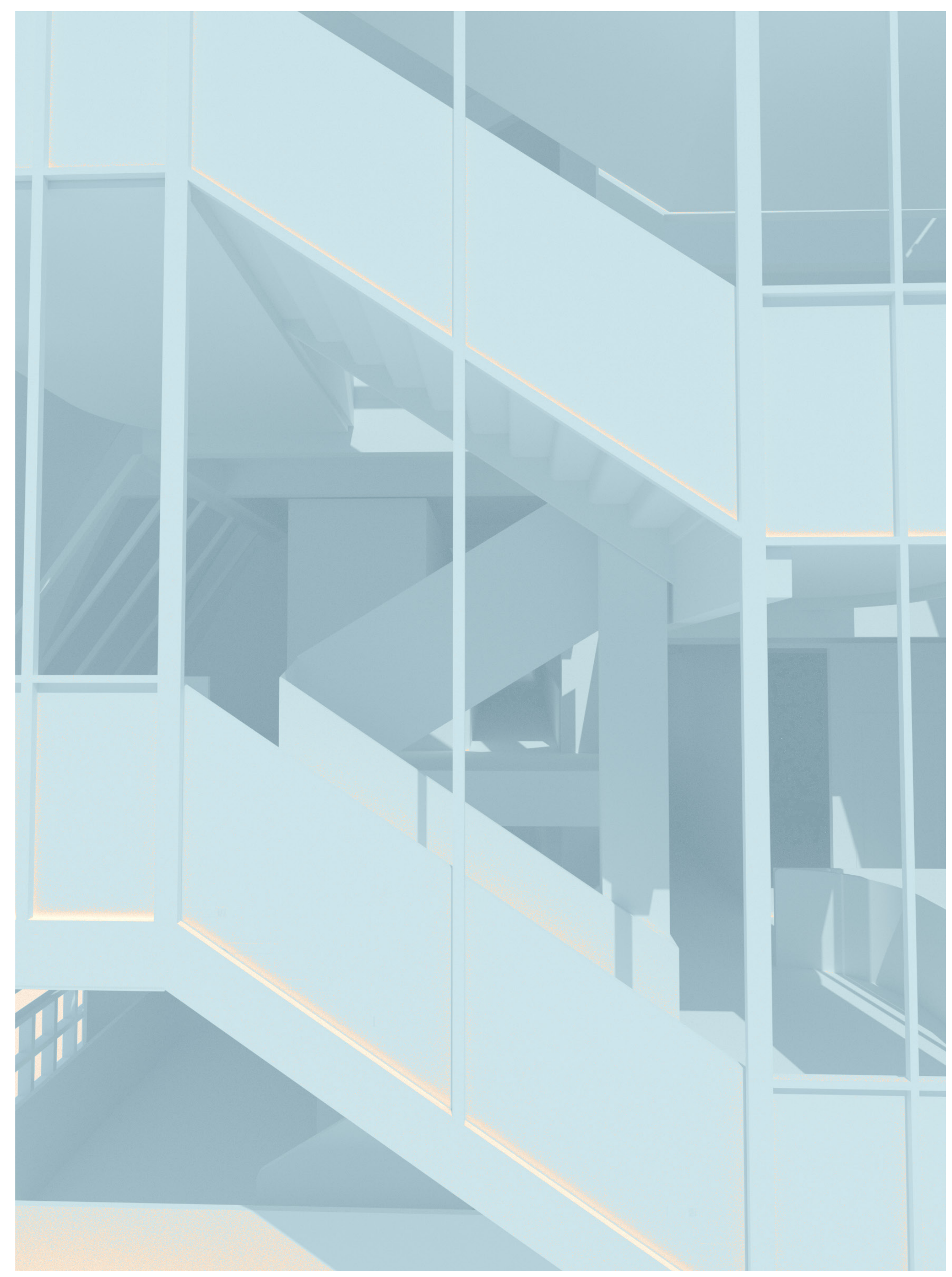



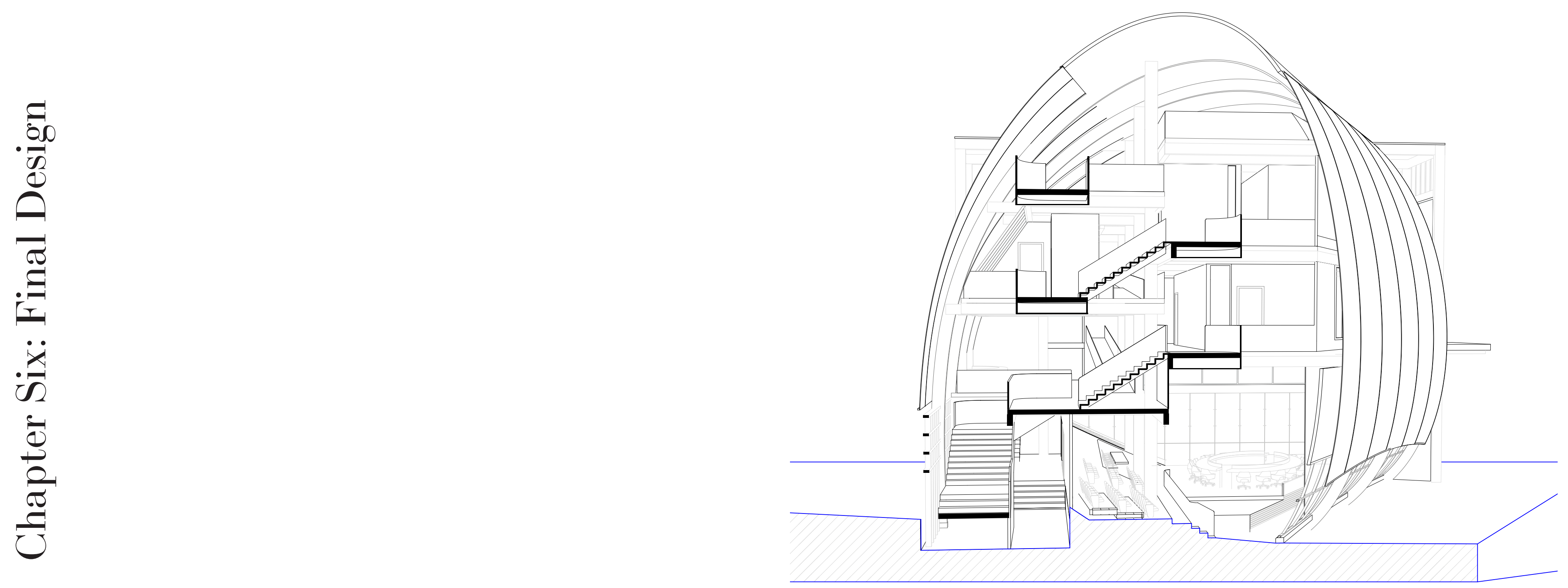



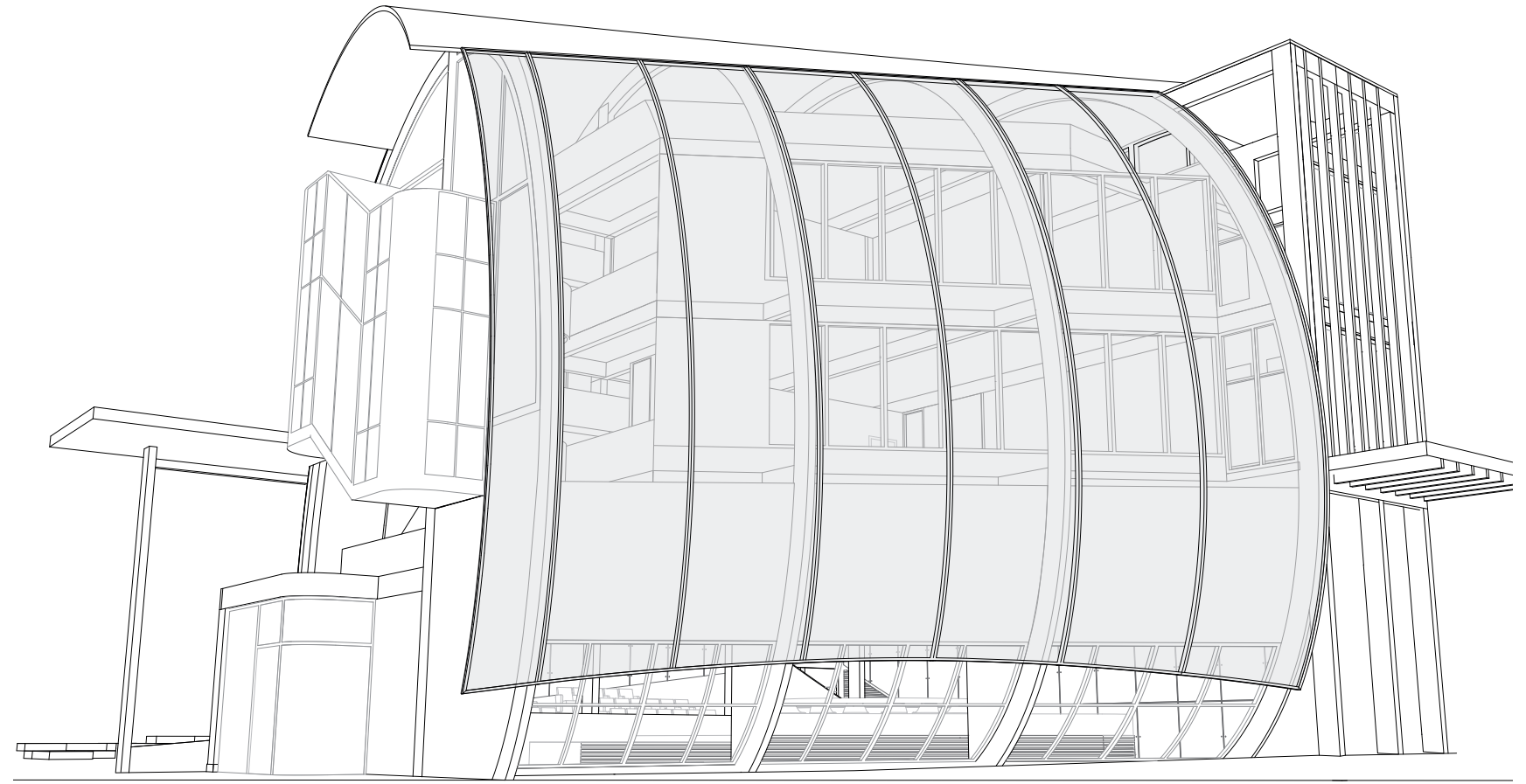

Fig. 164. Queen Street facade. The curved building envelop is clad with a metal mesh. allowing for the interior to be perceived from the

outside Behind the facade the meeting rooms are glazed for view into and outwards

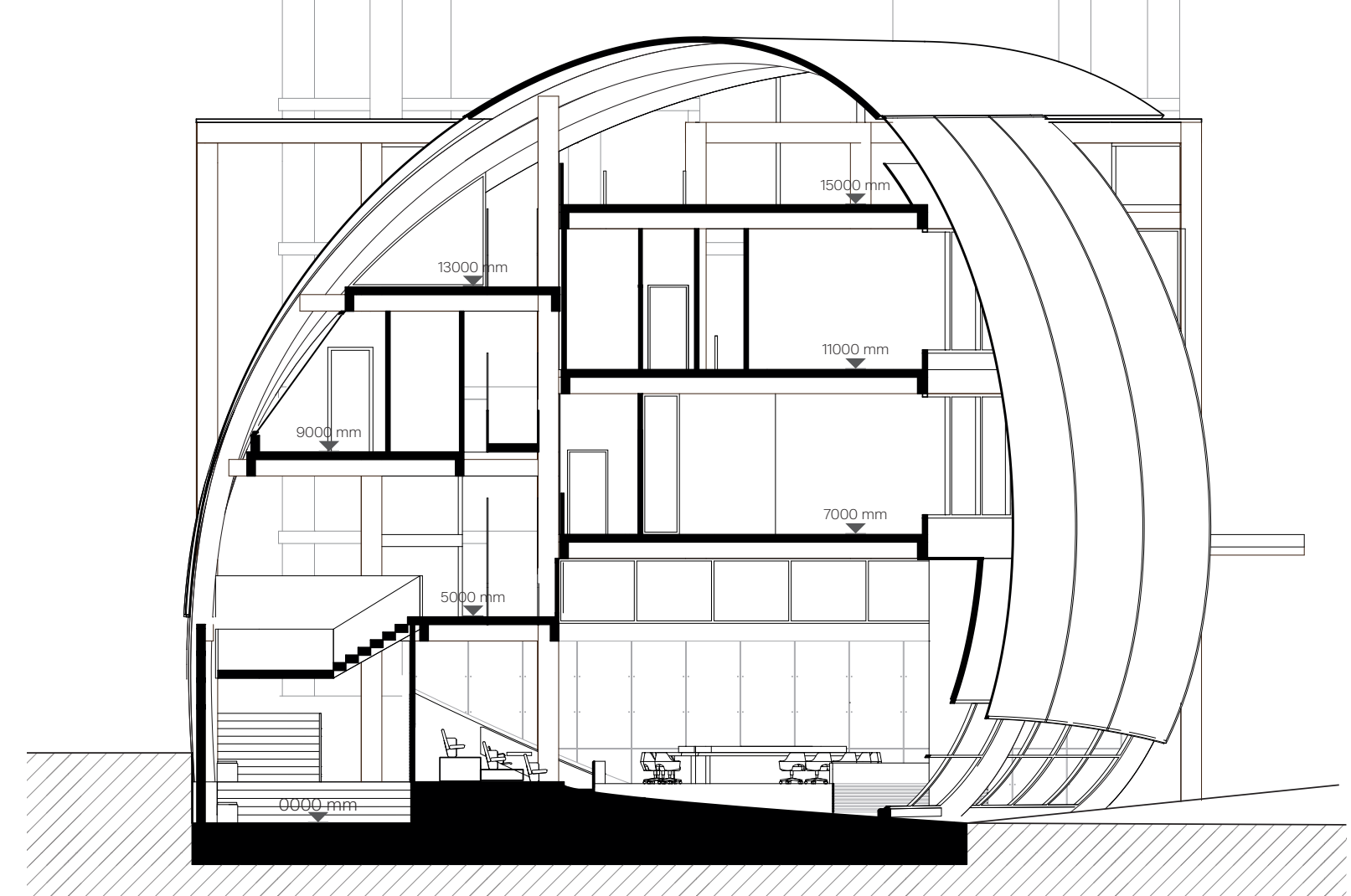

Fig. 165. Section AA. through the main meeting room and ground floor reception space. Smaller meeting rooms and the top function room.

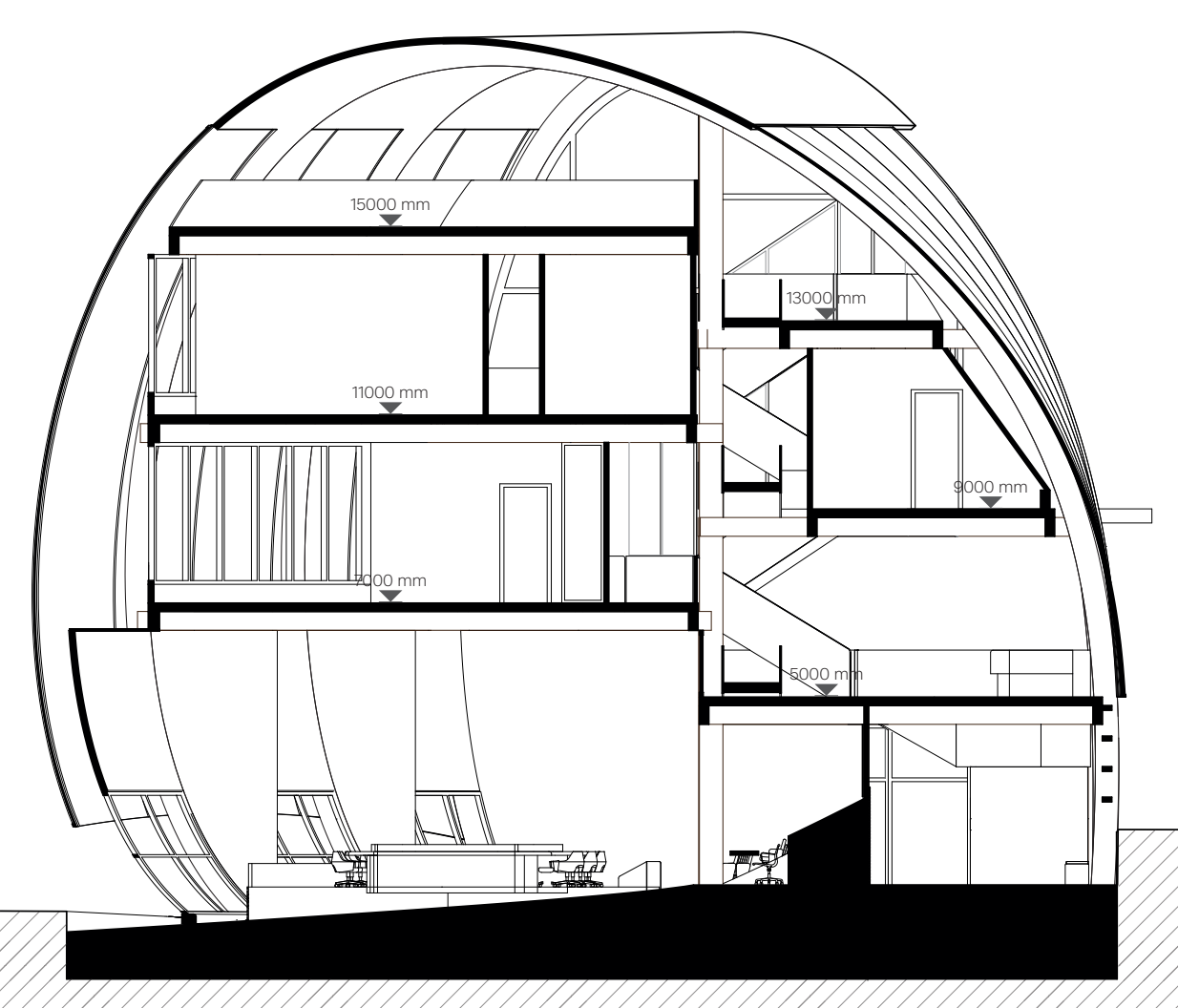

Fig. 166. Section BB. through the main meeting room and ground floor reception space. 169 
Renamed the Main Meeting Room, a space which can host a variation of meetings. The spatial layout is suited to accommodate for meetings of the Governing body, Chamber.

Public can observe the main meeting room from above at level 1 and at street level. Attendance of public to the meetings is open
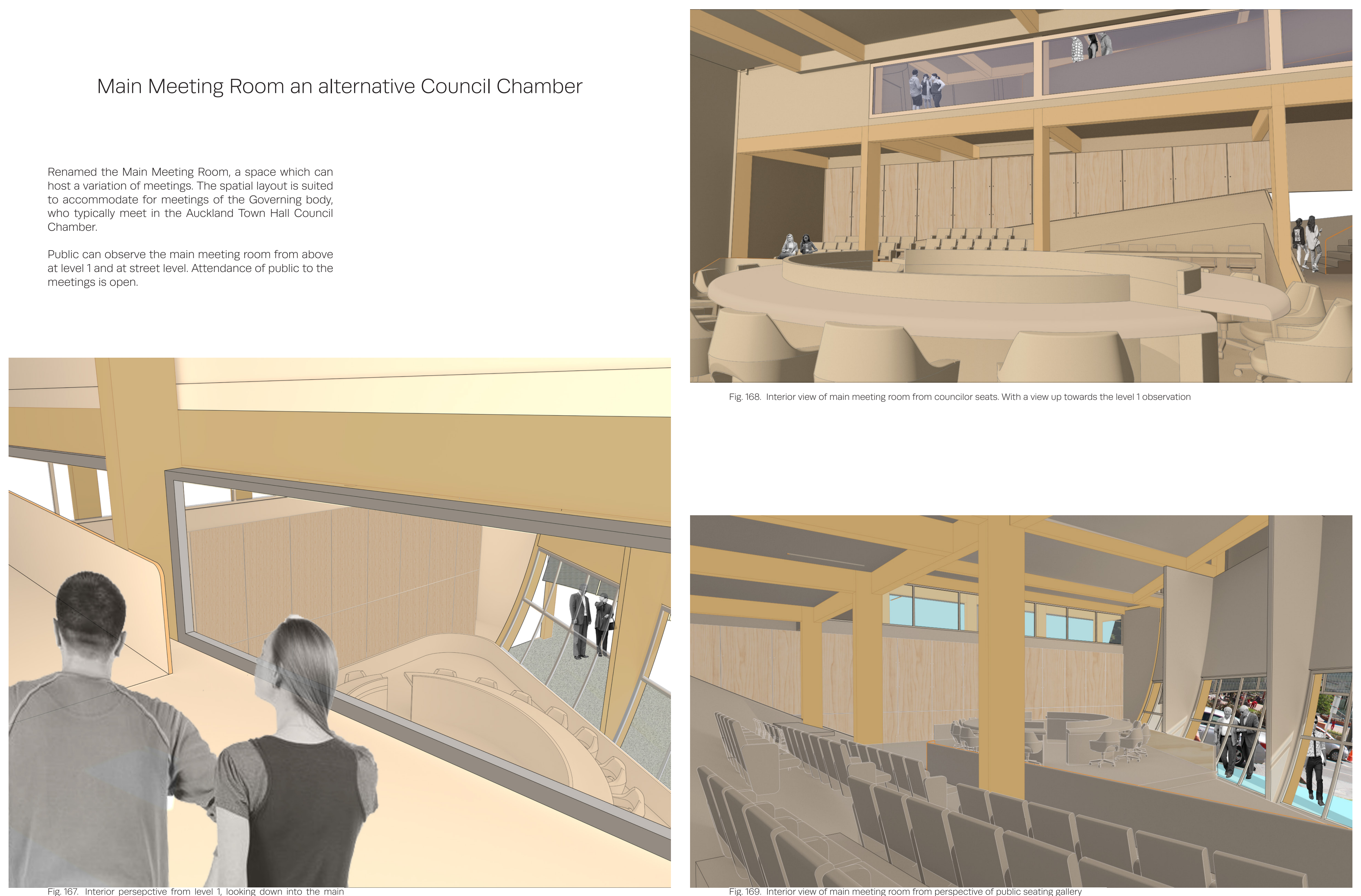


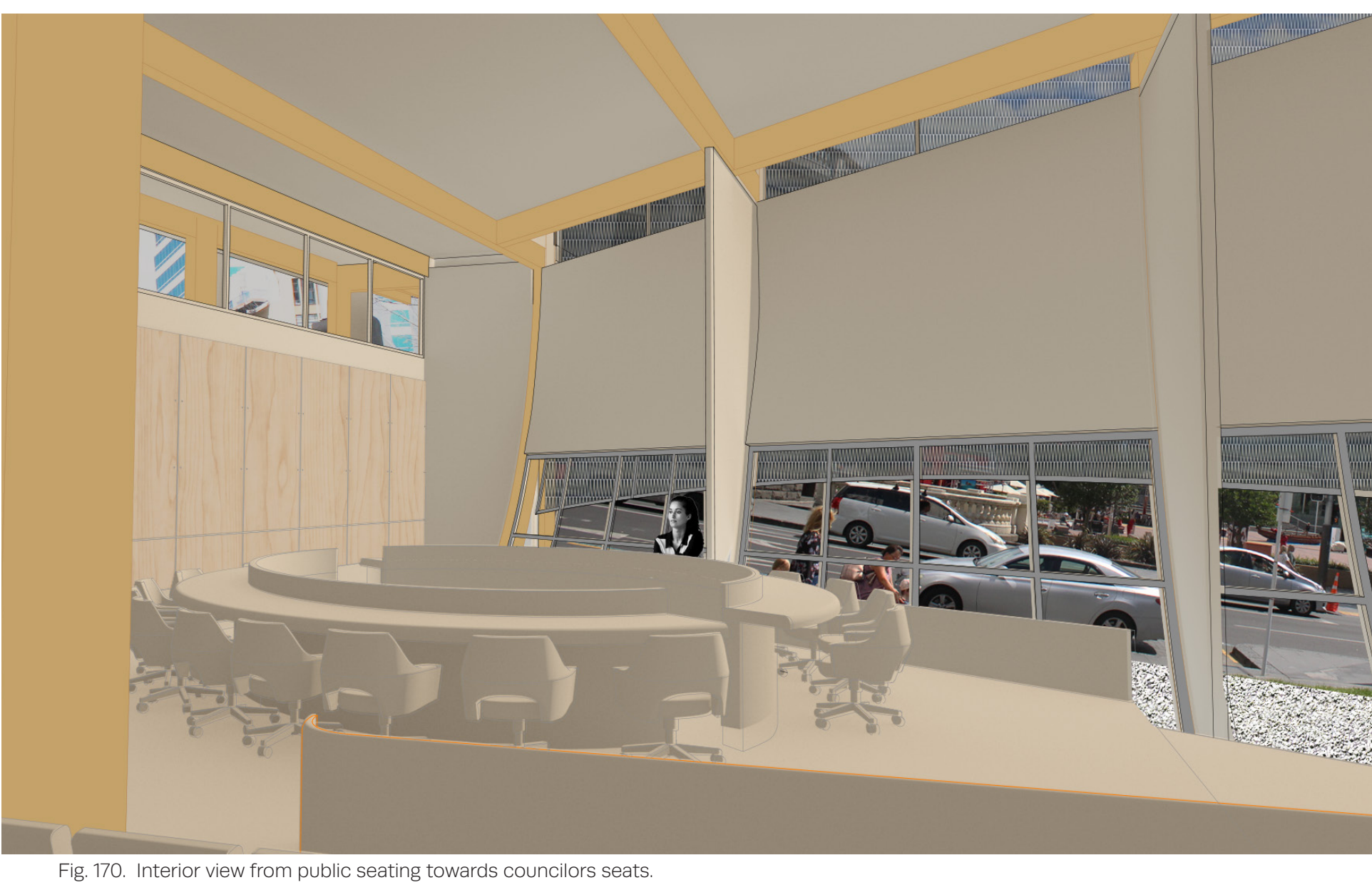

Fig. 170. Interior view from public seating towards councilors seats
The Main Meeting Room occupies a majority of the ground floor. It has one large entrance from the inside. Therea fows into the Main Meeting Room from street out to the street from inside.

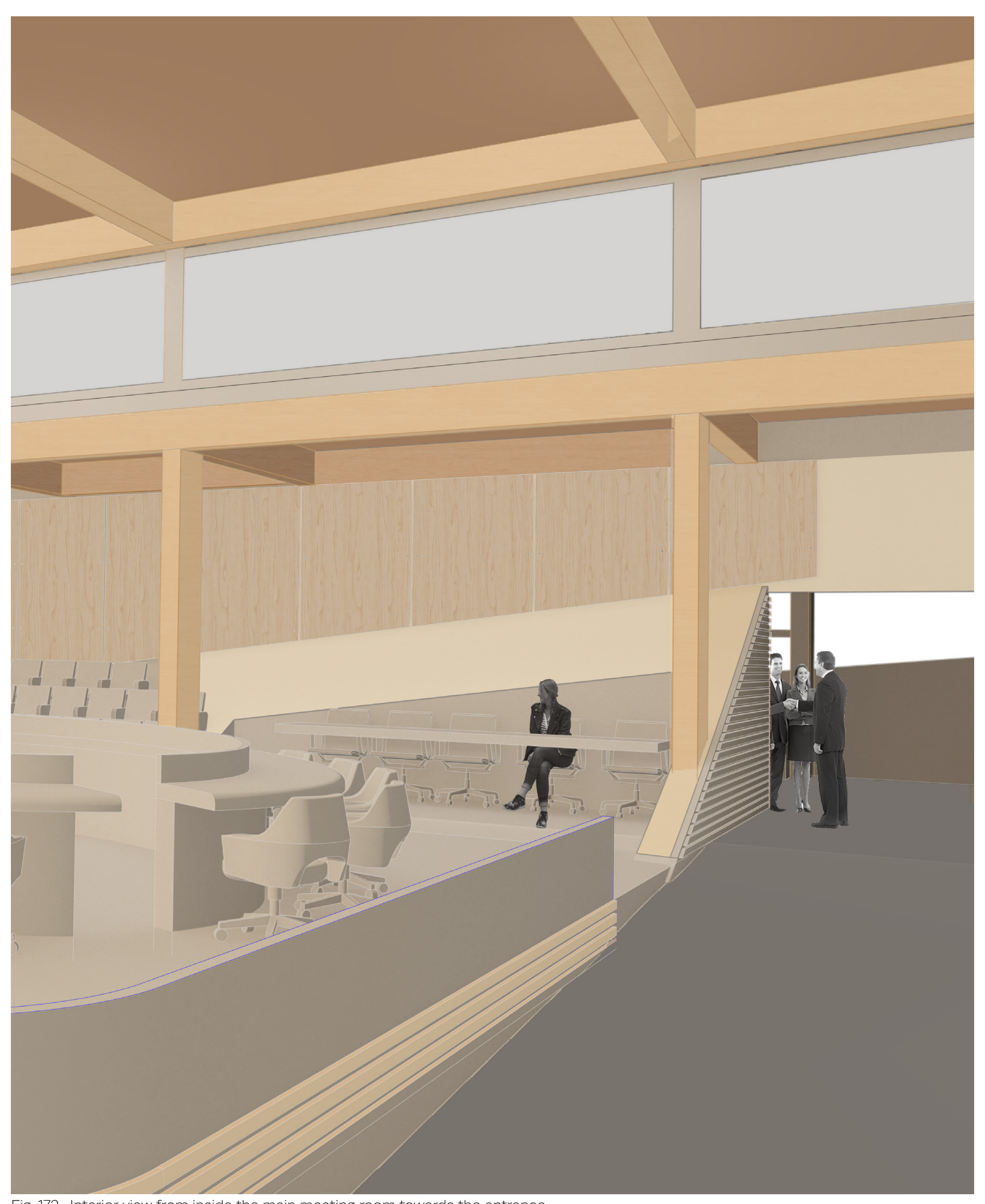




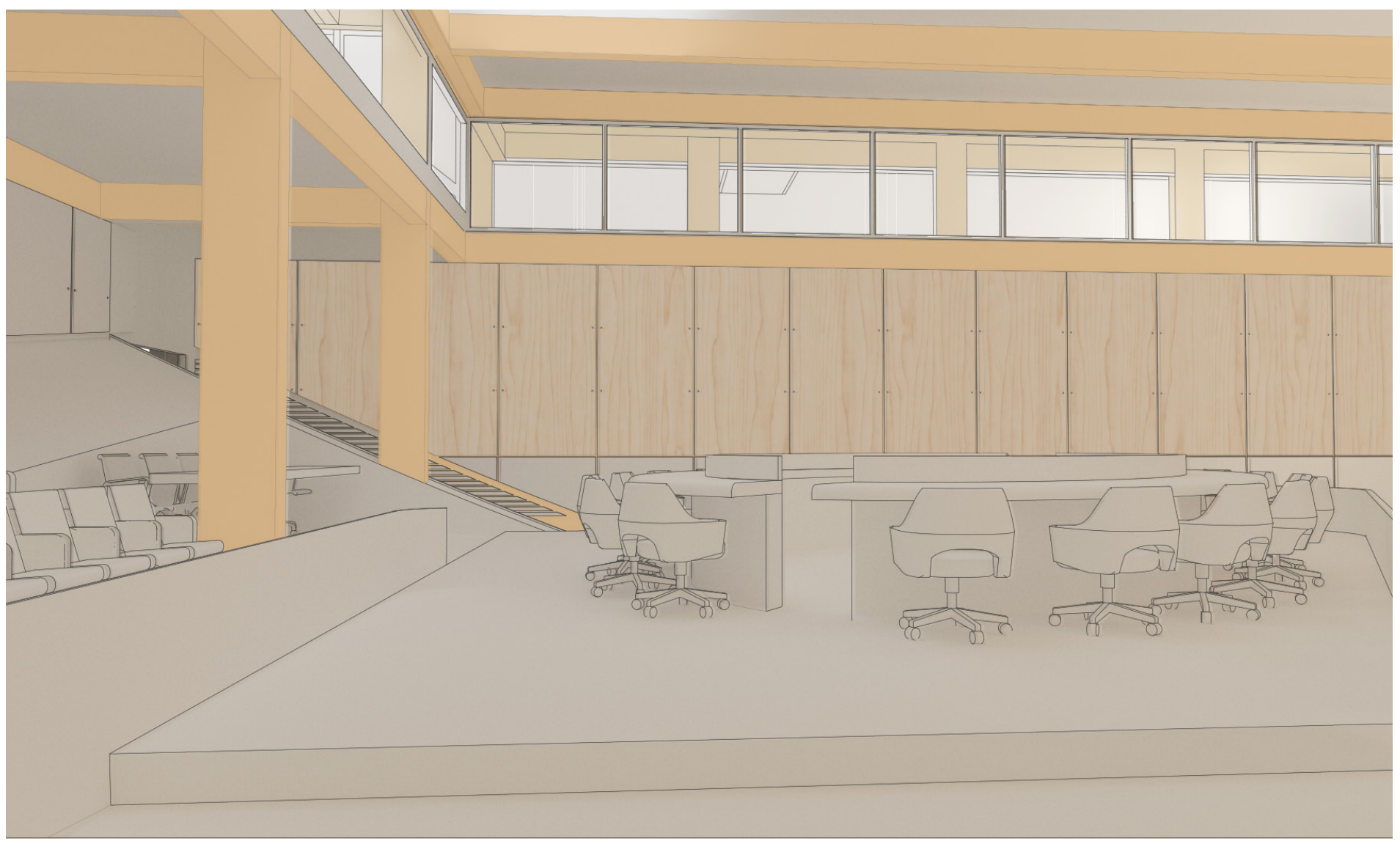

Fig. 173. Interior view of main meeting room from the position of public address. It is this position that allows the spatial power to be dynamic.

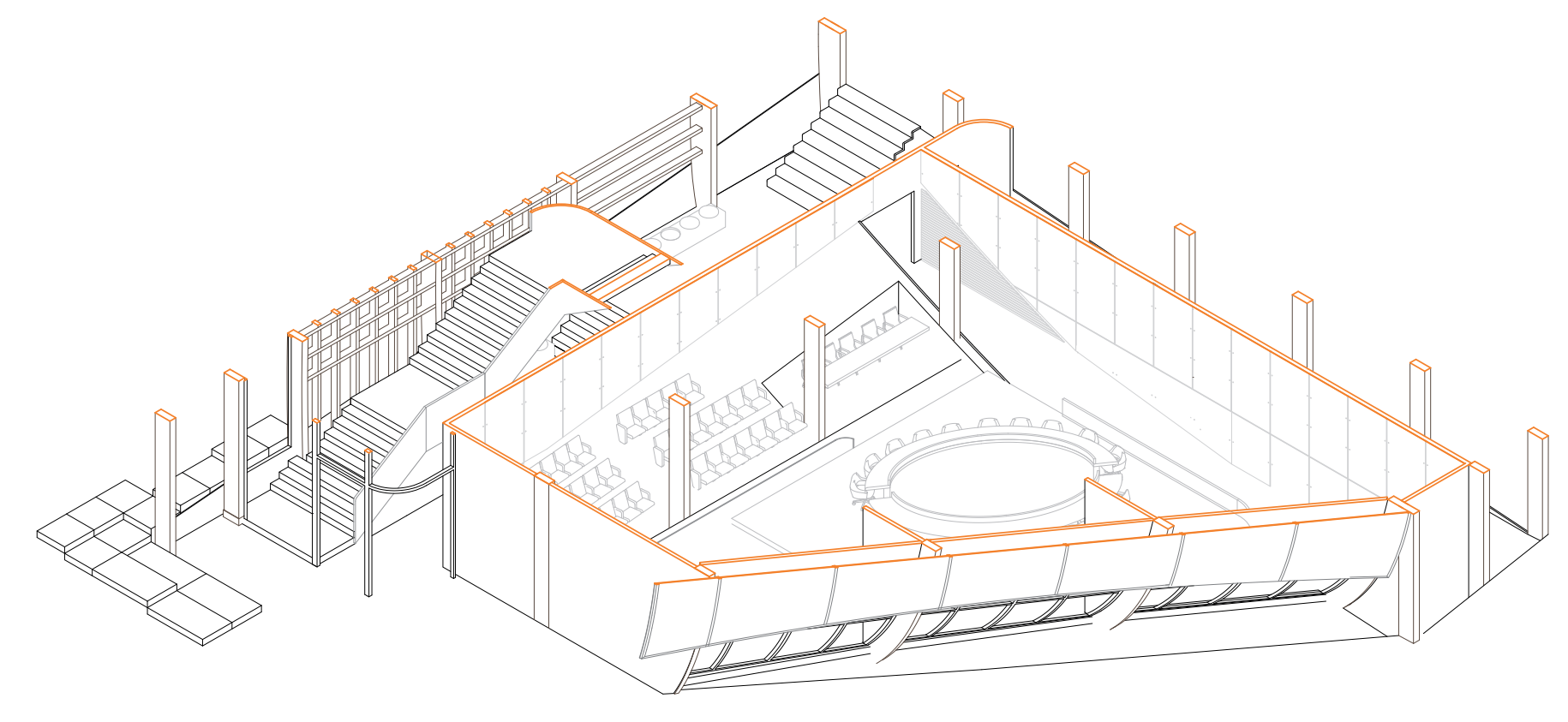

Fig. 174. Isometric plan drawing of the ground floor. Ground floor is divided into circulation and meeting space. The circulation spaces have opportunity to facilitate informal meetings and encounters.

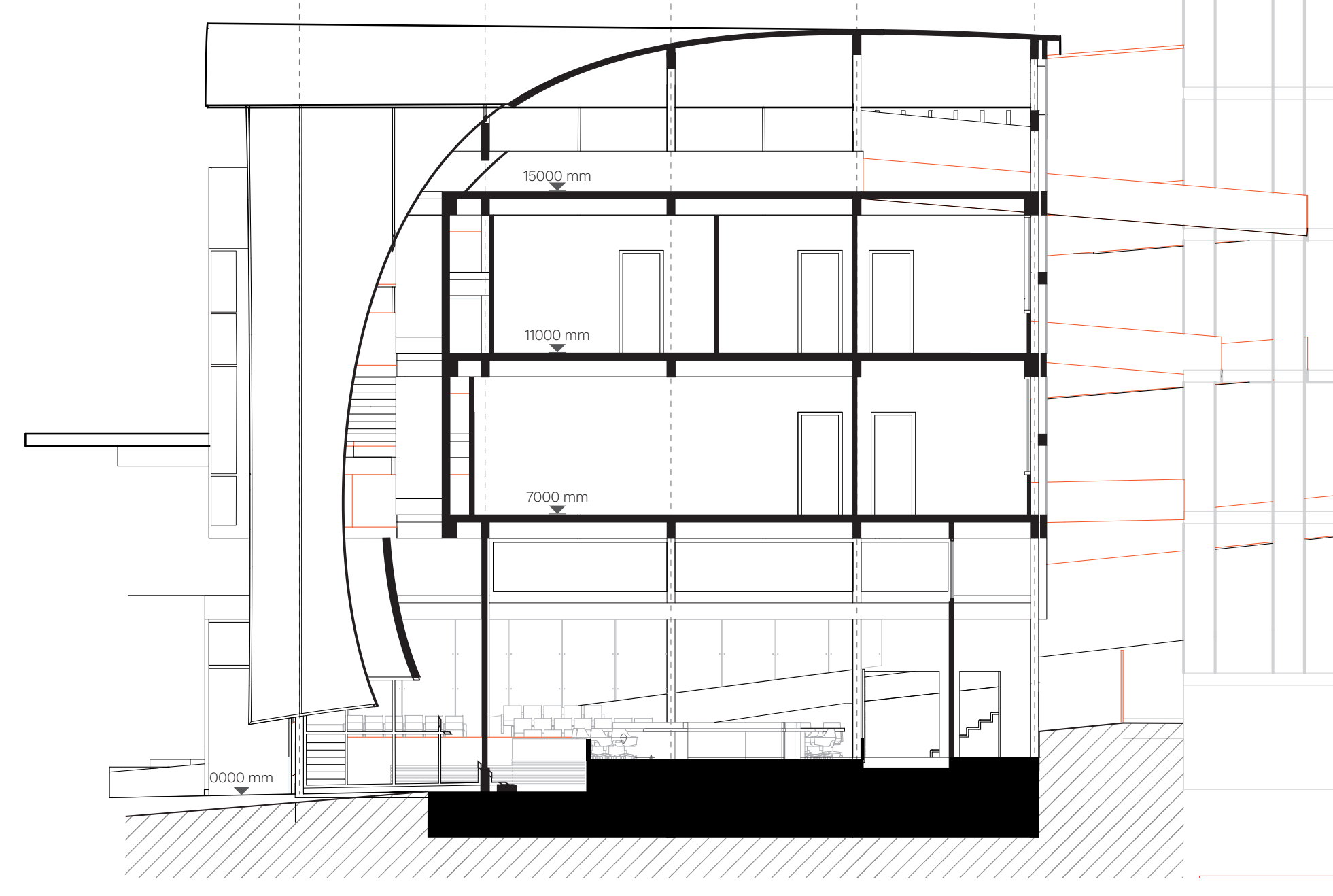

Fig. 175. Section CC. Into the main meeting room, smaller meeting rooms and function space at the top 
Level one is dominated by circulation and public

eception. This space has views down to the main

meeting room and out towards the city.
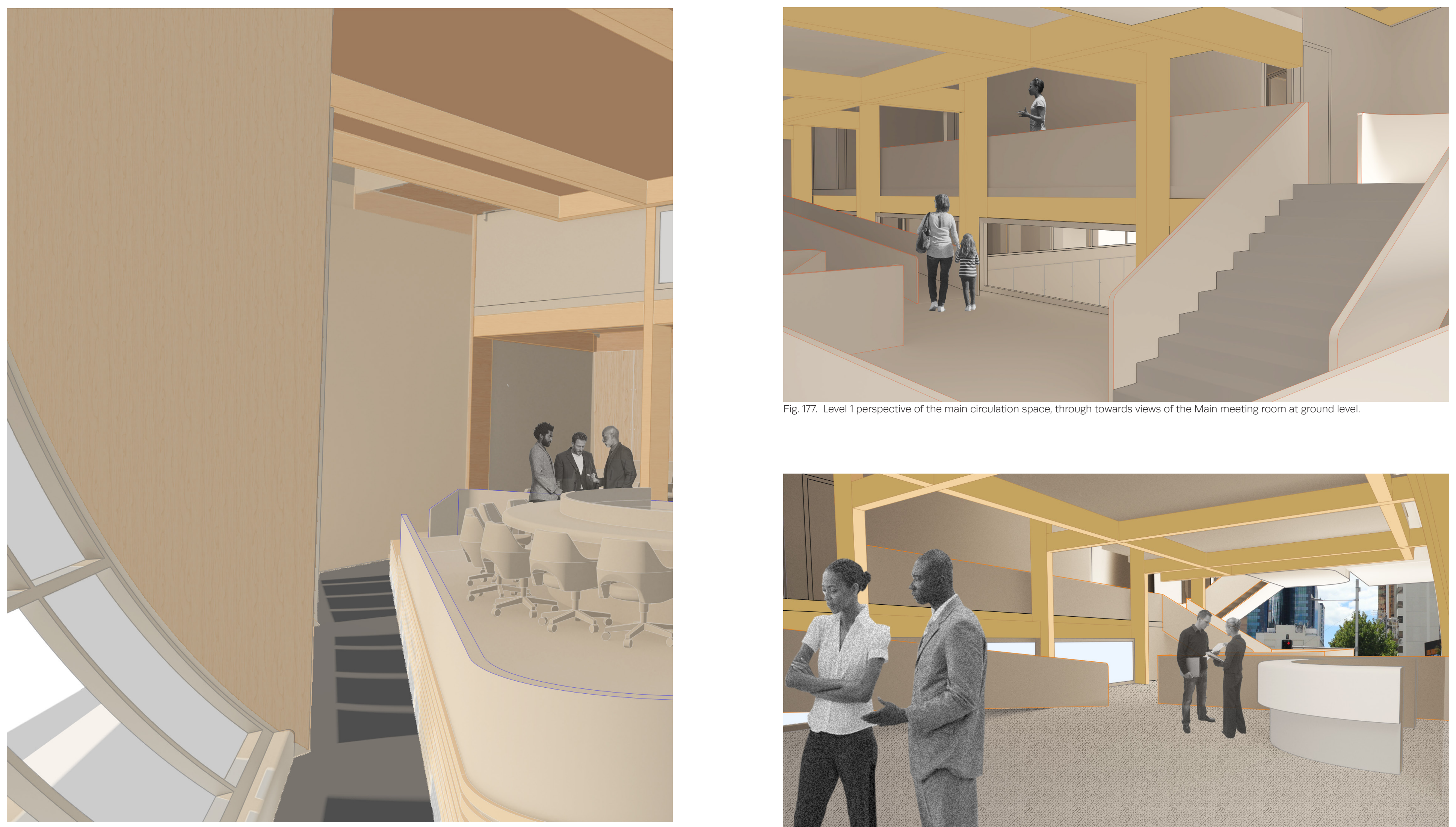

Fig 177 Level 1 perspective of the main circulation space, through towards views of the Main meeting room at ground level

Fig. 176. Interior view from the main meeting room, down the side walkways. An alternative route to the public seats.

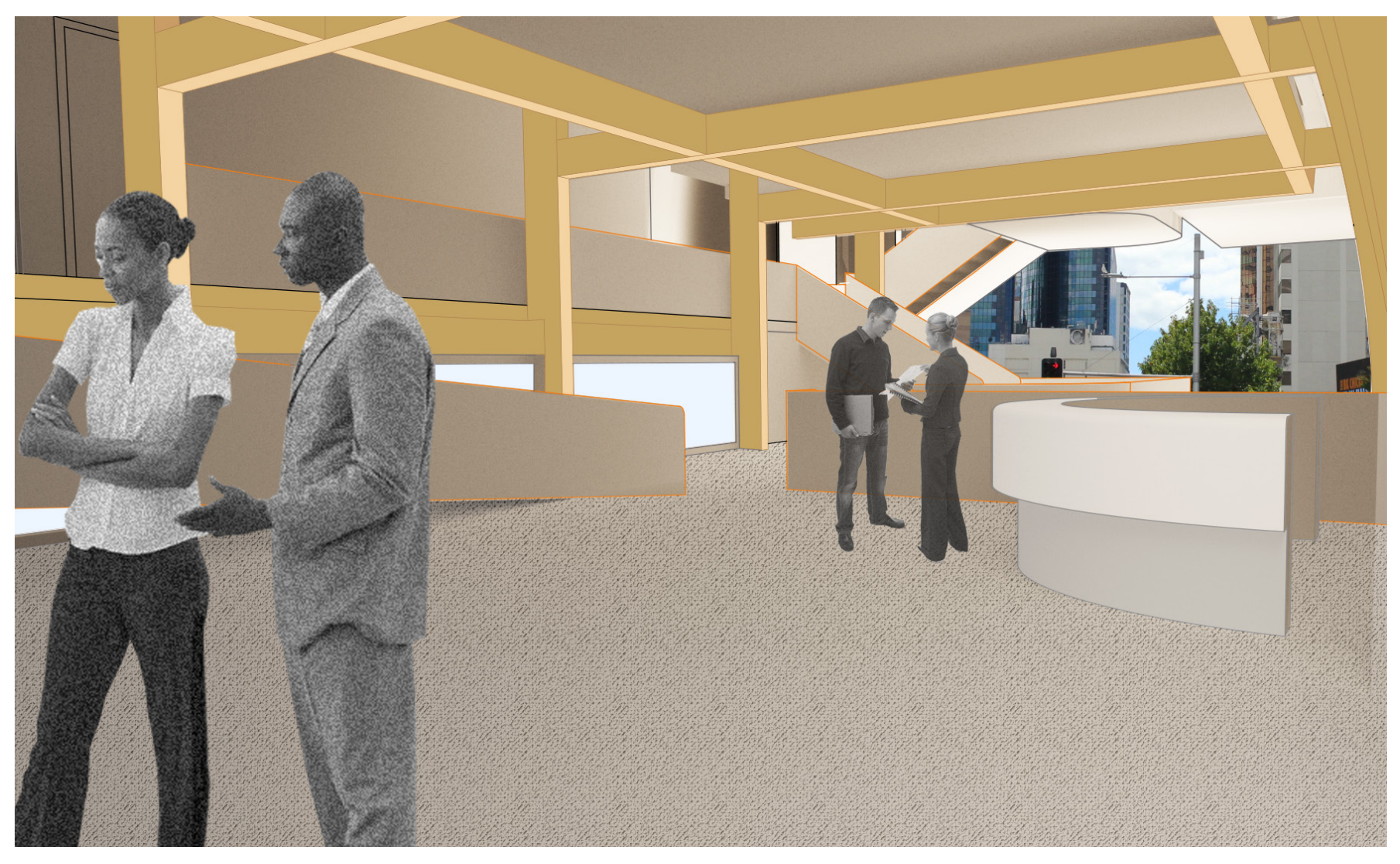




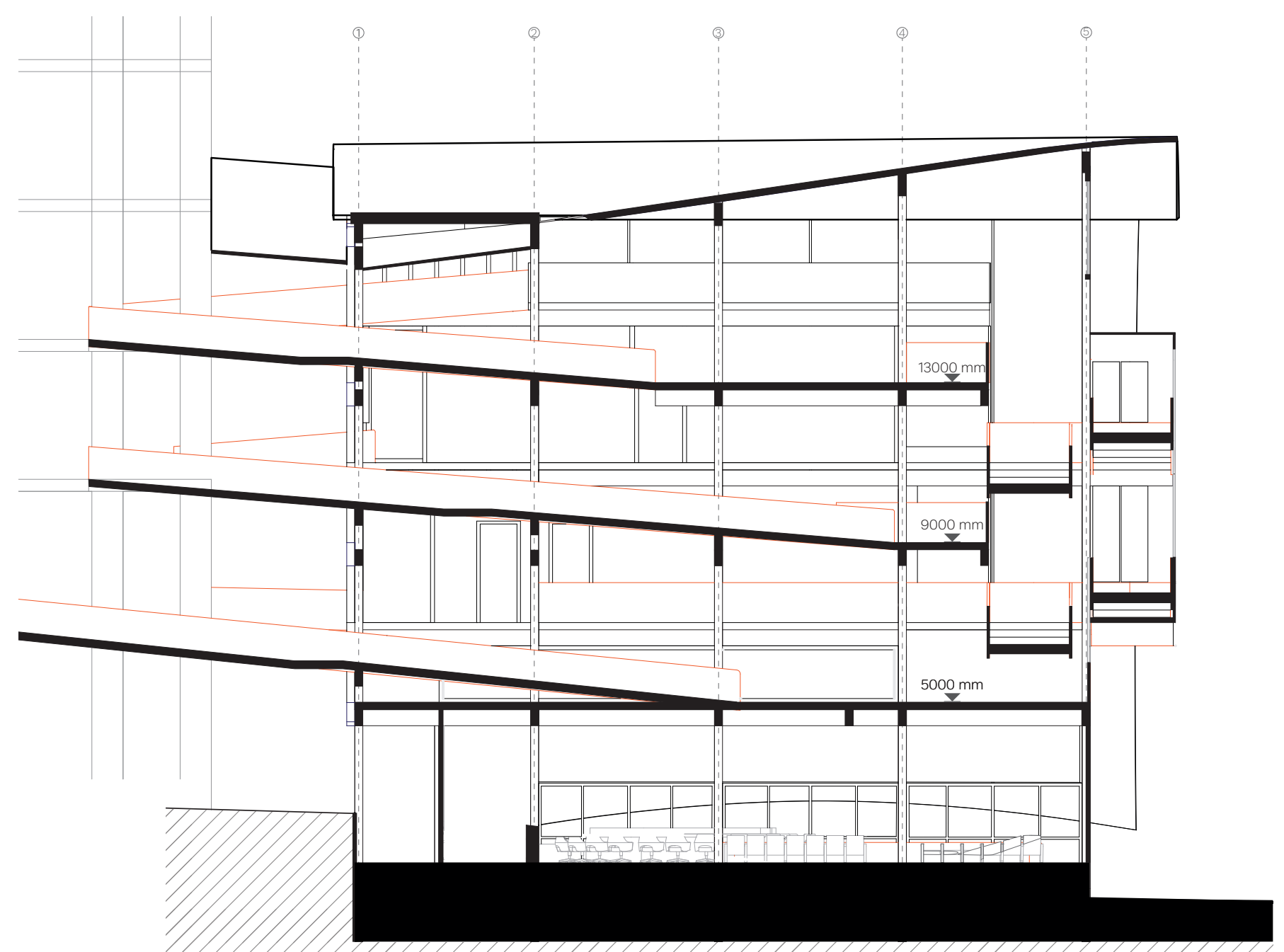

Fig. 179. Section CC. Long section through main meeting room and circulation ramps or adjoining re-purposed building.

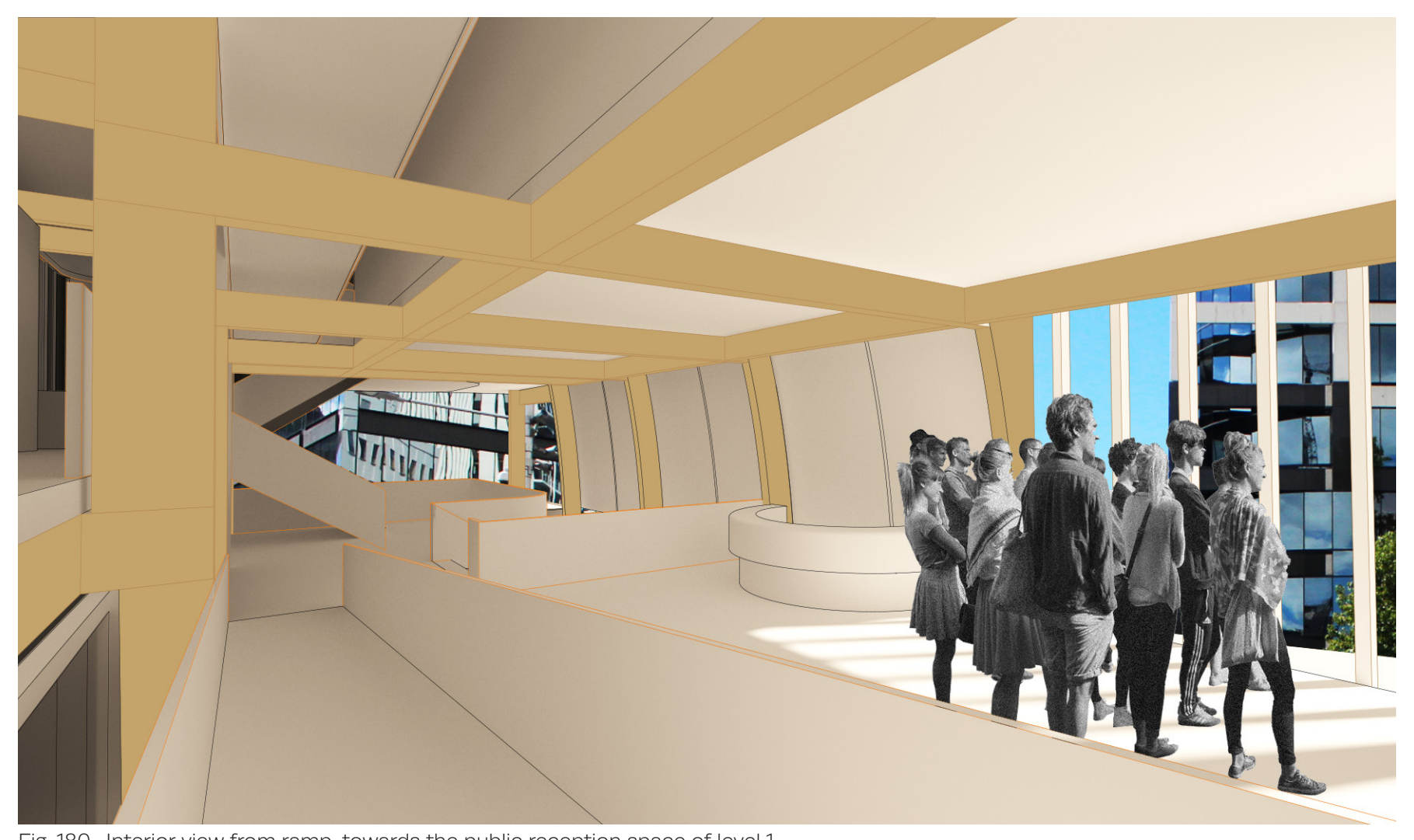

All smaller meeting rooms have exterior views and glazing. Supporting the desire to create trasnparency of

the operations of local government.

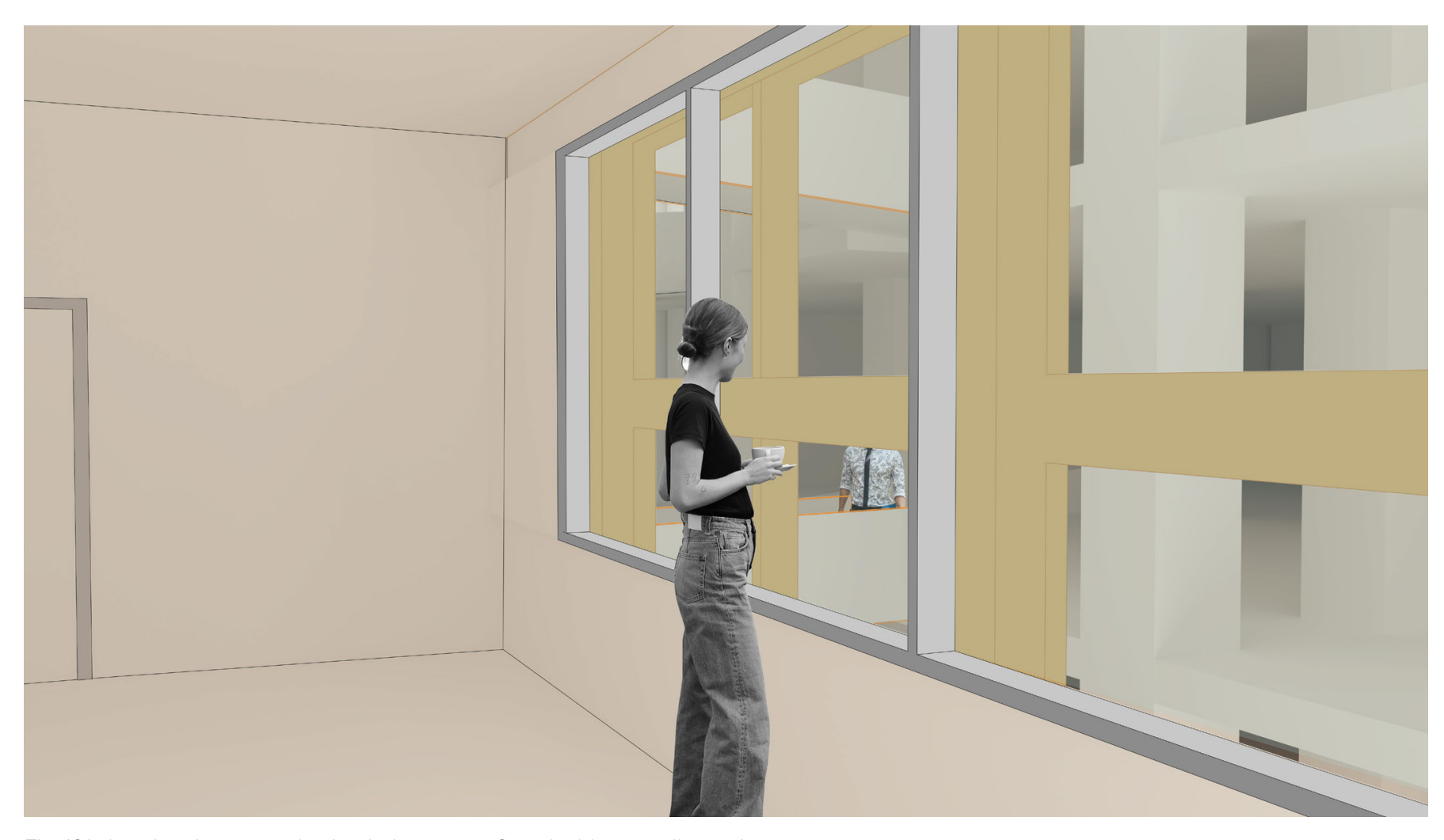

Fig. 181. Interior view towards circulation ramps from inside a small meeting room.

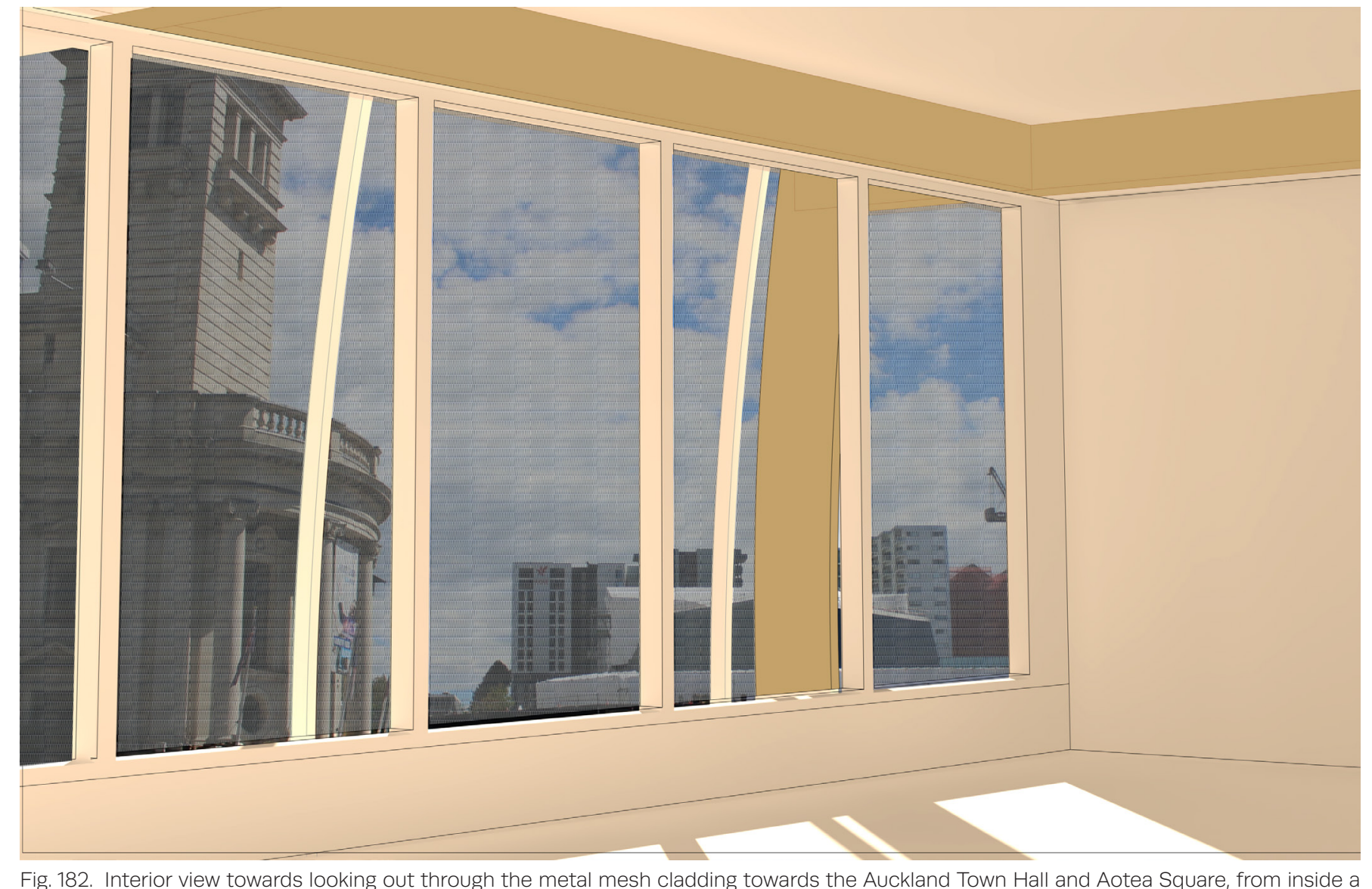
Fig. 182. Interior view
large meeting room 


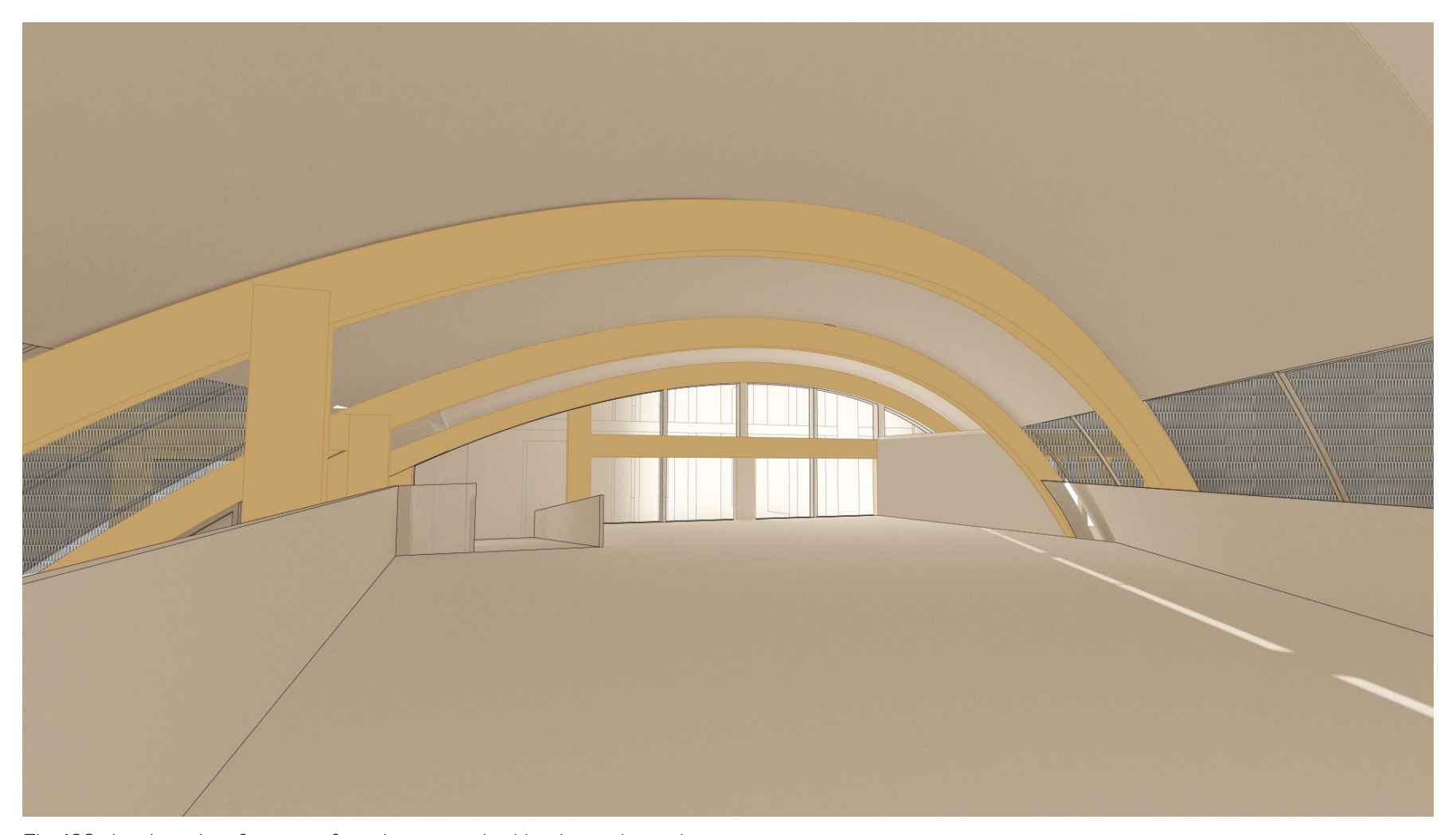

Fig. 183. Inteiror view from top function room, looking inwards. at the ramp entrance.
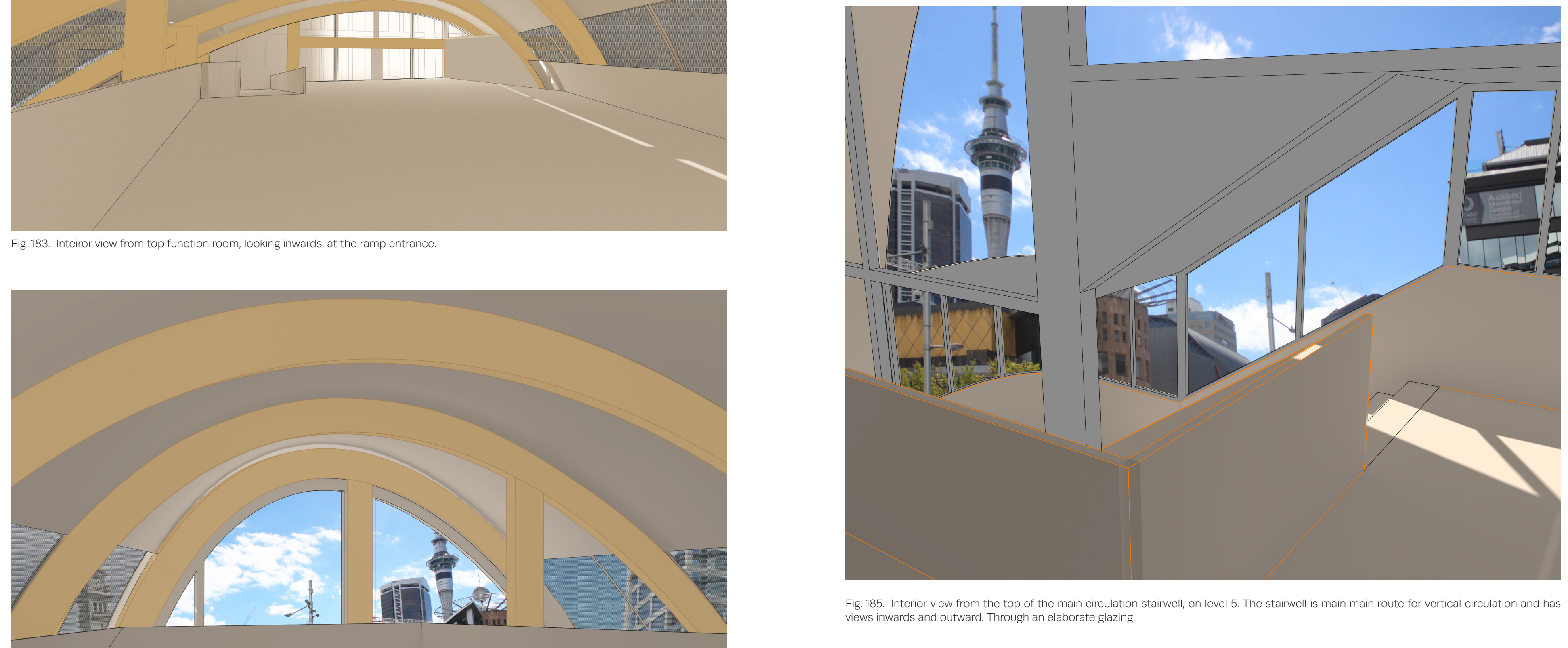

Fig. 185. Interior view from the top of the main circulation stairwell, on level 5 . The stairwell is main main route for vertical circulation and has views inwards and outward. Through an elaborate glazing.

The top floor is dedicated to a function space. With views out down Queen Street. The space is small but adaptable to suit small performances or formal 
Circulation ramps throughout the building create and

activate a flow of people. At the front of the building a

staircase provides vertical circulation while ramps are

used through the neighbouring building for accessible

circulation.

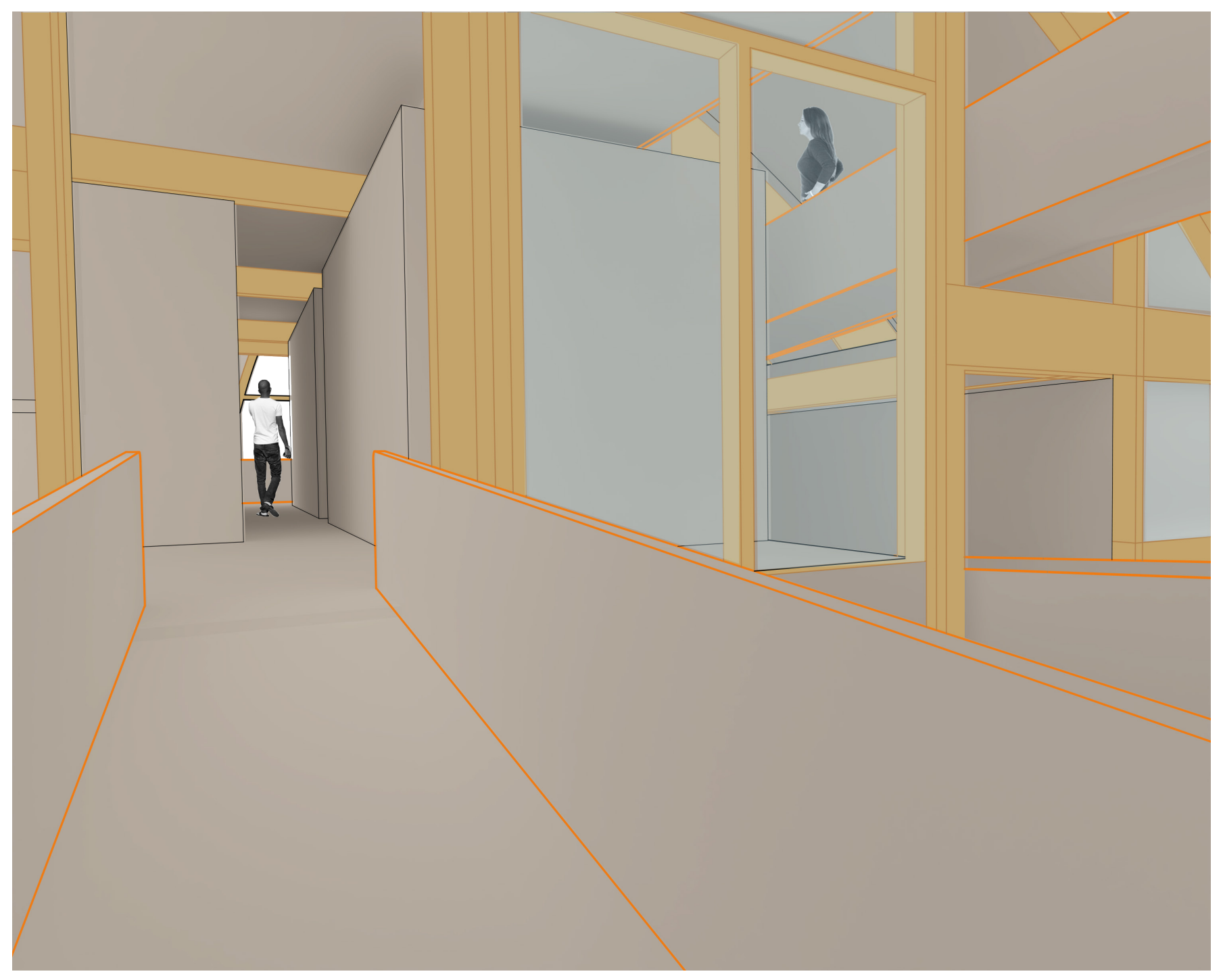

Fig. 186. Perspective from an external ramp, which joins the design to the neighbouring building, to be used as vertical circulation
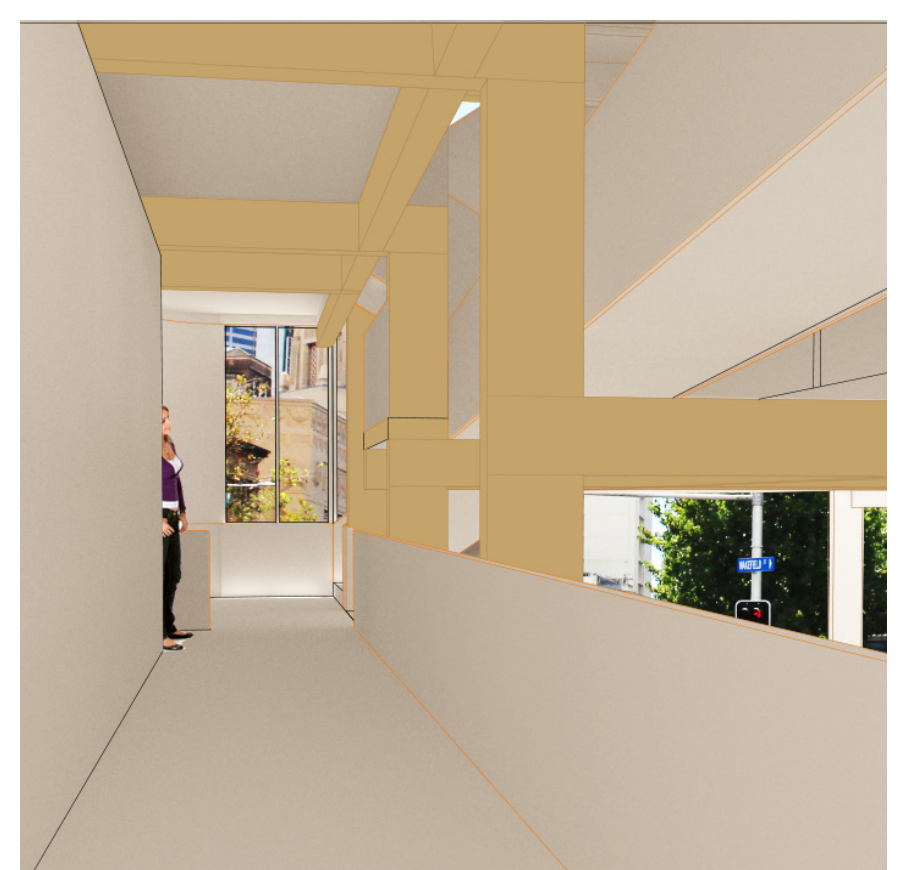

Circulation ramps are centred around the main structure of the building. Views to and from the ramps are visible

\section{Fig. 187. Interior corridor perspective.}

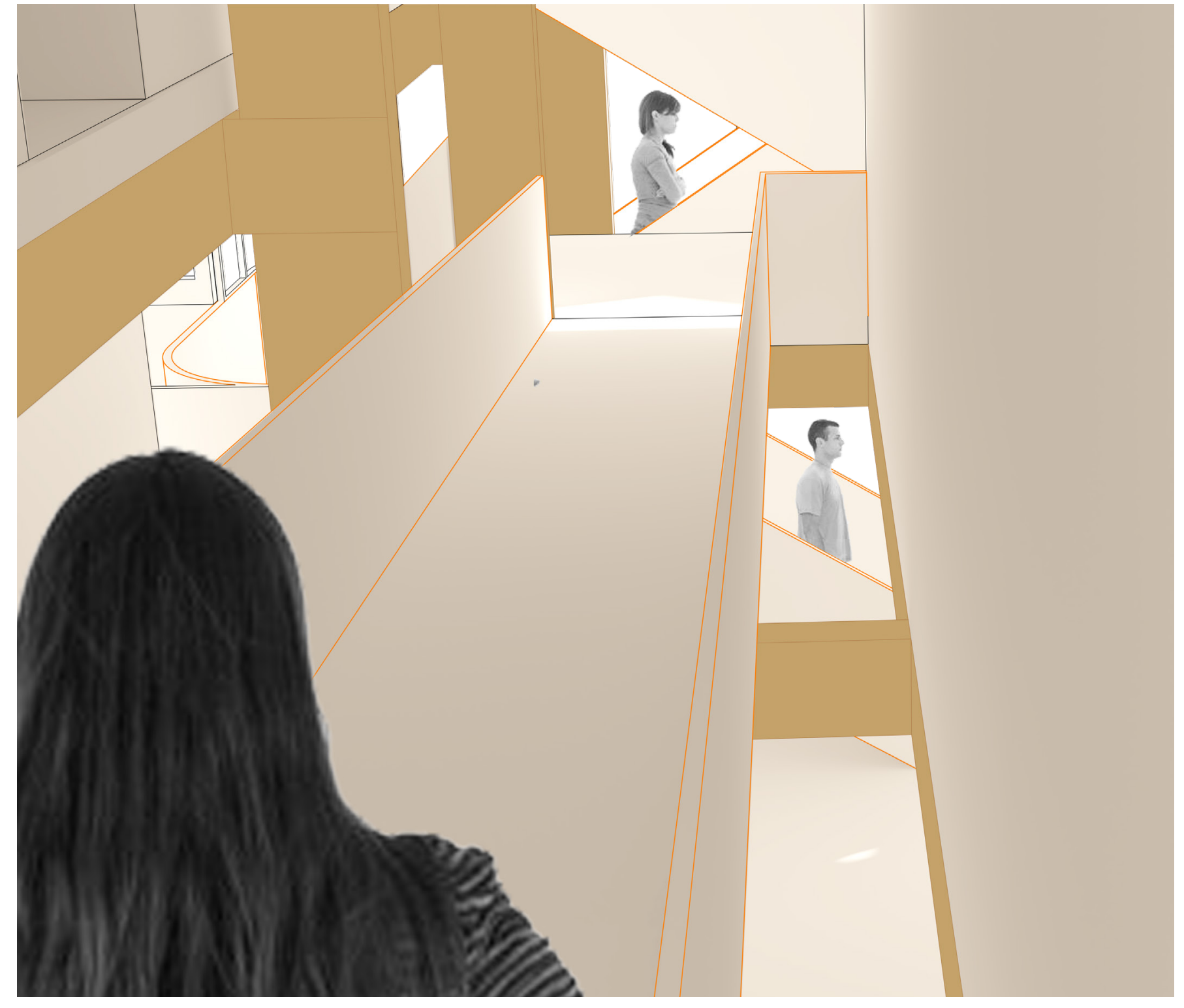




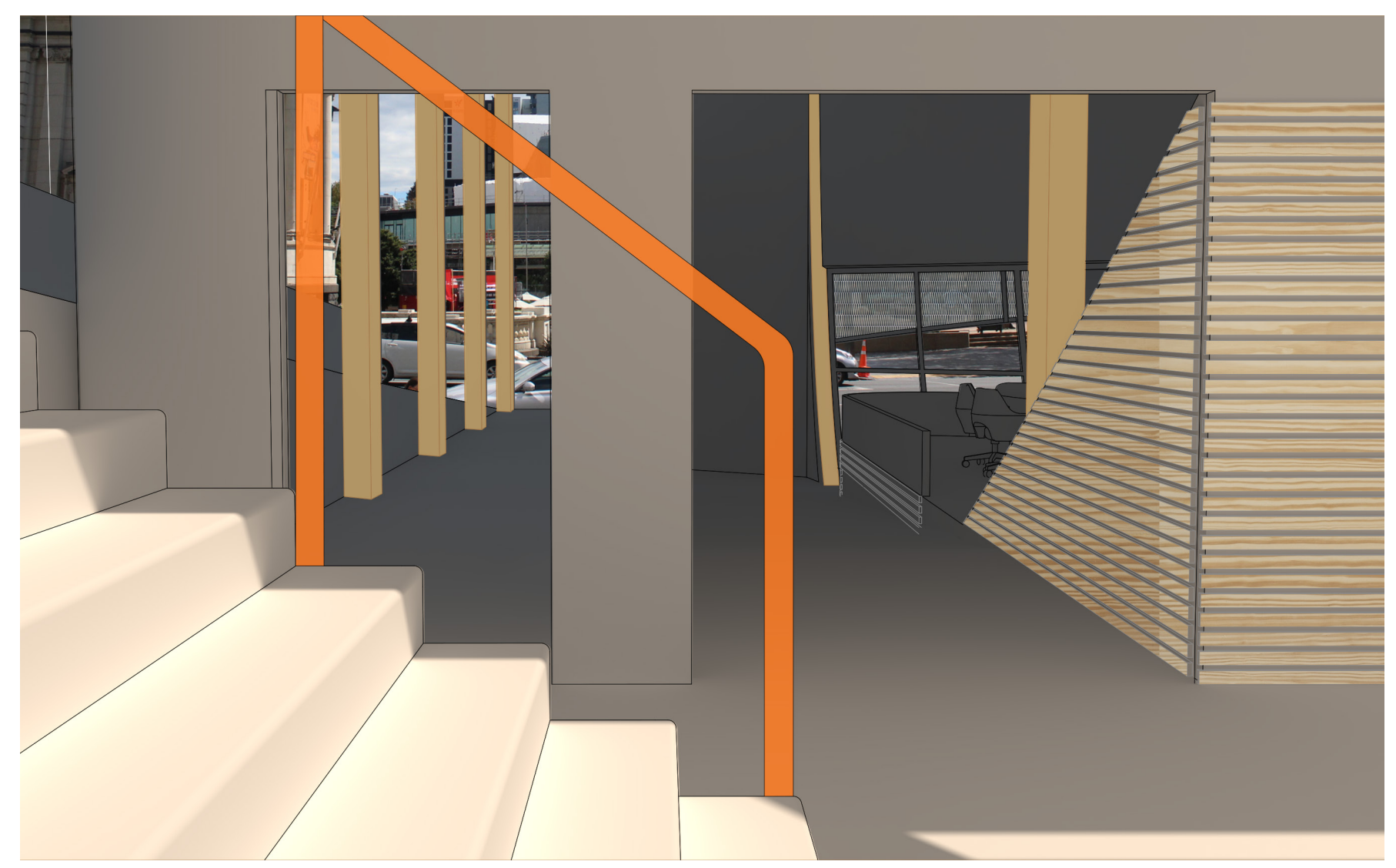

Fig. 189. Interior of the ground floor, looking towards the main meeting room entrance and Queen Street 'back' entrance.
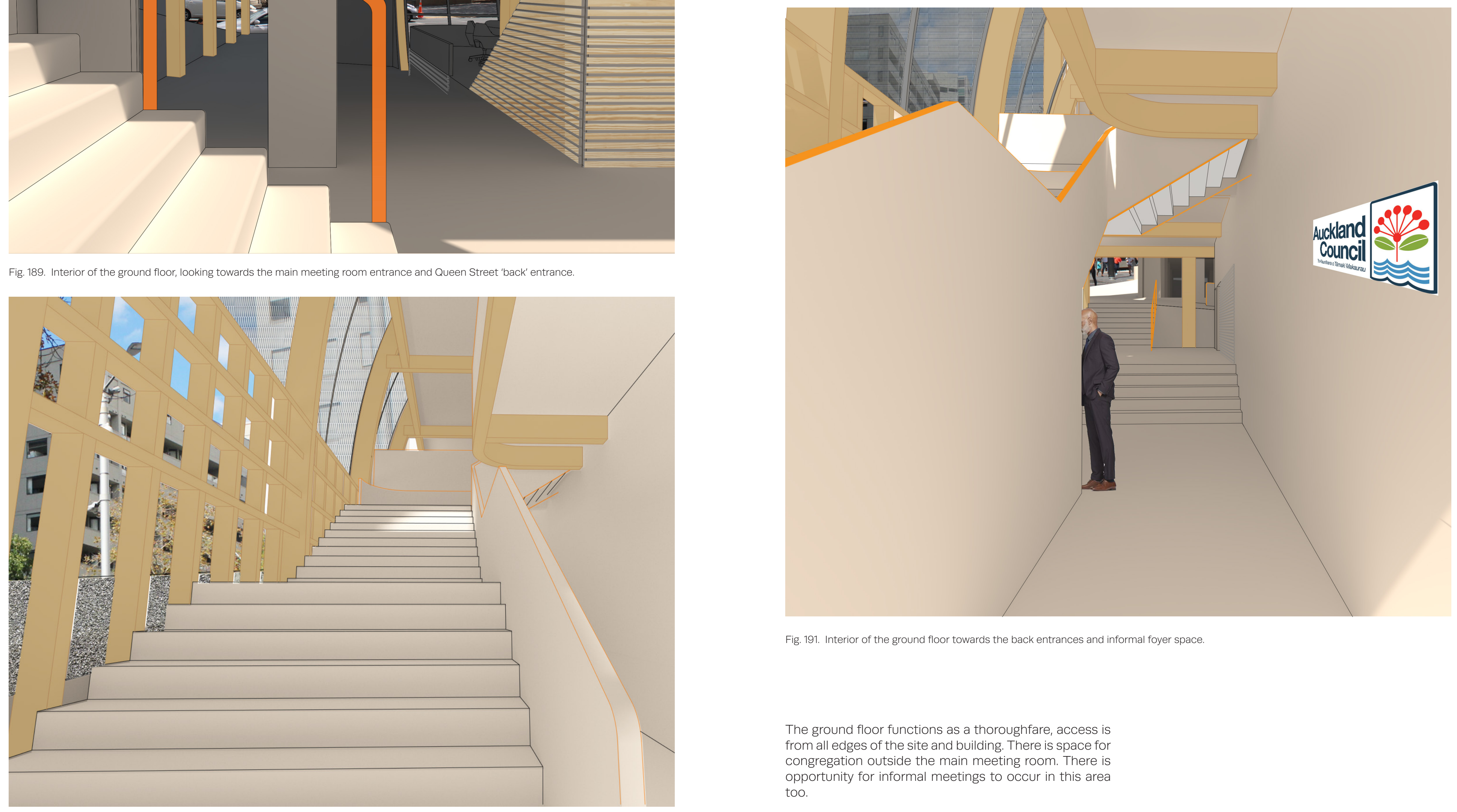

Fig. 191. Interior of the ground floor towards the back entrances and informal foyer space.

The ground floor functions as a thoroughfare, access is

from all edges of the site and building. There is space for

opportunity for informal meetings to occur in this area

too. 


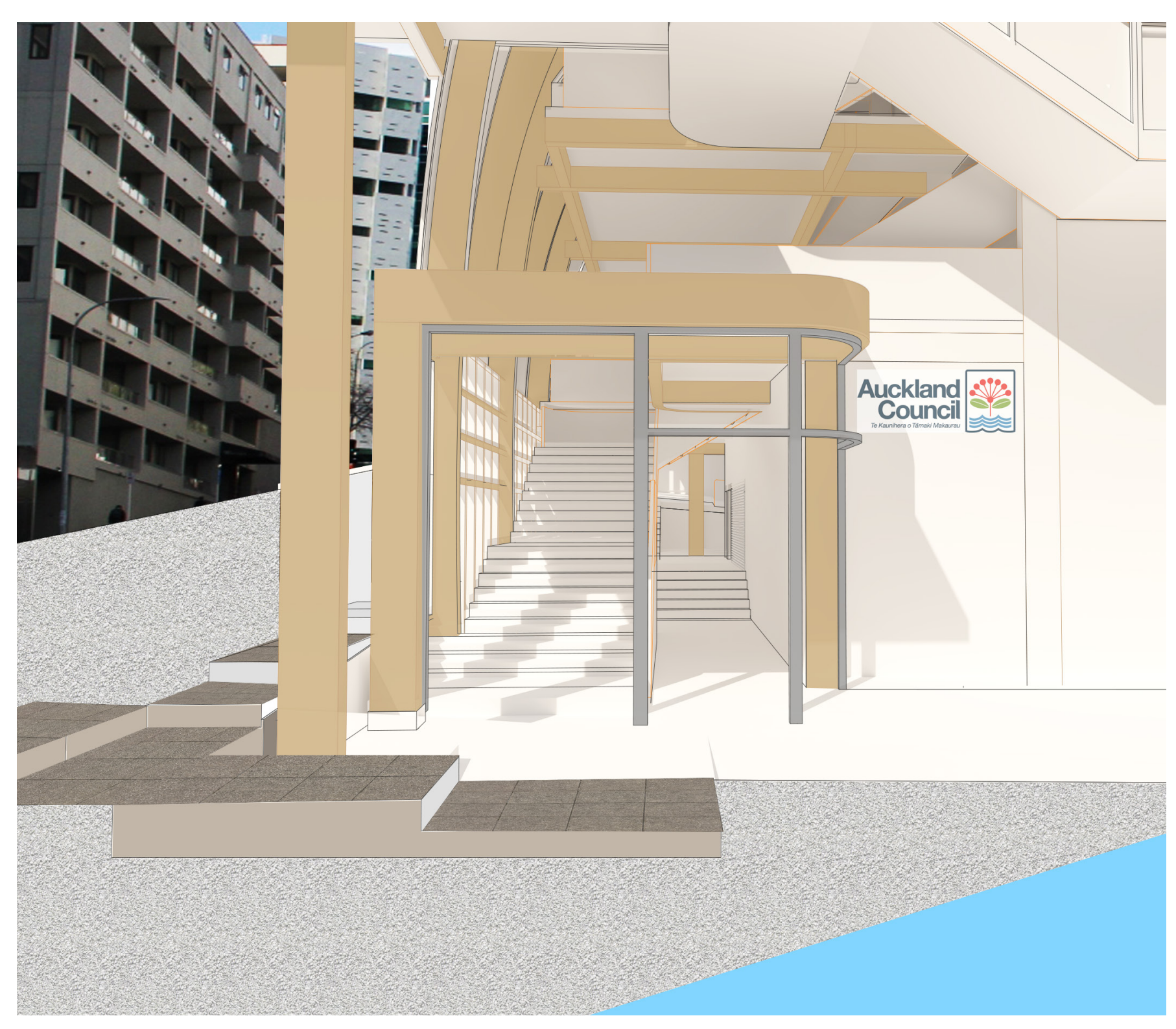

Fig. 192. Main entrance from Queen Street intersection. When approaching the entrance it is open and inviting and leads the users upstairs inside th building.

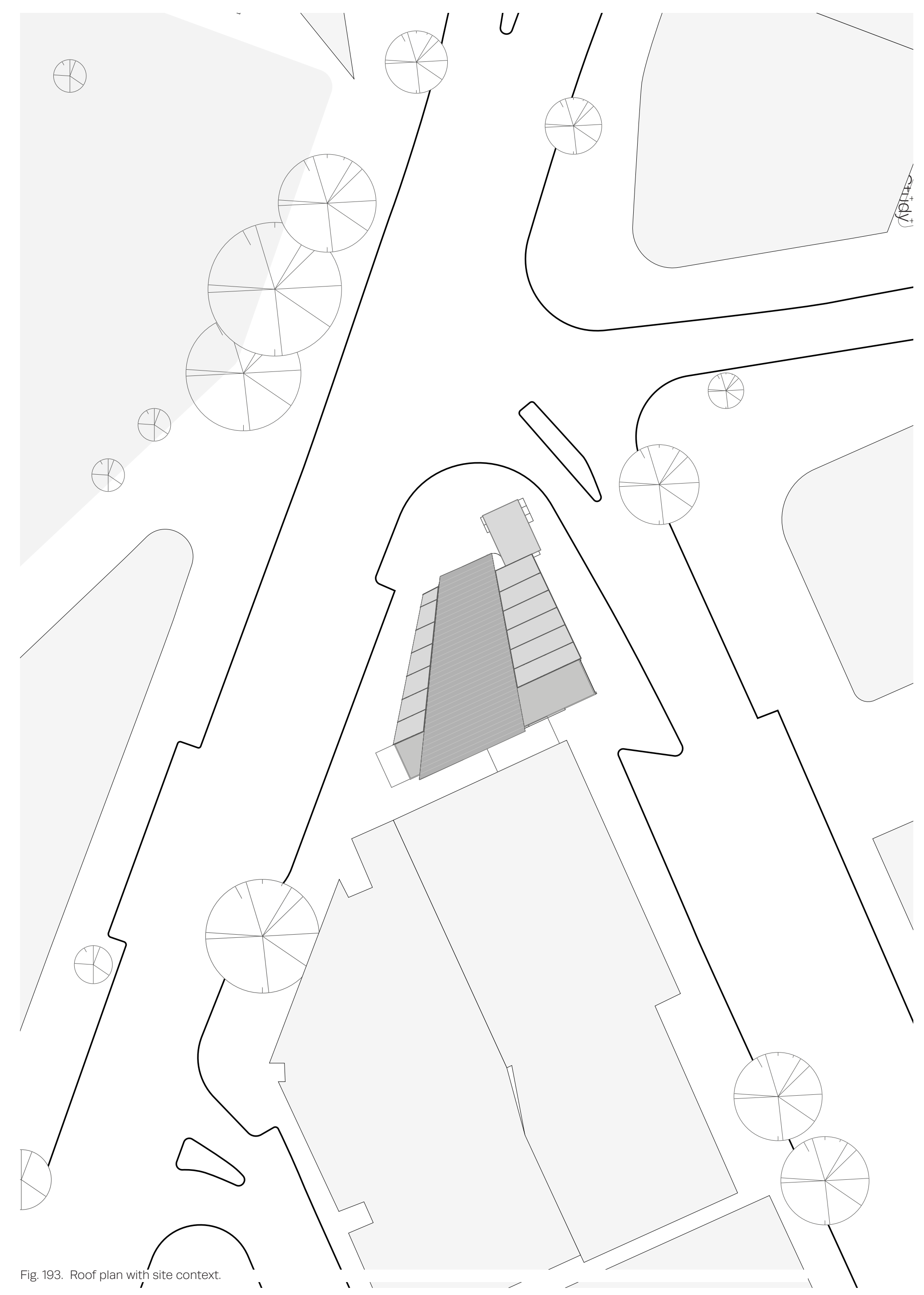



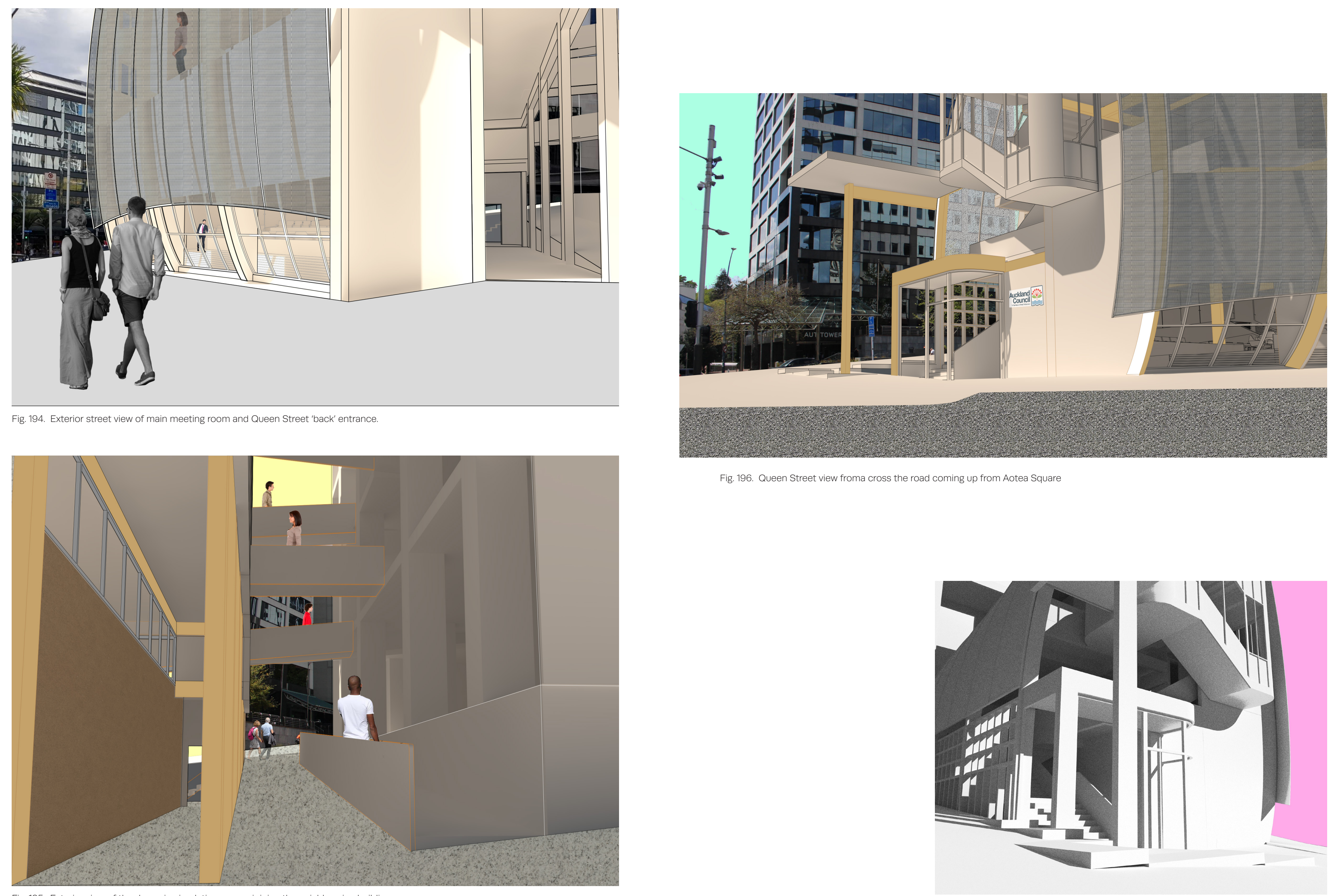

Fig. 196. Queen Street view froma cross the road coming up from Aotea Square

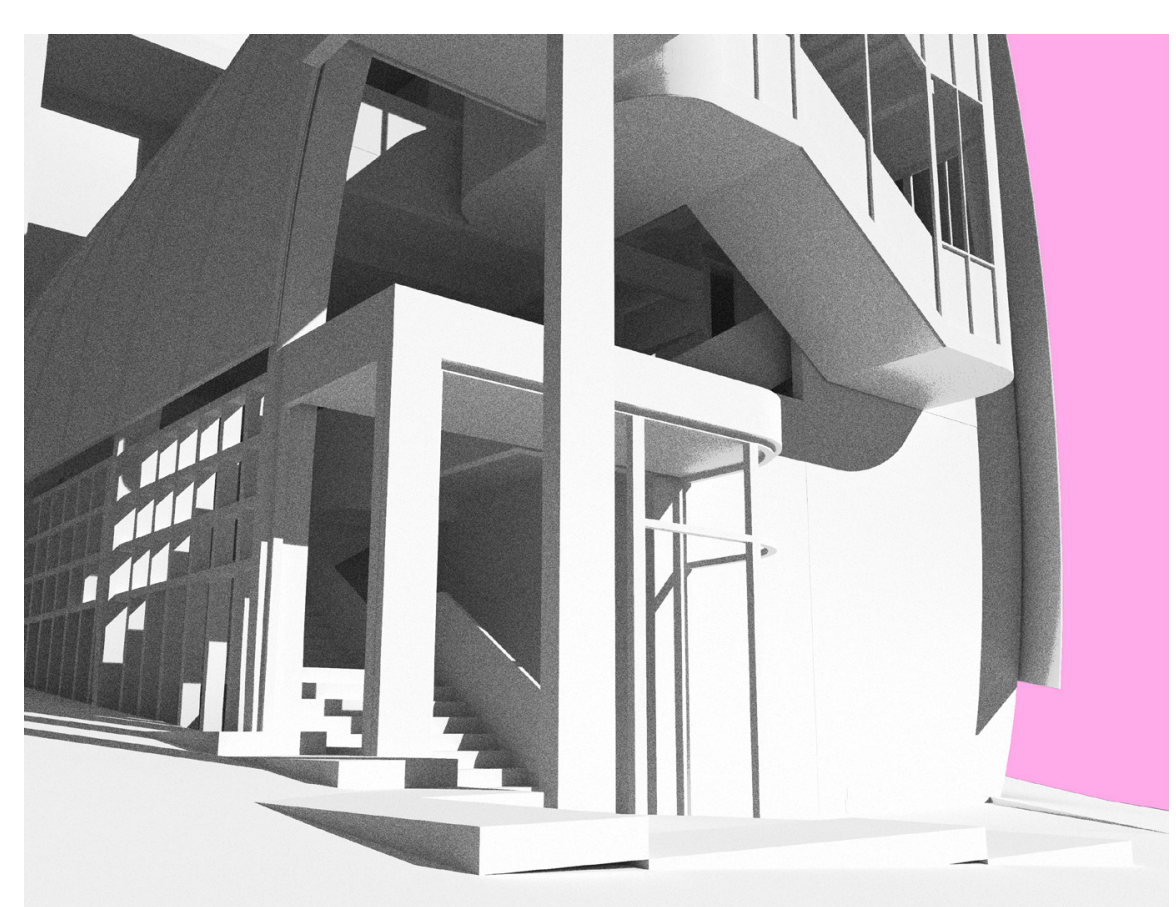




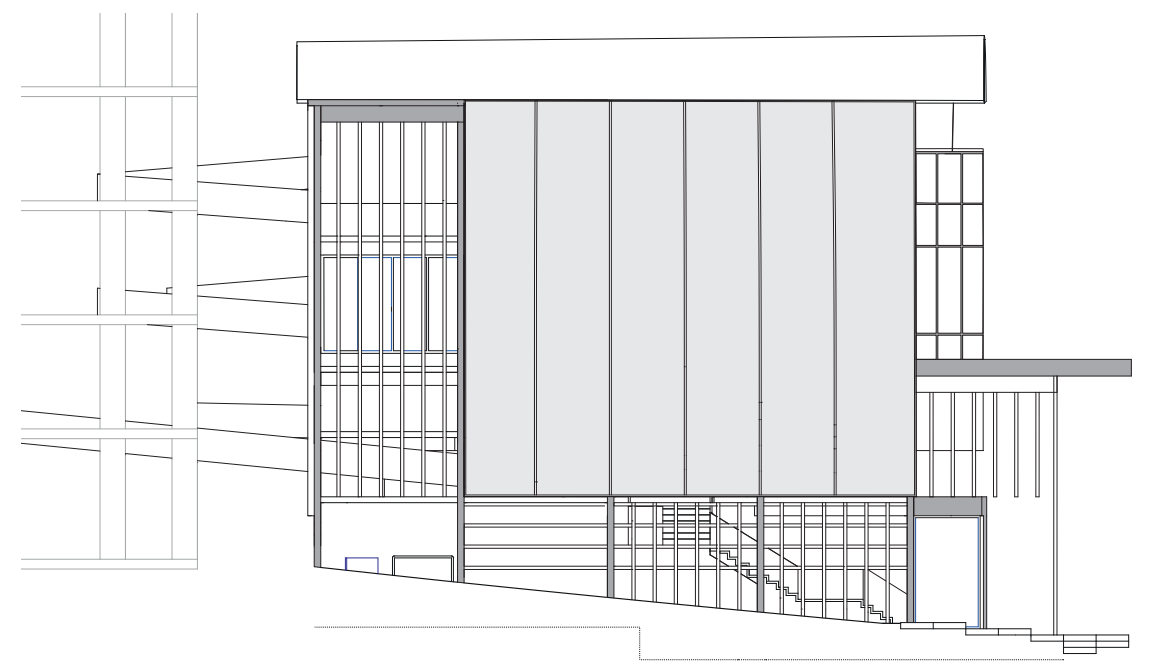

Fig. 198. Wakefield Street elevation.

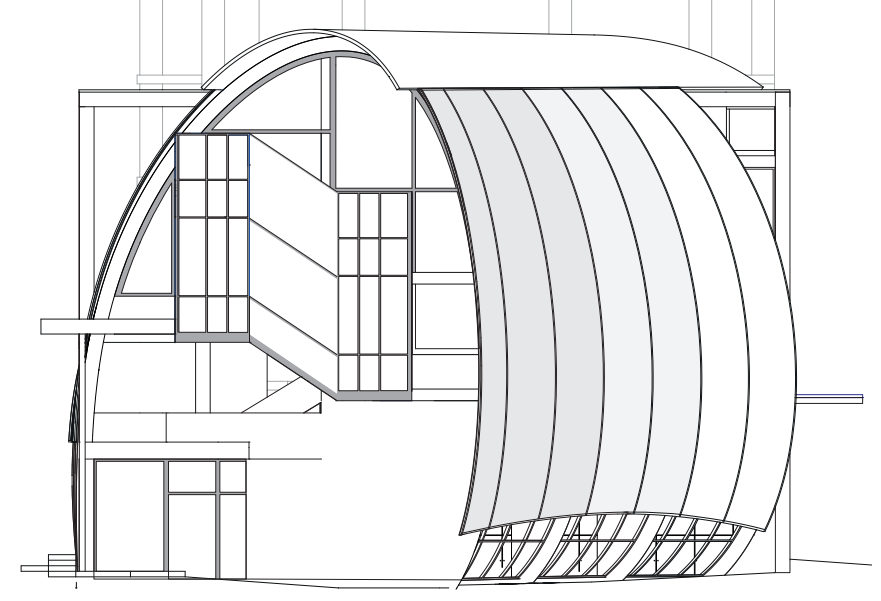

Fig. 199. Front elevation.

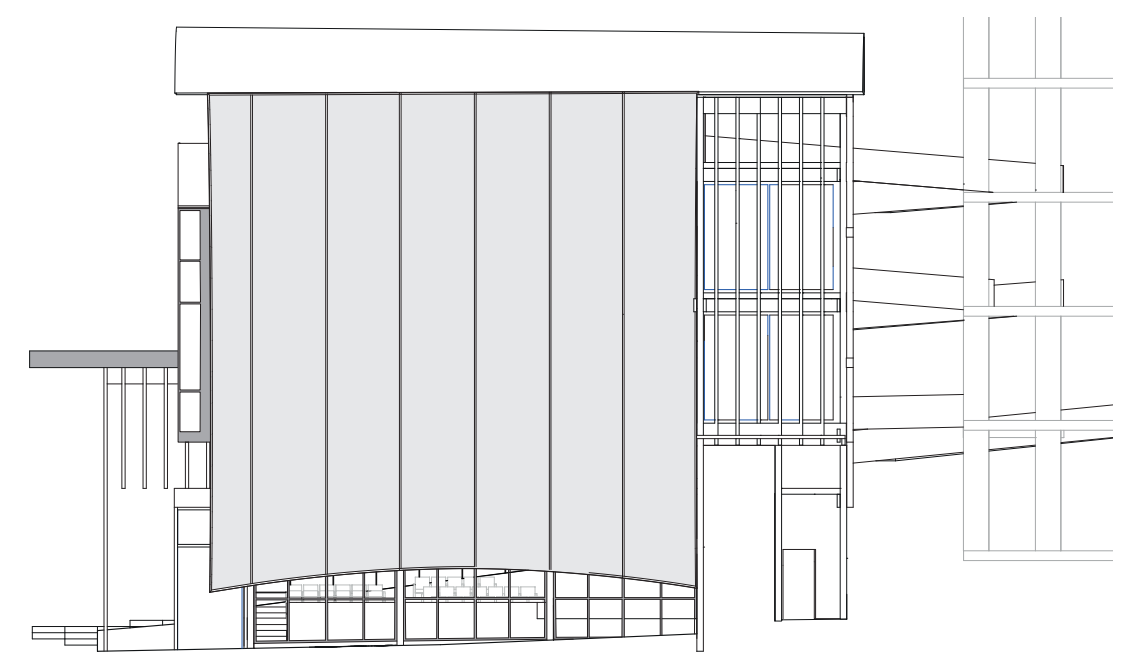

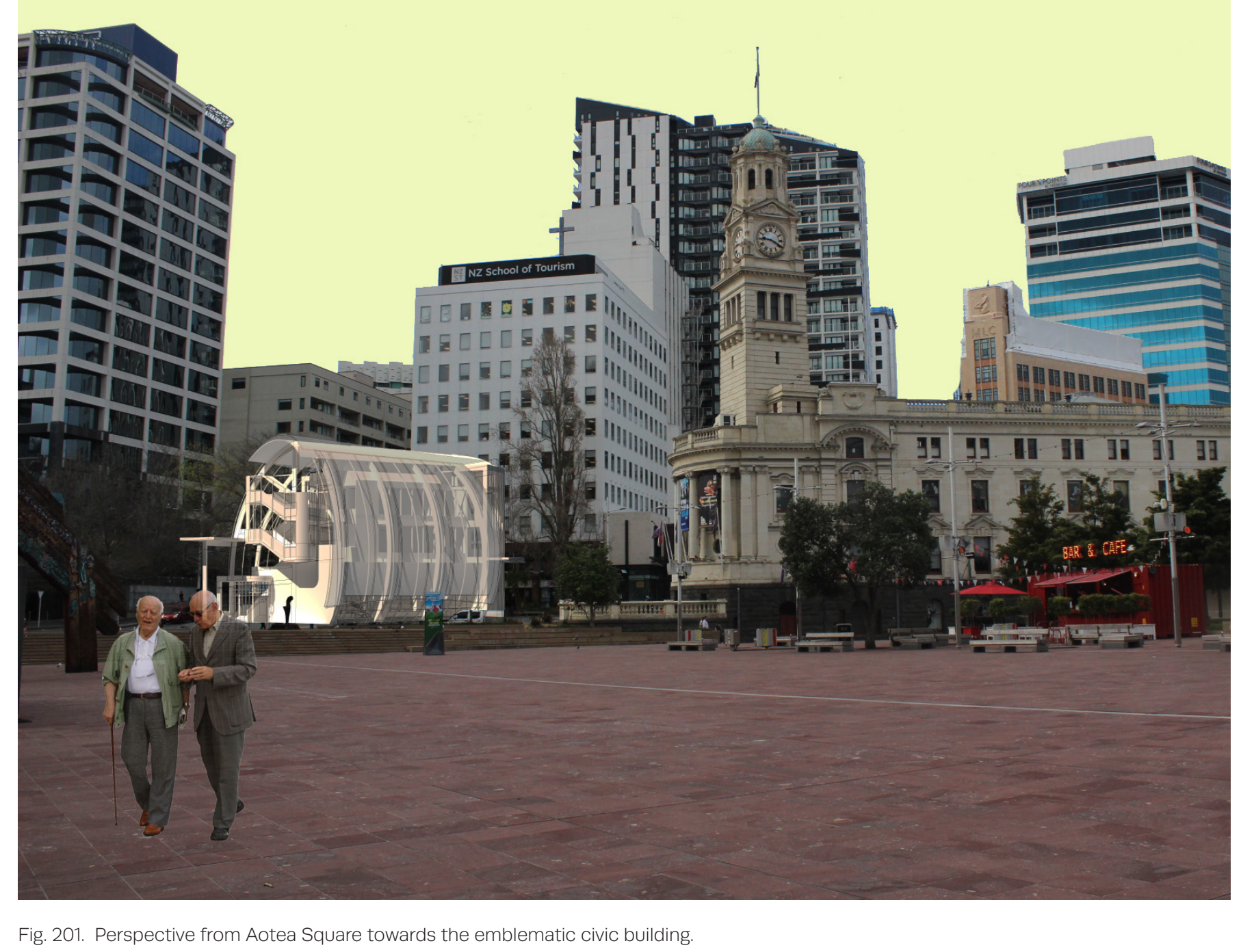

Fig. 201. Perspective from Aotea Square towards the emblematic civic building. 


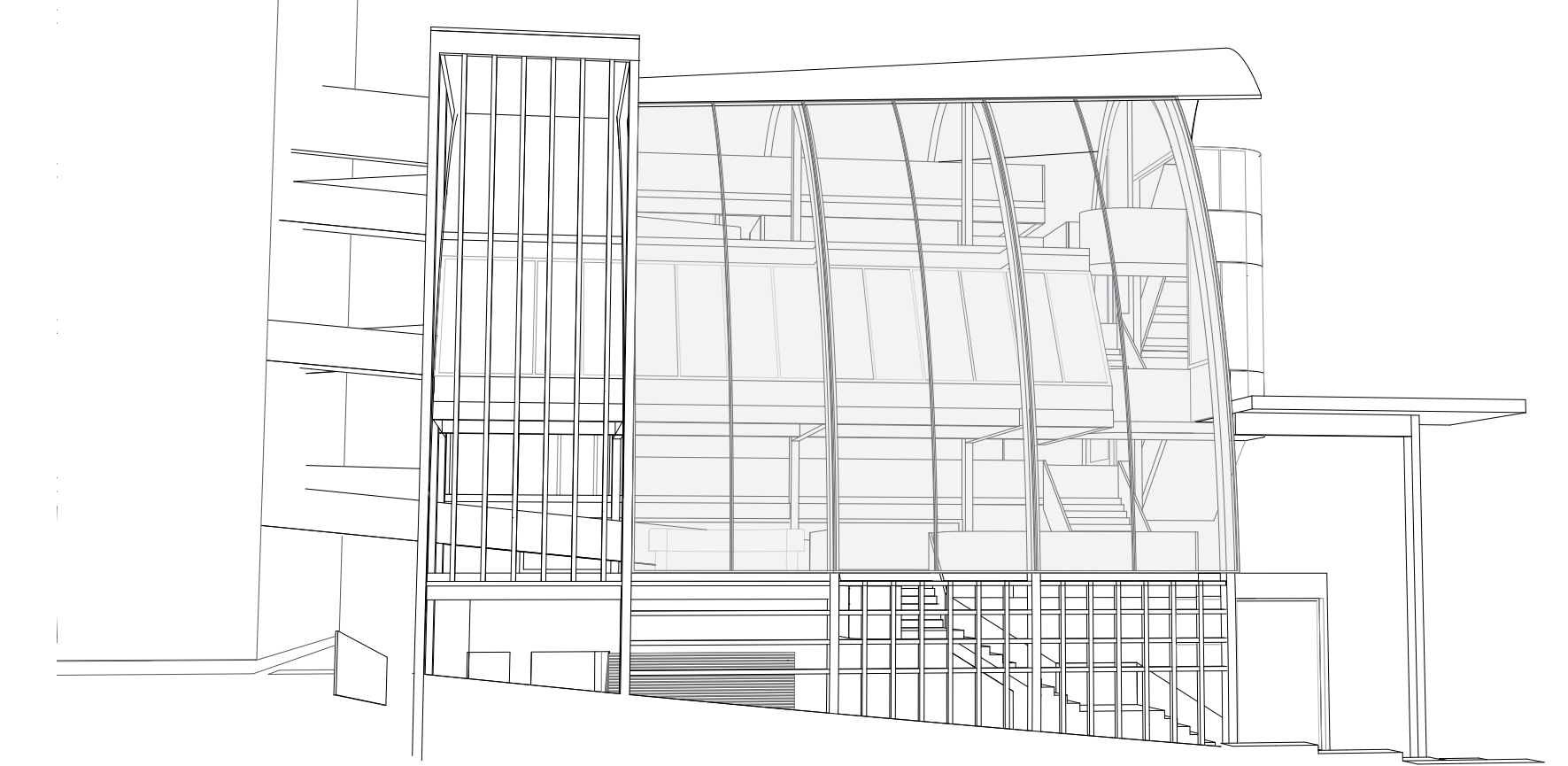

Fig. 202. Depiction of the building envelops metal mesh facade.
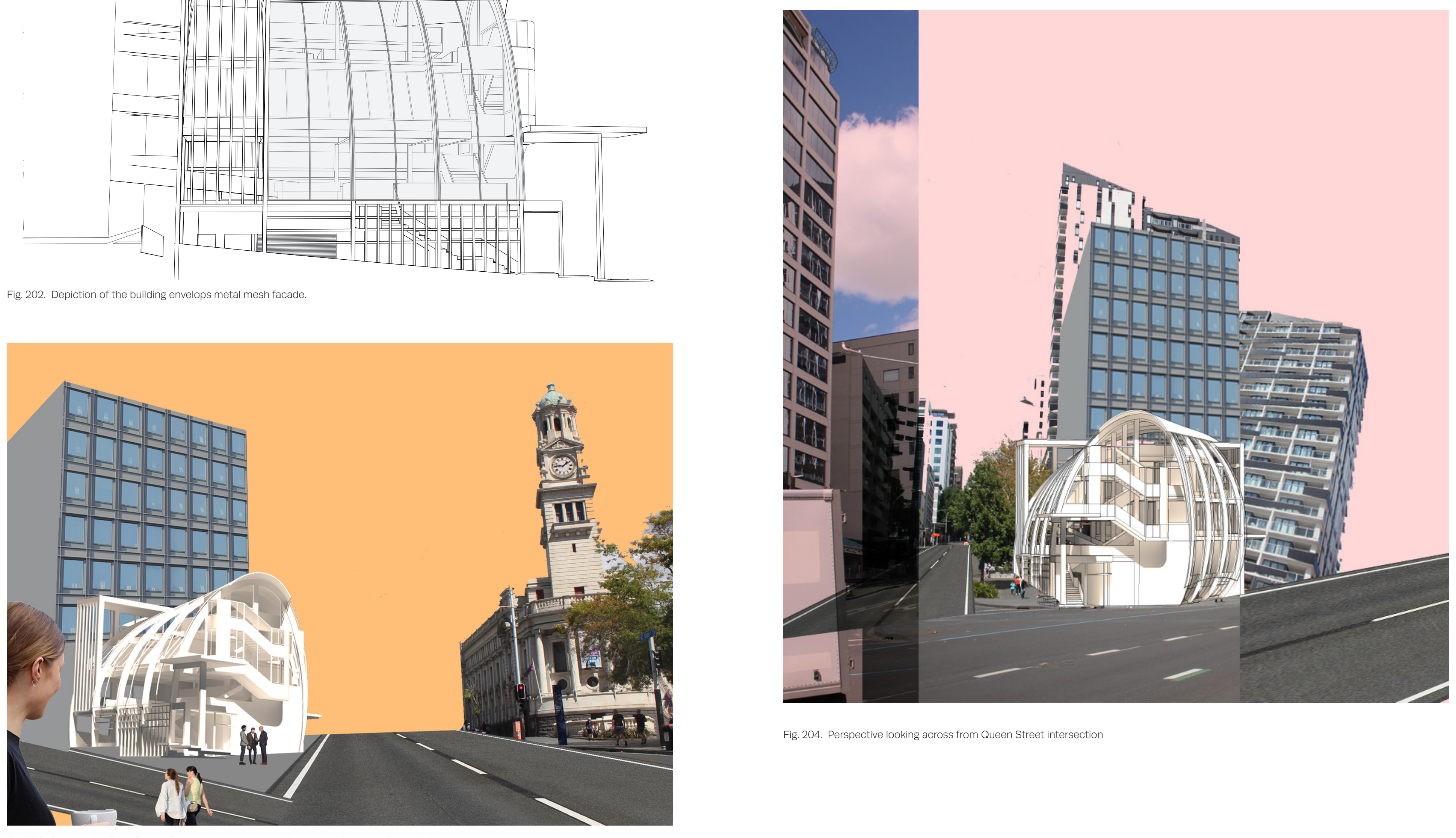

Fig. 203. Perspective from Queen Street intersection, next door to the Auckland Town Hall 

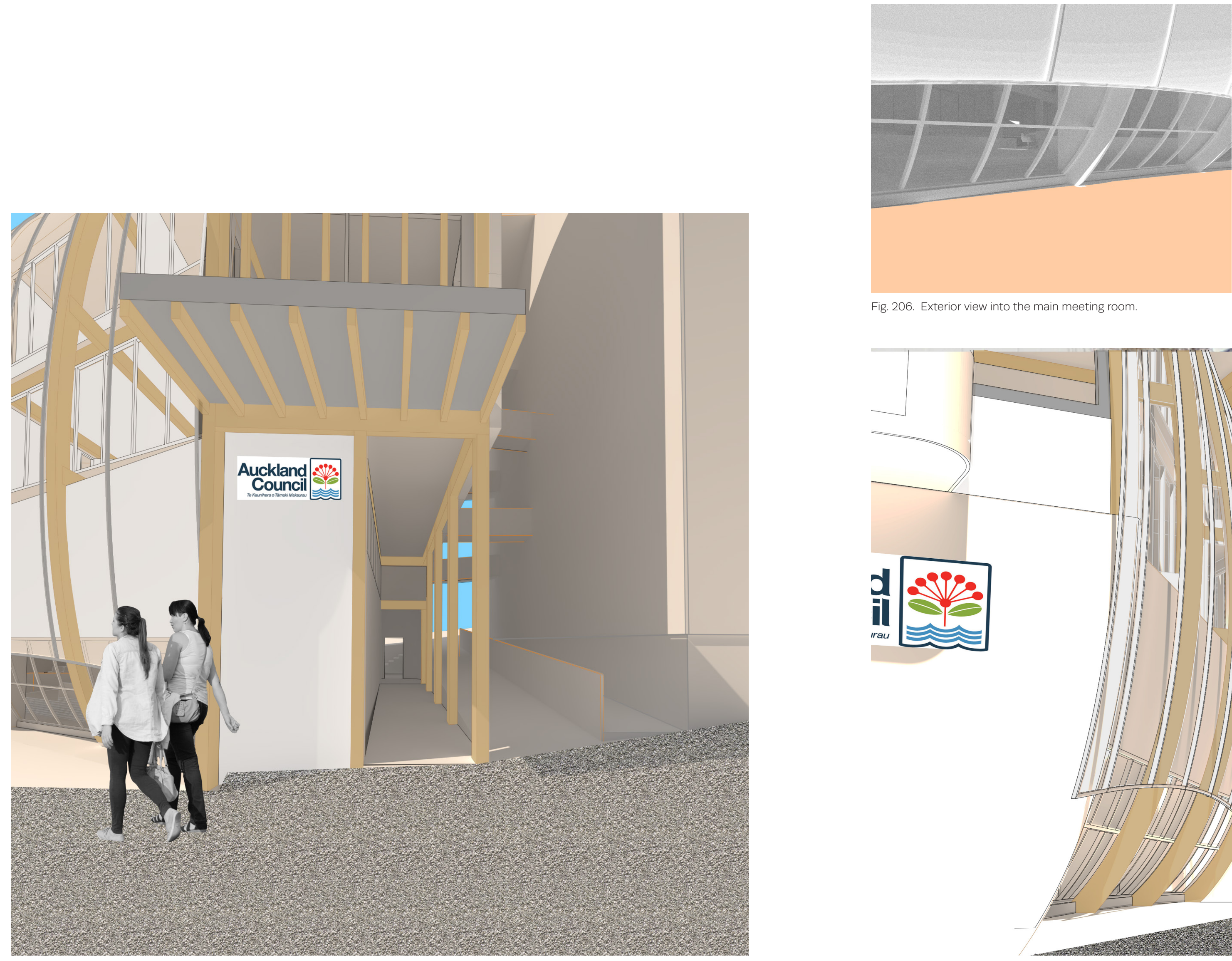

Fig. 206. Exterior view into the main meeting room.

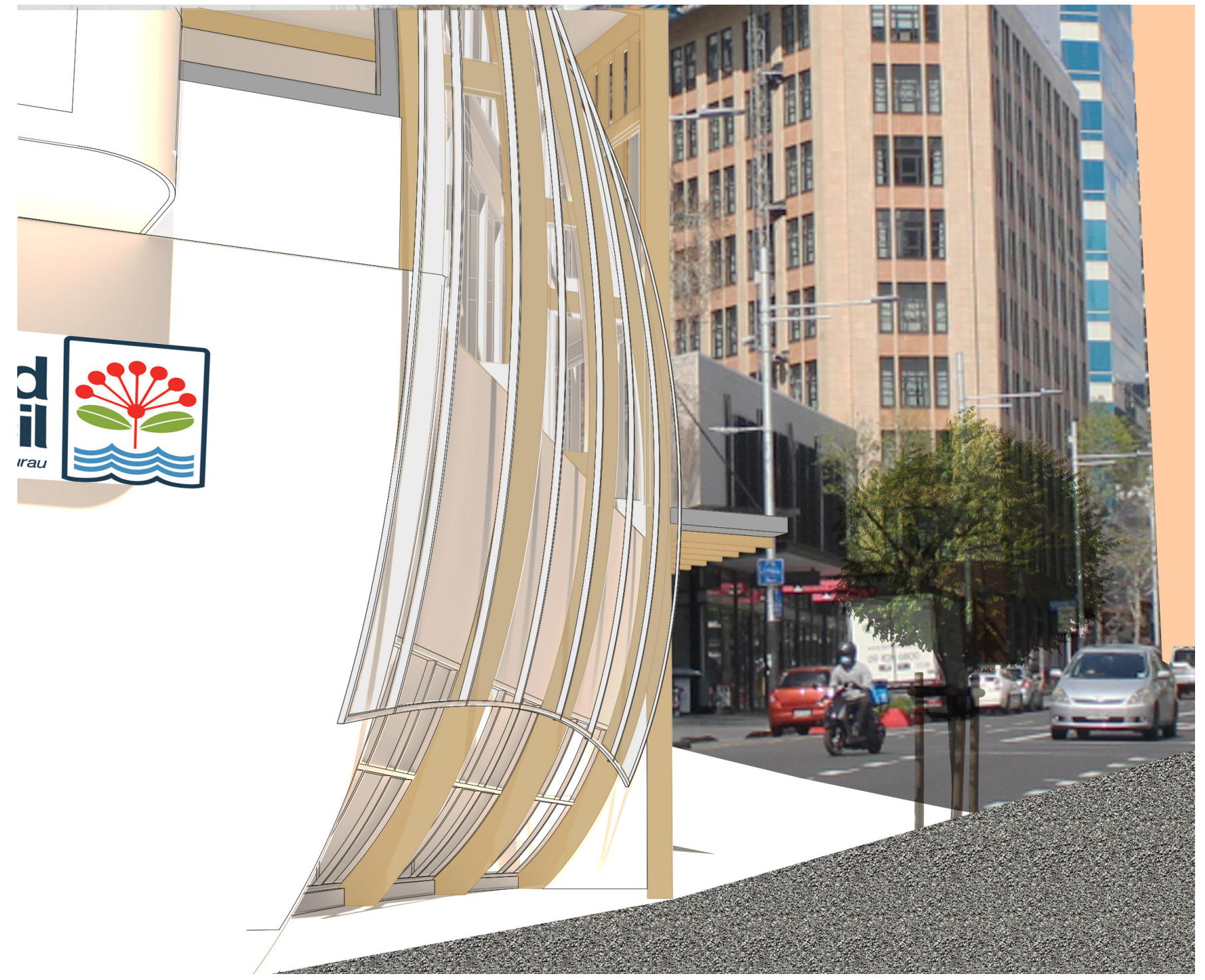




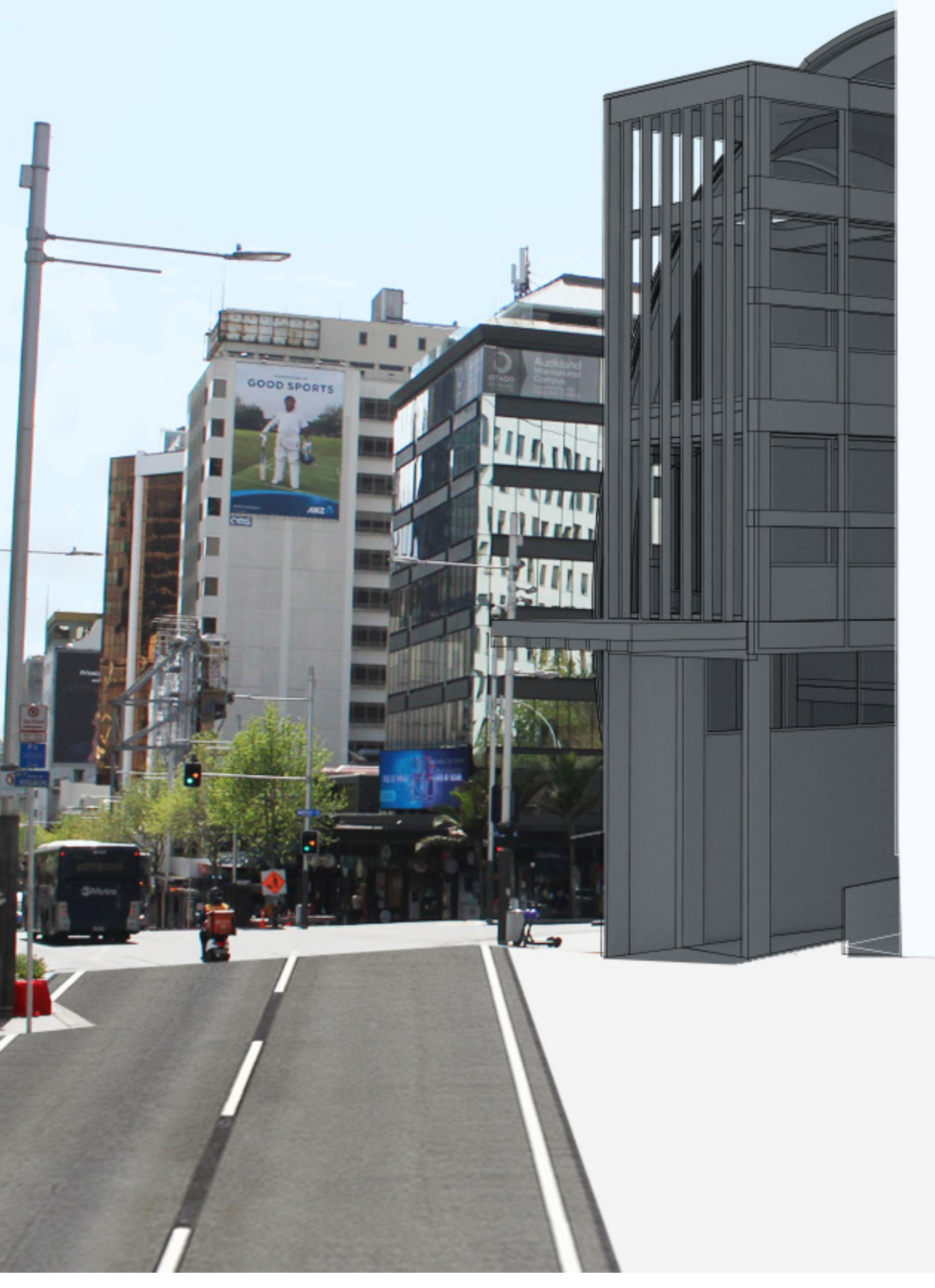

Fig. 208. Exterior view looking down Queen Street.

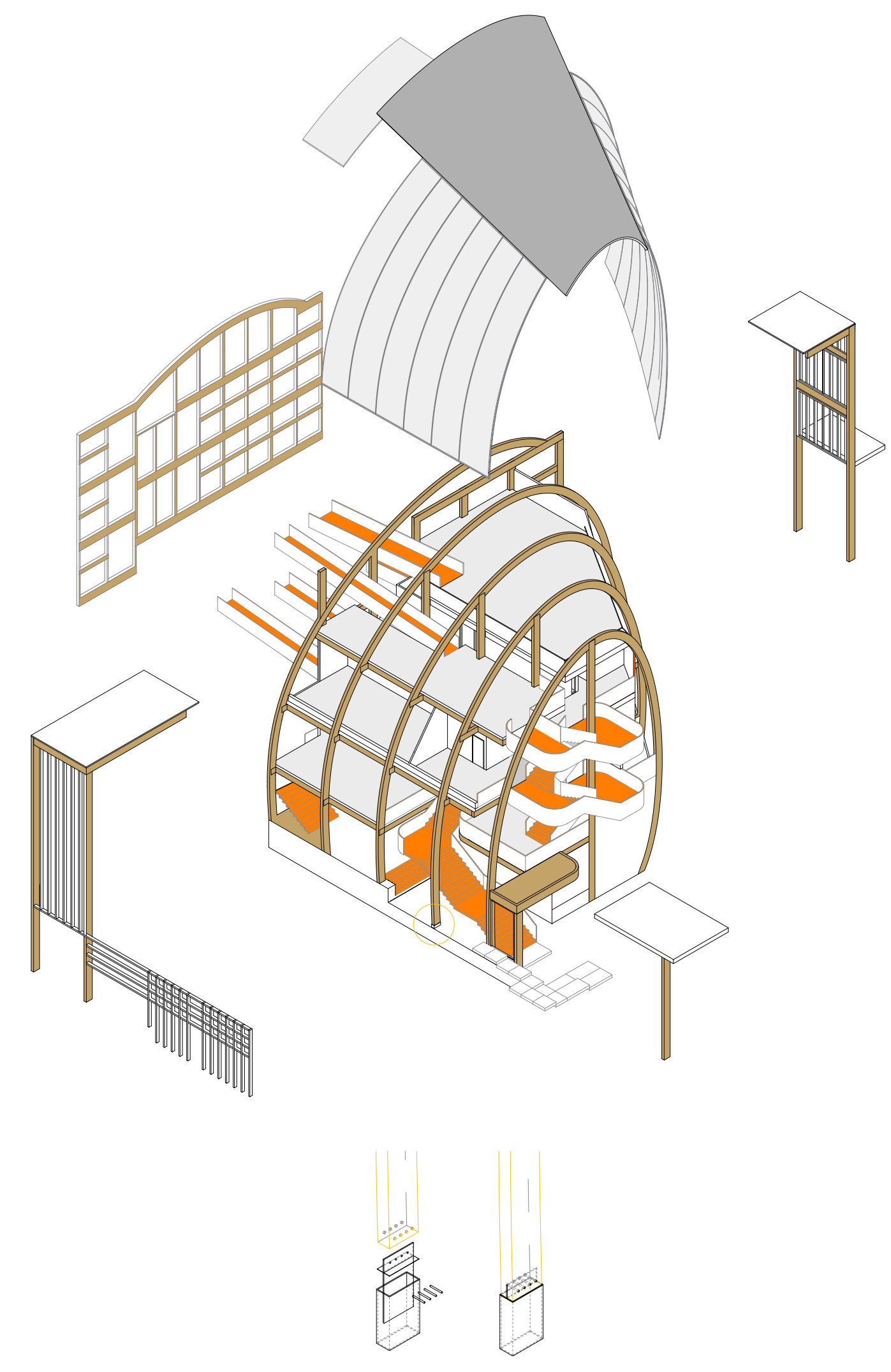

Fig. 209. Axonometric illustration of the make up of the building. The structure is glulam moment frames and of the interior. Additional timber structure compliments the curved form, which indicates points of access Smaller timber elements along the ground plane. The 'back' of the building is clad with timber, a composition which staggers with the floor levels and/or where openings are required. 


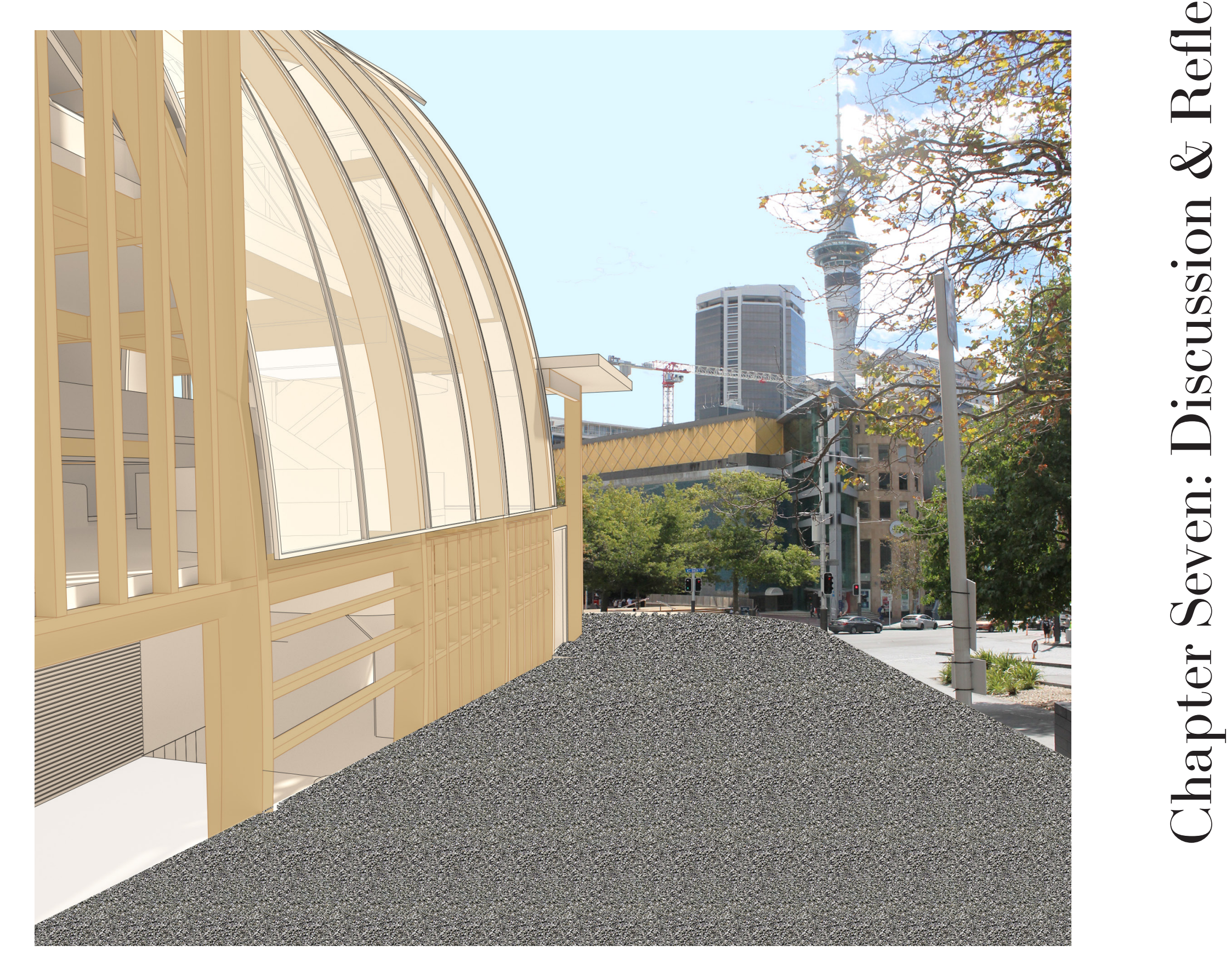




\section{Introduction}

Evaluation

The essence of this research has explored how the physical presence of local government strengthened the experience of the city.

This chapter will evaluate the design case study against the set of criteria, principles and objectives, which were established and developed through the background research. Chapter four highlighted the design principles, this evolved through an understanding of Dovey's work on civic realism. These principles are understood as the overarching requirement for civic architecture to mimic everyday political practices. The practices of local government and how the complex relationship between the collective and authority are negotiated. It was then from these principles where a set of criteria were formed, what the principles could be tested against.

\section{principle \\ COMPLEXITY \\ to inegrate a diversity \\ BALANCE \\ haramony where \\ spaces are neutral \\ SHIFT \\ dynamic \\ EXPERIENCE \\ commemorate \\ everday activity \\ PATHWAY}

fields of encounters

\begin{tabular}{|c|c|}
\hline criteria & strategies \\
\hline $\begin{array}{l}\text { ACCESS } \\
\text { Treatment of threshold } \\
\text { with the street and users }\end{array}$ & $\begin{array}{c}\text { Various public and private access } \\
\text { points }\end{array}$ \\
\hline & Transparency $\bullet \bullet$ \\
\hline $\begin{array}{l}\text { FUNCTIONALITY } \\
\text { All users to be given due } \\
\text { consideration }\end{array}$ & $\begin{array}{l}\text { Physical connection to the ground } \\
\text { plane }\end{array}$ \\
\hline & Pedestrian/circulation routes \\
\hline $\begin{array}{l}\text { HIERARCHY } \\
\text { Landmark status }\end{array}$ & $\begin{array}{l}\text { Adaptable and multi-functional } \\
\text { spaces }\end{array}$ \\
\hline Spatial hierarchy & $\begin{array}{c}\text { Reorient Traditional Town Hall } \\
\text { Façade }\end{array}$ \\
\hline $\begin{array}{l}\text { SCALE } \\
\text { commensurate with }\end{array}$ & $\begin{array}{c}\text { Main meeting room spatial } \\
\text { arrangement }\end{array}$ \\
\hline muman stature & Choice of site $\bullet$ \\
\hline & Reference line $\bullet \bullet$ \\
\hline $\begin{array}{l}\text { COMPOSITION } \\
\text { A sense of balance }\end{array}$ & $\begin{array}{l}\text { Architectural elements function in } \\
\text { unison. }\end{array}$ \\
\hline
\end{tabular}

Table. 4. Design principle, criteria and strategy table. Colour coded links across criteria and strategies.

The table (4.) has been established throughout this thesis during the background enquiries. The principles were informed by Peter Rowe's, identification of a desired balancing act for civic architecture to be successfully achieved. Strategies were then recognised. The following sections outlines strengths and weakness of how each strategy has been executed in the design case study. 


\section{Various public \& private access points}

Having multiple points of access was a major driver of The site is at the edge of a prominent intersection for this design. The various entrances achieve the positive both cars and pedestrians. Therefore to incorporate outcome of activating each building edge. The choice of the pedestrian user it was an obvious design aspect. the site, with each edge open to busy pedestrians allowed The main staircase at the north facade emphasis the this to be the outcome. The main entrance, facing Queen circulation within the building. This element juts out Street intersection has heavy foot traffic and opens the from the building envelop, bringing further attention building down Queen Street. A direct link is designed to the staircase and the vertical movement associated on the south edge, joining the repurposed neighboring with it. Circulation ramps which link to the neighboring building. There are additional entrances with lessor repurposed administration building are visible through importance; one is on Queen Street, parallel to the Town the narrow gap between the two buildings. Movement Hall. This entrance can be considered the main council across these ramps helps to activate the space above meeting room entrance, the corridor runs parallel to the ground level, achieving the objective of emphasising the south edge of the site and leads to the entrance of the spectacle of everyday rituals/pathways. main meeting room.

Circulation has been prioritized over other functional These access points are all located on the ground floor, spaces such as the smaller meeting rooms in the upper one main staircase creates vertical access. For accessible levels. The external ramps lead to the centre of the vertical circulation the repurposed neighboring building's building and the main staircase occupies the front edge. ground floor is optimised. While there are various This strategy caused the meeting rooms to occupy the entrances for this design, they all activate difference perimeter of the floor plates, where these rooms are spaces and accommodate for the variety of users. There pressed against the curved building envelop. This was a is no divide or allocation of entrances, although the back design challenge and resulted in reducing the floor plates entrances can be considered for the staff, whereas main so that the internal walls become vertical. entrances are for public use. There are three different access points, all on the ground exterior canopy. This contrasts with the overall curved plane. This strengthens the relationship between the shape of the building envelop but compliments the linear street and the building. Through an understanding of how extrusions at the back. This canopy is elevated and aligns important it is for public buildings to have an engaging with the building's second level it also aligns with the presence in the city, these entrances were developed. The beginning of the stairwell.
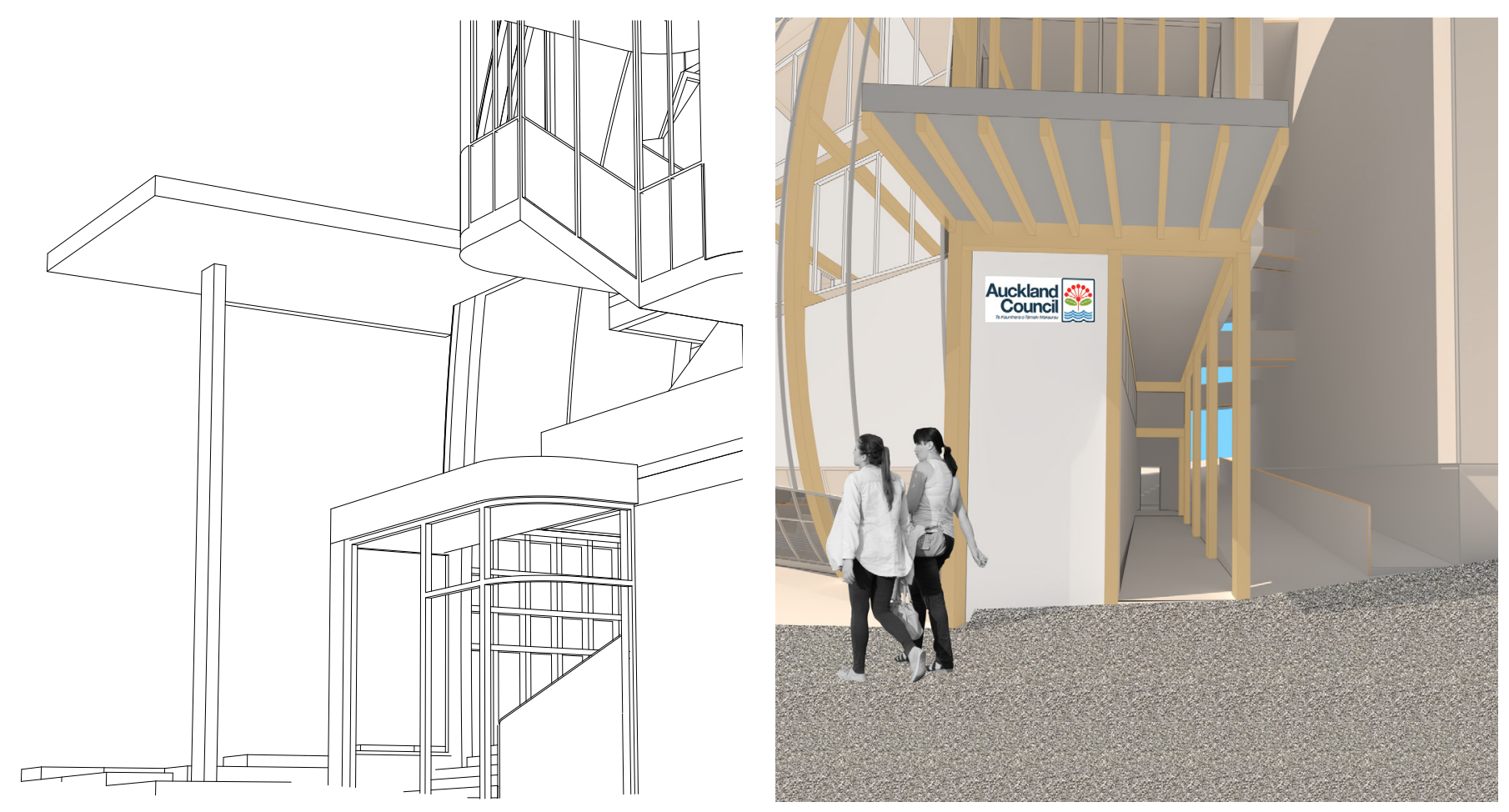

Fig. 211.
entrance.

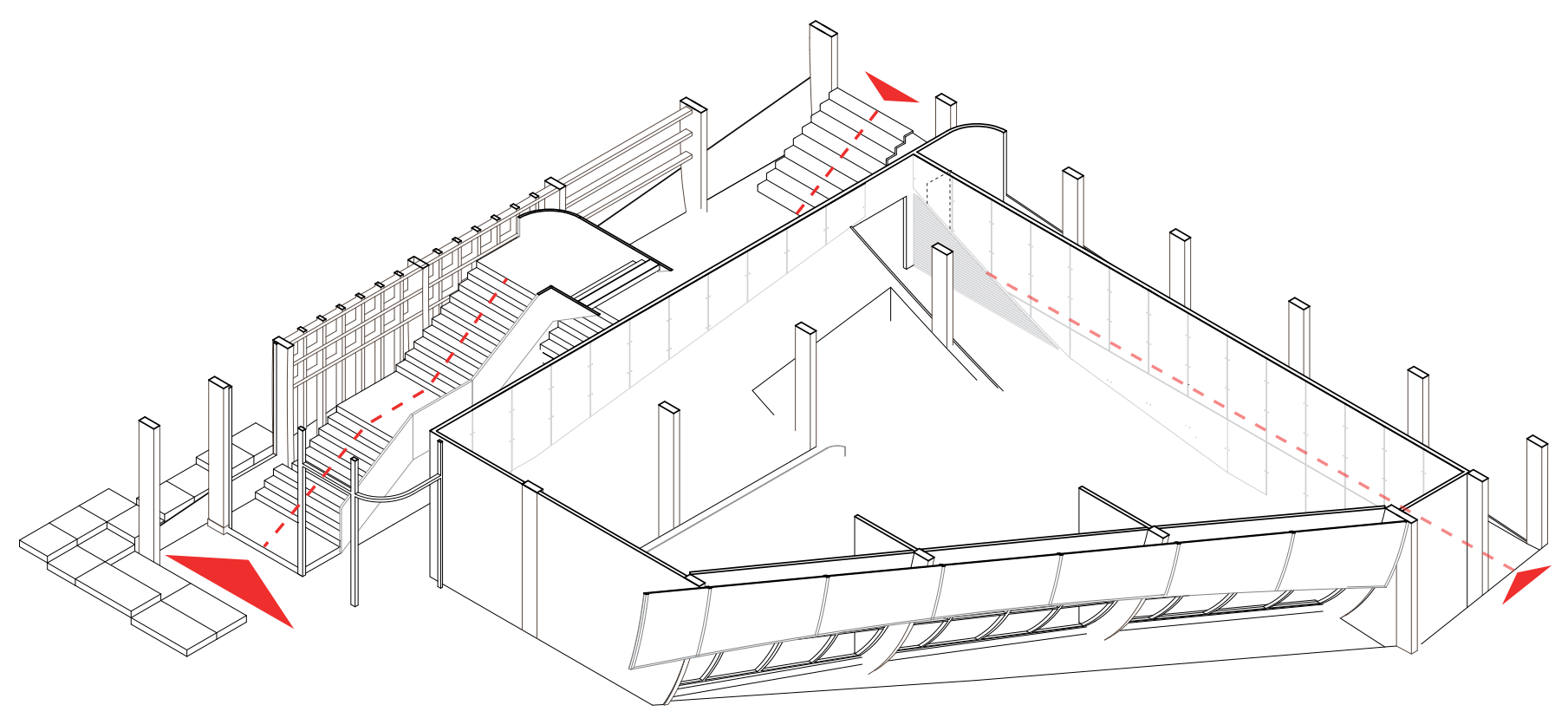

Fig. 213. Three different entrance points on the ground floor. Hierarchy reinstated through the size and location of the entrance. 


\section{COMPOSITION}

\section{Architectural elements function in unison}

The design adopts two contrasting architectural languages.

The building envelop; wraps over the interior from west to east. The concaved exterior envelop is interrupted at the back with vertical linear forms. The linear forms are complimented at the main north facing entrance with a similarly shaped canopy. The language used in the upper floors further compliments the linear characteristics of the exposed timber structure. However in the main meeting room, the curves are expressed in both the interior and exterior. This room has the most significance. The public can experience it from the outside because of its location at the ground floor and its treatment of the buildings skin.

The contrasting curved and linear architectural language has been developed in the main meeting room and between the structure and the façade. In the smaller meeting rooms their architectural character is linear, best suited for its multi-function purpose.

\section{Reference line}

The design has a central reference point where the circulation is oriented around. There are eight floor each with a height of $2000 \mathrm{~mm}$ difference. The building can be considered as having two sides, divided and identified by circulation. The reference line can be seen clearly in section, and experienced horizontally. Placed asymmetrically this has resulted in a divide between larger and smaller spaces. This contributes to a complex balance in the design, rather than pure symmetry. A reflection of the traditional town hall highlighted a typical offset in plan of the main auditorium.

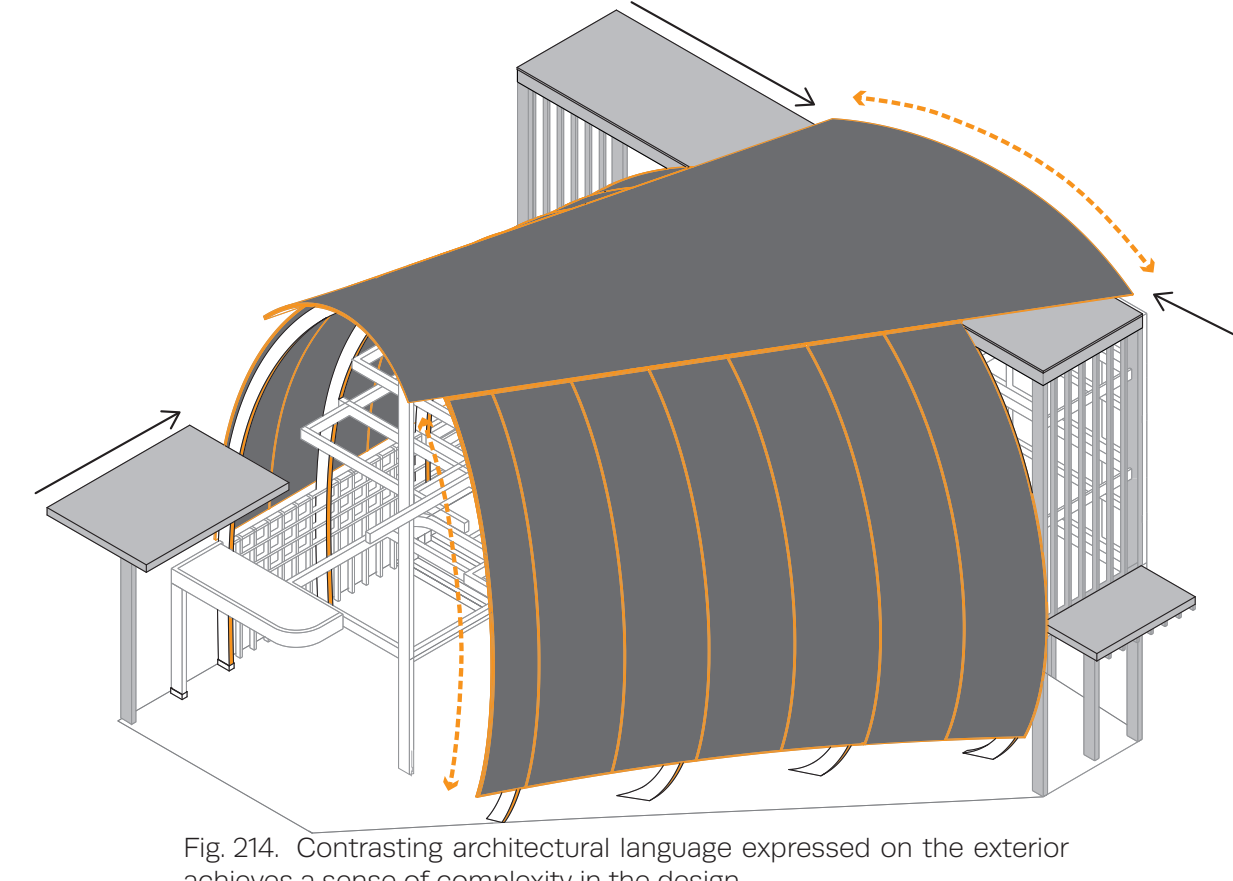

achieves a sense of complexity in the design.

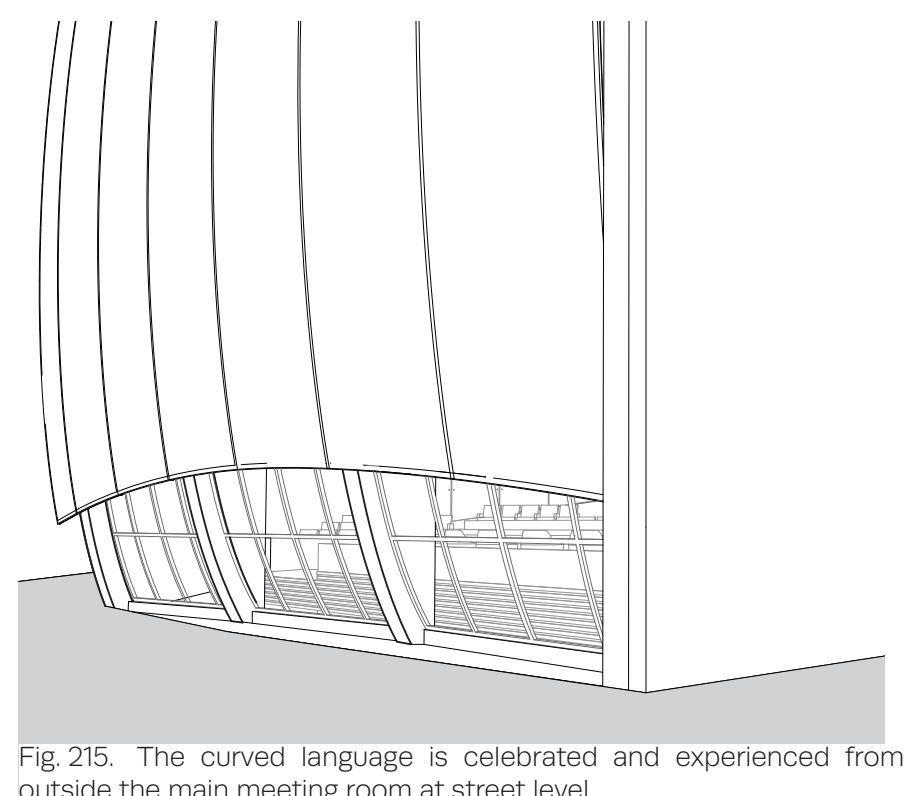

Fig. 215. The curved language is celebrated and experienced from

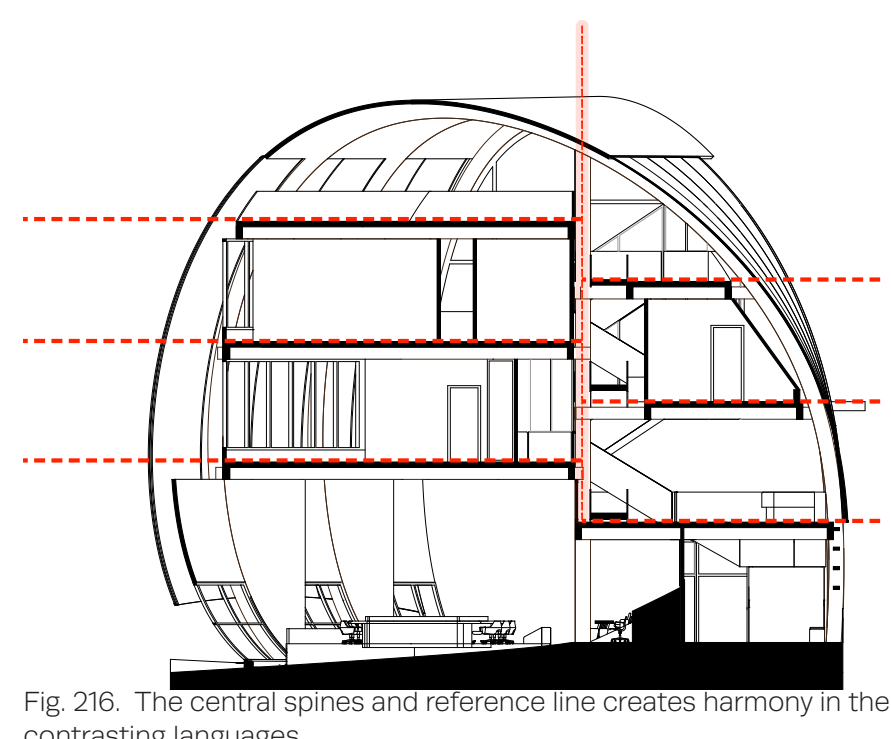




\section{Transparency}

The access at all three edges of the building invites and The selection of the site has allowed the overall size of the activates the building at ground level. These entrances design to be modest. As one of the smaller sites from the have not been over dimensioned with the consideration options the best suited one meant the design could take of the user's immediate experience of the building. advantage of the entire space. The sites location close to Having the ground plane stimulated and experienced, an adaptable office block has allowed for the design to allows humans to relate to the building.

\section{Overall Height}

an adaptable office block has allowed for the design to
have a symbolic presence in the city. The alternative site options did not have immediate neighboring buildings for the design to occupy. The design uses the neighboring The overall height of the design is $19 \mathrm{~m}$ to the roof building for circulation, if this were not an option the apex, four complete levels. Symbolically the height of a design may not so successfully achieve the sense of scale building has connotations with capital and wealth. ${ }^{2}$ It has which it does.

been one of the aims of this case study to intentionally

distance itself from the corporate functions of the Auckland City Council. Therefore the overall height achieves engagement with its users. The building can be experienced vertically against the surrounding office blocks of Auckland City. The companion of the neighboring office block enables vertical circulation and has permitted the emblematic component of the new council building. Allowing the building to be smaller and approachable by the public.

\section{Reference line}

The reference line can be experienced along the horizontal plane and understood in section. It acts as a circulation spine emphasised by the ramps which activate the central area. The reference line divides each floor space and staggers them. This results in appropriate dimensioning of spaces relating to human and the experience.

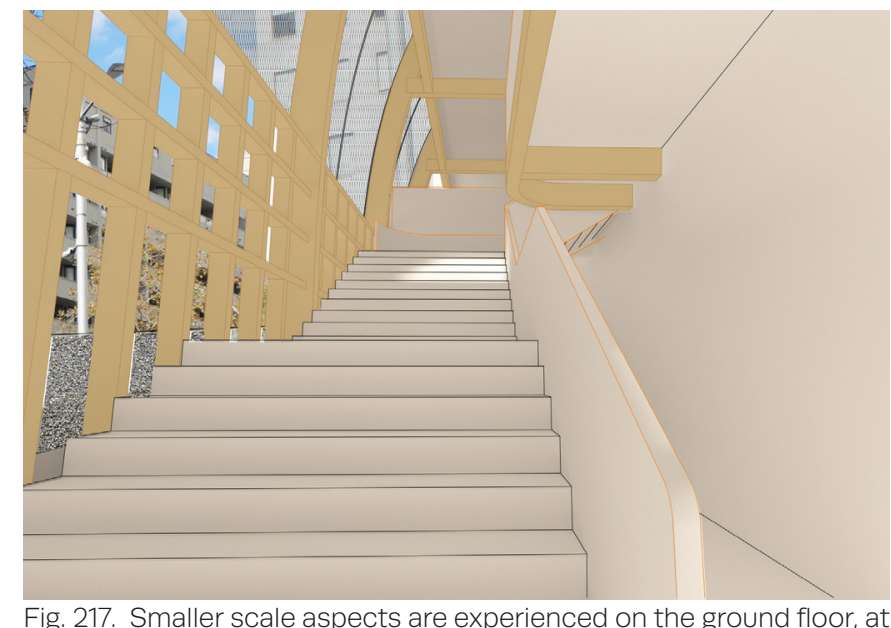

Fig. 217. Smaller scale aspects are experienced on the ground floor, at

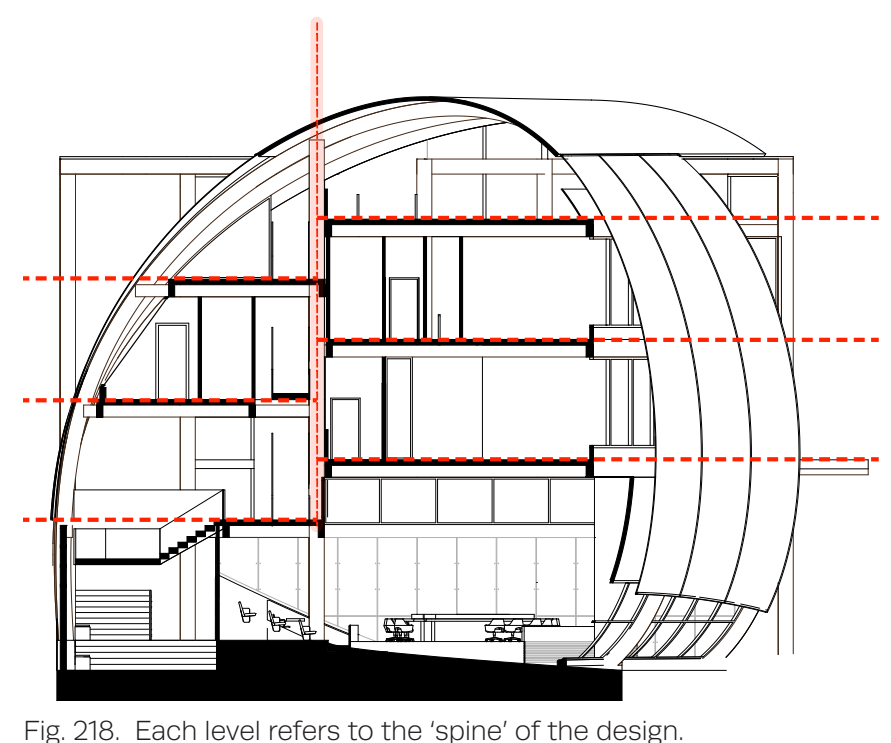

Fig. 218. Each level refers to the 'spine' of the desig

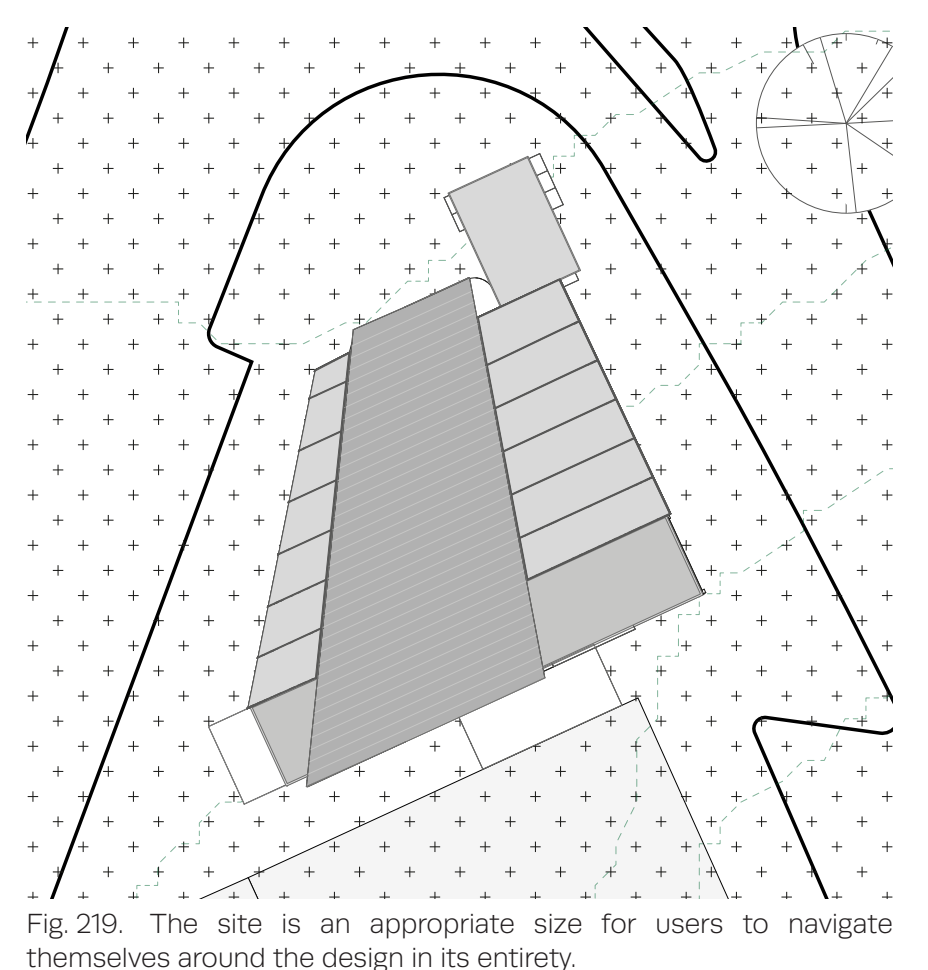




\section{Adaptable/multi-functional}

The rooms which are considered multi-functional are the smaller meeting rooms. Their purpose is to accommodate for the committees and smaller groups within the Auckland City Council. The way in which these spaces are made dynamic is through their rectangular shape. Allowing the adaptable use of each space.

A consequence of the spaces requirement to be adaptable is that the architectural language contrasts with that of the main meeting room and function space.

\section{Circulation}

The dynamic circulation throughout the building has activated spaces for users. Similar to access there are multiple circulation routes which can be used throughout the building. One reason for this was the need for accessibility to and from the neighboring building. The design case study employs the neighboring building for vertical circulation which as a result activates the space between the two buildings with a series of ramps.

\section{Reorient Traditional Town Hall Façade}

The design of the curved façade is a manipulation of the orientation of the current Auckland town hall. The form of the design case study reorients this wrapping gesutre so that the encompassing will become a shelter/roof with multiple visual and physical links between the inside and the outside. The wrapping over the interior spaces causes the front and the back to become open to the street, challenging a hierarchy of spaces. The solid material of the Auckland Town Hall symbolises and encloses the interior away from the street. The design case study takes the form and turns it vertically to expose the interior and reposition the council chamber room on the ground floor. In contrast the function and movement throughout each level of the design case study is visible from the outside, creating total transparency of the internal operations.

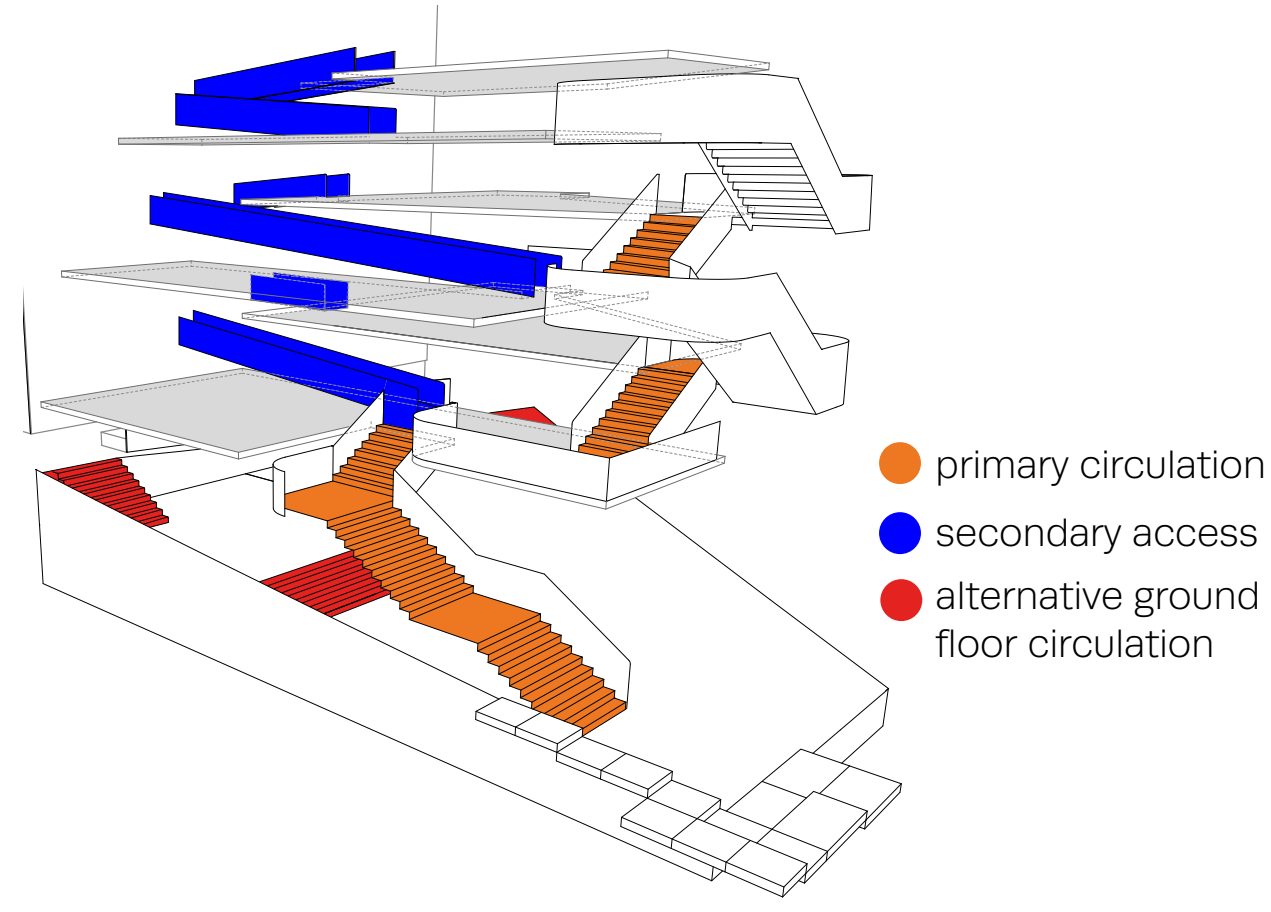

Fig. 220. multiple circulation routes and pathways are used in unison for the building to function harmonically.

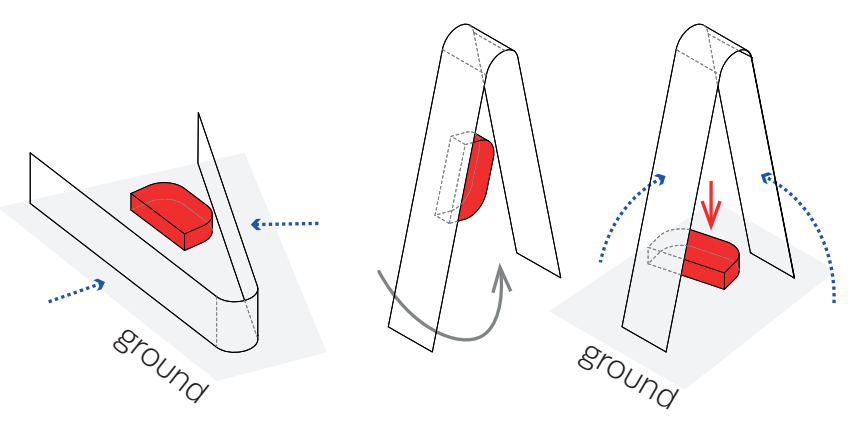




\section{HIERARCHY}

\section{Overall Spatial Hierarchy}

\section{Main meeting room spatial arrangement}

The vertical order of spaces does not reflect the importance The organisations of space in the main meeting room is of the spaces. Typically corporate office blocks will be deliberately offset. The space is designed for three main designed with the space of highest importance in the users, the councilors, the public audience and addressers upper floors. The analysis of the traditional town hall and the council administration staff. In the traditional identified the council chamber room to be buried within chamber room the council is located at the centre with the building. Its location is not spatially understood a clear divide between the administration and the public. from the street or often the ground floor. Although as an This design allocates each group to one corner of the intentional symbolic gesture, the main council meeting triangular shape. The result is deliberate destablising of room is at ground level. It has a direct relationship to the spatial relationship. It creates a dynamic space with no street. The main meeting room reveals its interior to the single centre. The centre can shift around depending on public through its floor level glazing, and the cladding which group commands the floor, during a public address. which arches.

\section{Transparency} interior building. No element is hidden behind a large of the site there were some design challenges. Corners of façade. This was a comment design principle which the the room can not be occupied by seats and as a result the traditional town hall analysis uncovered. It has been perimeter is not functional for any users.

identified that the design of traditional town hall enclosed the interior, with little that suggested the happening of the interior. This created a physical separation between the public and the local authority. This design intervention uses transparent materials to create a positive effect on the overall experience of the architecture. It suggest that not only are the occupants of the building aware and exposed to the workings of the inside but also the public.

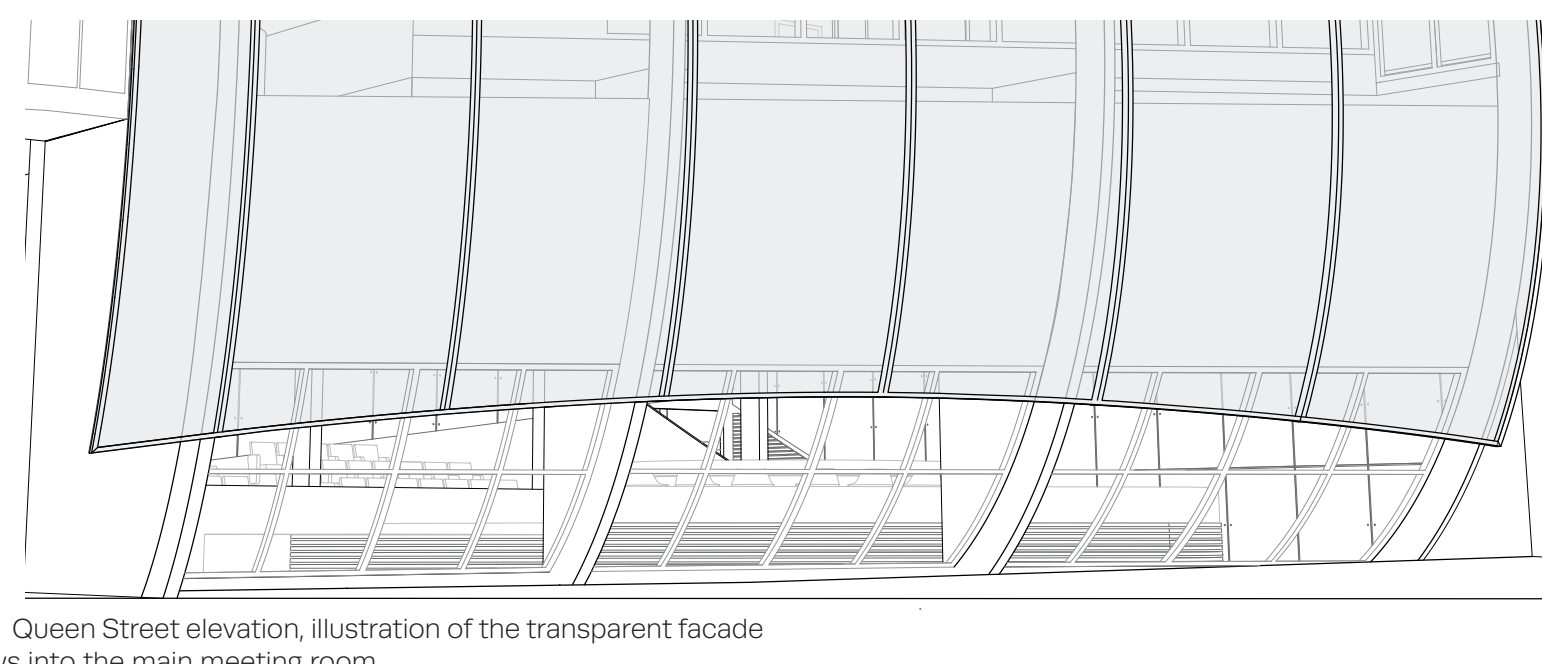

Fig. 222. Queen Street elevation, illustr
and views into the main meeting room

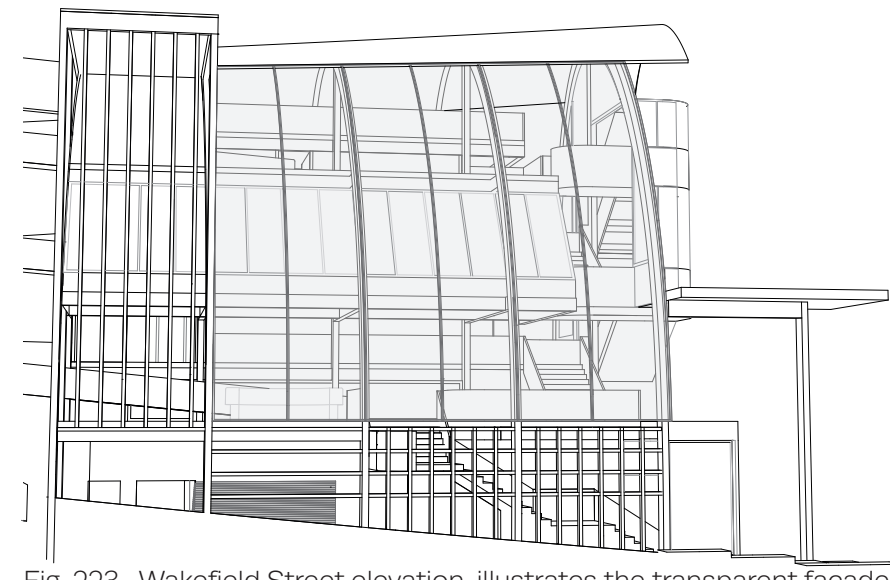

helps to celebrate the function and workings of the councit

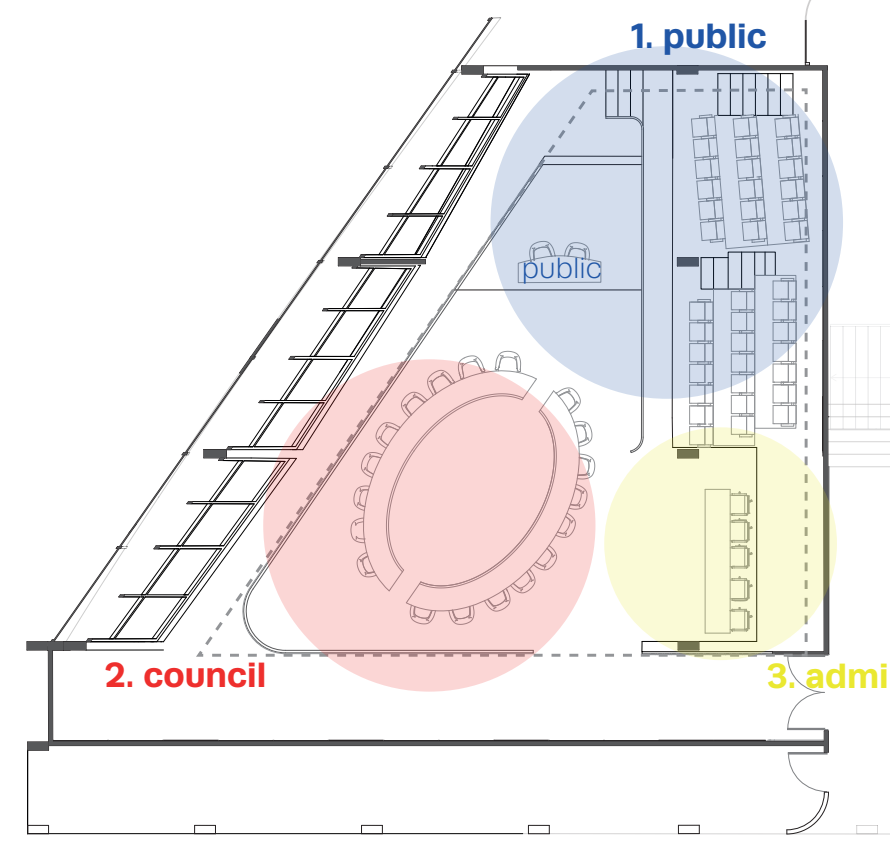

Fig. 224. An offset floor plan inside the main meeting room challenges 


\section{Conclusion}

This research considers how the performance of rituals pertaining to political life can inform the design of contemporary civic architecture. Here, the architecture serves to celebrate everyday movements and interactions between people within the community and local government. A conceptual framework informed by notions of place and civic realism, have been used to define a set of design strategies. When applied to the design case study; the effectiveness of the strategies was tested and evaluated against principles and criteria informed by connectivity with the immediate site, the role circulation plays in the design and functionality. The following points summarise the key findings from this research.

The proposed outer shell reorients Auckland's Town Hall façade to achieve an inviting street front. The wrapping gesture unifies the complex internal programme, while celebrating the political activities it contains. This approach successfully achieves an open, inviting ground floor, dissolving the (traditionally) hard threshold to the street, and thus encouraging public engagement. The façade expresses an inversion of vertical hierarchy; relocating spaces of greater importance in the lower levels (where they would traditionally be contained in upper levels), to support and enable the transparency of everyday political practices.

The offset reference line organises the complexity of the building, contrary to symmetrical tradition. Offset and staggered, this configuration forms spaces that range in size according to function. This also establishes varying relationships to the human scale and the spatial experience, dependent on function; for example, the ground floor which is multifunctional with the main meeting room reception space, the multiplicity space creates an intimate mingling of users within the defined area. In addition, this organisational strategy helps to clarify circulation, centering it within the building (rather than being closed off), to encourage public use. Similarly, by 'destabilising' the traditional four-walled main meeting room to instead be triangular in form, to create a less intimidating space. Where a traditional four walled room becomes imposing when users are given halves. Rather the triangular shape creates a dynamic room power is given to whomever is commanding the room. While the symbolic hierarchy in the main meeting room the shape presents a challenge of the functional arrangement and balance.
In summary, this design approach aims to supports the advantage of civic architecture as an emblematic representation of local government. It uncouples the corporate functions from the formal congregational and decision making functions of Auckland City Council. As a result this design is symbolic of a council that operates with greater transparency and community engagement. By revealing the inner workings of local government, the design aims to empower the central Auckland community. Through a dynamic circulation design, transparency of form, and a softened threshold between interior and exterior on the ground floor, the design seeks to establish both physical and visual connections to between the public, and the decision-making processes that govern their city.

The design strategies can be divided into groups of primary and secondary approaches to the design of civic architecture:

\begin{tabular}{|c|c|}
\hline $\begin{array}{l}\text { PRIMARY } \\
\text { STATEGY }\end{array}$ & $\begin{array}{l}\text { - Inverted vertical hierarchy } \\
\text { - Re-oriented "wrapping" of facade } \\
\text { - Multiple physical/visual access } \\
\text { - Complexity in balance }\end{array}$ \\
\hline $\begin{array}{l}\text { SECONDARY } \\
\text { STATEGY }\end{array}$ & $\begin{array}{l}\text { - Reference line (offset) } \\
\text { - Adaptable spaces } \\
\text { - Selection of site }\end{array}$ \\
\hline
\end{tabular}




\section{Significance}

Significance

Limitations

Further Research

Final Statement

the lives and environment of local people.

The research was driven by a lack of physical representation of local government in cities across $\mathrm{New}$ Zealand, resulting in a decline of public engagenent, and awareness of local issues. Civic architecture contains an enables practices of political life, significantly affecting communities, and thus a presence is important. Throug recognition of collective culture, major stakeholders, and the operation of local politics; a set of design criteria (based on connectivity, experience, and the ritual of meeting), were developed. The criteria were applied to a design case study to restore a physical presence of the local council within the community, celebrating meetings and interactions as a generator of public engagement thus reinforcing Auckland City's Councils values to enhance
To understand the role of a traditional town hall and the implications of its design, three town halls were analysed in terms of, their spatial arrangement, and hierarchy of functional spaces, with respect to various user groups. This revealed that important spaces (such as main meeting chambers) are hidden from visibility, emphasising the need for greater transparency, legibility, access and dynamic circulation. This was not always the case with more contemporary civic spaces, which suggests that the traditional model is outdated. . The design case study has revealed how, by adopting the strategies to improve access through dynamic circulation, architecture can facilitate and enable interactions.

This research will contribute to discourse on the role of local governments within communities, and how architecture serves to support their visual presence in the city. 


\section{Limitations}

approaches towards circulation should be implemented.

It is important to recognise the limitations of this research, affecting the extent to which findings can be generalised beyond this site.

The design case study is enabled through physically uncoupling the corporate function from the formal meeting aspect. The functional brief has been developed (in part) based on the current operations of the Auckland The specific location within the city provided opportunity City Council. If the structure of the Auckland City for the success of visibility, circulation which results in Council, particularly the meeting and decision-making positive public engagement. The shape of the site allows processes, were to be modified, an adaptation of the access to all edges, creating a fluid threshold between programme should be revised.

the city and the building. When this design approach is

applied beyond this site, the strategies which correspond This design case study is located in the centre of Auckland to the principles of experience and pathway may need to city. With the largest population in New Zealand, the be adapted. To achieve similar success in these principles, streets are active and lively. Although when these findings which the design case study has shown, supplementary

are observed in a range of contexts; cities or towns of smaller populations in New Zealand, it should be noted that activation of the design is determined by factors which include the number of users.

\section{Final Statement}

In response to a lack of symbolic presence of local government presence in Auckland City, this research proposes a set of design criteria to enable productive, and positive engagements within civic spaces, between local governing bodies and the communities they serve. The design outcome reappropriates the traditional town hall model through challenging traditional spatial hierarchies. This approach to civic architecture ultimately reconsiders human engagement in the city, celebrating everyday rituals and movements, tested through a dynamic, yet balanced building which inserts itself into the central Auckland city/ Tamaki Makaurau.

\section{Further Research}

This research defines a set of criteria to restructure the traditional approach to civic architecture and applies it to a specific site in Auckland City. In terms of the application at the chosen site, further research could examine how the neighbouring building at 360 Queen Street could be assimilated into the design case study, by continuing the circulation design, and accommodating administration staff. In addition, (or alternatively) it could accommodate a programme of multi-use spaces to attract a diverse group of people to strengthen the civic experience.

The design criteria could be developed and expanded to incorporate other outdated civic buildings such as traditional parliament buildings. This research integrates the concept of civic, which has been defined as architecture that balances tensions between society and authority which the design case study equally addresses. Small scale explorations could test the short-term success of this approach to civic spaces. 


\section{List of Figures}

Note: All figures and tables not attributed are author's own

Fig. 6- "Auckland 24-28 [Auckland Central]". Auckland City Council. Department of Works and Services. Town Planning Division, in Kura, Auckland Libraries Heritage Collections. Accessed on May 13, 2020. https://kura.aucklandlibraries.govt.nz/digital/collection/maps/id/249/rec/1

Fig. 7- Ellis, Vera Jane. "Protest against All Blacks South African Tour", Sir George Grey Special Collections, Auckland Libraries Heritage Images. Accessed on January 28, 2021

http://www aucklandcity $\& Q F 0=I D \& N P=2 \& M R=5 \& R F=H I O R e c o r d S e a r c h \& Q I 0=03 \mathrm{D} \% 22958-161 \% 22$

Fig. 9- Richardson, James D. "Showing a crowd outside Auckland Town Hall... 1920s". in Auckland Libraries Heritage Images. Accessed on April, 22, 2020.

http://www.aucklandcity.govt.nz/dbtwwpd/exec/dbtwpub.dll?BU=http\%3A\%2F\%2Fwww.aucklandcit y.govt.nz $\% 2 \mathrm{Fdbtwwpd} \% 2 \mathrm{FH}$ eritageImages\%2Findex.htm\&AC=QBE_QUERY\&TN=heritageimages $\& Q F 0=I D \& N P=2 \& M R=5 \& R F=H I O R e c o r d S e a r c h \& Q I 0=\% 3 D \% 224-7103 \% 22$
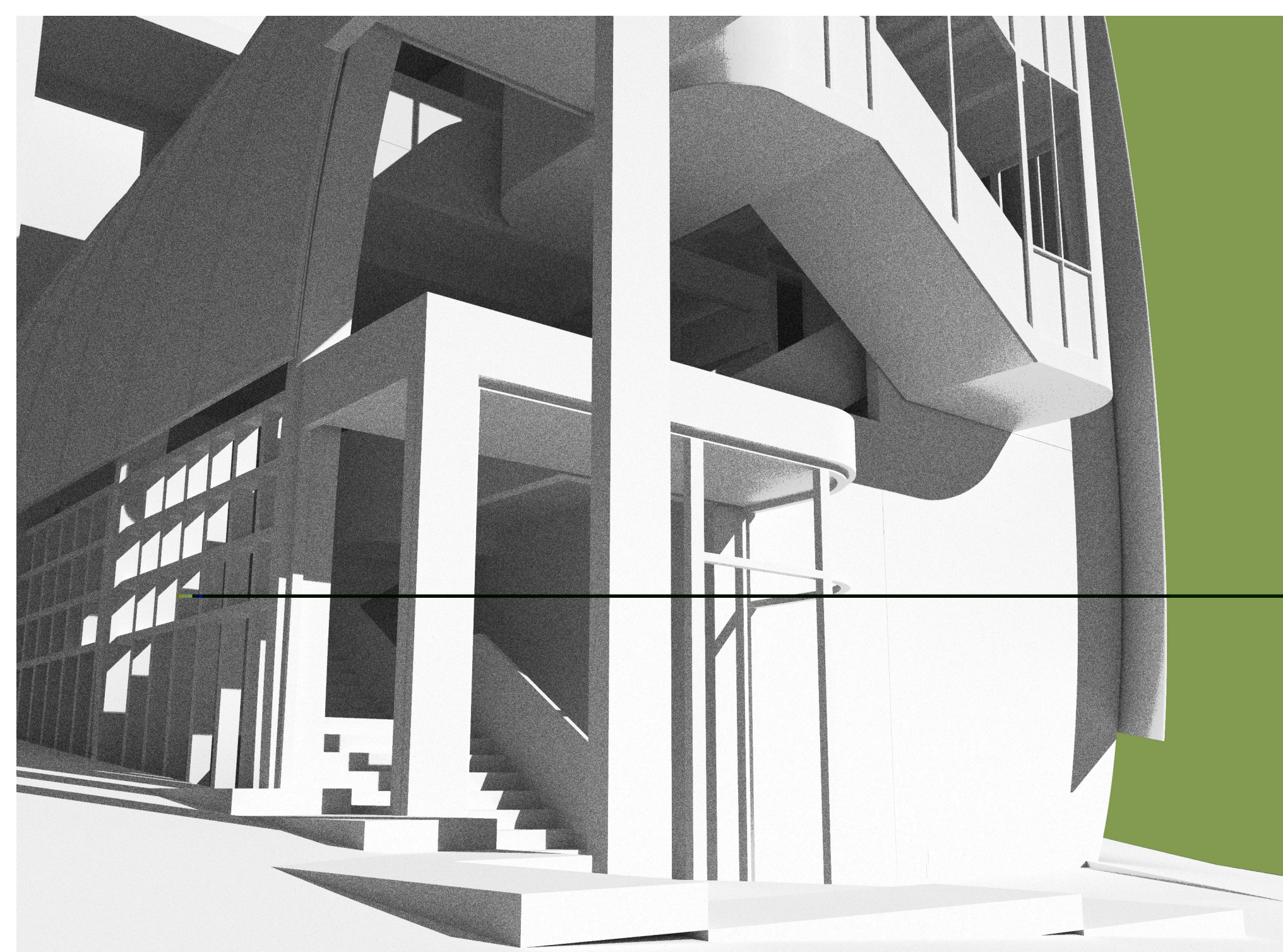

Fig. 10- "Pipe organ, Auckland Town Hall." in Auckland Libraries Heritage Images. Accessed on April, 23, 2020

http://www.aucklandcity.govt.nz/dbtwwpd/exec/dbtwpub.dll?BU=http\%3A\%2F\%2Fwww.aucklandcit y govt $n$ z $\% 2 \mathrm{Fdbtwwpd} \% 2 \mathrm{FH}$ ritagelmages $\% 2 \mathrm{Findex}$ htm $\& \mathrm{AC}=\mathrm{QBE} \quad \mathrm{QUERY} \& \mathrm{TN}=$ heritageimages

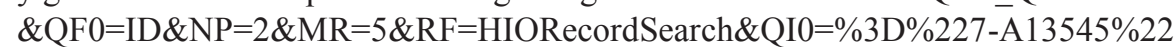

Fig. 13- "Wellington Town Hall", in MacDonald Wilson Collection, Wellington City Libraries. 500002-6-133. Accessed on May 1, 2020. https://wellington.recollect.co.nz/nodes/view/307

Fig. 14- "Interior of Wellington Town Hall in 1906", from Wellington City Council. Accessed on May 2, 2020 https://wellington.govt.nz/Your-Council/Projects/Earthquake-Strengthening-Projects/Town-HallStrengthening/Town-Hall-Architectural-History

Fig. 17- Ebert, "Dunedin Town Hall" from Encircle Photos. Accessed on May 15, 2020. https://www.encirclephotos.com/image/dunedin-town-hall-in-dunedin-new-zealand/

Fig. 18- Collins, C.M. "Almost completed Dunedin Town Hall” from Dunedin City Archive's photostream, photo album 160/25. Accessed on May 15, 2020. https://www.flickr.com/photos/dccarchives/26781400013/in/album-72157669065888932/

Fig 39- Mork, Adam. "Bodø Town Hall / Atelier Lorentzen Langkilde." ArchDaily. Accessed on August 1, 2020. https://www.archdaily.com/931586/bodo-town-hall-atelier-lorentzen-langkilde

Fig. 40- Mork, Adam. "Bodø Town Hall / Atelier Lorentzen Langkilde." ArchDaily. Accessed on August 1, 2020. https://www.archdaily.com/931586/bodo-town-hall-atelier-lorentzen-langkilde 
Fig. 43- Morris, Dave and Paul Zanre. in Dundee Council Civic Offices project report. Accessed on July 28, 2020. https://www.reiachandhall.co.uk/work-workplace-office/dundee-council-civic-offices-dundee

Fig. 44- Morris, Dave and Paul Zanre. in Dundee Council Civic Offices project report. Accessed on July 28 , 2020. https://www.reiachandhall.co.uk/work-workplace-office/dundee-council-civic-offices-dundee

Fig. 45- Morris, Dave and Paul Zanre. in Dundee Council Civic Offices project report. Accessed on July 28 , 2020. https://www.reiachandhall.co.uk/work-workplace-office/dundee-council-civic-offices-dundee

Fig. 49- Hamilton, Andrea. "City Hall" in London Every Day project, AH Studio. Accessed on March 12, 2021 https://www.andreahamilton.com/exhibitions/london-every-day-at-city-hall/\#image-0

Fig. 50- Greater London Authority. "What can you visit city hall." London Local Authority. Accessed on July 2, 2020. https://www.london.gov.uk/about-us/our-building-and-squares/what-can-you-visit-city-hall

Fig. 51- Welch, Arian. "GLA Building London City Hall" in E-architect. Accessed on July 2, 2020. https://www.e-architect.com/london/gla-building

Fig. 54- Hopkins Architects, "Brent Civic centre." Hopkins Architects. Accessed on July 15, 2020 https://www.hopkins.co.uk/projects/5/145/

Fig. 55- Hopkins Architects. "Brent Civic centre." Hopkins Architects. Accessed on July 15, 2020. https://www.hopkins.co.uk/projects/5/145/

Fig.56- Hopkins Architects. "Brent Civic centre.” Hopkins Architects. Accessed on July 15, 2020 https://www.hopkins.co.uk/projects/5/145/

Fig. 59- Athfield Architect. "Selwyn District Council" Athfield Architects. Accessed on July 162020. https://athfieldarchitects.co.nz/projects/civic-community/selwyn-district-council

Fig. 60- Athfield Architect. "Selwyn District Council" Athfield Architects. Accessed on July 162020 https://athfieldarchitects.co.nz/projects/civic-community/selwyn-district-council

Fig. 61- Athfield Architect. "Selwyn District Council" Athfield Architects. Accessed on July 162020 https://athfieldarchitects.co.nz/projects/civic-community/selwyn-district-council

Fig. 64- Architectus, "Henderson Service Centre \& Transport Change" Architectus. Accessed on July 20, 2020 https://architectus.co.nz/work/waitakere-civic-centre/

Fig. 65- Architectus, "Henderson Service Centre \& Transport Change" Architectus. Accessed on July 20, 2020. https://architectus.co.nz/work/waitakere-civic-centre/
Fig. 68- Devitt, Simon. "Christchurch Civic building”, Architecture Now, April 4 , 2013.https://architecturenow.co.nz/articles/christchurch-civic-building/

Fig. 69- Devitt, Simon. "Christchurch Civic building", Architecture Now, April 4, 2013.https://architecturenow.co.nz/articles/christchurch-civic-building

Fig. 70- Devitt, Simon. "Christchurch Civic building", Architecture Now, April 4, 2013.https://architecturenow.co.nz/articles/christchurch-civic-building/

Fig. 73- Boegly, Luc. "Bagnolet Town Hall / Jean-Pierre Lott Architecte.” ArchDaily. Accessed on July 23, 2020. https://www archdaily.com/496281/bagnolet-town-hall-jean-pierre-lott-architecte

Fig. 74- Boegly, Luc. "Bagnolet Town Hall / Jean-Pierre Lott Architecte." ArchDaily. Accessed on July 23 2020. https://www.archdaily.com/496281/bagnolet-town-hall-jean-pierre-lott-architecte

Fig. 75: Boegly, Luc. "Bagnolet Town Hall / Jean-Pierre Lott Architecte." ArchDaily. Accessed on July 23, 2020. https://www.archdaily.com/496281/bagnolet-town-hall-jean-pierre-lott-architecte

Fig. 78- Hufton + Crow. “The Crystal - Kiruna Town Hall / Henning Larsen” ArchDaily. Accessed july 28, 2020. https://www.archdaily.com/906543/the-crystal-kiruna-town-hall-henning-larsen

Fig. 79- Hufton + Crow. "The Crystal - Kiruna Town Hall / Henning Larsen” ArchDaily. Accessed july 28 2020. https://www.archdaily.com/906543/the-crystal-kiruna-town-hall-henning-larsen

Fig. 80- Hufton + Crow. "The Crystal - Kiruna Town Hall / Henning Larsen" ArchDaily. Accessed july 28, 2020. https://www archdaily.com/906543/the-crystal-kiruna-town-hall-henning-larsen

Fig. 85- Hochstetter, Ferdinand von and Justus Perthes, "The isthmus of Auckland with its extinct volcanoes by Dr Ferdinand von Hochstetter 1859" from Kura, Auckland Libraries heritage collection. Accessed on May 5, 2020. https://kura.aucklandlibraries.govt.nz/digital/collection/maps/id/741/rec/1

Fig. 88- Tucker, Rob. “Aerial view south along Queen Street from above Queen's Wharf." From Kura, Auckland Libraries Heritage Collections. Accessed on March 1,2020.

http://www.aucklandcity govt.nz/dbtw-

wpd/exec/dbtwpub.dll?BU=http\%3A\%2F\%2Fwww.aucklandcity.govt.nz\%2Fdbtw-

wpd\%2FHeritageImages $\% 2$ Findex.htm\&AC=QBE QUERY\&TN=heritageimages\&QF0 $=I D \& N P=2 \&$

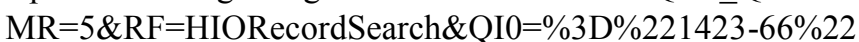

Fig. 104- "Aerial view of Auckland public library." From Auckland Libraries Heritage Images. Accessed on May 2, 2020. http://www.aucklandcity.govt.nz/dbtw-

wpd/exec/dbtwpub.dll?BU=http\%3A\%2F\%2Fwww.aucklandcity.govt.nz\%2Fdbtw-

wpd\% 2 FHeritageImages $\% 2$ Findex htm \& $A C=Q B E$ QUERY\&TN=heritageimages $\& Q F 0=I D \& N P=2$ $\& \mathrm{MR}=5 \& \mathrm{RF}=\mathrm{HIORecordSearch} \& \mathrm{QIO}=\% 3 \mathrm{D} \% 227-\mathrm{A} 5218 \% 22$ 


\section{Bibliography}

Allen, Stan. "From Object to Field: Field Conditions in Architecture and Urbanism." Architectural Design no. 67 (1997): 24-31.

Amin, Ash. "Collective Culture and Urban Public Space." City (London, England) 12, no. 1 (2008): 5-24. https://doi.org/10.1080/13604810801933495.

Astbury, Jon. "ALL designs faceted facade to create play of light across Bodo City Hall." Dezeen. Updated December 18, 2019. https://www.dezeen.com/2019/12/18/bodo-town-hall-atelie-lo-
rentzen-langkilde-all-norway-architecture/

"Bagnolet Town Hall / Jean-Pierre Lott Architecte". ArchDaily. April 16, 2014. https://www.archdaily.com/496281/bagnolet-town-hall-jean-pierre-lott-architecte

"Brent Civic Centre." Hopkins Architects. Accessed August 4, 2020. https://www.hopkins.co.uk/projects/5/145/

"City Hall." Accessed August 1, 2020. Foster+Partners https://www.fosterandpartners.com/projects city-hall/

Collins, Charles. "Wellington Town Hall". Wellington City Council. Updated March 3, 2017. https:// wellingtoncityheritage.org.nz/buildings/301-450/325-wellington-town-hall

De Landa, Manuel. A New Philosophy of Society Assemblage Theory and Social Complexity. London ;: Continuum, 2006.

Dovey, Kim. Becoming Places. Edited by Kim Dovey. London ;: Routledge, 2009.

_. Framing Places : Mediating Power in Built Form. The Architext Series. 2nd ed. ed. London ;: Routledge, 2008

Gates, Charlie. "Christchurch Civic Building.” Architecture New Zealand March, 2013 2013, 53-60.

Gehl, Jan. Cities for People. Washington, DC: Island Press, 2010

. Life between Buildings : Using Public Space. Washington, DC: Island Press, 2011.

Gehl, Jan, Lotte Johansen Kaefer, and Solvejg Reigstad. "Close Encounters with Buildings.” Urban design international (London, England) 11, no. 1 (2006): 29-47. https://doi.org/10.1057/palgrave.udi.9000162.

González, María Francisca. "The Crystal - Kiruna Town Hall/ Henning Larsen” ArchDaily. Updated November 27, 2018. https://www.archdaily.com/906543/the-crystal-kiruna-town-hall-henning-larsen
"Henderson Service Centre and transport change." Architectus. Accessed August 3, 2020. https://architectus.co.nz/work/waitakere-civic-centre/

Hillier, Bill, and Julienne Hanson. The Social Logic of Space. Cambridge, England: Cambridge University Press, 2003. ProQuest Ebook Central.

Hillier, Jean. "Editorial: Habitus - a Sense of Place." Urban policy and research 17, no. 3 (1999): 177-78. https://doi.org/10.1080/08111149908727803.

“Auckland Town Hall " New Zealand Heritage List, Heritage New Zealand 2011, accessed April 2020, https://www heritage. org nz/the-list/details/549.

"Wellington Town Hall “ New Zealand Heritage List, Heritage New Zealand 2003, accessed April 20, 2020, https://www.heritage.org.nz/the-list/details/3275.

Lewis, Penny, "Dundee Council Civic Offices". From Reich and Hall Architects. Edinburgh: Sleeper publications, 2012

Monsalve, Frederico. "Dunedin Town Hall “. Interior. no. 14 (December 2014): 54-59.

Murphy, Laurence. "Third-Wave Gentrification in New Zealand: The Case of Auckland." Urban Studies 45, no. 12 (2008/11/01 2008): 2521-40. https://doi.org/10.1177/0042098008097106.

Niall, Todd. "Heritage Auckland Council HQ on track to be sold and turned into apartments" Stuff, May 31, 2019. stuff.co.nz/auckland/113070450/heritage-auckland-council-hq-on-track-to-besold-and-turned-into-apartments

Paul, Jones. "Putting Architecture in Its Social Place: A Cultural Political Economy of Architecture." Urban studies (Edinburgh, Scotland) 46, no. 12 (2009): 2519-36. https://doi. org/10.1177/0042098009344230.

Pintos, Paula. "Bodo Town Hall/ Atelier Lorentzen Langkilde." ArchDaily. Updated January 10, 2020. https://www.archdaily.com/931586/bodo-town-hall-atelier-lorentzen-langkilde

Pownall, L. L. "Metropolitan Auckland 1740-1945: The Historical Geography of a New Zealand City*." New Zealand Geographer 6, no. 2 (1950/10/01 1950): 107-24. https://doi.org/https:// doi.org/10.1111/j.1745-7939.1950.tb01716.x.

Rowe, Peter G. Civic Realism. Cambridge, Mass: MIT Press, 1997. 
"Selwyn District Council." Athfield Architects. Accessed July 28, 2020. https://athfieldarchitects.

co.nz/projects/civic-community/selwyn-district-council

Smith, Dennis. "A Short History of the Sixties Downtown." Architecture New Zealand, no. 2 (March 2013 2013): 25-37

Sudjic, Deyan. "The thriller on the river." The Guardian. Updated on May 05, 2002 https://www. theguardian.com/theobserver/2002/may/05/1

Venturi, Robert. Complexity and Contradiction in Architecture. The Museum of Modern Art Papers on Architecture. 2d ed. ed. New York: Museum of Modern Art, 1977.

Yoffe, Susan and Tania Mace. "Auckland city heritage walk: downtown, midtown, uptown”. Auckland Council. https://www.aucklandcouncil.govt.nz/arts-culture-heritage/heritage-walks-places/Documents/auckland-city-heritage-walks.pdf

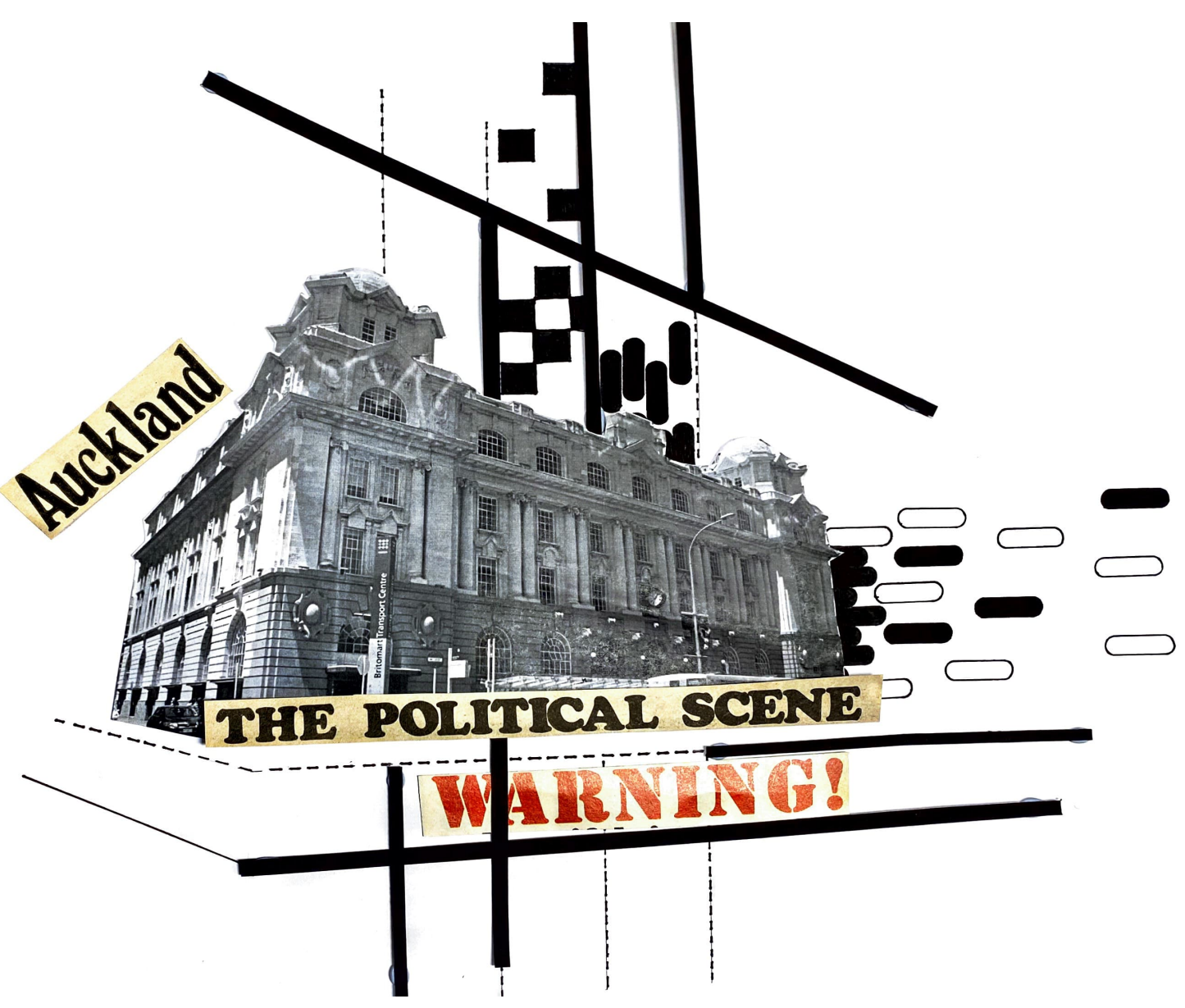

